\title{
VEHICLE-TO-GRID (V2G) BIDIRECTIONAL POWER CONVERTER DESIGN AND INTEGRATION FOR 2011 \\ CHEVROLET VOLT - EXTENDED RANGE ELECTRIC VEHICLE (EREV) DRIVETRAIN
}

\author{
A Thesis \\ Presented to the \\ Faculty of California Polytechnic State University, \\ San Luis Obispo \\ In Partial Fulfillment \\ of the Requirements for the Degree \\ Master of Science in Electrical Engineering
}

by

Rithy-Newton Mao Chhean

December 2012 
(C) 2012

Rithy-Newton Mao Chhean

ALL RIGHTS RESERVED 


\section{Committee Membership}

TITLE:

VEHICLE-TO-GRID (V2G) BIDIRECTIONAL POWER

CONVERTER DESIGN AND INTEGRATION FOR 2011

CHEVROLET VOLT - EXTENDED RANGE ELECTRIC

VEHICLE (EREV) DRIVETRAIN

AUTHOR: $\quad$ Rithy-Newton Mao Chhean

DATE SUBMITTED: December 2012

COMMITTEE CHAIR: Dr. Dale Dolan, Assistant Professor

COMMITTEE MEMBER: Dr. Taufik, Professor

COMMITTEE MEMBER: Dr. Ahmad Nafisi, Professor 


\begin{abstract}
VEHICLE-TO-GRID (V2G) BIDIRECTIONAL POWER CONVERTER DESIGN

AND INTEGRATION FOR 2011 CHEVROLET VOLT - EXTENDED RANGE

ELECTRIC VEHICLE (EREV) DRIVETRAIN
\end{abstract}

Rithy-Newton Mao Chhean

This thesis proposes of an integrated two-stage V2G bidirectional power converter for the 2011 Chevy Volt's EREV drivetrain. The power converter consists of a four switch bidirectional buck-boost DC-DC converter, 2-legged HB bidirectional DCAC converter, and LCL grid filter. Designs in literature have integrated DC-AC converter via traction inverter, but this design also integrates DC-DC converter via modified secondary traction inverter. The proposed structure allows battery charging and V2G functionality to be integrated into existing electronics of the 2011 Chevy Volt; only the following additional components are needed: GFI, a few passive components, diodes, and relays. The converter structure is advantageous as cost, volume, and weight are minimized. Those factors are automakers main concerns. The proposed structure shows the feasibility of bringing V2G functionality to the mass market. Matlab Simulink was used to verify the design. Simulations were performed for high and low battery SOC to show voltage versatility, stiff and weak grid conditions to show filter robustness, and generator powering V2G to show topology DG capabilities. Results of simulations prove the topology to be promising as grid current has low distortion, almost meeting all IEEE 1547 current harmonic limit requirements. 


\section{Acknowledgements}

My first thanks are to Dr. Dolan, Dr. Taufik, and Dr. Nafisi for being on my thesis committee. Next, I thank my parents, Phala and Pisey Chhean. I will never be able to repay them for all of their support as well as the sacrifices that they've made for me. I would like to give a special thanks to Becky Powell. I really appreciate what you have done for me. I hope you have a great retirement! I have to thank the best family in the world; the Chhean family. If I was born into any other family, I would never feel as proud, have as much fun, eat as well, or fit so well. Family bonded through name and blood, but ours is so much more than that. Of course, I have to thank all of my friends who have helped me on my way. I especially want to thank those friends that are always there for me and who I will always be there for.

As I promised on Facebook, I would like to thank the following people: M.S. Martin Kou, Benjamin Vu, Haleigh Vierra, Allan Agatep, Mason Ung, Ritchie Ly, the great Hienry Van, Kobe Bryant, M.S. Jameson Thornton, Ryan Chun, Michael Wu, Daniel Gutierrez, and Vickie Le. Finally, I would like to thank my greatness! Without it, I wouldn't have been able to achieve so much. 


\section{Table of Contents}

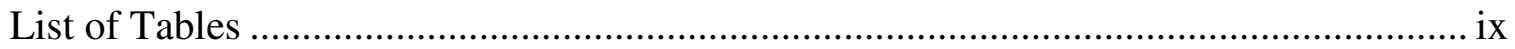

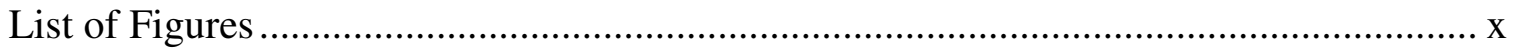

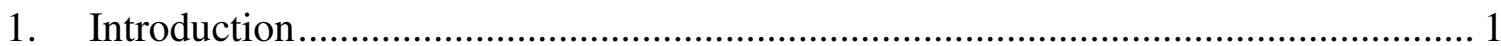

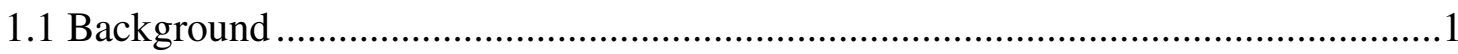

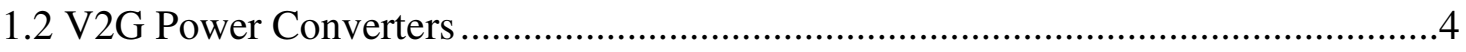

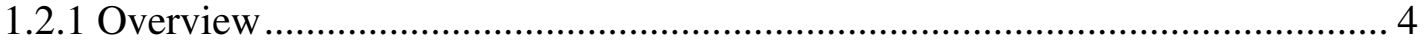

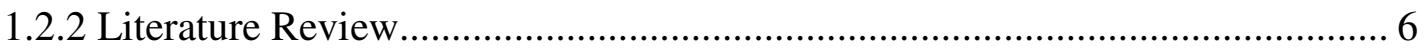

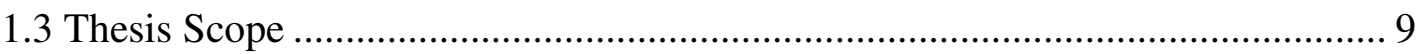

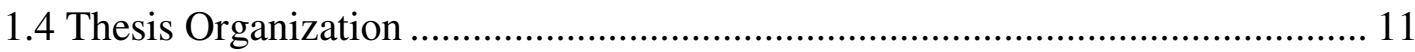

2. Design Considerations and Specifications ......................................................... 13

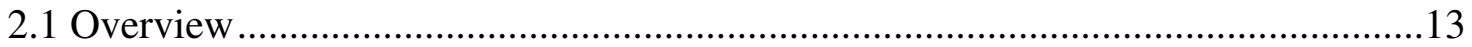

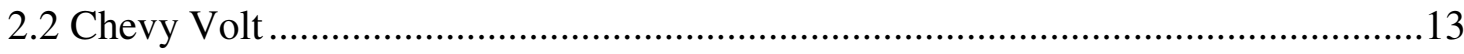

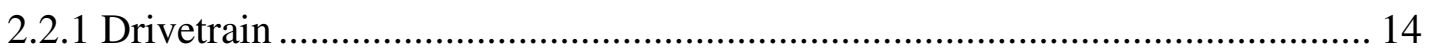

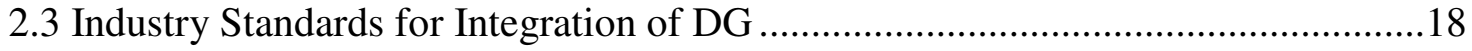

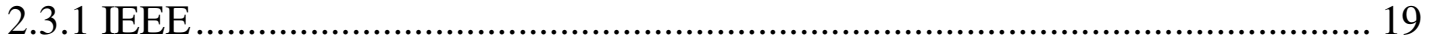

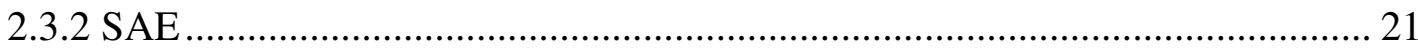

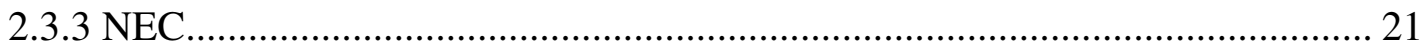

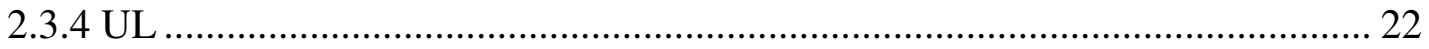

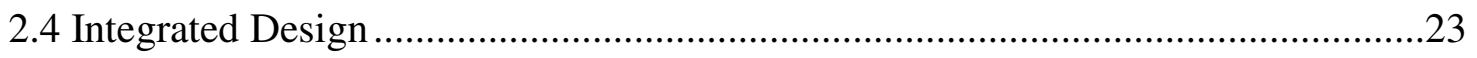


2.5 Summary

3. G2V-V2G Power Converter Topology Considerations \& Selection ........................ 25

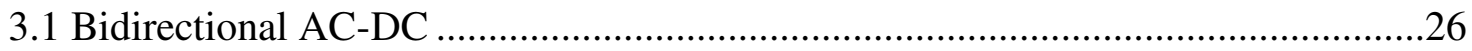

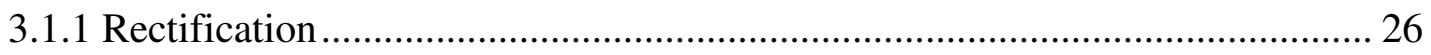

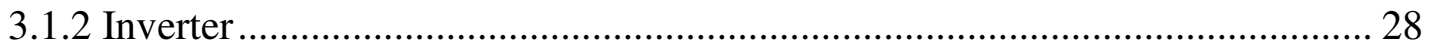

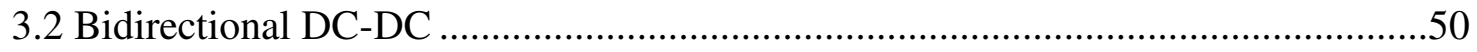

3.2.1 Comparison of Non-Isolated DC-DC Topologies for V2G Power Converter. 50

3.2.2 Four Switch Bidirectional Buck-Boost Converter....................................... 52

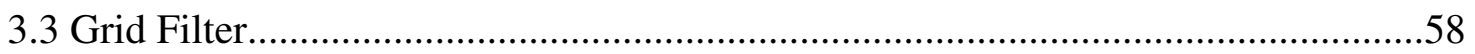

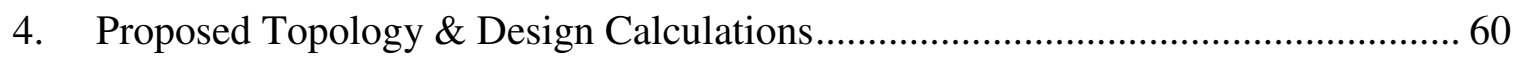

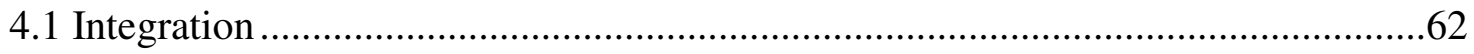

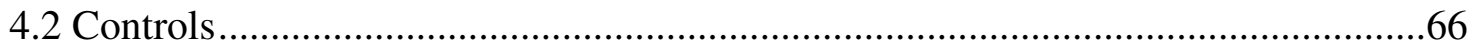

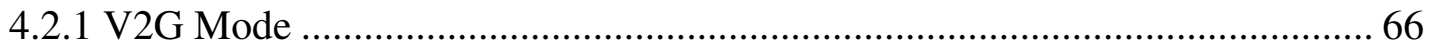

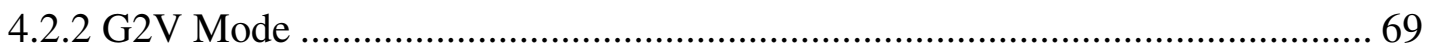

4.3 Passive Component Design Calculations..........................................................69

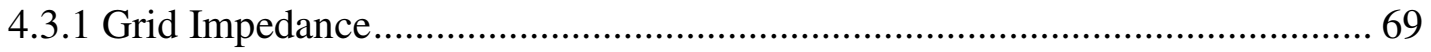

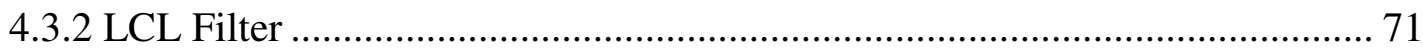

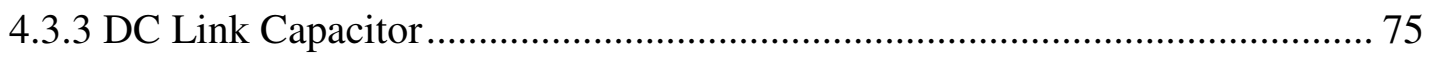

4.3.4 DC-DC four switch Bidirectional Buck-Boost Converter ............................ 75

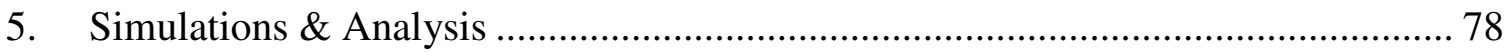


5.1 Overview

5.2 V2G - Stiff Grid, Generator Off, Battery Full SOC .78

5.3 V2G - Stiff Grid, Generator Off, Battery Low SOC .88

5.4 V2G - Weak Grid, Generator Off, Battery Full SOC.

5.5 V2G - Stiff Grid, Generator On 96

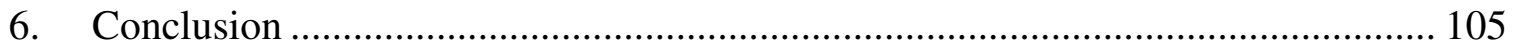

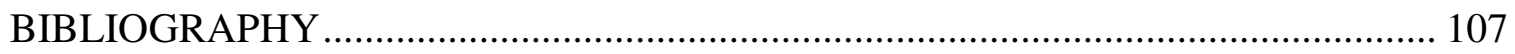

Appendix A - Grid Switch Controller Code......................................................... 113

Appendix B - Inverter Unipolar Hysteresis Controller Code.................................... 114

Appendix C - Hysteresis Band Calculation Code .................................................... 117

Appendix D - List of Current Harmonic Characteristics: V2G Mode - Stiff

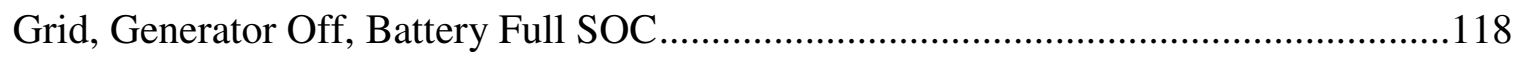

Appendix E - List of Current Harmonic Characteristics: V2G Mode - Stiff Grid,

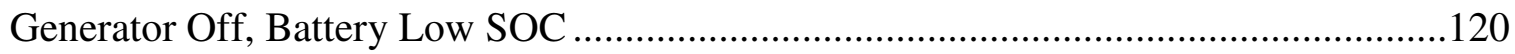

Appendix F - List of Current Harmonic Characteristics: V2G Mode - Weak Grid, Generator Off, Battery Full SOC.

Appendix G - List of Current Harmonic Characteristics: V2G Mode - Stiff Grid, Generator On. 


\section{List of Tables}

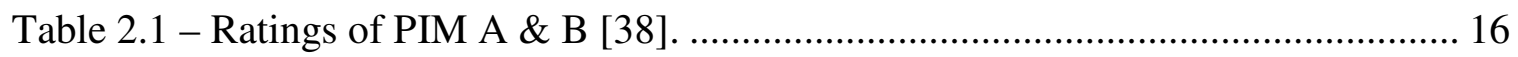

Table 2.2 - IEEE 1547 current harmonic limits [43] ............................................... 20

Table 2.3 - Summary of EVSE continuous operating ratings from 2011 NEC 625.14 .. 21

Table 3.1 - Summary 2-legged HB inverter modulation techniques............................. 36

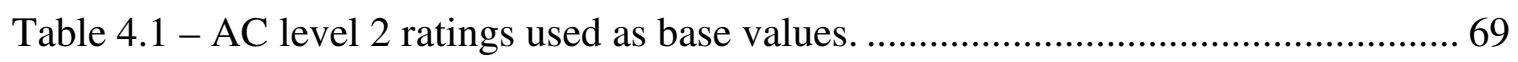

Table 4.2 - Stiff and weak grid impedance parameters......................................... 71

Table 4.3 - LCL component values.............................................................. 75

Table 5.1 - Pre-Charge DC-DC converter PI parameters......................................... 79

Table 5.2 - DC-DC converter V2G PI parameters................................................. 81

Table 5.3 - DC generator characteristics. ........................................................ 99

Table 5.4 - Pre-Charge DC generator PI parameters. ............................................ 99

Table 5.5 - DC generator PI parameters........................................................... 99 


\section{List of Figures}

Figure 1.1 - Typical daily system load and the effect of 5 million PHEV load [6]...........3

Figure 1.2 - Black box diagram of general G2V-V2G single-stage power converter. ........5

Figure 1.3 - Black box diagram of general G2V-V2G two-stage power converter...........6

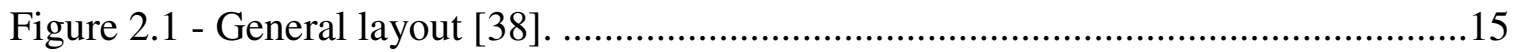

Figure 2.2 - PIM-A, PIM-B, and system interface [38] ........................................ 17

Figure 3.1 - Full wave bridge rectifier with smoothing capacitor and DC-DC

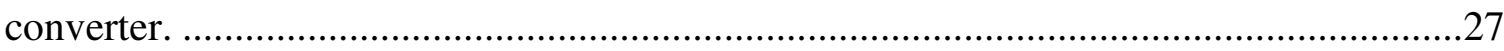

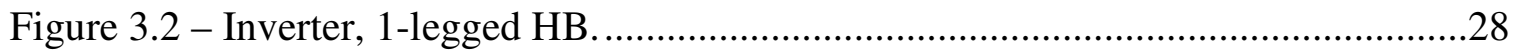

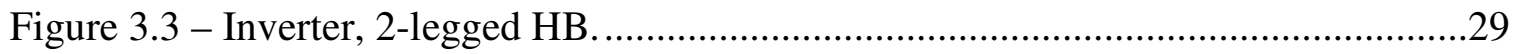

Figure 3.4 - Positive output voltage state of 2-legged HB with BP modulation. ...............30

Figure 3.5 - Negative output voltage state of 2-legged HB with BP modulation..............31

Figure 3.6 - Positive output voltage state of 2-legged HB with UP modulation...............32

Figure 3.7 - Negative output voltage state of 2-legged HB with UP modulation..............32

Figure 3.8 - Zero output voltage states of 2-legged HB with UP modulation:

a) positive output current states, b) negative output current states. ................................33

Figure 3.9 - Positive output voltage state of 2-legged HB with hybrid modulation..........34

Figure 3.10 - Negative output voltage state of 2-legged HB with hybrid modulation. .....34

Figure 3.11 - Zero output voltage states of 2-legged HB with hybrid modulation:............35

Figure 3.12 - Positive output voltage state of H5 inverter.........................................38

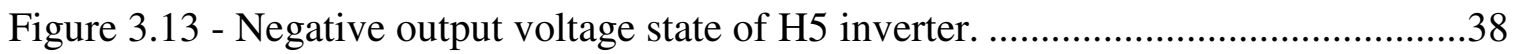

Figure 3.14 - Zero output voltage states of H5 inverter:.............................................39

Figure 3.15 - Positive output voltage state of HERIC inverter......................................41 
Figure 3.16 - Negative output voltage state of HERIC inverter.

Figure 3.17 - Zero output voltage states of HERIC inverter:

Figure 3.18 - Positive output voltage state of NPC inverter.

Figure 3.19 - Negative output voltage state of NPC inverter.

Figure 3.20 - Zero output voltage states of NPC inverter:

Figure 3.21 - Positive output voltage state of Conergy inverter. .48

Figure 3.22 - Negative output voltage state of Conergy inverter. .48

Figure 3.23 - Zero output voltage states of Conergy inverter:

Figure 3.24 - Four switch bidirectional buck-boost converter showing buck mode switching states. Blue represents when S1 is on, current path is conducting through S1 and D3. Red represents when all switches are off, current path is conducting through D2 and D3.

Figure 3.25 - Four switch bidirectional buck-boost converter showing boost mode switching states. Blue represents when S1 and S4 are on, current path is conducting through S1 and S4. Red represents when S1 is on, current path is conducting through S1 and D3.

Figure 3.26 - Four switch bidirectional buck-boost converter showing buck-boost mode switching states. Blue represents when S1 and S4 are on, current path is conducting through S1 and S4. Red represents when all switches are off, current path is conducting through D2 and D3.

Figure 3.27 - VSI grid filters: (a) L, (b) LC, c) LCL.

Figure $4.1-\mathrm{G} 2 \mathrm{~V}-\mathrm{V} 2 \mathrm{G}$ power converter system layout.

Figure 4.2 - Modified general layout. 
Figure 4.3 - Modified system interface for PIM-A, PIM-B, and main propulsion bus with relays engaged in G2V-V2G power converter mode. The RESS is connected while the generator is disconnected.

Figure 4.4 - Modified system interface for PIM-A, PIM-B, and main propulsion bus with relays engaged in G2V-V2G power converter mode. The RESS is disconnected while the generator is connected.

Figure 4.5 - V2G mode DC-DC controls.

Figure 4.6 - V2G mode generator controls.

Figure 4.7 - V2G mode inverter controls.

Figure 5.1 - Simulink implementation of DC-DC Controls for V2G with generator off.

Figure 5.2 - Pre-charge of DC link capacitor via DC-DC converter: (a) grid switch (b) actual grid voltage and inverter unfiltered unipolar modulated voltage (c) DC link bus voltage.

Figure 5.3 - Simulink implementation of V2G with a stiff grid connection. Battery is connected and generator disconnected.......

Figure 5.4 - V2G simulation results of inverter's unfiltered output with a stiff grid connection: (a) unipolar modulated voltage (b) current. Battery is at full SOC and connected. Generator is disconnected.

Figure 5.5 - V2G simulation results of grid voltage and filtered output current with a stiff grid connection. Battery is at full SOC and connected. Generator is disconnected...84 Figure 5.6 - V2G simulation results of filtered output current with a stiff grid connection. Battery is at full SOC and connected. Generator is disconnected. 
Figure 5.7 - V2G simulation results of DC link bus capacitor voltage (a) and current (b). Connection is to a stiff grid. Battery is at full SOC and connected. Generator is disconnected.

Figure 5.8 - Simulation results of full SOC battery pack powering V2G operation. Battery pack voltage (a) and current (b) are shown. Connection is to a stiff grid. Generator is disconnected.

Figure 5.9 - V2G simulation results of grid current harmonics in respect to harmonic order. Connection is to a stiff grid. Battery is at full SOC and connected. Generator is disconnected.

Figure 5.10 - V2G simulation results of grid current harmonics in respect to frequency. Connection is to a stiff grid. Battery is at full SOC and connected. Generator is disconnected.

Figure 5.11 - Simulation results of low SOC battery pack powering V2G operation. Battery pack (a) voltage and (b) current are shown. Connection is to a stiff grid. Generator is disconnected.

Figure 5.12 - V2G simulation results of grid voltage and filtered output current with a stiff grid connection. Battery is at low SOC and connected. Generator is disconnected.

Figure 5.13 - V2G simulation results of filtered output current with a stiff grid connection. Battery is at low SOC and connected. Generator is disconnected.

Figure 5.14 - V2G simulation results of grid current harmonics in respect to harmonic order. Connection is to a stiff grid. Battery is at low SOC and connected. Generator is disconnected. 
Figure 5.15 - V2G simulation results of grid current harmonics in respect to frequency. Connection is to a stiff grid. Battery is at low SOC and connected. Generator is disconnected.

Figure 5.16 - V2G simulation results of grid voltage and filtered output current with a weak grid connection. Battery is at full SOC and connected. Generator is disconnected.

Figure 5.17 - Zoomed view of grid voltage and current simulation results (see Figure 5.16): (a) starting transient and (b) steady state.

Figure 5.18 - V2G simulation results of filtered output current with a weak grid connection. Battery is at full SOC and connected. Generator is disconnected.

Figure 5.19 - V2G simulation results of grid current in respect to harmonic order. Connection is to a weak grid. Battery is at full SOC and connected. Generator is disconnected.

Figure 5.20 - V2G simulation results of grid current harmonics in respect to frequency. Connection is to a weak grid. Battery is at full SOC and connected. Generator is disconnected.

Figure 5.21 - Simulink implementation of V2G in a stiff grid connection. The battery is disconnected and generator is on.

Figure 5.22 - V2G simulation results of DC link bus capacitor voltage (a) and current (b). Connection is to a stiff grid. Battery is disconnected. Generator is connected and on......

Figure 5.23 - V2G simulation results for DC generator shaft speed (a), current (b), and torque (c). Connection is to a stiff grid and battery is disconnected. 102 
Figure 5.24 - V2G simulation results of grid voltage and filtered output current with a stiff grid connection. Battery is disconnected. Generator is connected and on.

Figure 5.25 - V2G simulation results of filtered output current with a stiff grid connection. Battery is disconnected. Generator is connected and on.

Figure 5.26 - V2G simulation results of grid current harmonics in respect to harmonic order. Connection is to a stiff grid. Battery is disconnected. Generator is connected and on.

Figure 5.27 - V2G simulation results of grid current harmonics in respect to frequency. Connection is to a stiff grid. Battery is disconnected. Generator is connected and on 


\section{Introduction}

\subsection{Background}

Currently there are an estimated 1.7 million plug-in electric hybrid vehicles (PHEVs) on roads worldwide [1]. There is a great potential to harness electric vehicles (EVs) for vehicle-to-grid (V2G) services as the number of EVs continue to increase in popularity for their high efficiency and reduction of greenhouse gas emissions compared to conventional vehicles. An EV is a vehicle which can be propelled electrically. This includes all vehicles with fully or partially electrified drivetrains. V2G is the transfer of electrical energy from the vehicle to the power grid. For a typical V2G capable EV, energy starts from the energy storage device, such as the battery pack, proceeds through a power converter and finally enters the grid through a plug. In essence, it is advantageous to have EVs enabled with V2G capabilities for electric utilities. An EV may act as distributed generation (DG) to supply power to the grid or loads [2].

Vehicles originally designed as plug-in electric vehicles (PEVs) are prime candidates for adding V2G capabilities. Commercialized PEVs are EVs that include PHEVs, hybrid electric vehicles (HEVs), plug-in all-electric vehicles, and Extended Range Electric Vehicles (EREVs). These PEVs have battery charging capabilities through a wall plug connection to the grid. Since battery charging power electronics are similar to V2G power electronics and operations, the added costs and volume from incorporating V2G power electronics is reduced. V2G capabilities can be integrated with available power electronics and modifications. PEVs have a certain all-electric range which requires larger battery capacities with respect to other EVs such as HEVs. Larger 
battery capacities can sustain V2G services for longer periods of time. Therefore, a lower amount of V2G capable vehicles are needed to positively affect the power grid and vehicle owners can collect increased monetary gains.

EVs with V2G functionality benefit both customers (vehicle owners) and the grid (owned by utilities). If the vehicle is connected to the grid for regulation services, annual average income is estimated at $\$ 2,000$ per vehicle [3]. Grid support services are only activated when the vehicle is not in use (e.g. parked). On average, vehicle usage in the USA is approximately 1 hour per day [4]. This leaves V2G capable PEVs to be available for grid support 23 hours per day. Regulation support not only includes discharging but charging the battery as well. For instance, customers benefit through monetary gain to charge their EVs during down regulation. Customers do not have to worry about low battery levels when the vehicles are needed since on average, there is minimal battery net power loss during regulation services [3]. The utility also benefits by having a more robust, efficient, and responsive grid. In contrast to typical power plants, EVs are directly located at loads, increasing operating transmission efficiency. Currently in the United States, electric power can travel through multiple states before reaching loads. Power plants respond slowly to up/down regulation commands due to inertia of rotating mass and chemical thermal properties. In comparison to power plant response times of 30 seconds to several minutes, V2G power converters can respond at $1 / 20^{\text {th }}$ second [3]. This feat is due to the inherent nature of V2G power electronics which do not use rotating masses or chemical thermal properties. The rapid response times of V2G offer faster regulation services such as frequency and voltage regulation. V2G capabilities may offer 
power quality improvements through peak load shaving and grid ancillary services (e.g. spinning or non-spinning reserve) [5].

Peak load services are extremely beneficial for the electric infrastructure. Figure 1.1 is an example of a typical daily system load in California where the system peaks at $\sim 3: 30 \mathrm{pm}$. The idea of peak shaving is to charge V2G capable PEVs during low load periods and discharge back into the grid during the peak periods. This would result in a lowered peak as seen by the electrical power system infrastructure (e.g. transmission lines). Infrastructure upgrades and design is based on the peak such that if the peak is lowered, infrastructure requirements would be reduced which is less costly for the electric utility.

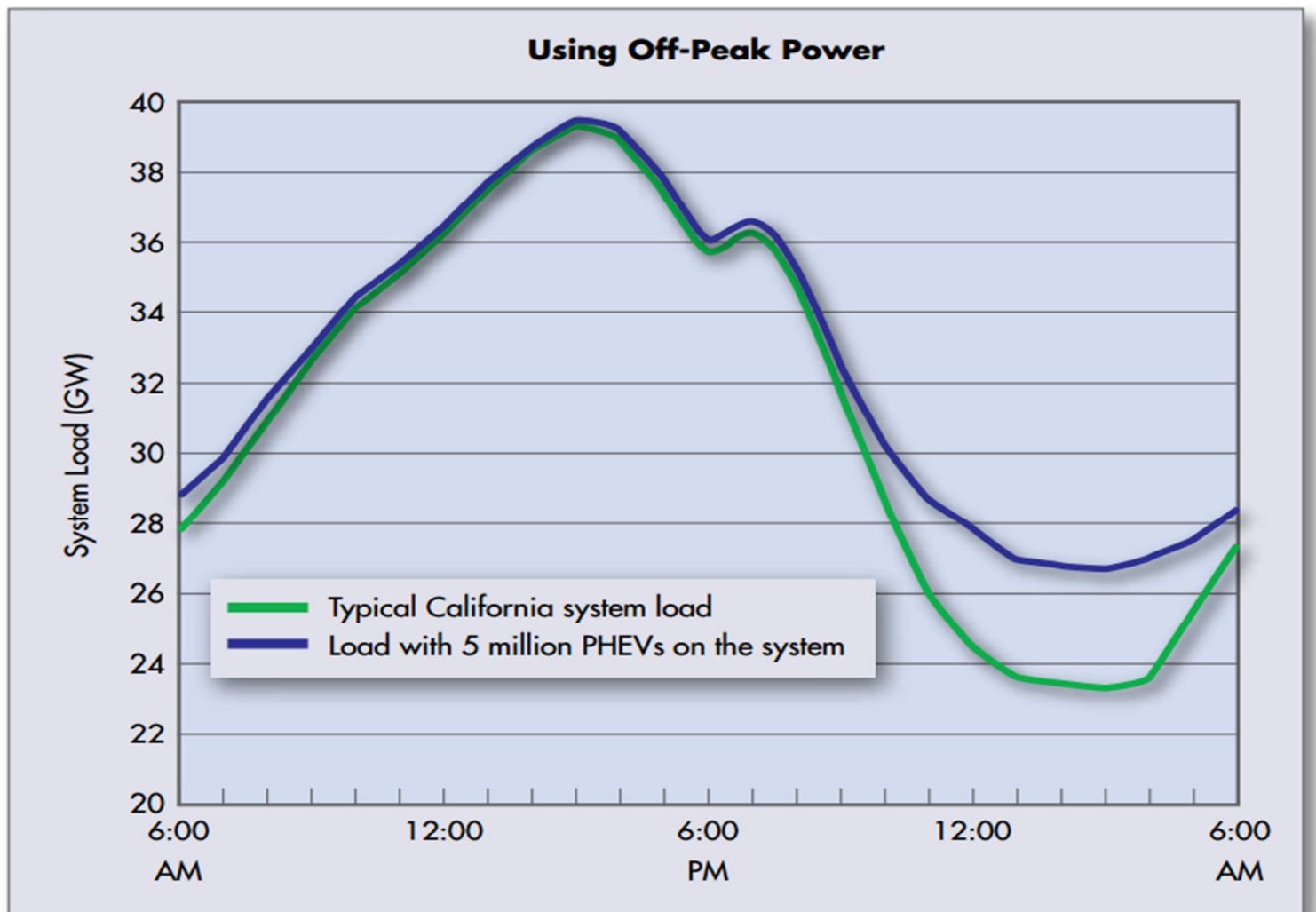

Figure 1.1 - Typical daily system load and the effect of 5 million PHEV load [6]. Only PHEV charging effects are shown, V2G effects are not shown since data does not currently exist. 


\subsection{V2G Power Converters}

\subsubsection{Overview}

PEVs all come with an off-line charger to recharge the energy storage device (e.g. battery pack). Generally, they are DC-DC power converters with power factor correction (PFC). The topology may inherently be bidirectional although they are only harnessed uni-directionally. V2G capable PEVs must maintain their G2V battery charging functionality while adding bidirectional power flow capabilities. An undesirable effect of adding V2G capabilities is that the cost, volume, and weight of the original charger will increase. Complexity, controls, semiconductor switches, gate drivers, and/or more processing power are required regardless of whether a uni- or bidirectional topology is chosen. A bidirectional power converter topology may be used to reduce undesirables in respect to a system of multiple uni-directional power converters. Further undesirable reductions may come from an EV drivetrain integrated $\mathrm{G} 2 \mathrm{~V}-\mathrm{V} 2 \mathrm{G}$ power converter design. Bidirectional topologies and EV drivetrain integrated designs offer the benefit of reusing many of the same components (i.e. passive components, semiconductor switches, and gate drivers) for each respective direction of power flow and varied functions (i.e. battery charging, V2G, and propulsion).

Bidirectional G2V-V2G power converters may be implemented as a single- or two-stage system. General block diagrams are shown Figure 1.2 and Figure 1.3 for single- or two-stage systems respectively. Single-stage implementations usually combine inverter/rectifier, bidirectional DC-DC battery charger, and high voltage traction bus DCDC power converters into one topology. Two-stage systems are a combination of two bidirectional subsystems: AC-DC and DC-DC. The total system must have the 
functionalities of a bidirectional battery charger, rectifier, and grid-tie inverter. Power flow must be controllable from the battery to grid and vice versa. Charging the battery entails grid power flowing through an AC-DC converter proceeding to a DC-DC converter that safely controls battery charging. In between the two subsystems usually exists a DC link to help regulate voltage levels as power is transferred from one converter to another. Discharging the battery power to the grid is much more challenging but the subsystems are similar. Power begins at the battery which is discharged through a DCDC converter proceeding to a DC-AC converter. More specifically the DC-AC converter is a grid-tie inverter. Notice the task of each subsystem is basically the same for both cases. Only the direction of power flow is opposite. Those reasons allow subsystems to use bidirectional topologies to reduce the final system cost, volume, and weight.

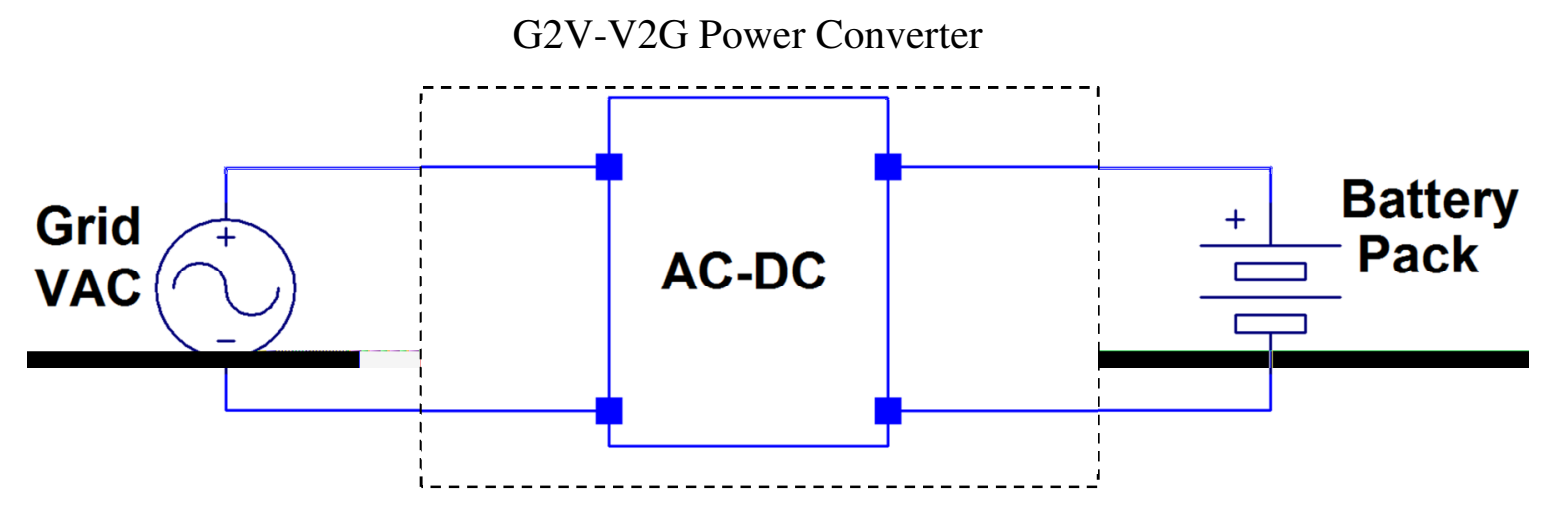

Figure 1.2 - Black box diagram of general G2V-V2G single-stage power converter. 


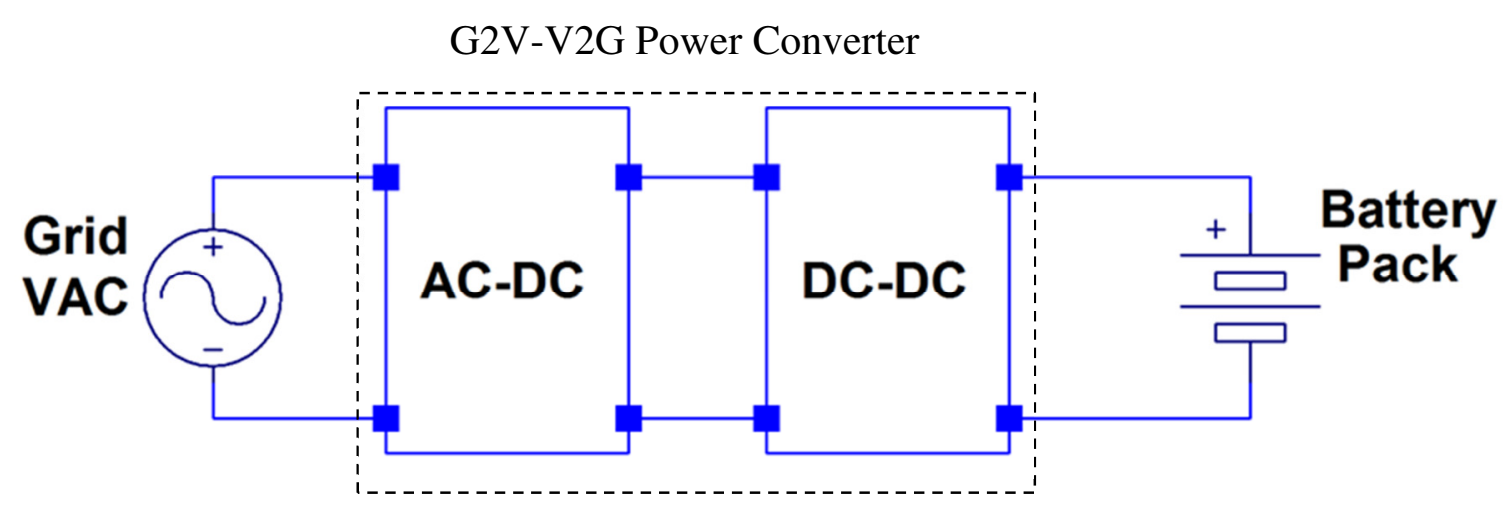

Figure 1.3 - Black box diagram of general G2V-V2G two-stage power converter.

\subsubsection{Literature Review}

The following literature review will summarize successfully utilized G2V-V2G topologies. The topologies that would be advantageous from an automaker's perspective will be identified. The primary concern of automakers is minimizing the additional cost, weight, and volume to the off-line charger system. Note, the actual process and selection of the proposed topology versus other candidates are discussed in chapter 3.

In literature, single-stage topologies have been successfully simulated with V2G capabilities. A modified bidirectional dual active bridge with zero voltage switching (ZVS) was explored in [7]. Unfortunately, the topology requires 12 switches, a resonant tank, and high frequency (HF) transformer. A single-stage solution eliminated the typical full wave rectifier/2-legged half-bridge (HB) combo in [8]. Rectification and inverter operations were integrated into a modified bidirectional non-inverting buck-boost converter. Both V2G and G2V operations are done via buck-boost mode. The topology has merits with a component count of only 8 switches, 1 inductor, and 1 capacitor. The low component count reduces additional cost, volume, and weight for enabling V2G. 
While [8]'s topology is a valid candidate from an automaker's perspective [7]'s topology is not.

Many different topologies have been used for the AC-DC bidirectional subsystem in a two-stage system. For a single phase connection, the most common bidirectional ACDC topology is a 2-legged H-bridge with anti-parallel diodes that form a full wave rectifier $[9,10,11,12,13]$. The 2-legged configuration popularity is due to low component count and simplicity. When a three phase connection is needed, a 3-legged HB with anti-parallel diodes is most prominently proposed $[14,15,16,17,18]$. It possesses the same advantageous of a 2-legged HB, but for a three phase system. Furthermore, 3-legged HB has been proposed for single phase grid-tie inverter operation $[2,19]$. The extra leg is connected to the neutral in a North American 240VAC, $60 \mathrm{~Hz}$ connection. A 2-legged HB handles such a connection by splitting the DC link capacitors into two series capacitors. The neutral is connected in between the capacitors so the neutral branch always has a current path. Otherwise, there may be a voltage offset. A 3legged HB uses its neutral leg to eliminate any voltage offset due to unbalanced loads. The neutral leg is pulse width modulated (PWM) at a 50\% duty cycle to achieve this [19]. Benefits also include the elimination of DC capacitor voltage balance issues, smaller output filter size, smaller DC bus current ripple, and higher utilization of dc bus voltage [20]. Use of three-level neutral-point-clamped (NPC) or modified versions have been proposed $[21,22]$. Any benefits from the three-level NPC are mitigated by the switch count of 6 and 8. Both 2- and 3-legged HBs are valid candidates and will be considered in chapter 3. 
A variety of topologies have been used for the DC-DC bidirectional subsystem in a two-stage system. Many topologies only work if the battery voltage is always greater than the required DC link bus voltage or vice versa. The HB converter topology, also known as a buck or boost, is most popular in literature for $\mathrm{G} 2 \mathrm{~V}-\mathrm{V} 2 \mathrm{G}$ power converters $[9,10,11,13,15,16,19,22]$. The low component count and simplicity makes it an ideal candidate if a few requirements are met. The battery voltage must always be greater than the DC link bus voltage. As a result, the HB converter charges the battery in boost mode and discharges the battery in buck mode. Otherwise HB converter cannot be used for the DC-DC subsystem. The dual active bridge and such based topologies are utilized in literature $[12,14]$. The topologies contain a HF transformer for galvanic isolation, but need at least 8 semiconductor switches to operate. The high parts count makes dual active bridge based topologies unattractive candidates unless galvanic isolation is a necessity. An $\mathrm{HB}$ converter is an attractive candidate if the battery voltage can be guaranteed to be greater than the DC link bus voltage level.

V2G technologies have motivated researchers since 1997, but more research is required to understand $\mathrm{V} 2 \mathrm{G}$ implementations for personal vehicles of the average consumer [23]. Grid support services from V2G EVs have been studied in economics and logistical requirements $[2,23,24,25,26,27,28]$. There are many technical challenges in V2G design and implementation. A wave of technical V2G designs and implementations have been discussed in literature. These technical designs and discussions include a number of topologies and control methods $[2,5,7,8,9,10,11,14,15,16,19,21,22,29$, 30, 31, 32, 33, 32, 34]. Furthermore, V2G systems have been studied in industry since patents exist $[17,18]$. 


\subsection{Thesis Scope}

This thesis will focus on designing and integrating a V2G power converter for a PEV available to average consumers. To reap all the benefits V2G services may provide, PEVs with V2G capabilities must be widely adopted. Automakers will only consider including V2G functionality if there are no major impacts to vehicle production prices. The motivation of this thesis is to integrate V2G functionality into a PEV which has the potential to be widely adopted. Power converter design and analysis will be from the automaker's perspective. Hopefully this thesis will encourage and assist in the adoption of V2G capable vehicles for automakers.

The main variables to consider for automakers will be cost, volume, weight, safety, reliability, and complexity of integration. PEVs are currently more expensive to produce than conventional vehicles and hybrids. Although the added cost of V2G functionality maybe minimized due to integration of already available components, the added costs still decreases automakers profits. It is ideal to keep costs low. The current vehicle (2011 Chevy Volt) may lack available space for additional components. If additional component volumes are minimized, it will ensure minimized time in finding available placement and modifications. The life expectancy of a car is at least 5 years so reliability is a crucial variable. Electrical power can be a safety hazard to human beings if electrical systems aren't properly designed. This is especially true since V2G EVs can exchange power with the grid. To ensure the correct safety precautions, electrical codes and standards will be considered. The focus of this thesis is the power converter topology for nominal grid conditions. Lastly, if the system implementation is too complex to integrate with the current PEV, it may not be viable. It is imperative that all design 
assumptions are conservative when system variables are unknown such as motor configuration or power ratings.

The V2G power converter system will be designed for the 2011 Chevy Volt for a variety of reasons. A large body of information is available about the 2011 Chevy Volt through the Society of Automotive Engineers (SAE) technical papers on its EREV drivetrain. The Chevy Volt is the first EREV in production. For V2G EVs to make an impact on the grid, a large number of V2G EVs are required. EVs with a larger battery pack capacity $(\mathrm{kWh})$ require a lower number of $\mathrm{V} 2 \mathrm{G}$ EVs to affect the grid via V2G services. Currently range anxiety can be subsided for certain PEVs such as PHEVs and EREVs due to increased ranged via internal combustion engine (ICE). Of the two, EREVs likely have a larger battery pack due to its longer all-electric range [35]. PEVs with V2G capabilities have been produced and released in low numbers. In literature, V2G technical analysis and designs focus on general EV assumptions for design requirements. For most vehicles, vehicle specific details are proprietary information. Luckily, General Motors published specific details of interest about the 2011 Chevy Volt in the Society of Automotive Engineers SAE. Those details will limit assumptions and unknown variables leading to a more accurate and comprehensive design with fewer unknowns. When EV specifications are used, they are usually limited to battery characteristics. Literature has widely used Toyota's Prius in V2G converter analysis and designs. The Prius is available in HEV and PHEV configurations. Literature has not yet based design considerations of a V2G power converter for an EREV. This thesis G2VV2G power converter design will focus on the 2011 Chevy Volt. 
Verification of the G2V-V2G power converter design will only be tested through computer simulations using MATLAB Simulink. MATLAB Simulink has been widely used in literature to verify V2G power converter designs $[5,11,15,22]$. The ability of MATLAB Simulink to handle complicated controls, and integrate different type of systems makes it the perfect candidate for simulations and verification. The focus is V2G operation, but G2V operation will still be discussed.

GM's engineers have already decided on the best charging algorithm and process for their batteries. With the limited amount of information available, it is better to assume that they will translate the same battery charging algorithm and process to the new topology. If the topology doesn't offer all they need for battery charging (e.g. galvanic isolation, power factor correction, pulse charging, etc.), they will make the necessary modifications. The main hope is they will see the advantages of using the proposed converter and use it at least as the framework.

\subsection{Thesis Organization}

The thesis is organized into 6 chapters. Chapter 1 introduces V2G, its benefits, and $\mathrm{V} 2 \mathrm{G}$ power converters. It is followed by the thesis scope and thesis organizational layout. Chapter 2 considers and specifies design constraints. Design specifications are summarized from the 2011 Chevy Volt characteristics. Both codes and industry standards of interest are discussed. Chapter 3 considers and selects which topologies are most suited for a G2V-V2G power converter in respect to the automaker's perspective. Chapter 4 integrates the proposed power converter topology and summaries. The controls are described and passive component calculations are given. Beginning chapter 5 is a quick overview of how the battery, grid, and semiconductor devices will be modeled in 
Matlab Simulink. Verification is presented for different G2V-V2G power converter modes in Matlab Simulink as well. Concluding the thesis will be chapter 6. A review of the results and its implications are stated with recommendations for future work. 


\section{Design Considerations and Specifications}

\subsection{Overview}

Design requirements are important to create a feasible and robust design. Again, the design will be considered from General Motor's perspective since they manufacture the 2011 Chevy Volt. To create design requirements, accurate specifications and capabilities of the EREV must be laid out. The least amount of modifications to the current 2011 Chevy Volt would make the design more feasible as it is more plausible to integrate. Industry standards of interest (e.g. DG connected to the grid, EV codes, etc.) must be carefully considered to uphold safety and quality. USA standards of interest to V2G power converters are summarized. Performance must be within industry standards to be considered feasible. A summary of the constraints will be available in chapter 2, section 5 .

\subsection{Chevy Volt}

Considering the Volt's has an 8 year warranty for the battery and Voltec (name of 2011 Chevy Volt's drivetrain) components, the life expectancy of the vehicle is at least 8 years [36]. Design reliability must at least meet the warranty duration. Safety is always of the upmost importance for any manufacturer including automakers. Defects or incorrect safety designs can cause life threatening events, negatively impacting the manufacturer and customers. To create a final package, power converter volume plays a major role. If the system cannot be fitted in the vehicle during the production process, major modifications must be done to the vehicle. Finally, profit from sales is what determines the success or failure for an automaker. At an MSRP of $\$ 39,145$ (without tax and rebate credits), the Chevy Volt is already expensive compared to conventional ICE vehicles 
[36]. Currently, its main competitor is the Nissan Leaf which has an MSRP that is approximately $\$ 4,000$ less [37]. Already highly priced compared to the competition, additional costs should be minimized for a feasible design. Cost is largely attributed to additional components which are also related to volume and weight. Limiting additional components is critical to a viable design.

\subsubsection{Drivetrain}

First, the existing systems of interest in the Chevy Volt must be understood. Even though all the specific details may not be known, an accurate model for our needs can be created from released information and educated assumptions from industry practices. It is important that the implementation of $\mathrm{V} 2 \mathrm{G}$ capabilities is unobtrusive so that all functionality of the Chevy Volt is maintained for consumer usage.

Functionalities that may be affected in V2G integration with the Chevy Volt include powering traction motors through the battery, maintaining SOC of the battery through an onboard generator, and battery charging through a power outlet. Please note that the information presented in the following section (2.2.1) was created through GM's released data. GM may have left out proprietary information or provided generalized data. The information should lead to a good model and starting point. Therefore it will provide an idea of bidirectional $\mathrm{V} 2 \mathrm{G}$ power converter design constraints. The model is not exact, therefore the V2G power converter may require modifications if the real 2011 Chevy Volt has different specifications (e.g. battery voltage). The general layout of the system with relay contactors was released in [38] and is reproduced in Figure 2.1. 


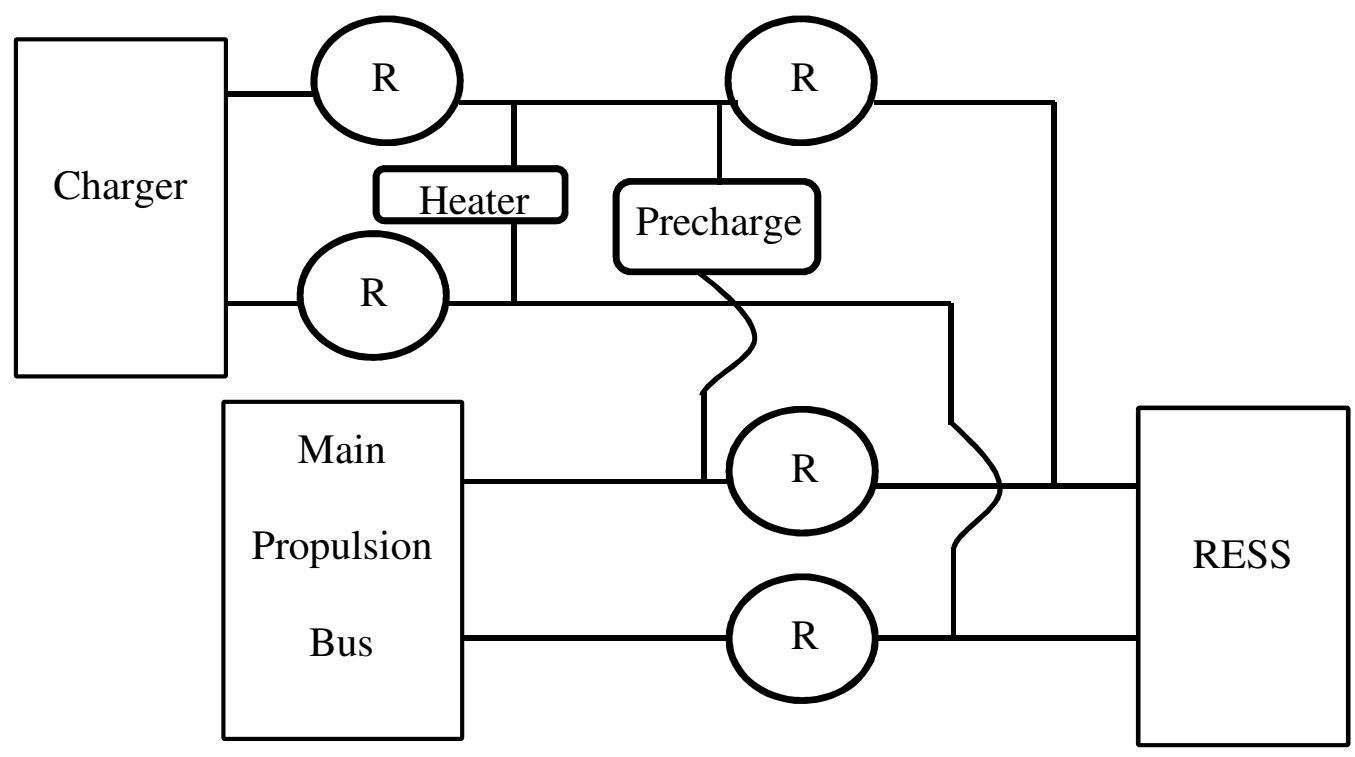

Figure 2.1 - General layout [38].

As shown in Figure 2.1, power flow from the onboard portable charger to rechargeable energy storage system (RESS) is controlled with relay contactors. Relay contactors are denoted with "R." Heater and precharge boxes each contain a semiconductor switch in series with passive components. Different contactors are triggered during different functions. Control of the relays will be needed to enable power flow to the V2G system. If layout changes are needed, they will be addressed when the topology is proposed in chapter 4 (see Figure 4.2). Control of the relays to enable charging and discharging to the grid will not change any of the Volt's functionalities since propulsion motors will be inactive.

Since the different systems in the Chevy Volt interact with each other, it is important that the ratings and specifications are maintained between interacting systems. The ratings and specifications will be used during design of each subsystem. To achieve this, the specifications and details of the Voltec drivetrain must include traction motors, traction electronics, battery pack, and on-board charger systems. 
The Chevy Volt propulsion depends on a main motor and a secondary motor/generator. Motor A, the main motor, is a 3-phase $\mathrm{AC}$ induction machine rated at $111 \mathrm{~kW}$. The secondary motor/generator, motor $\mathrm{B}$, is a high-flux permanent-magnet $\mathrm{dc}$ machine rated at $55 \mathrm{~kW}$ [38]. The machines interact with a system called the traction power inverter module (TPIM) which controls functions of the motors and RESS. Each motor has its own respective power inverter module (PIM), but are identical in specifications (see Table 2.1). Each PIM is encased in the TPIM which is liquid cooled. PIMs are voltage source inverters (VSIs) with a 3-legged H-bridge configuration. PIMs also include EMC filters, DC bus filter capacitor, and other necessary components shown in Figure 2.2 [38]. To show all systems of interest, Figure 2.2 was modified from [38] with assumptions: all PIMs are 3-legged VSI, All PIMs connect to the same high voltage bus and DC link capacitor, and battery pack connects to high voltage bus during propulsion. These assumptions were made since there was some missing and/or conflicting information. This is to no surprise since design ambiguity maintains an automakers competitive edge.

Table 2.1 - Ratings of PIM A \& B [38].

\begin{tabular}{|c|c|c|}
\hline Power Rating & Current & Voltage \\
{$[\mathrm{kW}]$} & Rating [A] & Rating [V] \\
\hline 120 & continuous, & 430 peak \\
& 450 peak & \\
\hline
\end{tabular}




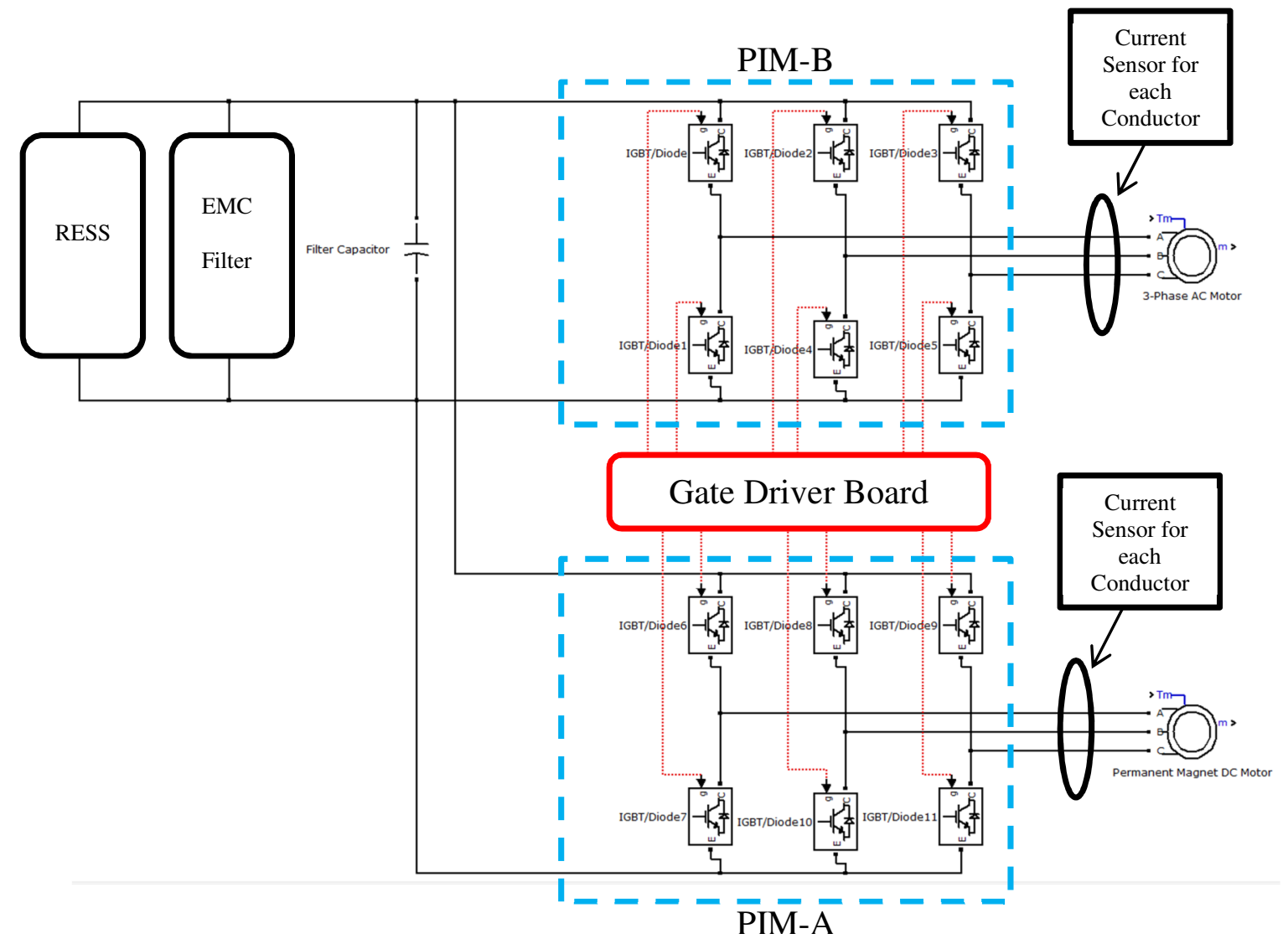

Figure 2.2 - PIM-A, PIM-B, and system interface [38].

Out of the factory, the Chevy Volt comes with an on-board portable battery charger. The portable battery charger can operate on AC level 1 single phase 120VAC, $60 \mathrm{~Hz}, 12 \mathrm{~A}_{\mathrm{MAX}}$, and $1.2 \mathrm{~kW}$. Also it is able to operate on AC level 2 single phase 208V/240V, 60Hz, $15 \mathrm{~A}_{\mathrm{MAX}}$, and $3.3 \mathrm{~kW}$ charging. The AC level 2 charge unit requires a single phase 2 wire with a ground connection [39]. The given specifications match exactly with SAE $\mathbf{J} 1772$ as required.

The Voltec battery pack powers V2G operation and must be properly identified. The Voltec prismatic battery cell technology is built on lithium-ion manganese-spinel $\left(\mathrm{LiMn}_{2} \mathrm{O}_{4}\right)$ chemistry, manufactured by LG Chem's subsidiary Compact Power Inc. Even 
though the exact cell charging/discharging curves were not released to the public, they are assumed to be approximately the same as other lithium-ion battery curves.

The battery pack is comprised of 288 cells with a nominal voltage of $360 \mathrm{~V}$. The $16 \mathrm{kWh}$ battery pack is only operated within a range of $85 \%$ to $20 \%$ SOC [40]. Note GM incorrectly states battery operation at $85 \%$ to $30 \%$ SOC in [38]. From the 8 year battery warranty, it must be reliable at least after 8 years of usage. V2G operation will increase charging and discharging cycles throughout its lifetime which will affect battery life. The effects must be thoroughly studied, but is not the purpose of this thesis. It is assumed that when implemented, $\mathrm{V} 2 \mathrm{G}$ effects on vehicle batteries have been taken into account. The battery technology and engineering design should accommodate for V2G throughout at least its 8 year lifespan by then. Operating the batteries outside of its acceptable ranges will be detrimental to battery life. Batteries based off lithium ion chemistries are highly sensitive to voltage and temperature. The Chevy Volt has already implemented their own battery management system (BMS) to protect the batteries. It would serve no purpose to create one in this study. GM has unreleased specific information and research on their Voltec hardware and batteries. The V2G system will assume BMS can stop V2G or G2V operations at any moment through relays connecting the battery pack to power converter (see Figure 4.2)

\subsection{Industry Standards for Integration of DG}

To ensure safety and correct designs practices, industry standards/codes must be considered pertaining to the $\mathrm{G} 2 \mathrm{~V}-\mathrm{V} 2 \mathrm{G}$ power converter. These include standards/codes from Institute of Electrical and Electronics Engineers (IEEE), Society of Automotive Engineers (SAE), National Electric Code (NEC), and Underwriters Laboratory (UL). 
These standards and codes do not pertain to the whole international community. This design will be based on the US market only, so the international standards such as International Electrotechnical Commission (IEC) will not be considered. Although they will not be used, the standards and codes are similar. They will lead to the same basic design requirements. Emphasis will be on code and standards on distributed energy resource (DER) grid interface as others do not fit into the scope of this thesis.

\subsubsection{IEEE}

G2V-V2G equipped EVs can be considered a distributed energy resource (DER). DERs are similar to DGs and are required to follow IEEE 1547. V2G systems are similar to one of the most popular forms of DG, photovoltaic (PV) systems. Lessons learned from PV systems can be applied to V2G systems [41].

IEEE 1547 has mandatory DER/DG requirements for abnormal grid conditions for safety of equipment, the public, and linemen. Abnormal grid conditions have specific time response requirements for DGs/DERs to disconnect or reconnect. Examples of abnormal grid conditions are unacceptable levels of voltage and/or frequency variations. A much more serious situation is the electric utility grid losing voltage where the EV and EVSE would not be allowed to energize the public utility infrastructure. It must detect the condition and cease to energize the area within an allotted time. This is to prevent damaging equipment or the line and most importantly utility workers who assume the lines are de-energized. The requirement is named anti-islanding and is the most challenging aspect of grid-tie inverters (GTI) [42]. For the purpose of this thesis, the grid will be assumed to be always nominal. No abnormal grid conditions will be tested since that is done via controls. The extra controls specially focus on the grid and not the G2V- 
V2G power converter. Standards and technology advancements for dealing with abnormal grid conditions are still being explored and may change dramatically by the time V2G capable PEVs are mass produced. When the time comes, it is important to borrow those technologies for PV systems as less development and more proven technology can be used for such purposes such as low voltage ride through (LVRT).

Power quality standards must be met when connected to the grid or utility connected equipment may be damaged [42]. The primary concern for GTIs is current harmonics. Current harmonics must be controlled or large current-distortion may negatively affect equipment connected to the grid. As per IEEE 1547, harmonic limitations are shown on Table 2.2. Total harmonic distortion (THD) is the summation of all harmonics. Note, even harmonics are only allowed to be $25 \%$ of odd harmonic counterparts. DC current injection is an issue as well for transformerless inverter topologies. DC current injection can cause utility distribution transformers to saturate causing overheating and trips [42]. As per IEEE 1547, DC current injection must be less than $0.5 \%$ of rated RMS current.

Table 2.2 - IEEE 1547 current harmonic limits [43].

\begin{tabular}{|c|c|c|c|c|c|c|}
\hline $\begin{array}{c}\text { Harmonic } \\
\text { Order }\end{array}$ & $\mathrm{h}<11$ & $11 \leq \mathrm{h}<17$ & $17 \leq \mathrm{h}<23$ & $23 \leq \mathrm{h}<35$ & $35 \leq \mathrm{h}$ & $\begin{array}{c}\text { THD } \\
{[\%]}\end{array}$ \\
\hline Odd [\%] & 4.0 & 2.0 & 1.5 & 0.6 & 0.3 & 5.0 \\
\hline Even [\%] & 1.0 & 0.5 & 0.375 & 0.15 & 0.075 & \\
\hline
\end{tabular}




\subsubsection{SAE}

Most SAE standards do not pertain to the scope of this thesis except those for the charging connector. The rest of the standards mainly focus on communication between PEVs, EVSE, utility grid, and customers. Standard SAE J1772 must be met by all highway capable PEVs for AC Level 1 and 2 charging [41].

The Volt already uses a coupler that meets the standard requirements. The plug and cord used for each charging/discharging condition will be identical since the same conditions will be present with the exception of power flow which may change.

\subsubsection{NEC}

The 2011 NEC, Article 625 covers all electrical wiring between PEV skin and service point connection. Article 625.14 focuses on EVSE ratings. EVSE ratings are assumed to be continuous as EV loads are considered continuous loads [44]. A summary of the ratings are available on Table 2.3 below.

Table 2.3 - Summary of EVSE continuous operating ratings from 2011 NEC 625.14.

\begin{tabular}{|c|c|c|c|c|}
\cline { 2 - 5 } & $\begin{array}{c}\text { Voltage Rating } \\
{[\text { VAC] }}\end{array}$ & $\begin{array}{c}\text { Current Rating } \\
{[\mathrm{A}]}\end{array}$ & $\begin{array}{c}\text { Power Rating } \\
{[\mathrm{kVA}]}\end{array}$ & $\begin{array}{c}\text { Overcurrent } \\
\text { Setting [A] }\end{array}$ \\
\hline AC level 1 & 120 & 12 & 1.4 & 15 \\
\hline AC level 2 & 208 & 32 & 6.7 & 40 \\
\cline { 2 - 3 } & 240 & & 7.7 & 40 \\
\hline
\end{tabular}

NEC 625.25 is an anti-islanding clause while NEC 625.26 is an exception for EVs providing grid support or back up power [44]. More specifically, NEC 625.25 states that during loss of voltage from utility or power source(s), power cannot be back fed from EV 
or EVSE unless under Article 625.26. The exception stated by Article 625.26 pertains to EVSE and EV systems connected, listed, and intended for the purpose of servicing standby system, electrical power production source, or provide bidirectional power. The V2G system will operate under NEC 625.26 since its intended purpose is to provide bidirectional power for grid services or backup power for your home.

The market for PV GTIs has moved towards transformerless systems. Transformerless inverters have advantages over galvanic isolated inverters, such as lowered volume, weight, and cost. Furthermore, efficiency is typically increased by $\sim 1-$ 2\% [45]. PV transformerless GTIs historically were not used in the USA since grounding was required for safety concerns. As PV transformerless GTIs became more prominent and mature, they have been widely accepted by most countries. NEC 690.35 has created the ability for an ungrounded PV system in the USA if certain requirements are met. Translating them to a V2G system, basically ground-fault protection is required for transformerless GTIs. Ground-fault protection can be met via a ground fault interrupter which has been proposed by $\mathrm{V} 2 \mathrm{G}$ converters such as [18, 19, 29].

\subsubsection{UL}

UL provides safety design and testing standards for various industries [41]. UL certifications are a hallmark of vigorous testing to meet industry testing. Tests are based on industry accepted standards and codes such as NEC, IEEE, and SAE. All standards and codes overlap since they are based off each other. Since those standards are already considered, UL standards and testing will not be considered. For example, UL 1741 is used to test IEEE 1547 requirements. 


\subsection{Integrated Design}

Integrated $\mathrm{G} 2 \mathrm{~V}-\mathrm{V} 2 \mathrm{G}$ power converter designs have modified and utilized existing drivetrain components to allow G2V-V2G operation $[5,17,18,46]$. When a PEV is parked or idle, the drive motor and traction power electronics is idle as well. If the drivetrain contains an AC 3-phase motor ( $\mathrm{Y}$ connected or open delta), motor winding inductances may be used as a grid filter [17, 18]. Three-phase motors are typically powered and controlled by a 3-legged HB based inverter. The inverter and many other drivetrain components will be available for usage. An integrated approach has made available two PIMs - three legs of HBs, gate driver circuitry, voltage and current sensors, capacitors, and inductances to create V2G power converter. An integrated approach minimizes the main disadvantages of increased cost, weight, and volume. For an integrated approach to be possible, it is important G2V-V2G power converter subsystem structures are similar to 2011 Chevy Volt PIMs structures (i.e. HB structures).

\subsection{Summary}

The 2011 Chevy Volt has a 360V nominal battery pack. Battery pack operates only at $85 \%$ to $20 \%$ SOC. The system has various contactors to connect different systems (see Figure 2.1). There are two PIMs with 3-legged H-Bridges connected to the same DC bus, EMC filter, and filter capacitor (see Figure 2.2). TPIM is voltage rated at 360V nominal, $430 \mathrm{~V}$ peak and current rated at 150A continuous, $450 \mathrm{~A}$ peak.

AC level 1 is not practical for $\mathrm{V} 2 \mathrm{G}$ due to low power capabilities which requires much higher vehicle penetration to meet grid support demands [41]. V2G operation will only be available in AC level 2, but AC level 1 charging will still be available. AC level 2 effects are considerable for $\mathrm{V} 2 \mathrm{G}$ since PEVs are expected to be connected to grid for 
long periods of time (e.g. workplace, public, or home). The power transfer capacity at AC level 2 may benefit both facilities and grid support services [41]. The Volt's official standalone off-board EVSE is rated at $240 \mathrm{VAC}$ at $3.3 \mathrm{~kW}$ and $14 \mathrm{~A}_{\text {Continous Max }}$, respectively. Chargers are within NEC 625.14 specifications. V2G power converter operation must have low current harmonics and DC current injection to ensure the safety of grid connected equipment. Currently, there are no power factor requirements from IEEE 1547 to allow DG of reactive power [42]. Galvanic isolation is not required if a GFI is included in the G2V-V2G power converter.

It is advantageous for an integrated $\mathrm{G} 2 \mathrm{~V}-\mathrm{V} 2 \mathrm{G}$ power converter. An integrated system decreases cost, volume, and weight. This requires chosen structures to be similar to PIMs which are made of HB structures. 


\section{G2V-V2G Power Converter Topology Considerations \& Selection}

The V2G power converter design is from GM's perspective where safety, reliability, cost, weight, and volume are of utmost importance. Cost, weight, and volume may be greatly minimized if topologies are bidirectional and can be integrated with current Chevy Volt drivetrain systems. If the selected power converter topologies are similar to the Voltec drivetrain topology, the converter may be highly integrated with few modifications. A two-stage power converter structure will be used to increase similarities with the TPIM structure.

Galvanic isolation will not be used so all stages will be non-isolated. GTIs are beginning to transition to transformerless topologies in the USA while some countries have already finished transitioning. The main concern of transformerless GTIs for PV is shock hazard due to leakage current and the capacitance of the solar panels. The solar panels are exposed while vehicle G2V-V2G system will be unexposed. The shock hazard associated with an unexposed system presents an extremely low risk factor.. Modern GTIs are extremely advanced and offer much more protection than a transformer. A Ground Fault Interrupter (GFI) will be added for ground current monitoring and short circuit protection. GFIs monitor ground currents and trip when a short circuit occurs to protect both the system and environment (including shock and electrocution prevention for personnel).

Note, if a transformer must be used, a transformer can be added between the grid filter and grid at line frequency. This is the simplest set-up but requires a large and expensive transformer. Otherwise, the DC-DC stage may be changed to an isolated 
topology in order to reduce the cost, weight, and volume of the transformer. However, this will significantly increase component count and complexity.

\subsection{Bidirectional AC-DC}

\subsubsection{Rectification}

Rectification is the conversion of $\mathrm{AC}$ to $\mathrm{DC}$, in this case grid-to-vehicle. Most topologies are either a 1- or 2-legged HB structure. Both structures may be implemented controlled, uncontrolled, and semi-controlled. Controllability depends strictly on the chosen switch characteristics such as a diode (uncontrolled), thyristor (semi-controlled), and MOSFET or IGBT (controlled). Regardless of controllability, the configuration and topologies are similar.

Controlled/semi-controlled rectification enables greater flexibility (i.e. average output voltage or current) and usually efficiency [47]. The disadvantage is being more expensive and complex to implement. Weight, volume, and reliability of four MOSFETs or IGBTs with controls are undesirable with respect to only four diodes. Controllable rectification is not justifiable for the Chevy Volt.

Of all control methods for rectifiers, uncontrolled rectification is the simplest and cheapest. Uncontrolled rectification can be implemented with a midpoint configuration, half wave bridge, or full wave bridge. A midpoint configuration requires a center tap transformer. In a G2V implementation using a midpoint configuration, the transformer would be connected to the grid, operating at line frequency $(60 \mathrm{~Hz})$. At such low frequencies, the transformer requirement is unjustifiable due to the added cost, volume, and decreased efficiency. 
Compared to a half wave bridge, only two more diodes are required for a full wave bridge. However, a full wave bridge is more commonly used because of its ability to convert AC-DC for the full sinusoid cycle. For that reason, a full wave will have double the average voltage of a half wave. In comparison to the half wave rectifier, the full wave bridge rectifier requires a smaller capacitor for the same ripple requirements, has no DC component of input current, has a higher input power factor, and has a lower THD [47]. An uncontrolled full wave bridge rectifier is shown in Figure 3.1. In this figure, red arrows represent current flow during positive half cycle of grid voltage. On the other hand, green arrows represent the negative half cycle of the grid voltage. Notice how the full wave bridge rectifier has a 2-legged HB structure. This may enable it to easily integrate into the current PEV drivetrain. The most suitable rectifier for the focus of this thesis is a non-isolated uncontrolled diode full wave bridge due to the advantages in cost, size, volume, parts, weight, reliability, and simplicity.

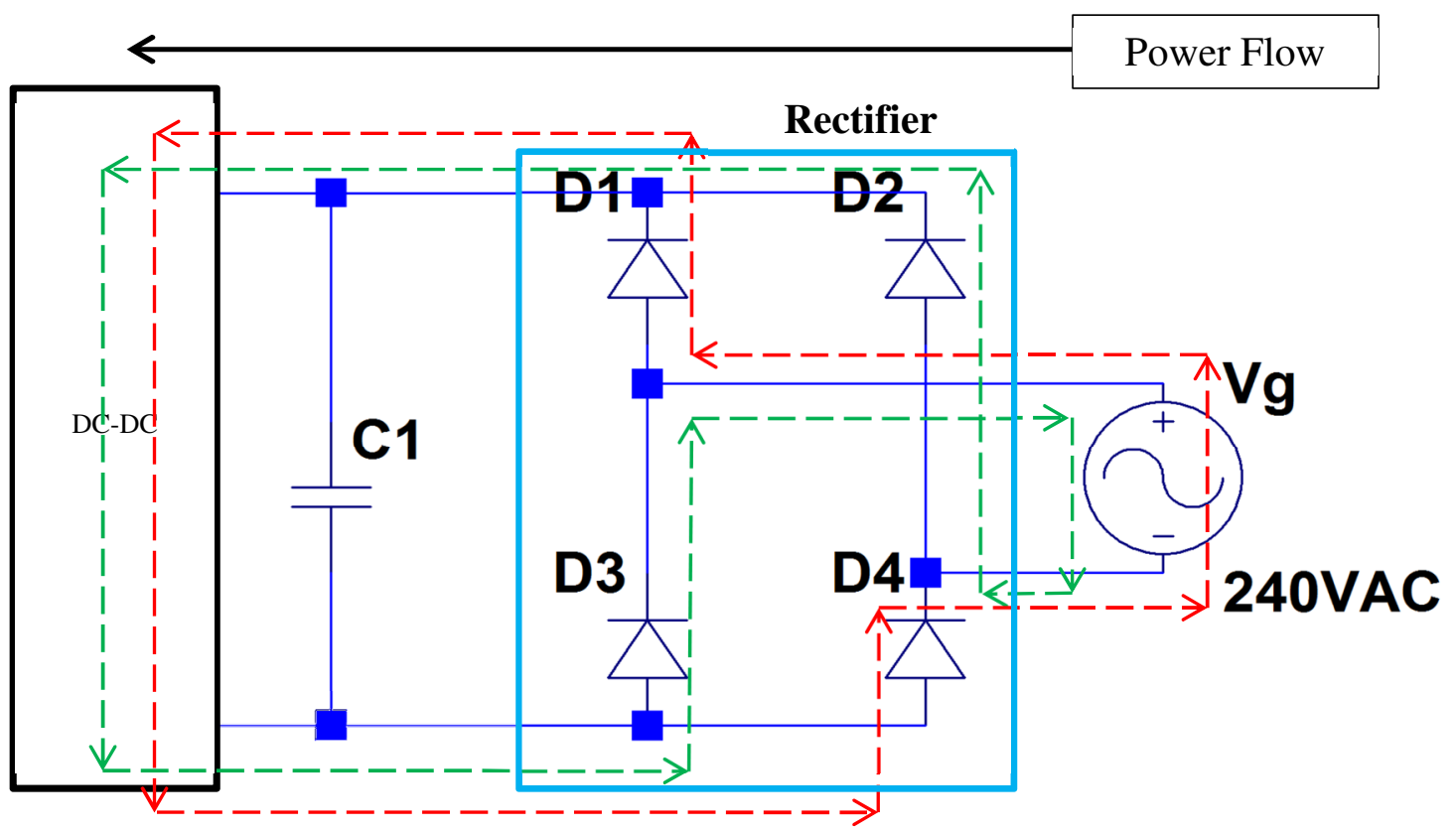

Figure 3.1 - Full wave bridge rectifier with smoothing capacitor and DC-DC converter. 


\subsubsection{Inverter}

\subsubsection{Analysis of HB Family of Inverters \& Modulation Schemes}

The bidirectional AC-DC system must maintain AC-DC capabilities in addition to grid-tie DC-AC capabilities. Grid-tie inverter capabilities allow V2G operations which are not yet available on the Volt. An inverter is another name for a DC-AC power converter. Interestingly, topologies for inverters have similar structures to rectifiers (see Figures Figure 3.2 and Figure 3.3). The light blue boxes highlight the inverter topologies. In Figure 3.2, the purpose of the DC link capacitors (labeled C1 and C2) is to maintain voltage of the DC link for a 1-legged HB inverter. In Figure 3.3, the purpose of the DC link capacitor (labeled C1) is to maintain the voltage of the DC link for a 2legged HB inverter.

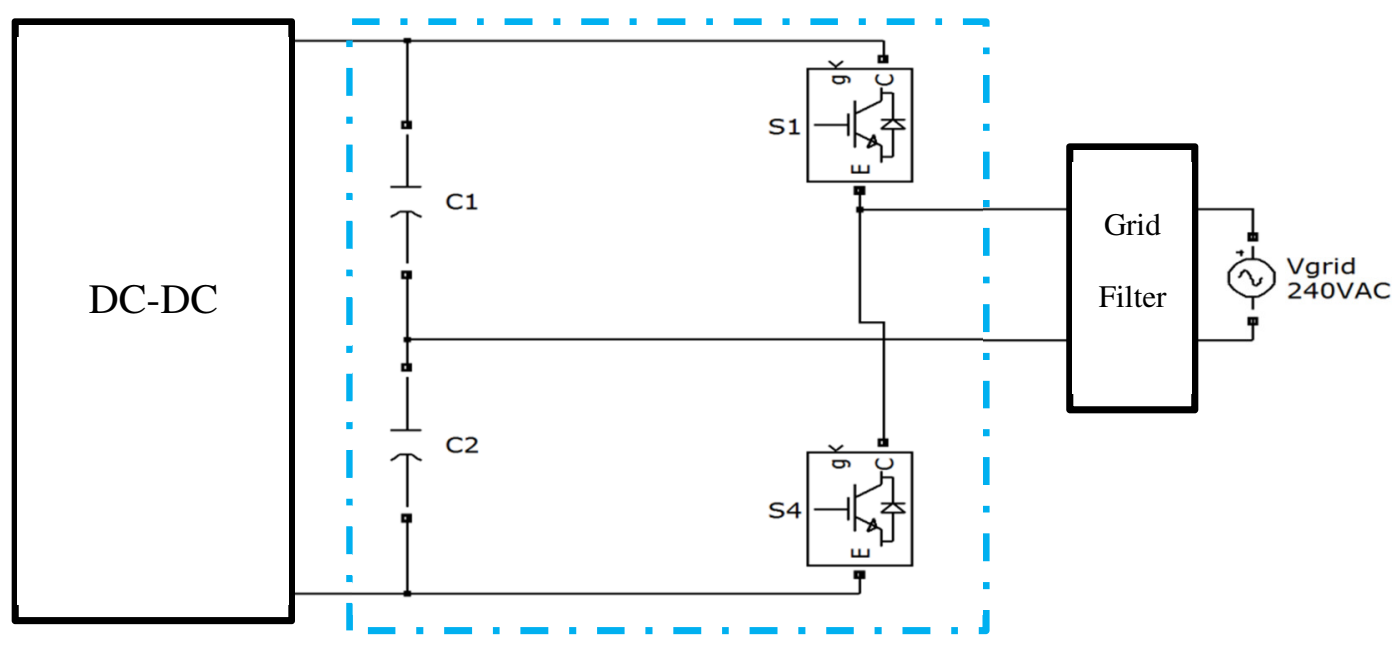

Figure 3.2 - Inverter, 1-legged HB. 


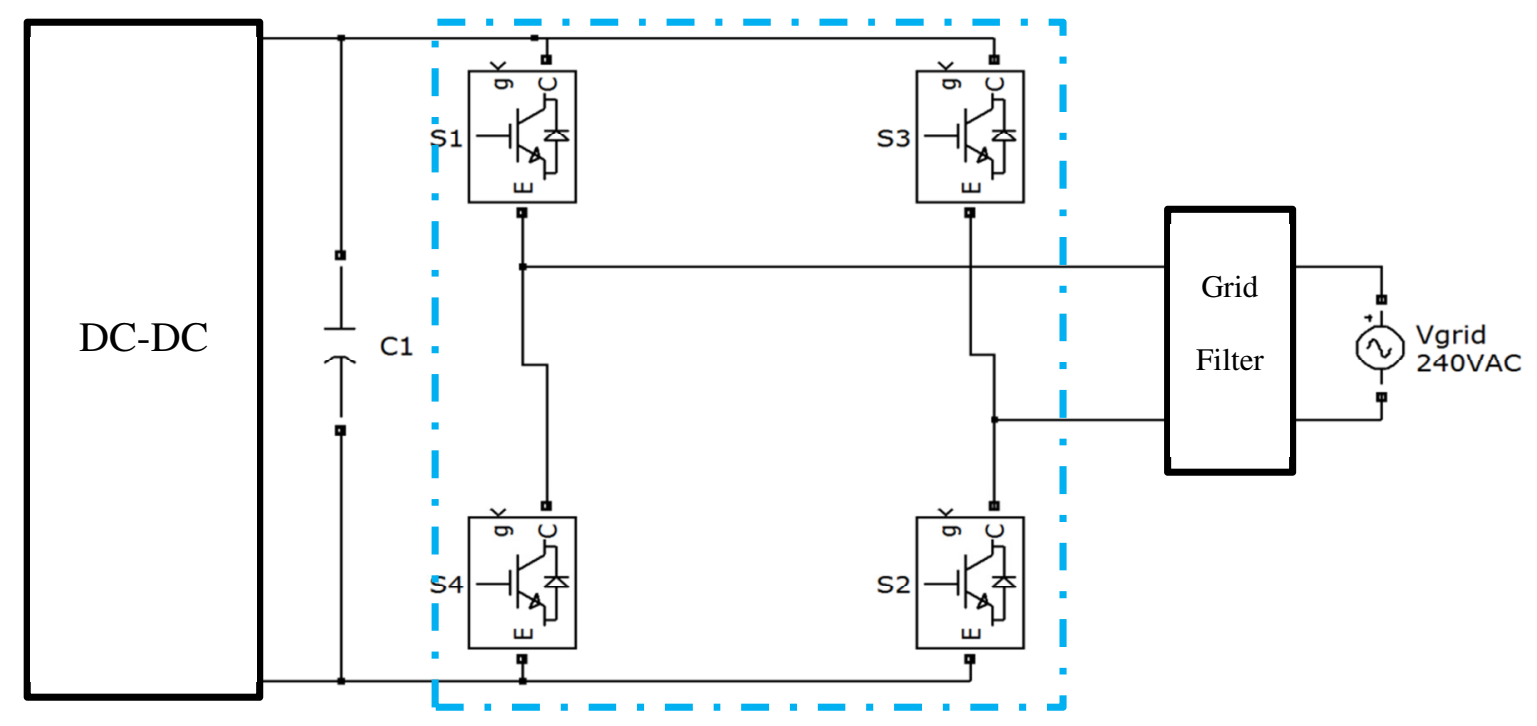

Figure 3.3 - Inverter, 2-legged HB.

A 1-legged HB system trades two switches for an extra capacitor. Notably, the 1legged HB converter outputs at (+/-) 1/2VDC while the 2-legged HB outputs at (+/-) VDC. For the purpose of this thesis, the 2-legged HB is more viable than the 1-legged HB. The 1-legged HB is disadvantageous due to an added capacitor and $1 / 2$ voltage magnitude output.

Different modulation techniques are available to control switching sequences that will produce $\mathrm{AC}$ waveforms. These modulation techniques are similar for topologies other than the 2-legged HB since topologies are from or derived from the HB family. The fundamentals of the three main modulation techniques will pertain to other topologies as well. The main modulation techniques are bipolar (BP), unipolar (UP), and hybrid modulation. The following modulation techniques will use a 2-legged HB as an example.

Bipolar modulation synchronously triggers diagonal switches to achieve (+/-) VDC at the output (see Figures Figure 3.4 and Figure 3.5). BP modulation has low efficiency from filter losses when compared to other modulation techniques since it 
cannot produce a zero voltage state. A lowered efficiency is due to 1) bipolar voltage across the grid filter and 2) reactive power exchange between the DC link capacitor and output filter [42]. Typical PV GTI grid filters are inductors, LC, or LCL (see section 3.3 for more information). BP modulation also has high switching losses as two switches are triggered every period. A BP modulated 2-legged HB inverter can reach up to $96.5 \%$ efficiency [42]. The current ripple due to switching is only at switching frequency leading to larger grid filter requirements than UP modulation.

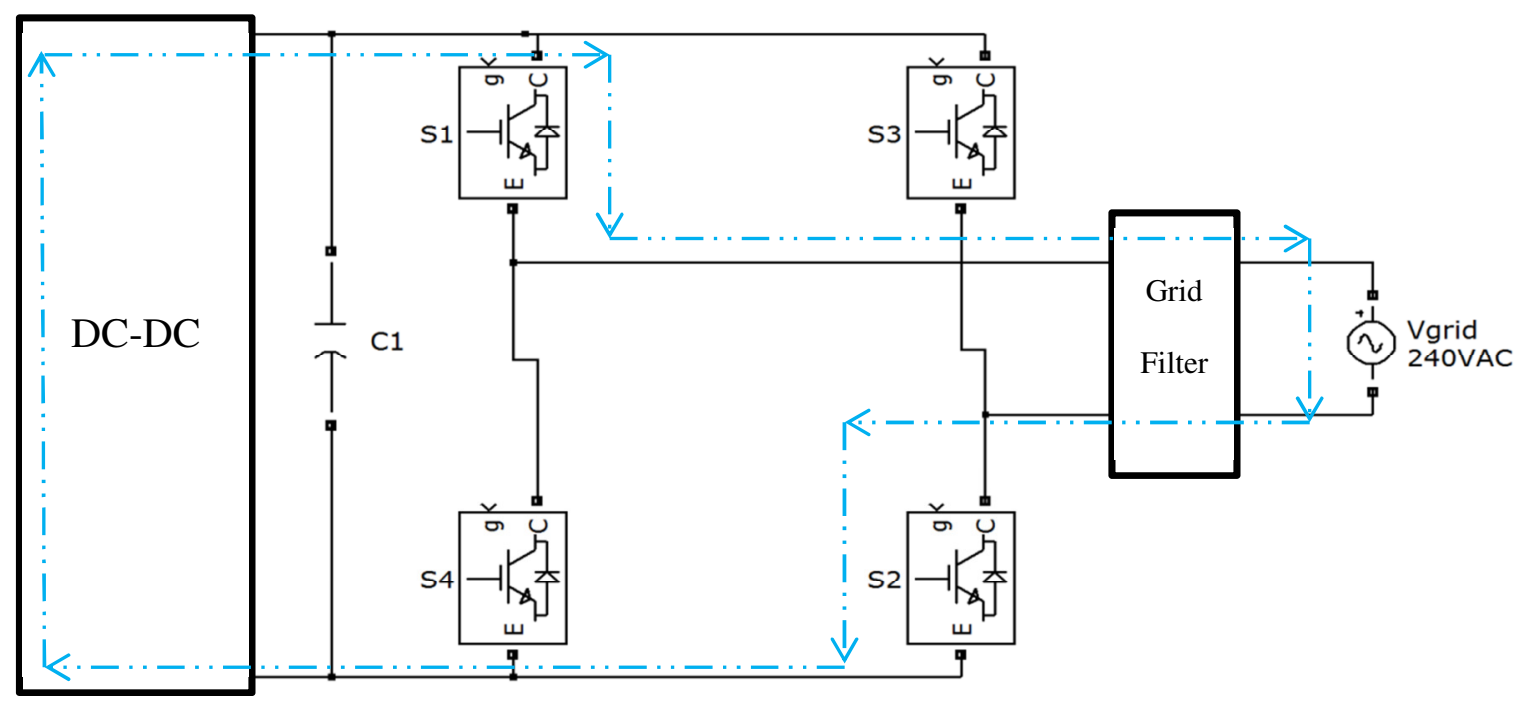

Figure 3.4 - Positive output voltage state of 2-legged HB with BP modulation. 


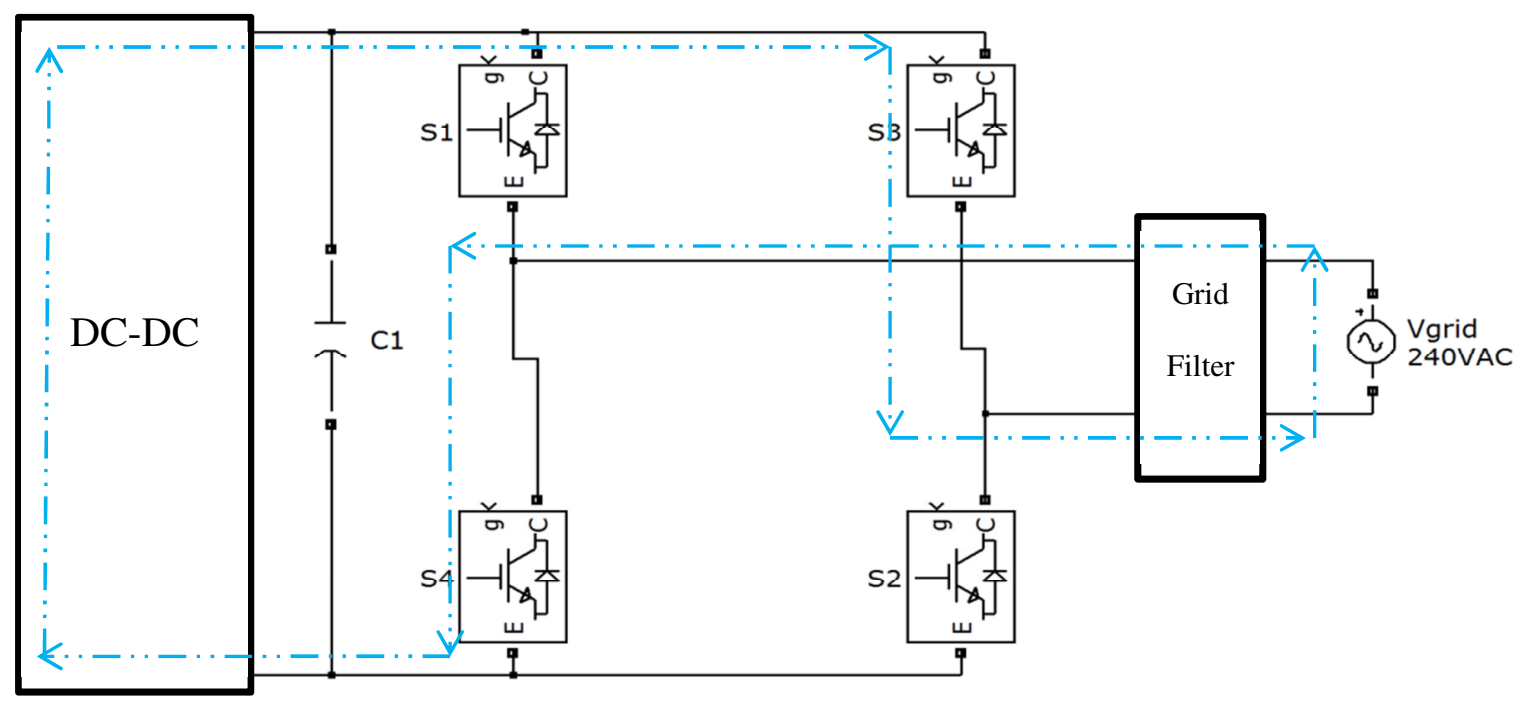

Figure 3.5 - Negative output voltage state of 2-legged HB with BP modulation.

UP modulation is advantageous versus BP modulation due to zero voltage output states. UP modulated positive, negative, and zero output voltage states are shown in Figures Figure 3.6, Figure 3.7, and Figure 3.8 respectively. Zero output voltage states enables UP voltage across the grid filter thus reducing filter losses. This enables efficiencies up to $98 \%$ [42]. The current ripple due to switching is twice the switching frequency leading to lower grid filtering requirements in comparison to BP modulation. 


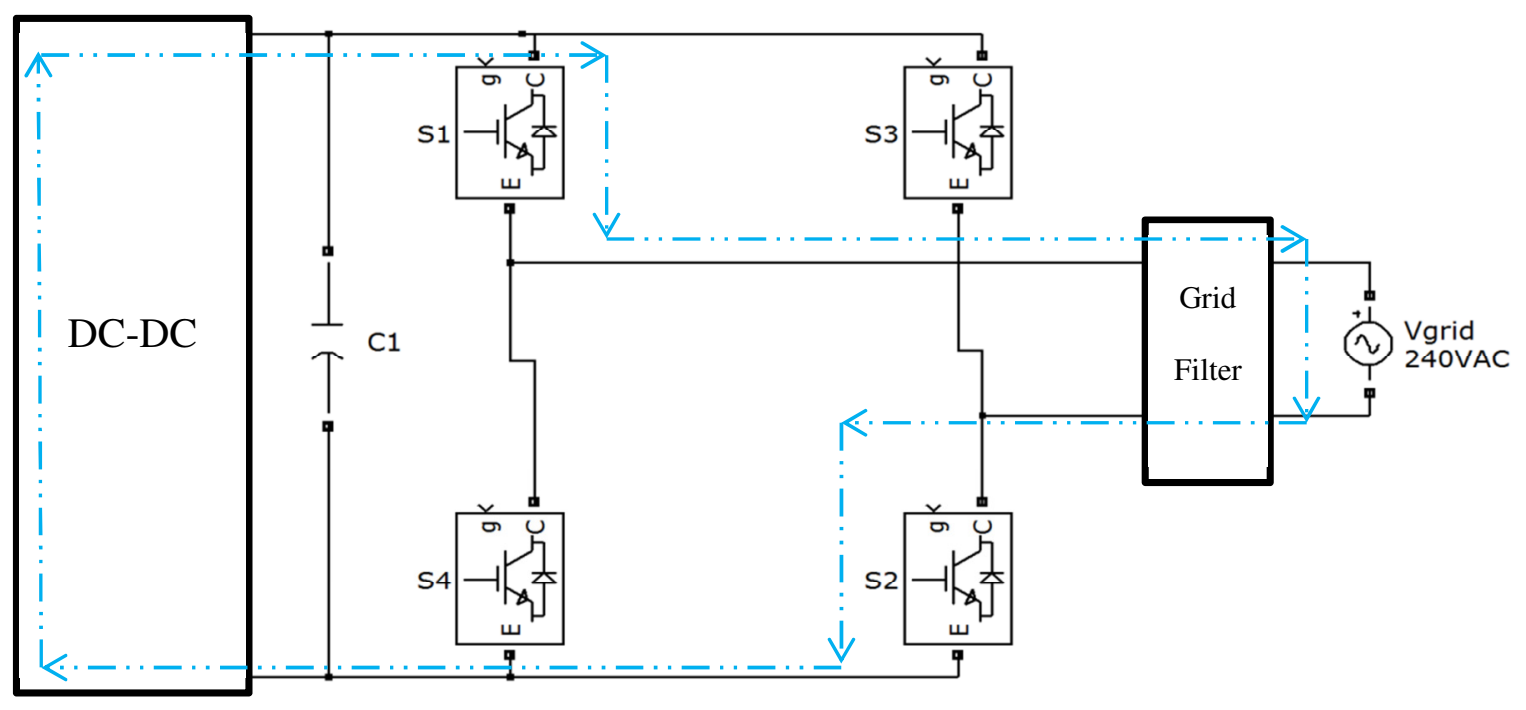

Figure 3.6 - Positive output voltage state of 2-legged HB with UP modulation.

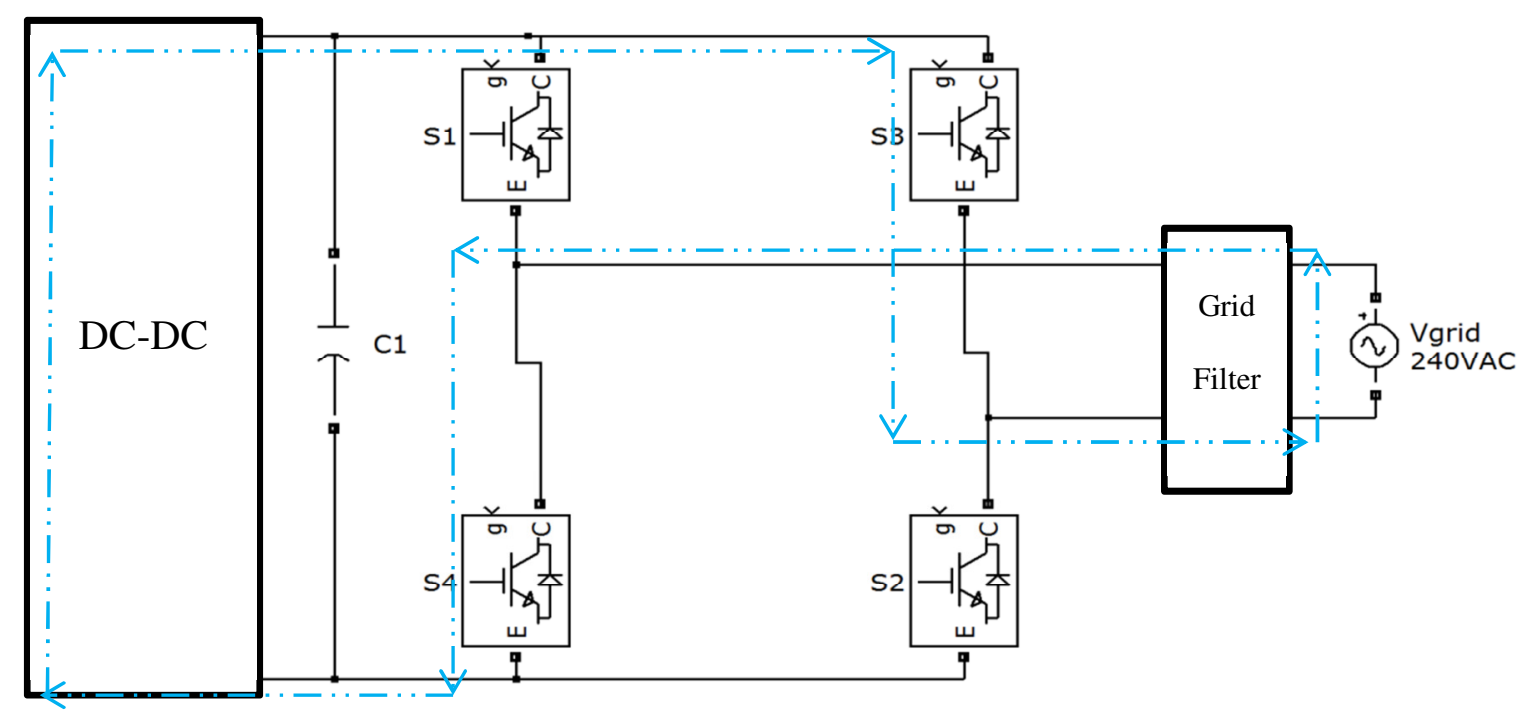

Figure 3.7 - Negative output voltage state of 2-legged HB with UP modulation. 


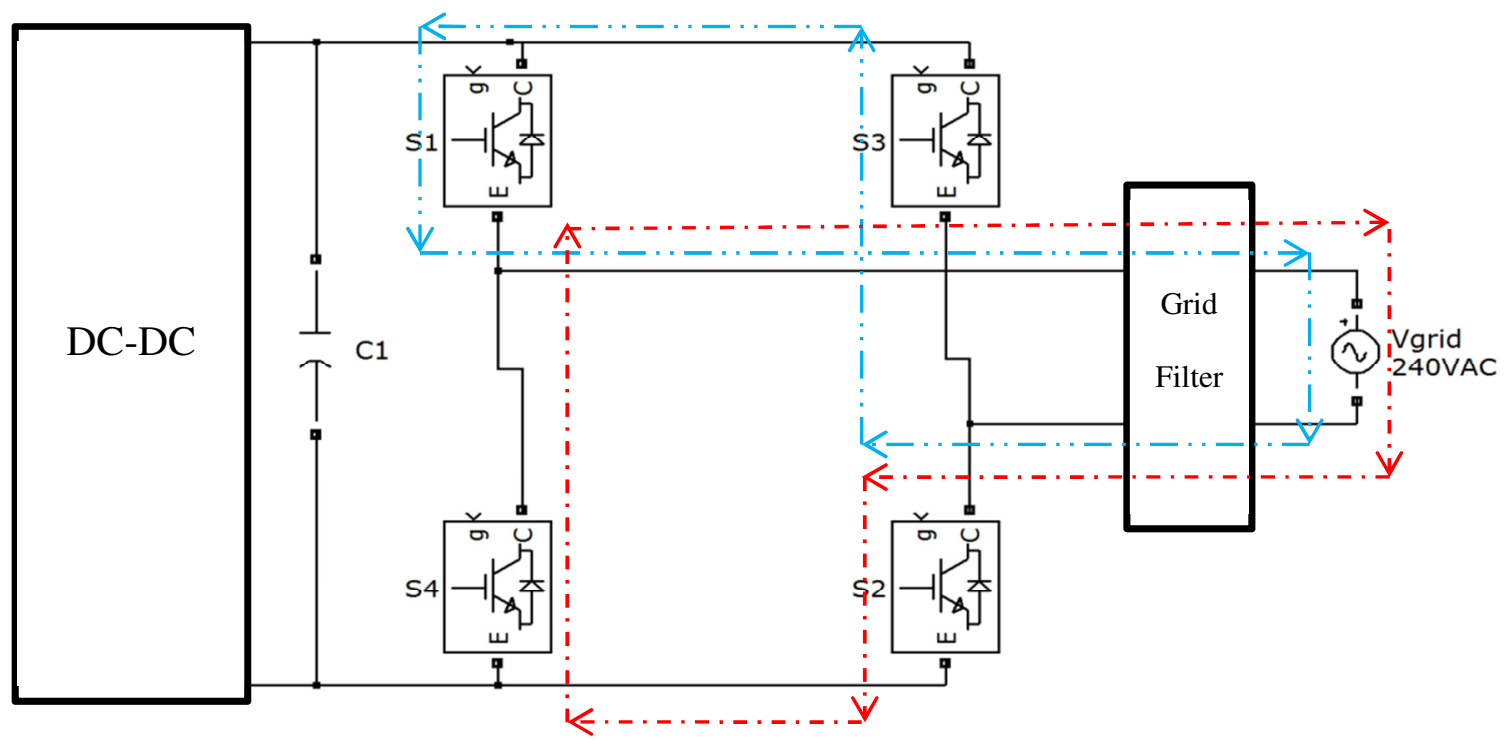

(a)

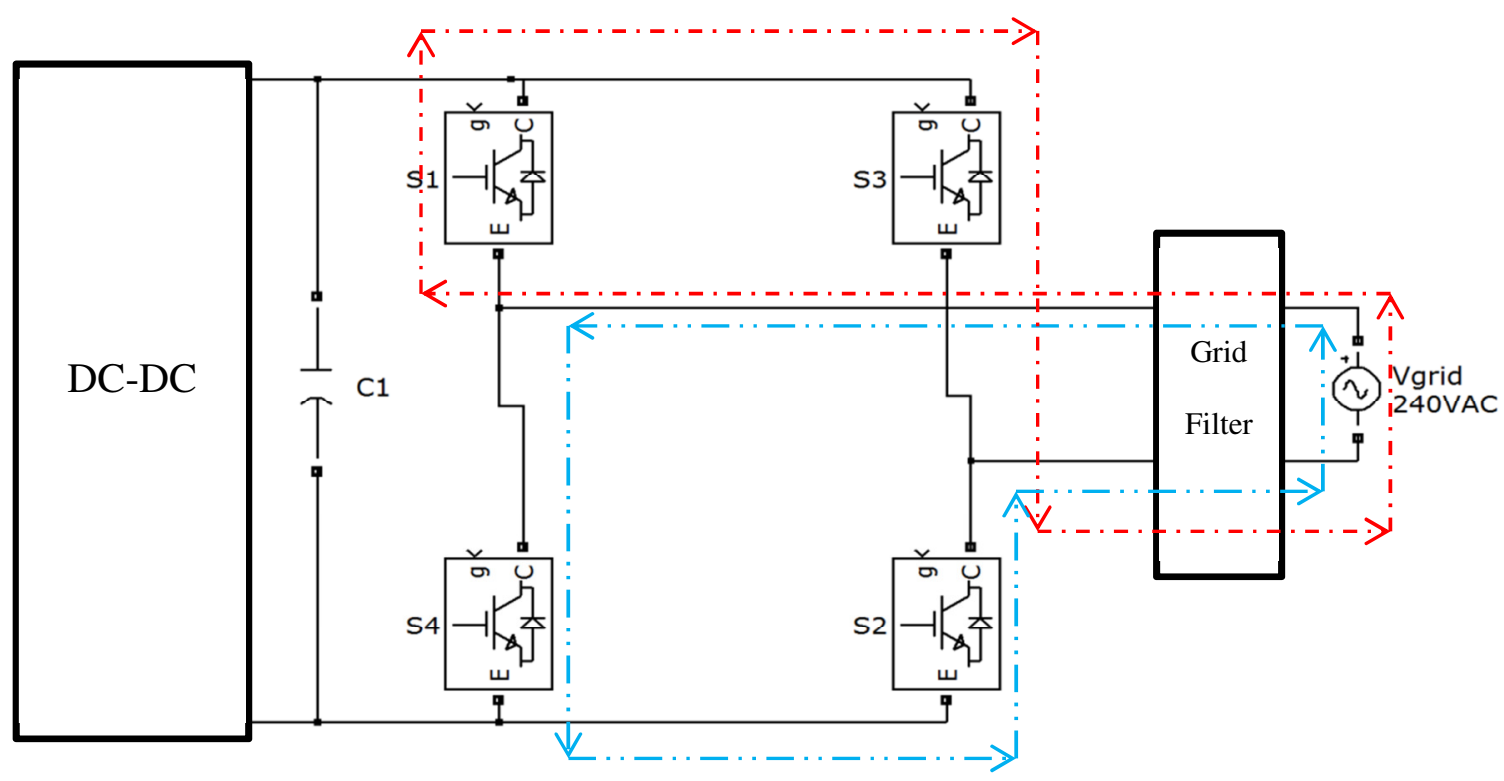

(b)

Figure 3.8 - Zero output voltage states of 2-legged HB with UP modulation: a) positive output current states, b) negative output current states.

Hybrid modulation is a modified version of UP modulation. One leg is switched as high frequency UP and the other leg is switched at line frequency. In hybrid modulation, positive and negative output voltage states are the same as UP modulation 
(see Figures Figure 3.9 and Figure 3.10). For hybrid modulation, there is only one positive and one negative output current for zero output voltage states (see Figure 3.11). Efficiency can reach up to $98 \%$ since the grid filter has UP voltage and no reactive power exchange from the grid filter to the DC link capacitor [42]. A major disadvantage of hybrid modulation is that current ripple has contributions from (square wave) as well as double switching frequency leading to a larger grid filter requirement than UP [47].

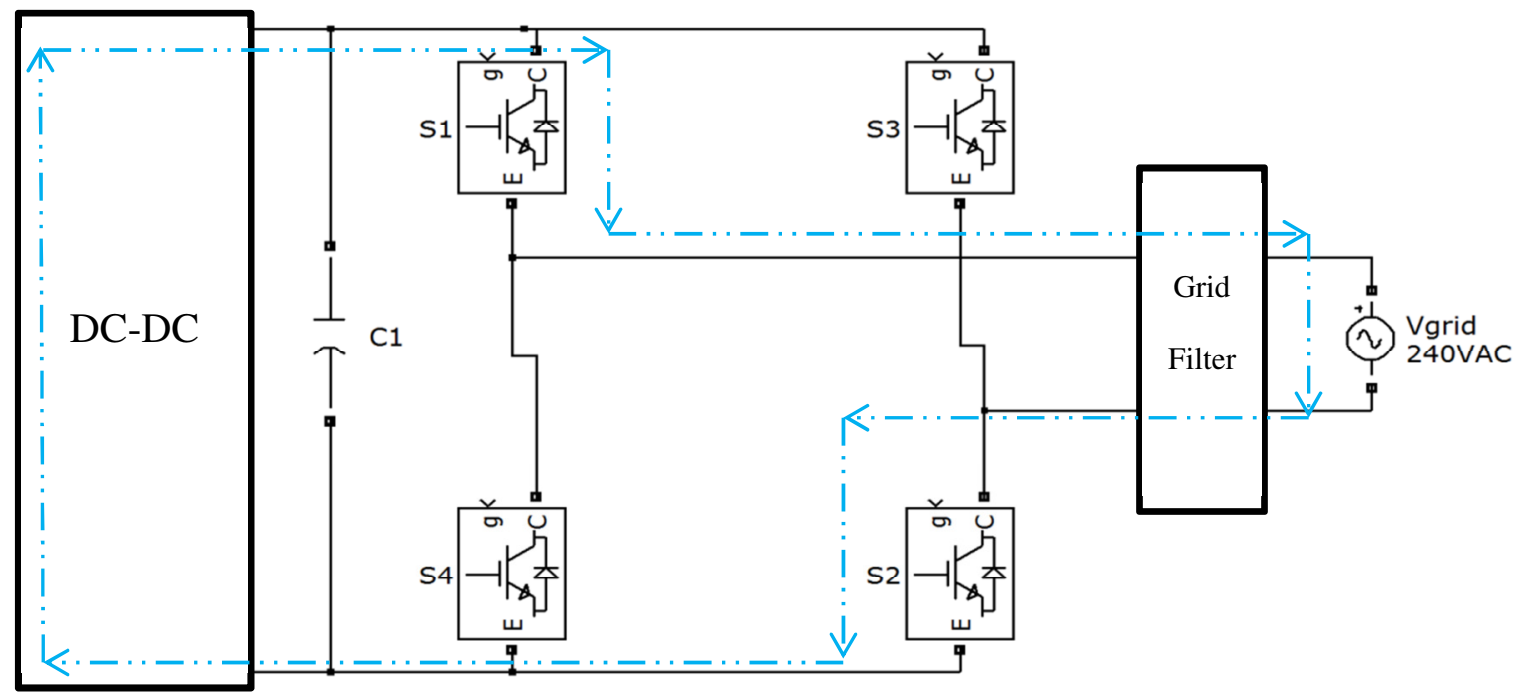

Figure 3.9 - Positive output voltage state of 2-legged HB with hybrid modulation.

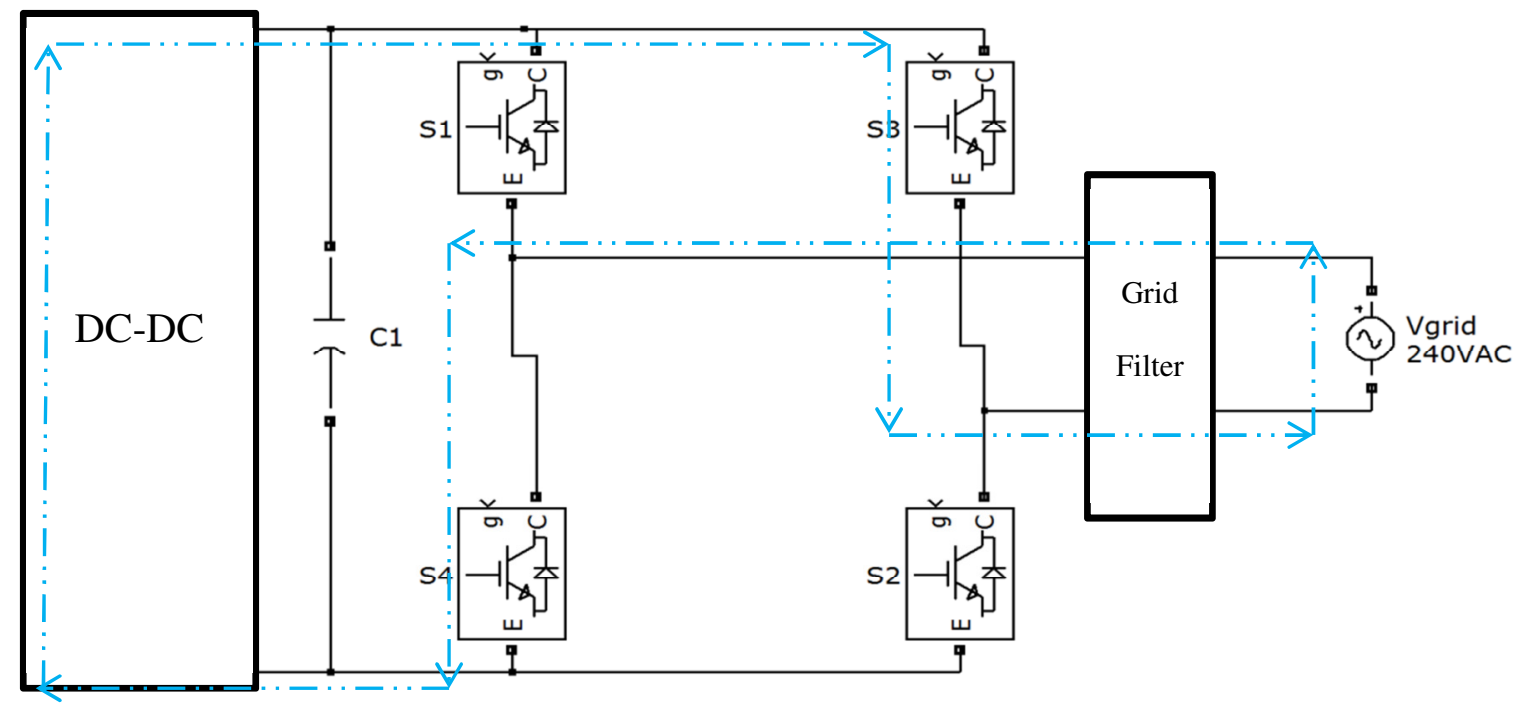

Figure 3.10 - Negative output voltage state of 2-legged HB with hybrid modulation. 


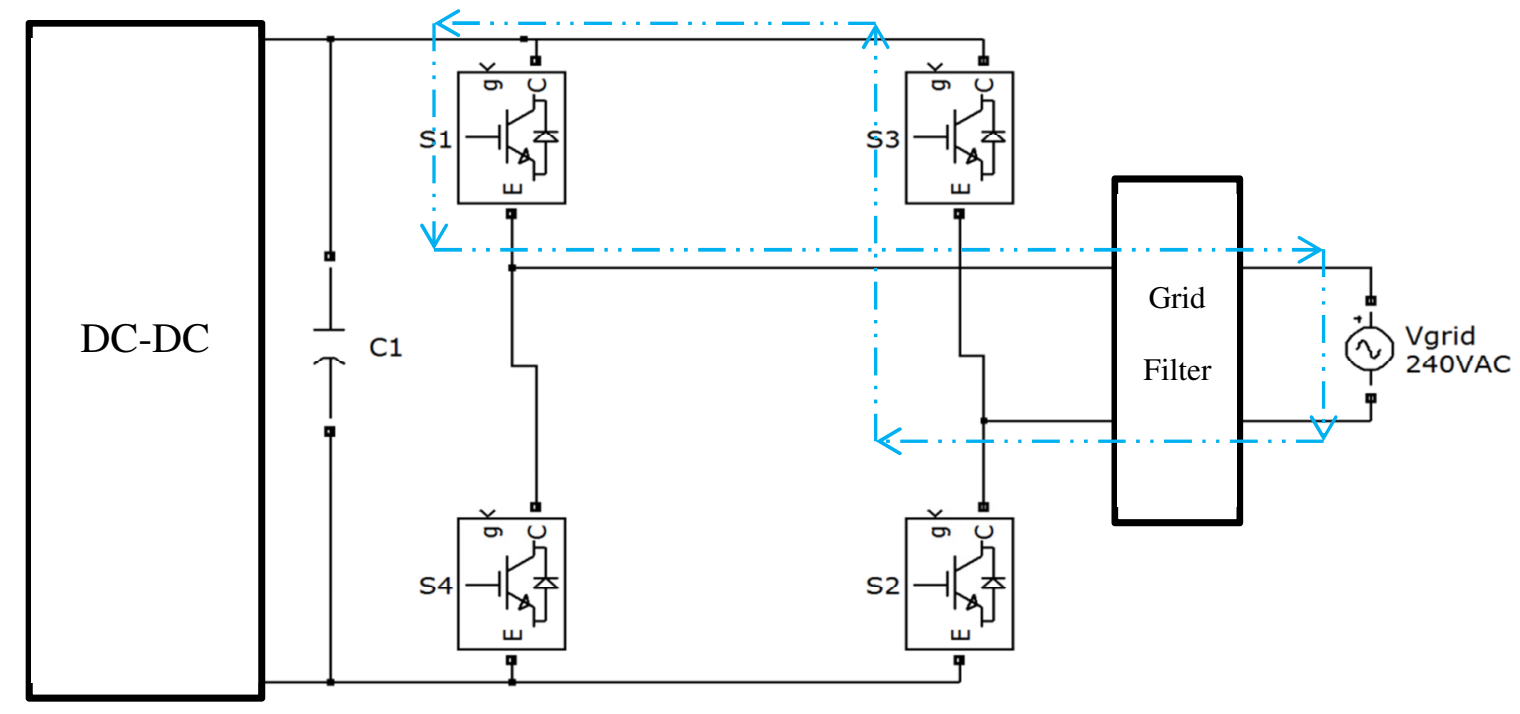

(a)

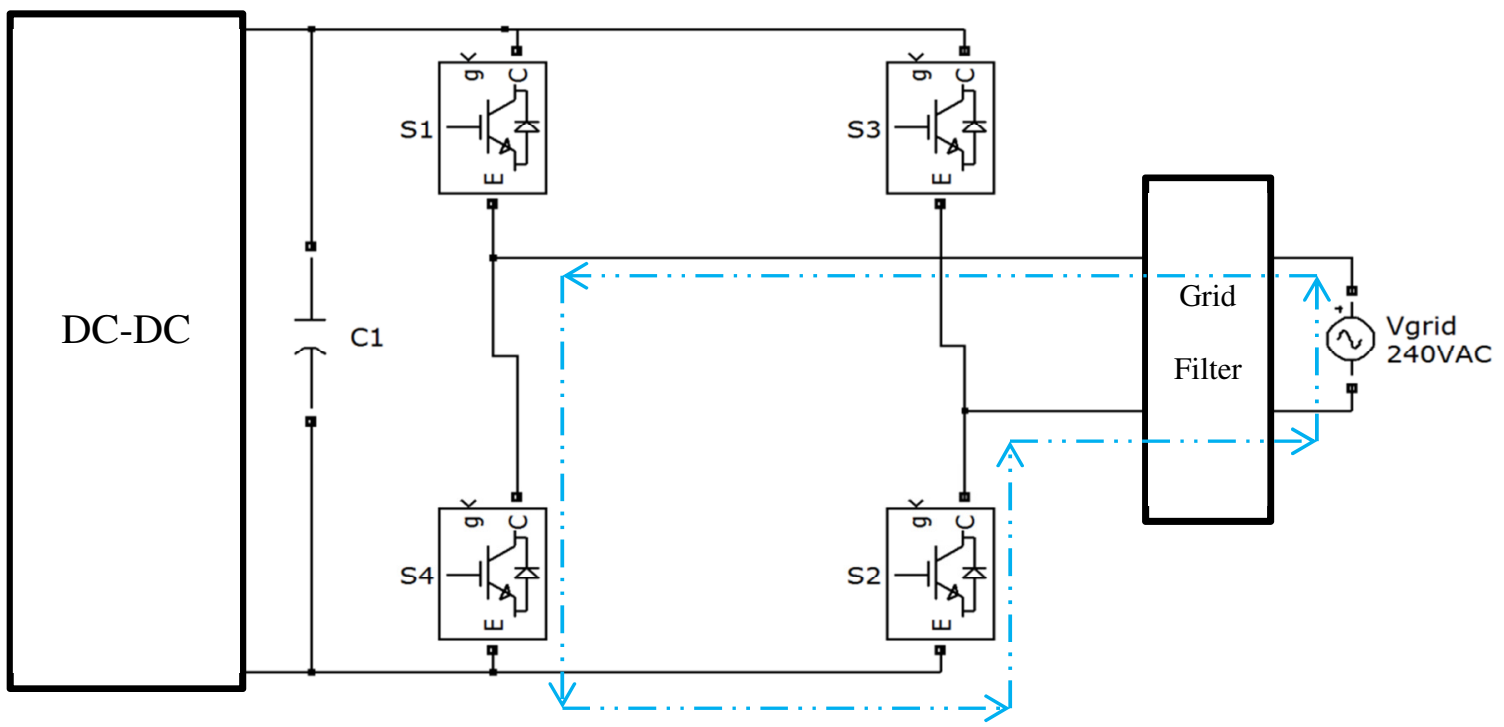

(b)

Figure 3.11 - Zero output voltage states of 2-legged HB with hybrid modulation: a) positive output current state, b) negative output current state.

A summary of the different modulation techniques for a 2-legged HB is available on Table 3.1. When compared to BP and hybrid modulation, UP modulation is the ideal candidate for this thesis. Efficiency is high and filtering requirements are the lowest. This 
enables reduced costs, volume, and heat management requirements in respect to other modulation techniques.

Table 3.1 - Summary 2-legged HB inverter modulation techniques.

\begin{tabular}{|l|c|c|c|}
\cline { 2 - 4 } \multicolumn{1}{c|}{} & BP & UP & Hybrid \\
\hline Efficiency Ceiling [\%] & 96.5 & 98 & 98 \\
\hline Filter Requirements & Larger & Small & Larger \\
\hline
\end{tabular}

\subsubsection{Analysis of Popular PV GTI Topologies for V2G Power Converters}

Since the full bridge inverter was invented, many full bridge derived topologies have been introduced for motor drive and photovoltaic applications. Given the robustness and inherent high inductance of motors, motor drive inverters generally do not have many requirements such as filtering. Electrical motors drive inverters has been driven by costs. The 2- or 3-legged HB topology has been accepted worldwide for most motor drive applications. On the other hand, photovoltaic (PV) inverters are driven by efficiency because of the high costs of solar energy. This has led to a variety of relatively new inverter topologies which are mostly based off the HB family [42].

PV power converter systems are similar to $\mathrm{V} 2 \mathrm{G}$ power converter systems and adoption of PV technology may lead to faster advancement of V2G technologies [41, 48]. PV GTI topologies will be discussed and analyzed for V2G operation. One major consideration of PV inverter design is the parasitic capacitance due to the solar panel. Due to the manufacturing process and physical composition of a solar panel, it acts as a capacitor to ground. With modern inverters moving toward transformerless designs, this 
creates a path for leakage current which is a concern for personal safety [42]. Luckily this is not a safety issue for PEVs; only advantages and disadvantages pertaining to V2G design will be discussed.

The H5 inverter was patented by SMA in 2005 [49]. The top switches (S1, S3) are switched at high frequency while the bottom switches (S2, S4) and extra switch (S5) are switched at line frequency. The extra switch is to increase efficiency during the zero voltage state by preventing reactive power exchange between the output grid filter and DC link capacitor. Filter voltage is UP which leads to lowered core losses. Even with an extra conducting switch, the maximum efficiency for the H5 is $98 \%$ [42]. The switching states of SMA's H5 are shown on Figures 3.12, 3.13, 3.14. Although the H5 was clearly beneficial to PV systems by limiting low leakage current through the solar panels compared to a UP modulated FB, it has no main advantage for V2G system. Increased efficiency from removing reactive power exchange during the zero output voltage state is thwarted by decreased efficiency due to the losses from a third conducting extra switch. The efficiency ceiling is the same as a UP 2-legged HB while adding the cost, size, complexity, and a need to pay patent royalties for an extra switch. 


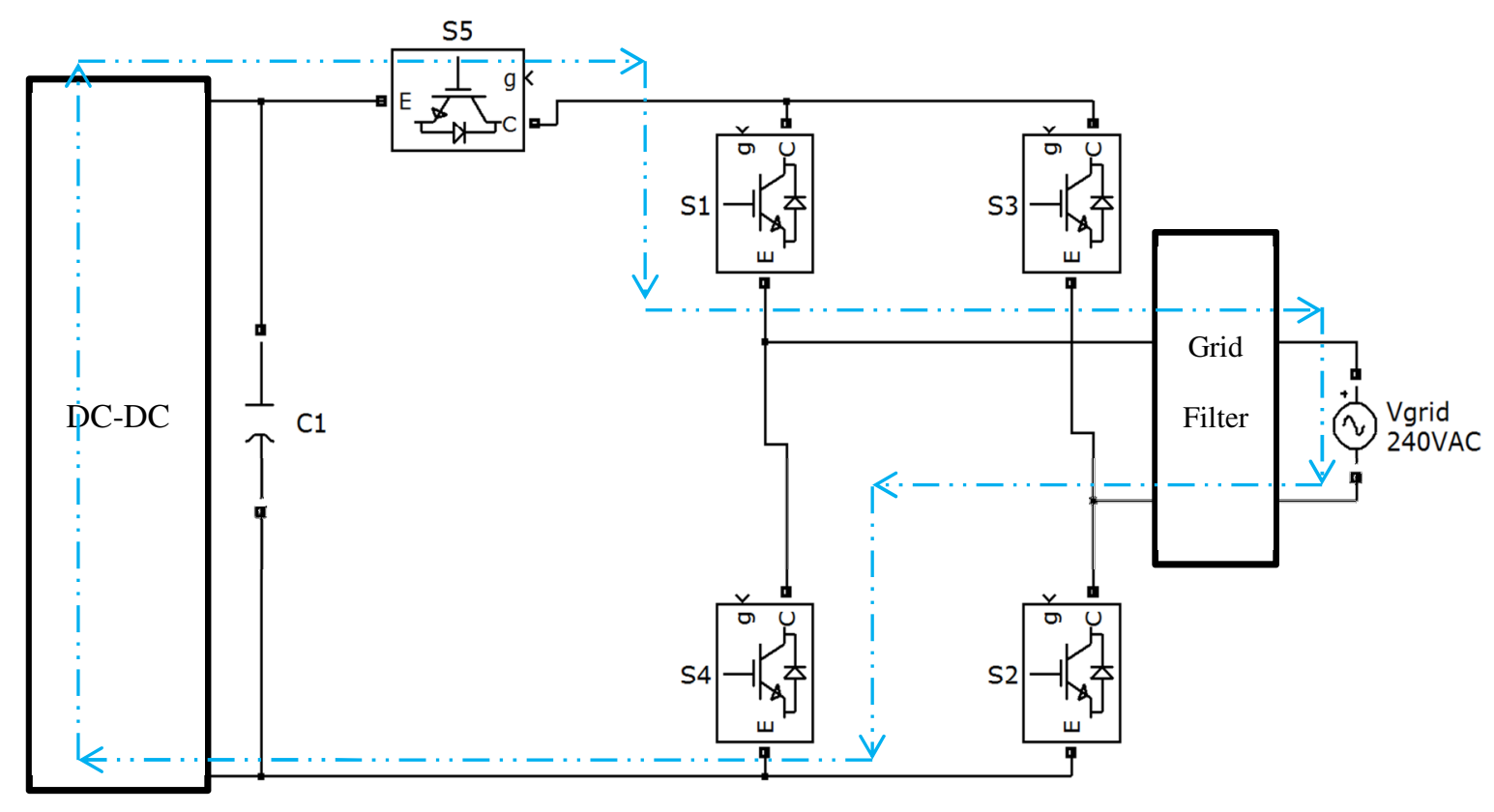

Figure 3.12 - Positive output voltage state of H5 inverter.

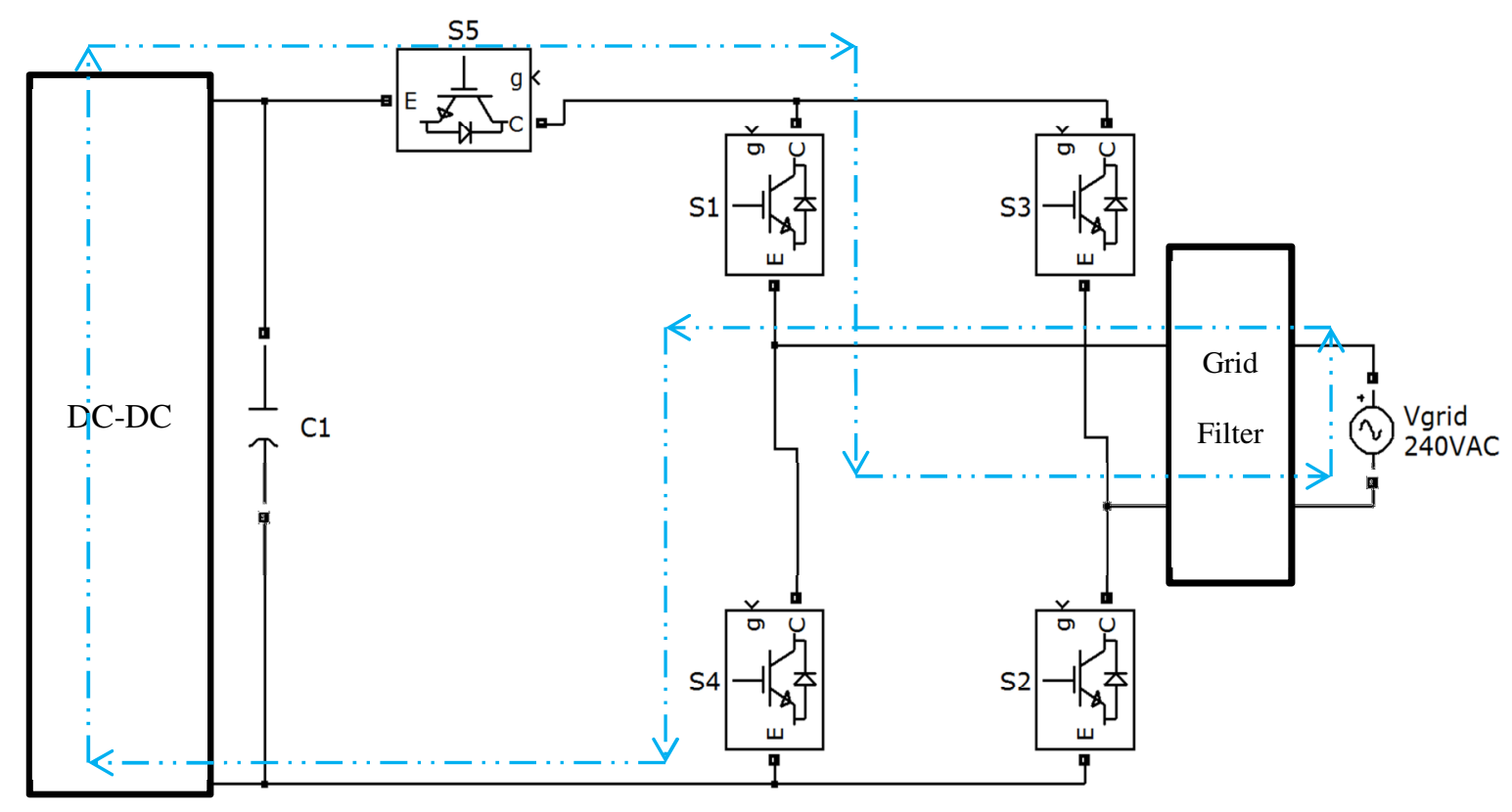

Figure 3.13 - Negative output voltage state of H5 inverter. 


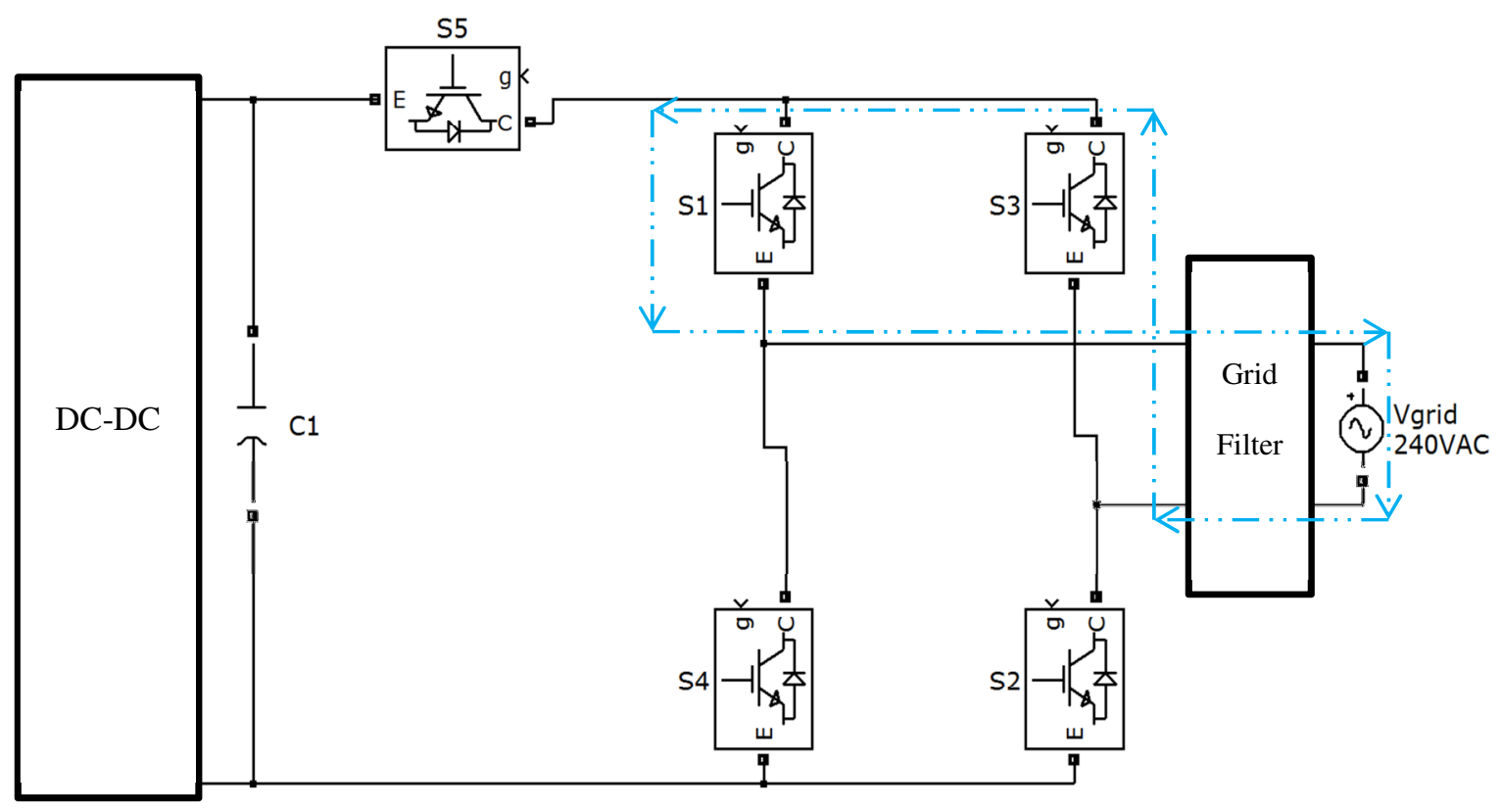

(a)

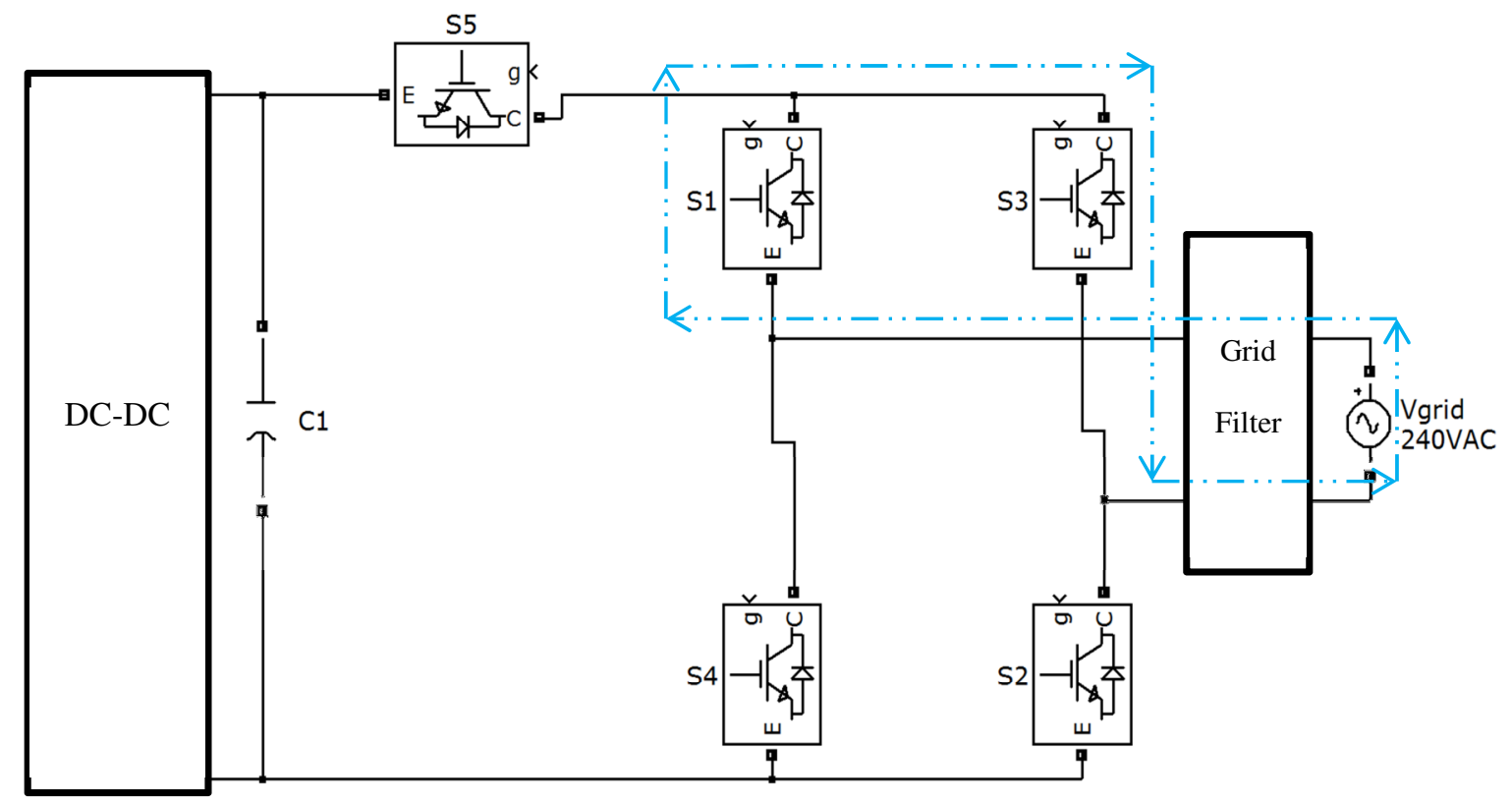

(b)

Figure 3.14 - Zero output voltage states of H5 inverter:

a) positive output current state, b) negative output current state. 
The highly efficient and reliable inverter concept (HERIC) inverter was patented in 2006 by Sunways [50]. Following the H5, the HERIC inverter was created to disconnect the DC link from the grid filter during the zero output voltage state. This increases efficiency by removing reactive power exchange between the DC link capacitor and grid filter. Leakage current was to be reduced to low levels as well. The feat was accomplished through a bypass leg attached in between the 2-legged HB and grid filter. The bypass leg is created from two IGBTs in anti-series, where the emitters are connected together in series. The intrinsic body diodes or IGBT anti-parallel intrinsic diodes are needed to complete the bypass leg. The bypass leg is switched on to create the zero output voltage states while the positive/negative cycle switching states are the same as a 2-legged HB UP modulation scheme (see Figures 3.15, 3.16, and 3.17. Grid filter voltage is unipolar which means lowered core losses. When compared to the H5 and UP 2-legged HB, the HERIC inverter has a low maximum efficiency of only 95.6\%. Include the disadvantages of adding two extra switches; the UP modulated 2-legged HB topology is a much better candidate for a $\mathrm{V} 2 \mathrm{G}$ power converter. 


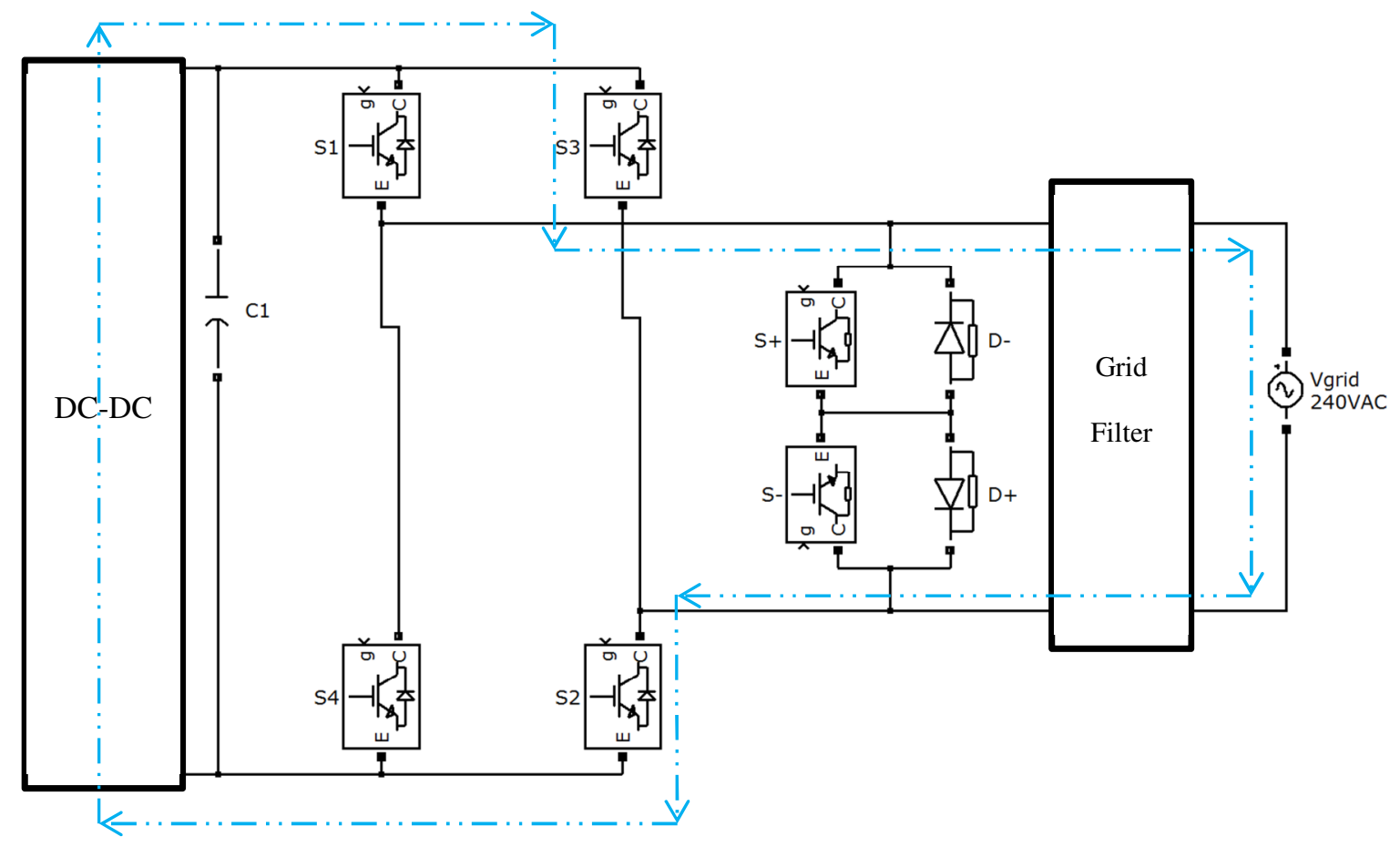

Figure 3.15 - Positive output voltage state of HERIC inverter.

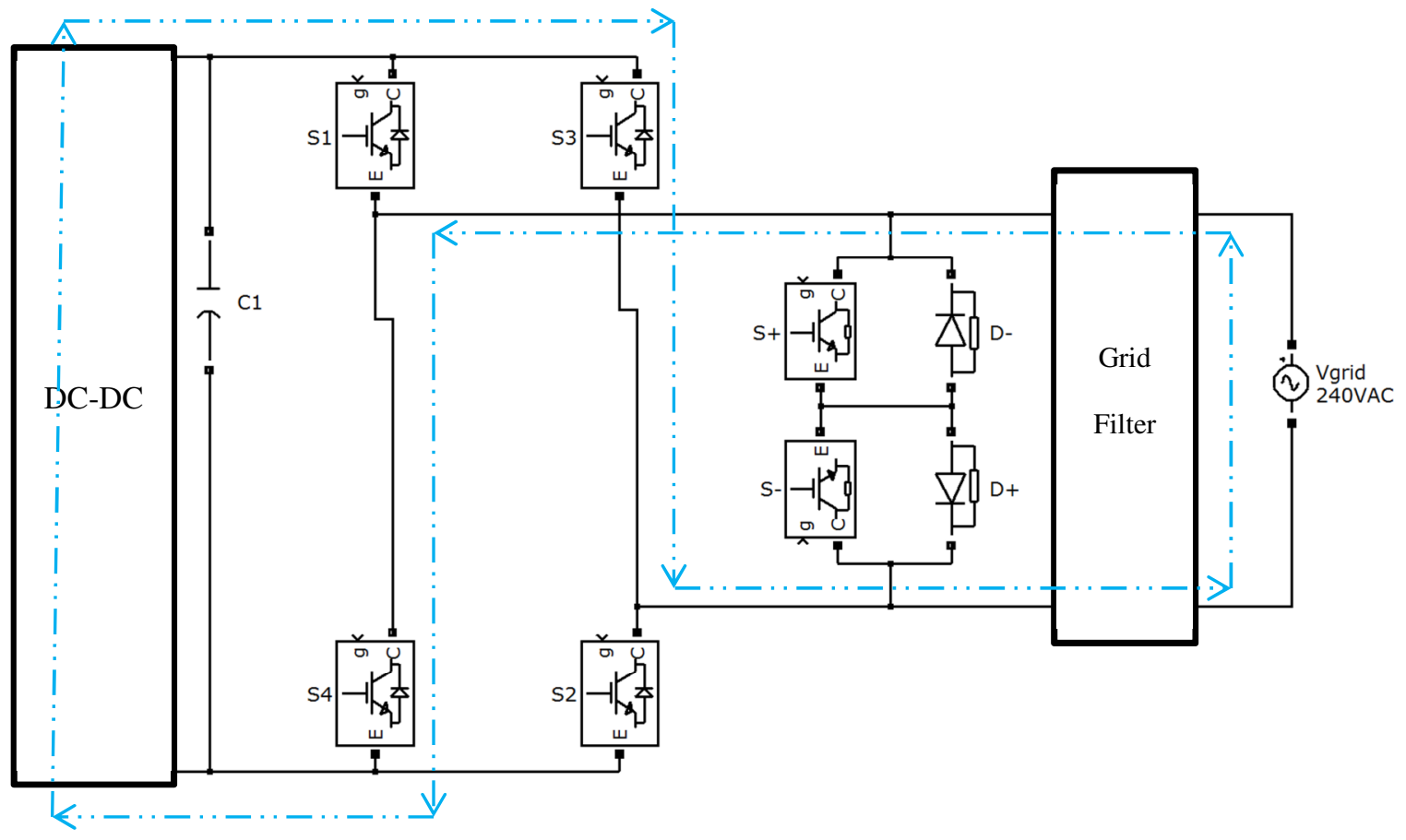

Figure 3.16 - Negative output voltage state of HERIC inverter. 


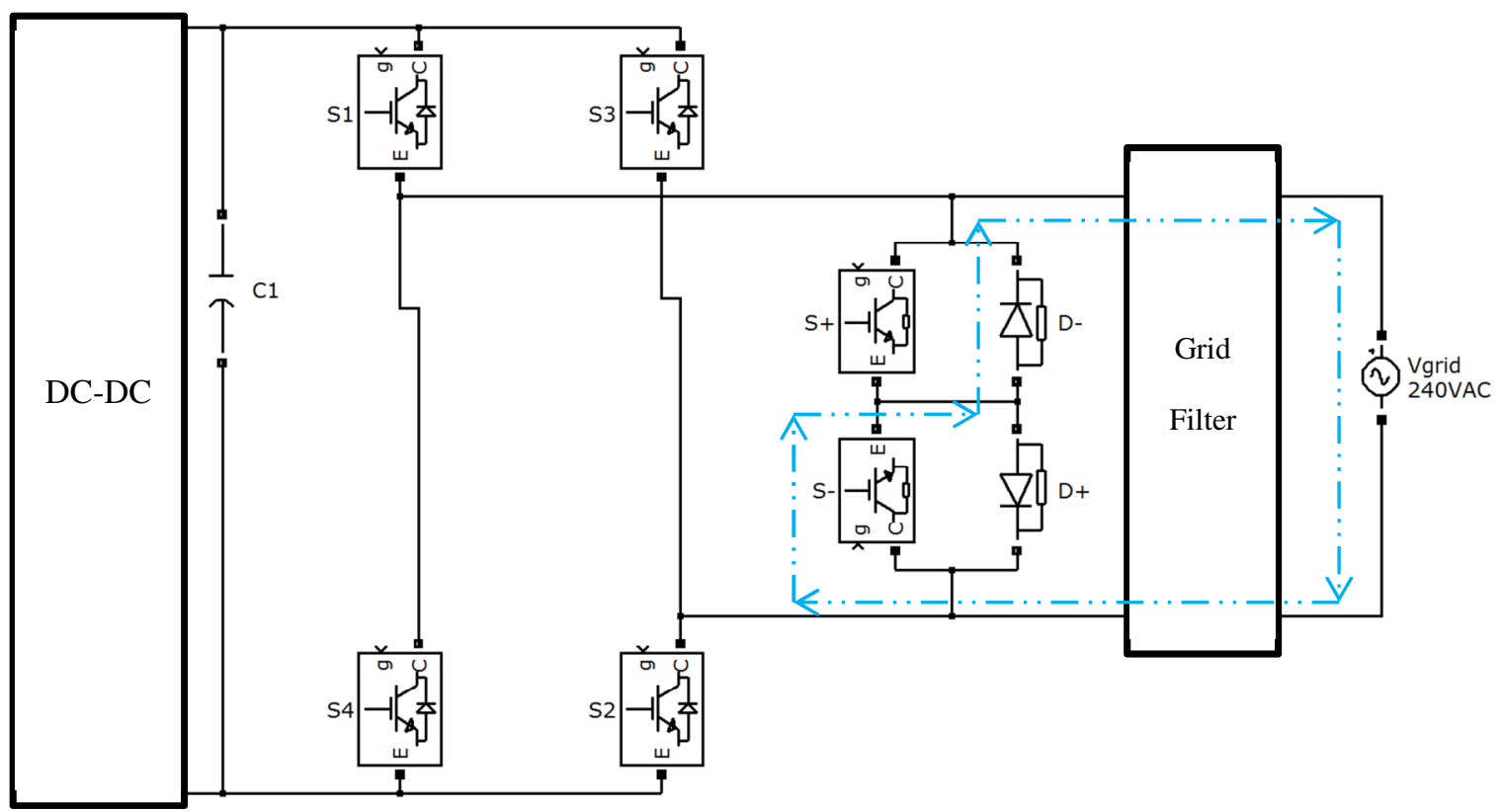

(a)

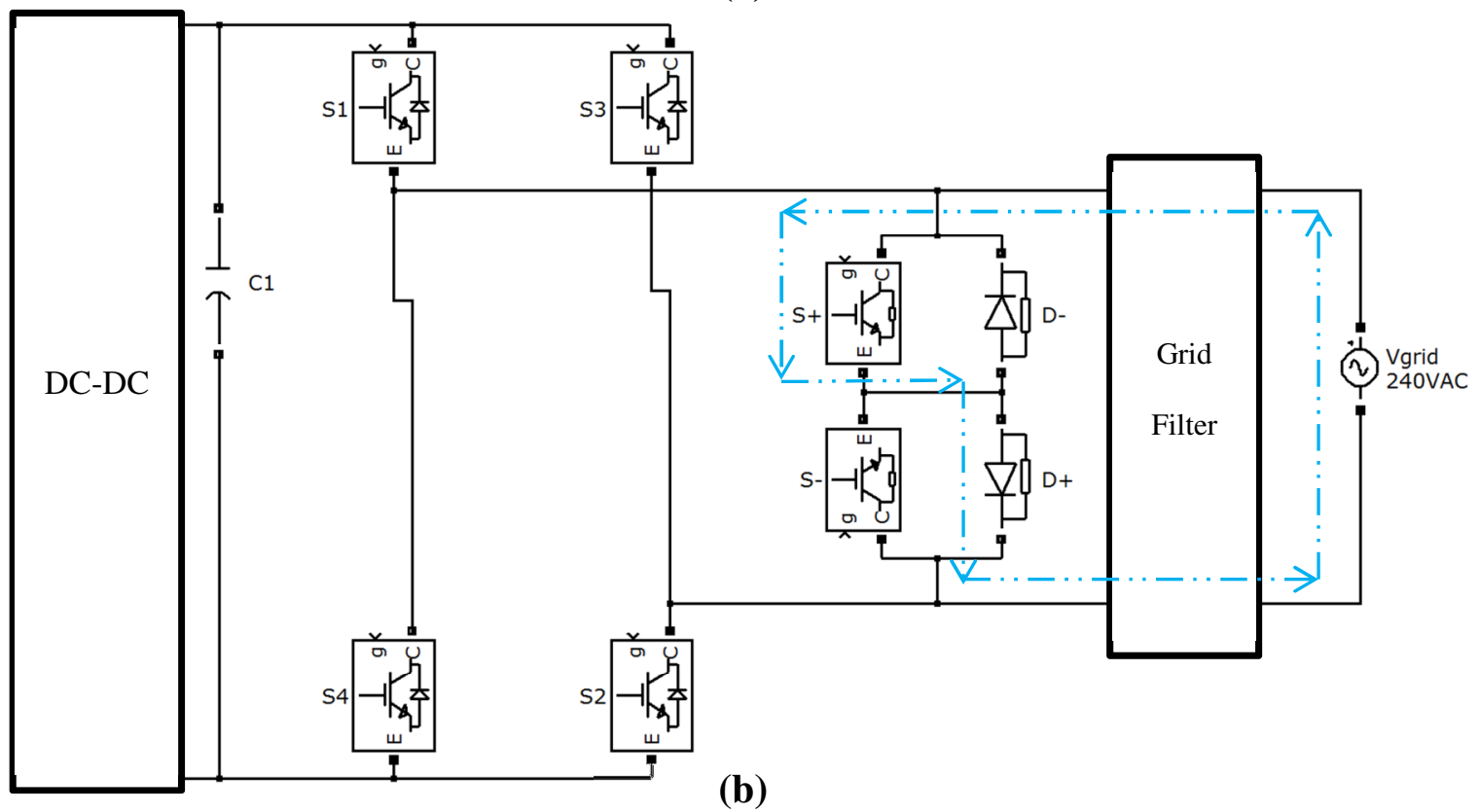

Figure 3.17 - Zero output voltage states of HERIC inverter:

a) positive output current state, b) negative output current state. 
If inverters are not derived from the $\mathrm{HB}$ topology, they are from the neutral point clamp (NPC) family. The NPC has various advantages and disadvantages over a conventional 2-legged HB inverter. A NPC inverter and its switching states are shown in Figures 3.18, 3.19, and 3.20. The NPC uses a type of hybrid modulation where the outer switches (S1, S4) are switched at high frequency and the inner switches (S2, S3) are switched at line frequency. The zero output voltage state can be achieved simply with only S2 triggered on or only S3 triggered on. The NPC has a comparable maximum efficiency of $98 \%$ to a UP modulated 2-legged HB. This is attributed to the DC link capacitor and grid filter does not exchange reactive power. Efficiency is increased through triggering inner switches at line frequency as well. The main advantage of NPC over a UP modulated 2-leged HB is the reduced switch stress. Ideally, the NPC switches are only required to block half the voltage and stress for $\mathrm{dV} / \mathrm{dt}$ is reduced in half in comparison [51]. This means the NPC has a higher reliability and switches can be purchased at a lower price. Disadvantages include two extra diodes, a DC link voltage that is halved during inverter operation, an additional capacitor for the DC link, and unbalanced switch losses. The outer switches (S1, S4) have higher losses than the inner switches (S2, S3). For a V2G system, an NPC and UP modulated 2-legged inverter has comparable performance. Given the tradeoffs and efficiencies of both topologies, the NPC has the potential to do well if implemented in a V2G system. The main factor that may sway using an NPC over a UP modulated 2-legged HB is voltage level, capacitance requirements, and halved DC link voltage is viable. For very high voltage levels, the reduced costs and size for the four switches may offset the extra capacitor and two diodes. Each V2G system will be different since it depends on the vehicle. Generally, 
electric vehicles have traction batteries that are 200V-600V. In this case, maximum TPIM voltage is 430VDC. At such low power levels and voltage levels, the benefits of an NPC topology are not greater than lower cost, weight, and volume of a UP modulated 2-legged HB.

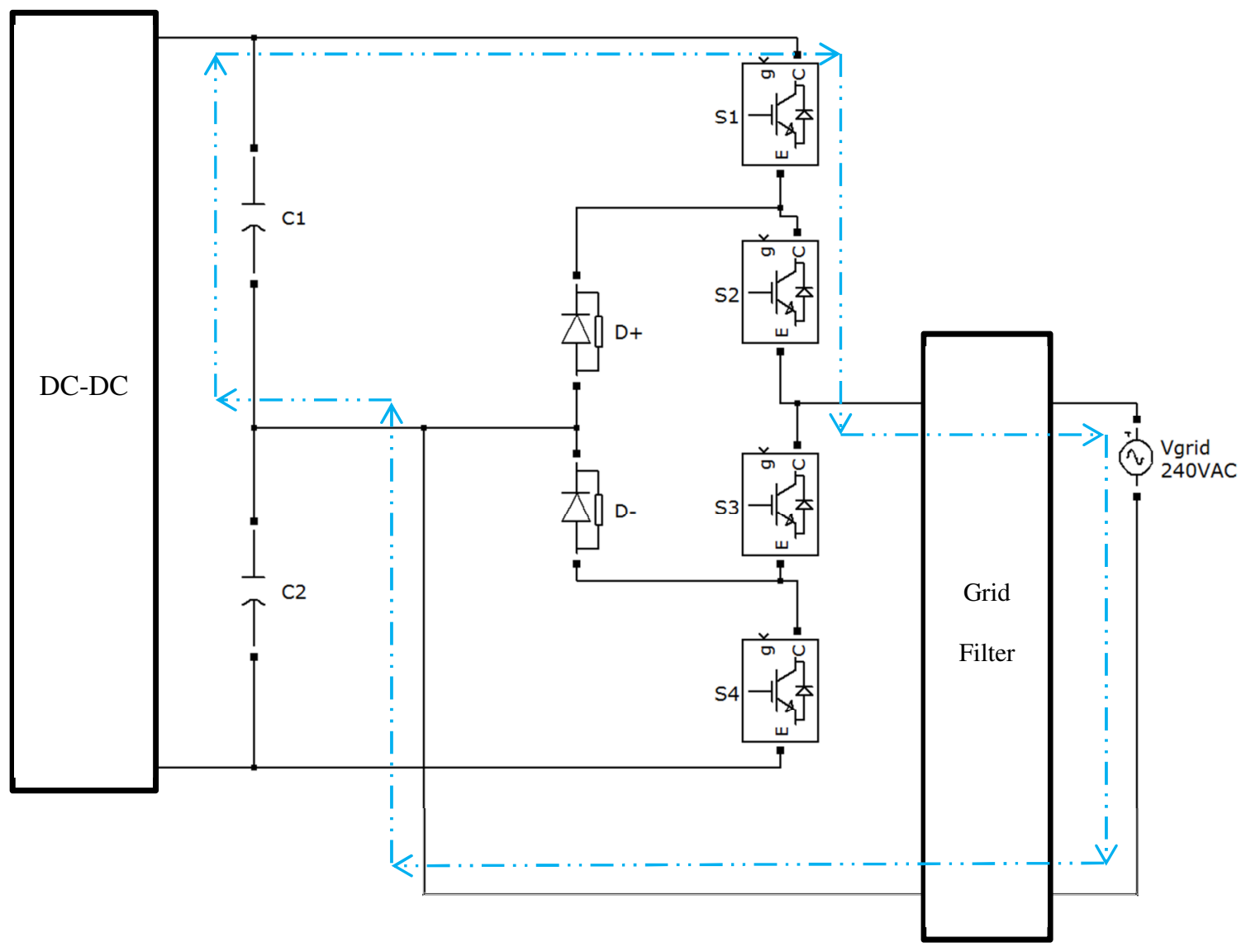

Figure 3.18 - Positive output voltage state of NPC inverter. 


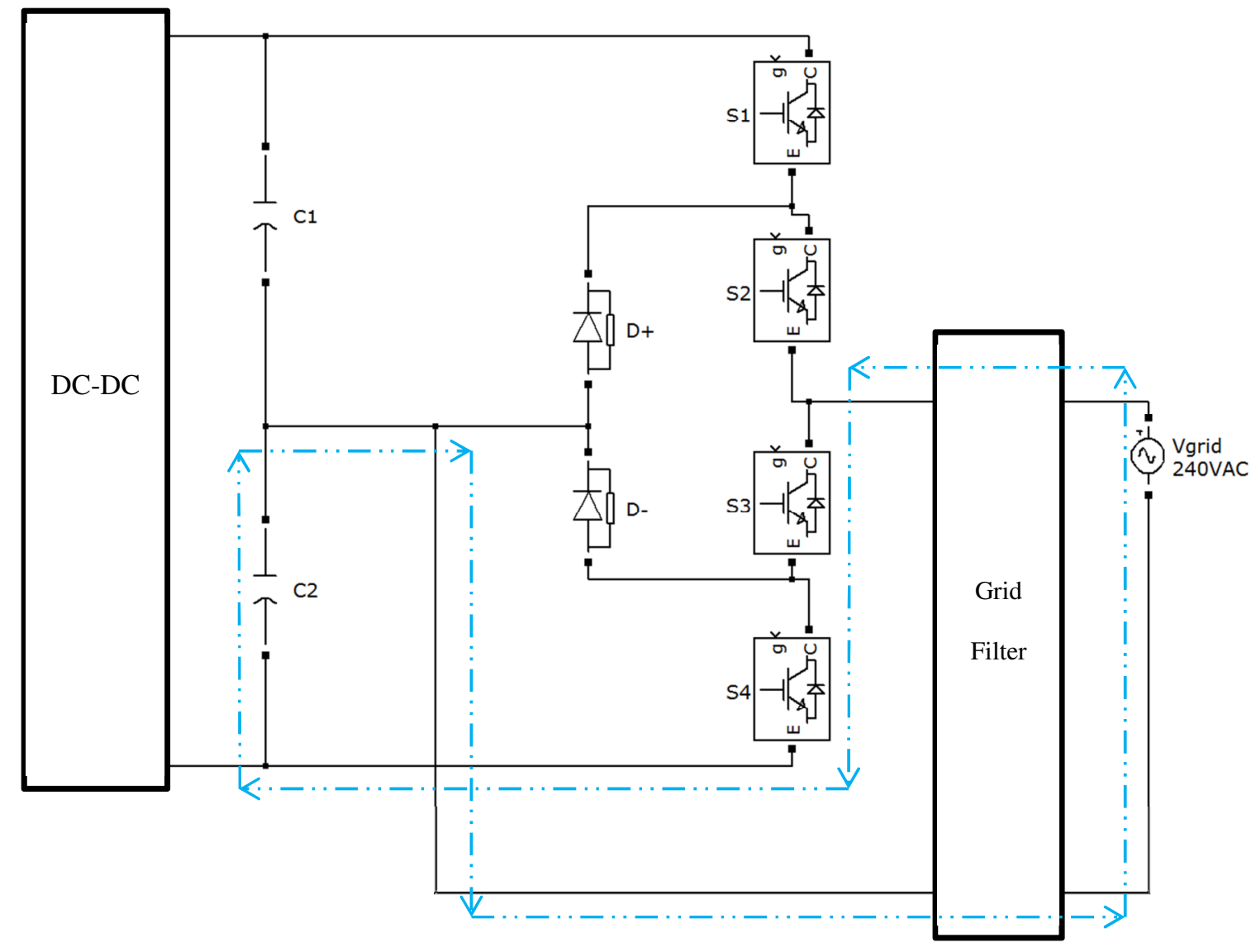

Figure 3.19 - Negative output voltage state of NPC inverter. 


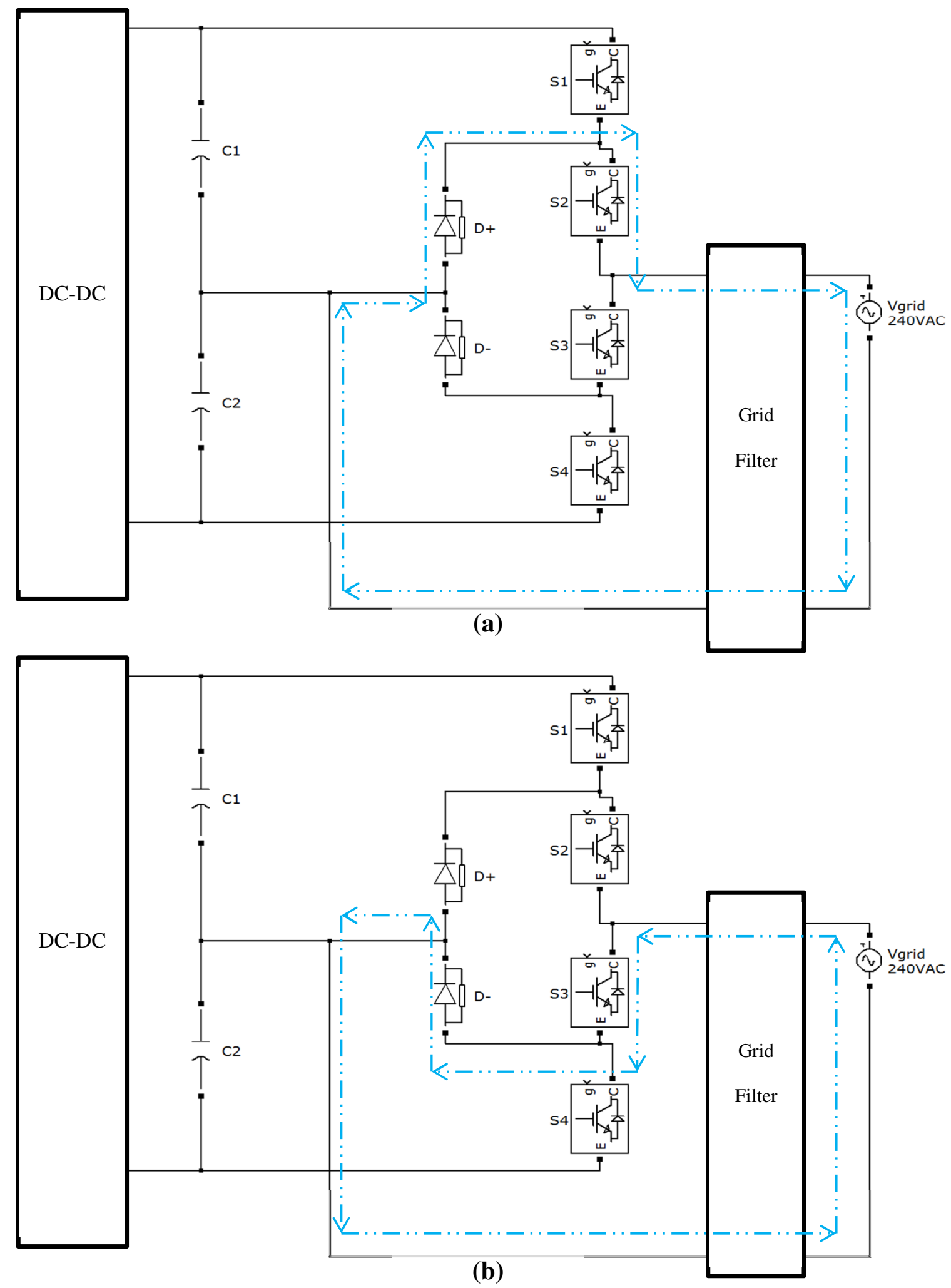

Figure 3.20 - Zero output voltage states of NPC inverter: a) positive output current state, b) negative output current state. 
Conergy created an inverter topology for PV applications; Conergy's topology was derived from the NPC topology [52]. Notice the inner switches were moved and two diodes removed. All the switches are triggered at high frequency alternating S1 with S2 and S3 with S4. A zero voltage output state occurs when either only S3 or S4 is on as this causes the respective diode to be line commutated. The switching states are shown in Figures 3.21, 3.22, and 3.23. The properties and advantages of the Conergy NPC are similar to the conventional NPC. Conergy NPC has a comparable maximum efficiency of 98\% to a UP modulated 2-legged HB and the conventional NPC inverter. The high efficiency is attributed to no reactive power exchange with the DC link capacitor and grid filter. Also only a single switch conducts during the positive or negative voltage output state. Importantly, Conergy's inverter does not have halved switch stress or voltage blocking as with the NPC. Although Conergy's inverter is comparable to a UP modulated 2-legged HB, it requires a two series capacitor at the DC link which takes extra cost, volume, weight, and a license agreement must be reached for usage. 


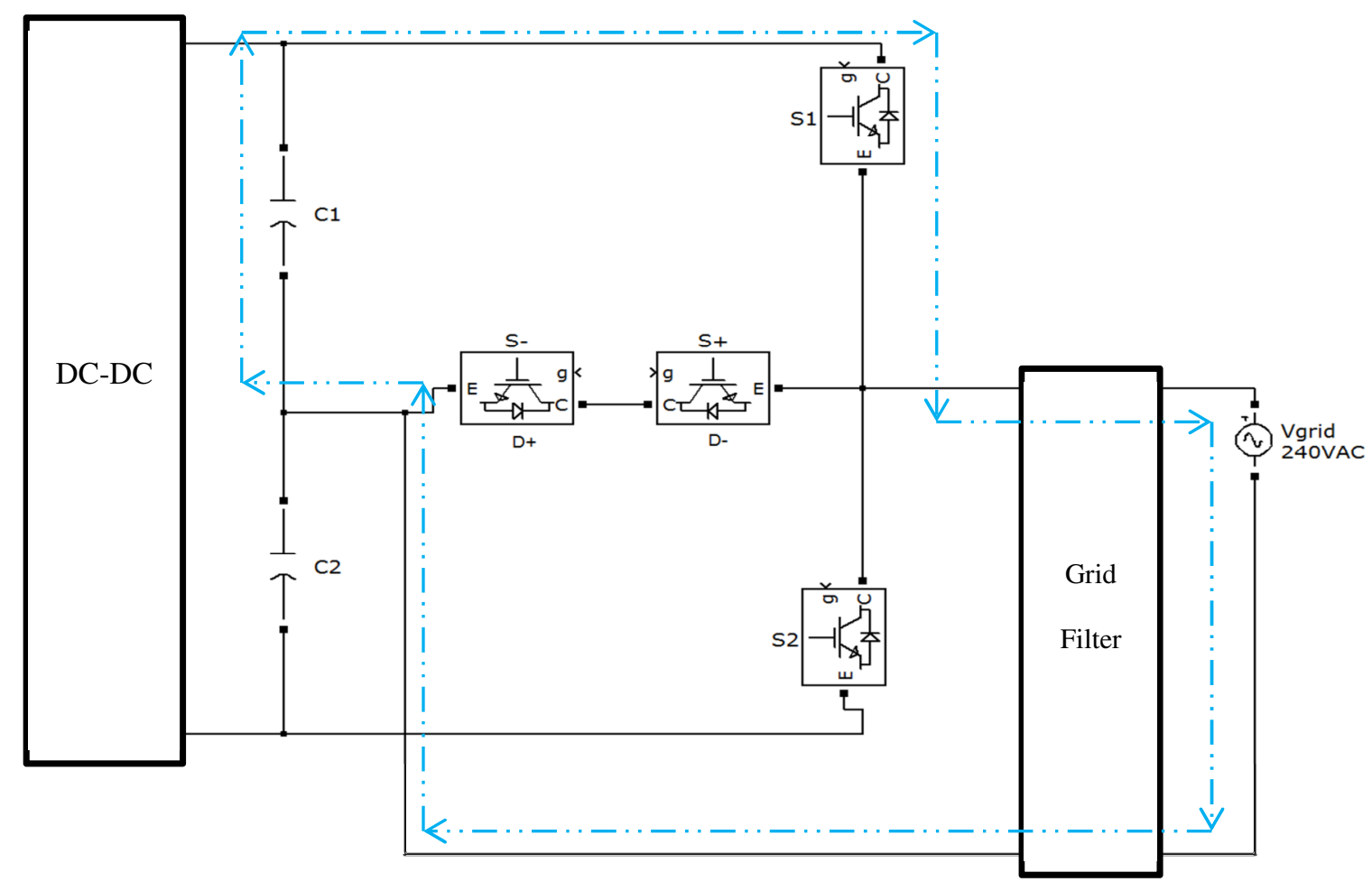

Figure 3.21 - Positive output voltage state of Conergy inverter.

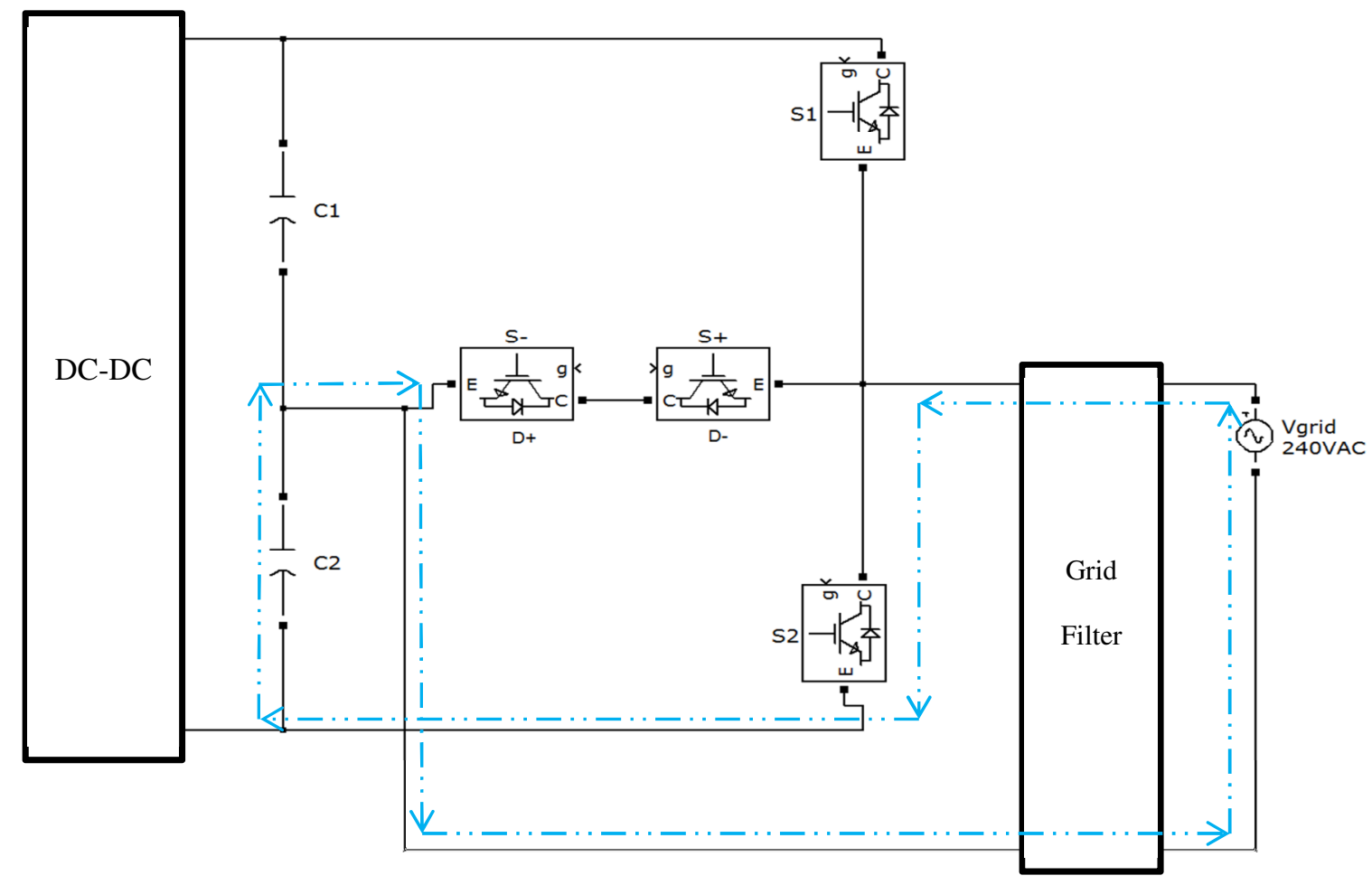

Figure 3.22 - Negative output voltage state of Conergy inverter. 

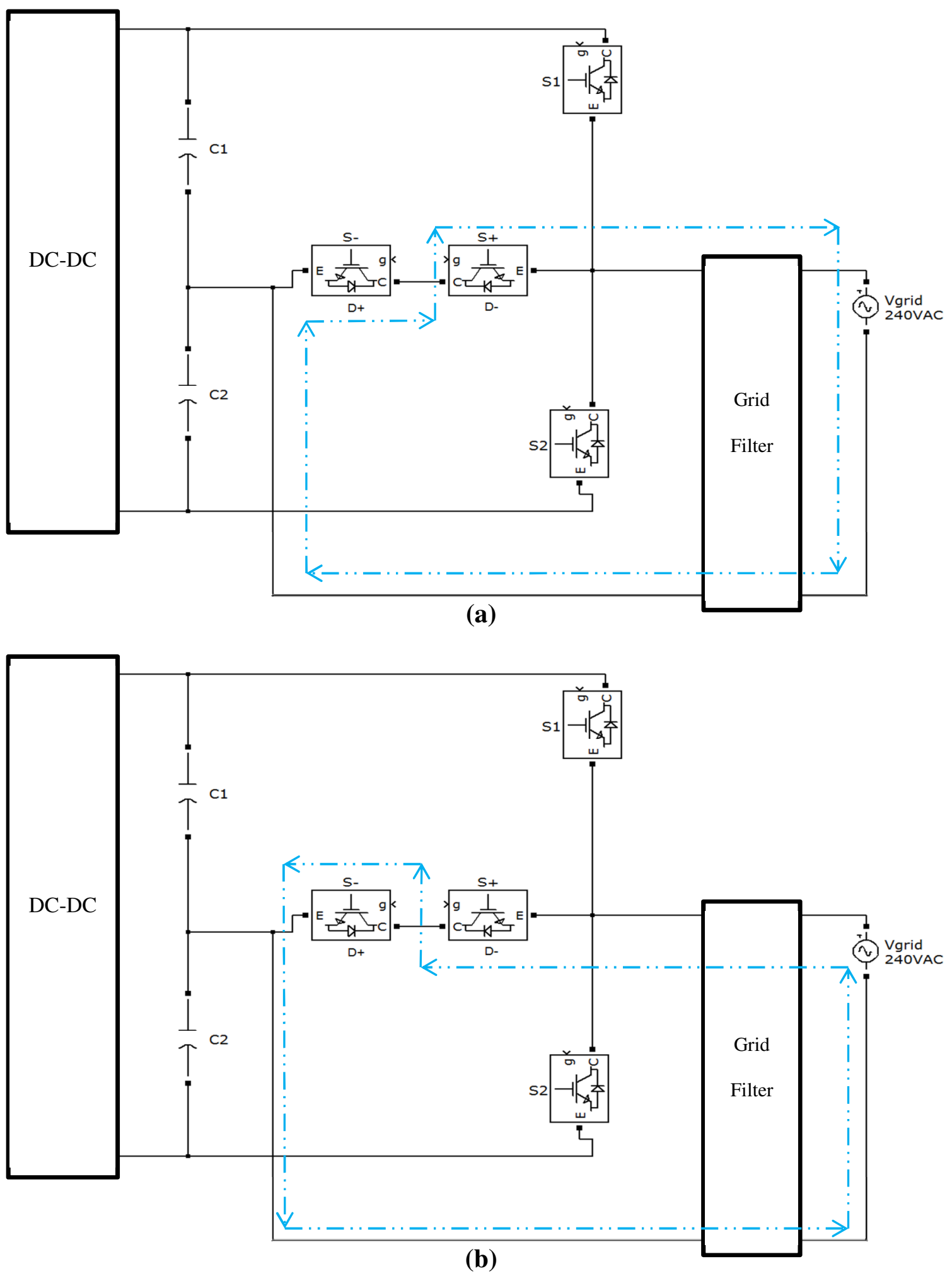

Figure 3.23 - Zero output voltage states of Conergy inverter:

a) positive output current state, b) negative output current state. 
PV inverter topologies strive to decrease leakage current and increase efficiency. Many other topologies are continually being proposed and implemented. The inverter topologies are derived from HB or NPC topology. New PV inverters do not outperform UP modulated 2-legged HB in cost, volume, weight, efficiency, or minimal grid filter requirements for a V2G implementation. This can be attributed to the fact that mitigation of leakage current is not a safety concern in V2G converters. The high efficiency of PV inverters is mostly achieved by removing VAR exchange between DC link capacitor and grid filter during the zero output voltage stage. Topologies modify UP modulated 2legged HB inverter to manipulate power flow with a zero output voltage bypass and/or disconnect from DC link capacitor to the grid filter. Although required functionality for a $\mathrm{PV}$ power converter and $\mathrm{V} 2 \mathrm{G}$ power converter are similar, current $\mathrm{PV}$ inverter topologies are not beneficial to implement for a V2G power converter. This trend will probably continue as long as design focuses are different. Ideally, full wave bridge noncontrollable rectifier and UP modulated 2-legged HB inverter topologies should be used for a 2-stage $\mathrm{V} 2 \mathrm{G}$ power converter. Given both are from a full bridge configuration, they are capable of both being implemented in a bidirectional circuit. Already in a 2-legged HB structure, the topology allows an integrated G2V-V2G power converter.

\subsection{Bidirectional DC-DC}

\subsubsection{Comparison of Non-Isolated DC-DC Topologies for V2G Power Converter}

[29] has studied bidirectional non-isolated dc-dc topologies for battery charging and V2G converter topologies. Topologies compared were the HB, Cuk, SEPIC/Luo, and Three-level (TL) NPC converters. The HB converter is the better candidate in comparison to the Cuk and SEPIC/Luo converters. Although the Cuk and SEPIC/Luo 
converters have lower current stress for semiconductor devices, this is mitigated by additional number of passive components. The extra passive components decrease efficiency while increasing volume, weight, and cost. TL NPC converter was to be found to have higher efficiency and require a smaller inductor than HB converter. In respect to the HB converter, TL NPC converter requires an extra capacitor and two more switches (e.g. IGBTs).

Problematically, both converters are bidirectional but can only buck in one power flow direction and boost in another. For AC level 2 applications, the battery pack voltage may be greater or less than peak grid voltage. The battery pack voltage level is determined by battery pack SOC and current. For example, low battery pack current at $85 \%$ SOC would lead to higher battery pack voltages than peak grid voltage. On the other hand, high battery pack current at $20 \%$ SOC would lead to lower battery pack voltages than peak grid voltage. The exact battery pack voltage is not released at maximum and minimum SOC. To cover all bases, it will be assumed that battery pack voltage level may be either above or below peak grid voltage. Unfortunately, HB and TL NPC require modifications to be able to buck and boost for each direction. That leads both converters to be unfit for DC-DC regulation in a 2011 Chevy Volt two-stage V2G power converter. However, with the addition of another $\mathrm{HB}$ leg, bidirectional power flow with bidirectional buck, boost, and buck-boost modes can be achieved. The converter is known as a cascaded HB, bidirectional buck-boost, buck-boost cascade, four switch bidirectional buck-boost $[29,53,54,55]$. This thesis will refer to it as a four switch bidirectional buck-boost converter and is elaborated upon in section 3.2.2. When compared to other topologies, the four switch bidirectional buck-boost power converter is 
an ideal candidate for non-isolated $\mathrm{V} 2 \mathrm{G}$ power converters. In comparison to other isolated DC-DC topologies, it has a simple structure, high reliability, high efficiency, and low parts count [56]. It also has a 2-legged HB structure which allows integration into existing 2011 Chevy Volt drivetrain PIMs.

\subsubsection{Four Switch Bidirectional Buck-Boost Converter}

A four switch bidirectional buck-boost converter can operate in buck, boost, or buck-boost mode (see Figures 3.24, 3.25, and 3.26 respectively). Buck, boost, and buckboost have to output voltage in relationship to input voltages. Buck converters step down, boost converters step up, and buck-boost converters may either step up or down voltages. In the case of $\mathrm{V} 2 \mathrm{G}$ power converters, buck mode is when the converter must send power from the higher voltage side to the lower voltage side. Boost mode is when power must be sent from the lower voltage side to the higher voltage side. Buck-boost mode is for power transfer usually when input voltage is near desired output voltages. This basically depends on the SOC or battery pack voltage in respect to the DC link bus. The topology is symmetrical so each mode only needs to be discussed in one power flow direction. In the same mode, opposite direction of power flow can be achieved by swapping gate driving signals to mirrored equivalent switches (i.e. S1 and S3 are mirrored). 


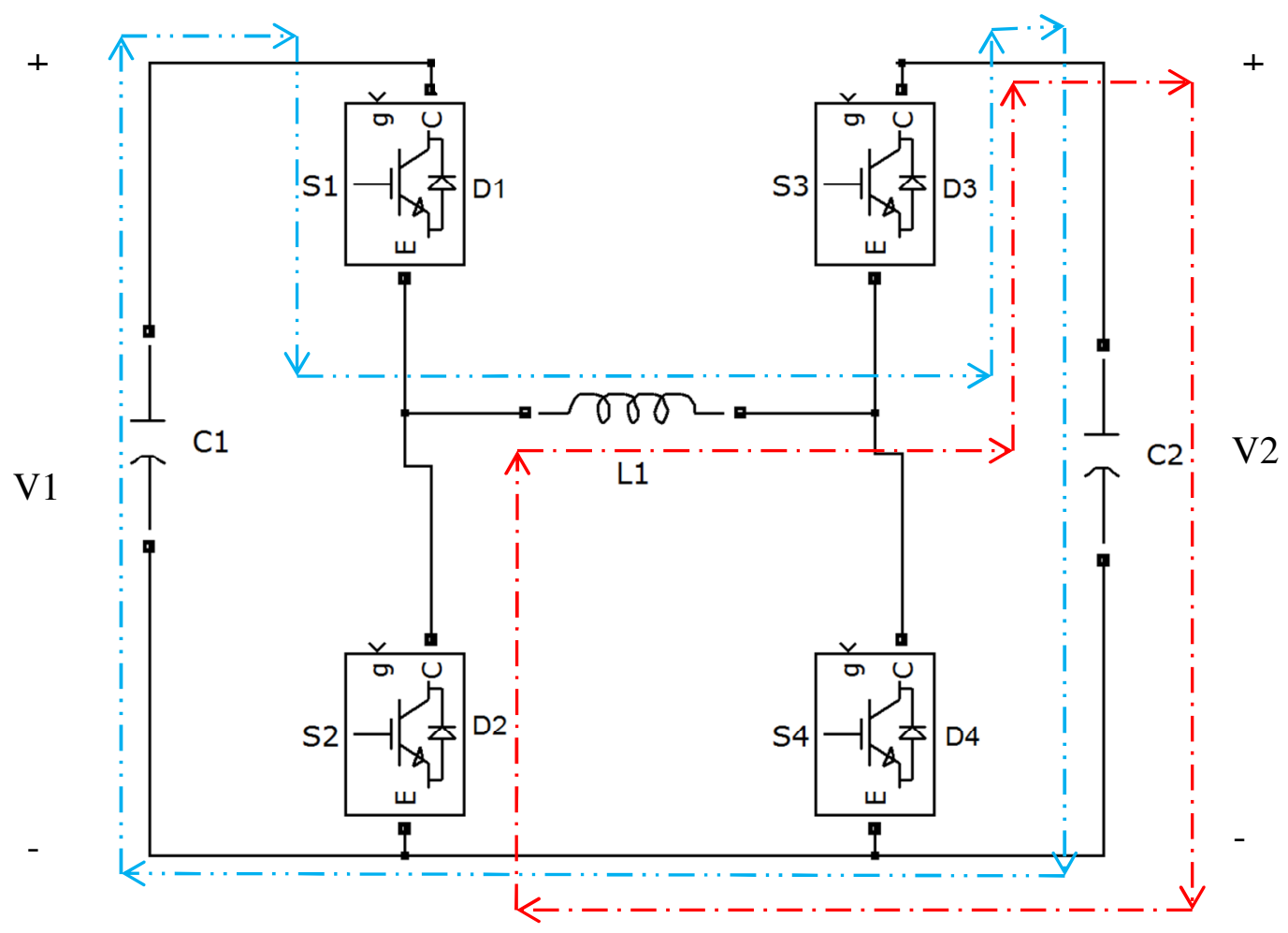

Figure 3.24 - Four switch bidirectional buck-boost converter showing buck mode switching states. Blue represents when $\mathrm{S} 1$ is on, current path is conducting through S1 and D3. Red represents when all switches are off, current path is conducting through D2 and D3. 


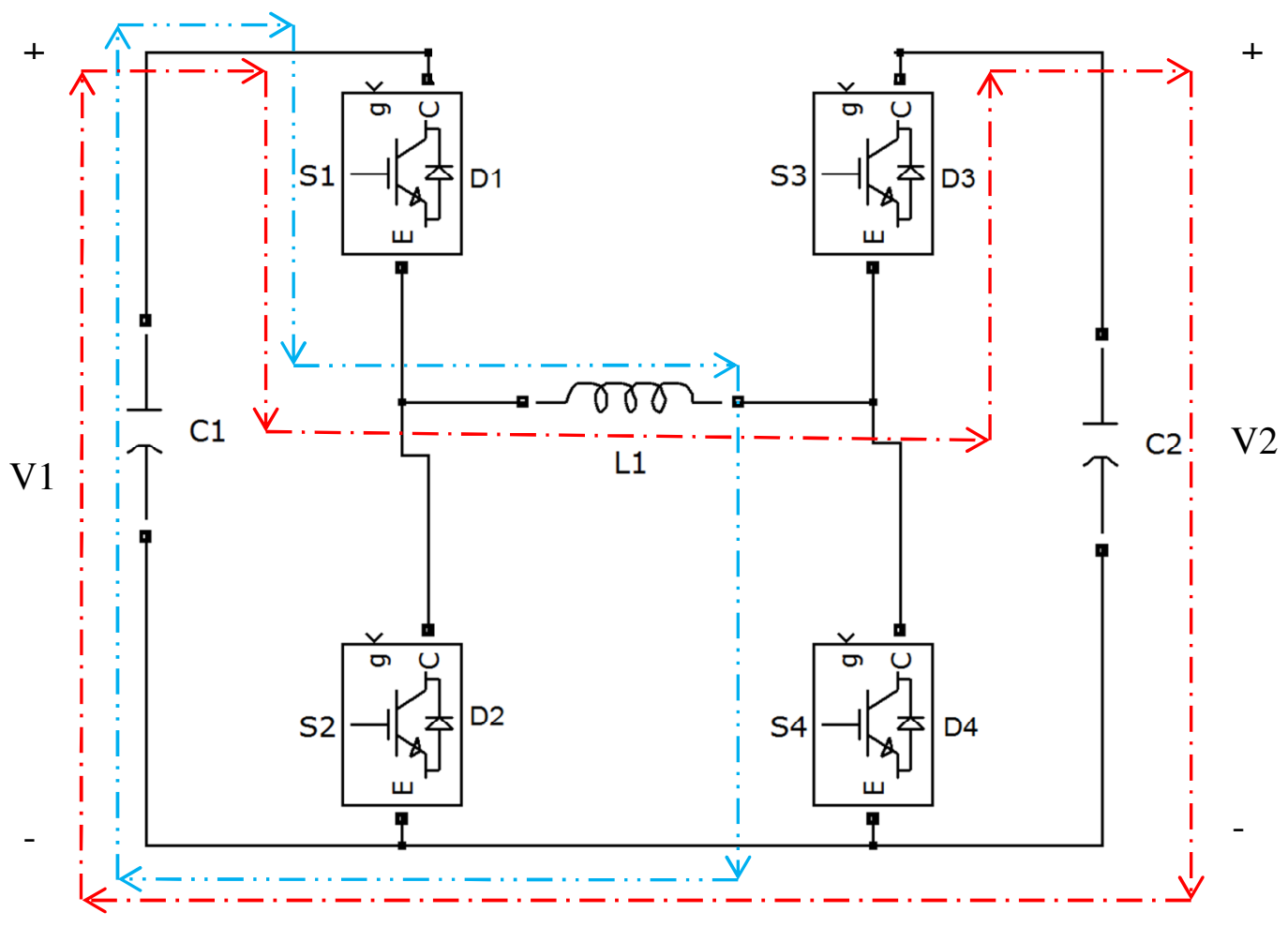

Figure 3.25 - Four switch bidirectional buck-boost converter showing boost mode switching states. Blue represents when S1 and S4 are on, current path is conducting through $\mathrm{S} 1$ and $\mathrm{S} 4$. Red represents when $\mathrm{S} 1$ is on, current path is conducting through S1 and D3. 


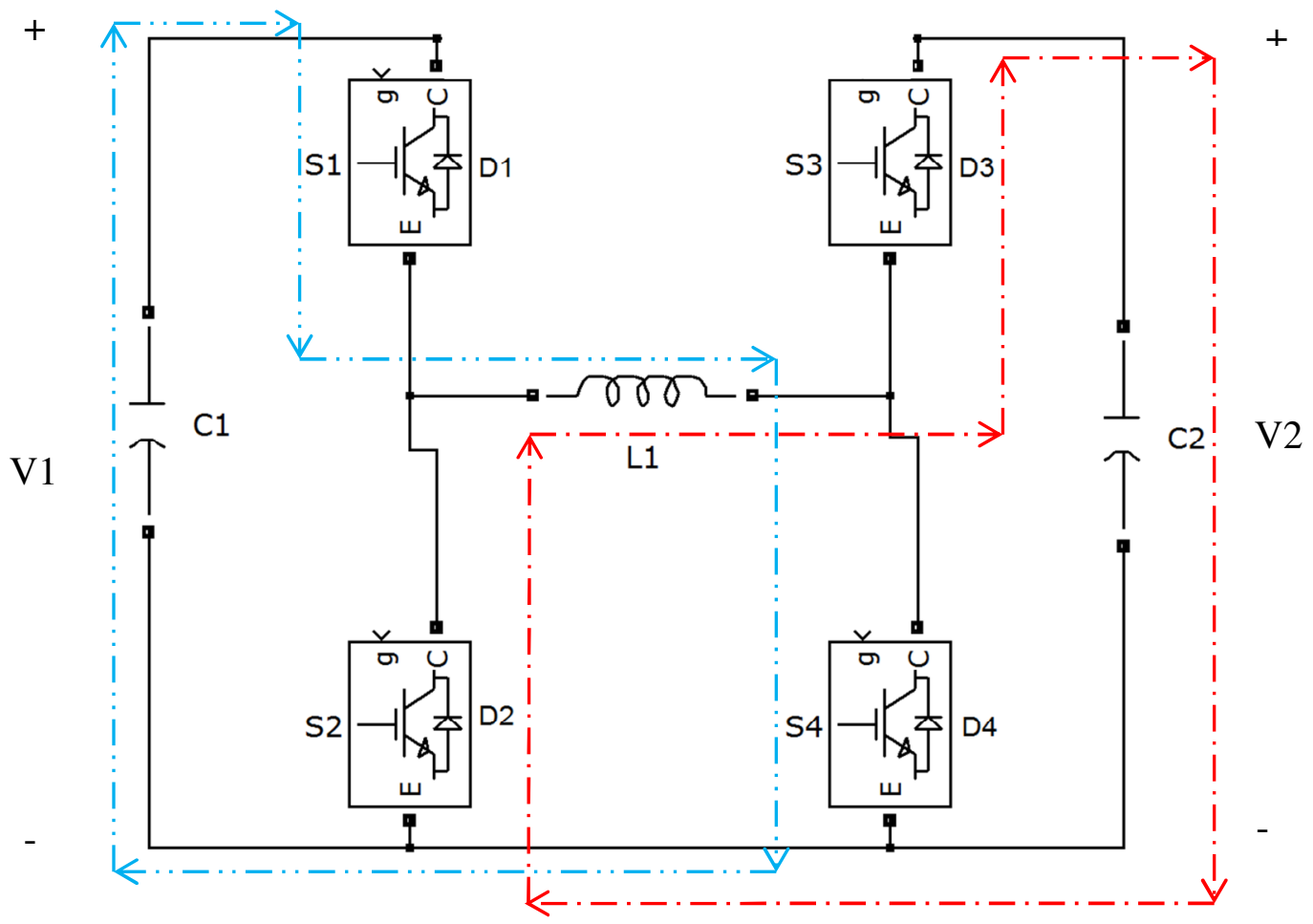

Figure 3.26 - Four switch bidirectional buck-boost converter showing buck-boost mode switching states. Blue represents when S1 and S4 are on, current path is conducting through S1 and S4. Red represents when all switches are off, current path is conducting through D2 and D3.

To prove the topology, only buck-boost mode will be used for simplicity. Otherwise, controls must be made for buck, boost, buck-boost and transitions. Buckboost mode will prove the four switch bidirectional buck-boost converters utility for V2G power converters and meet the thesis scope.

Following Figure 3.26, transfer function can be derived for a four switch bidirectional buck-boost converter in buck-boost mode. Note, the assumption that all components are ideal will be made to simplify calculations. There will be no losses through switches, diodes, capacitors, PCB traces, etc. The differences are negligible since a robust controller will correct the differences thus making them negligible. The second assumption is power is transferring from left (V1 side) to right (V2 side). The transfer 
function may be derived the fact average current through an inductor is equal to 0 , shown below.

State 1 (shown as blue in Figure 3.26):

Starting by observation, voltage across the inductor can be equated as...

$$
\begin{gathered}
V_{L 1}=V_{1} \\
V_{L 1}=\frac{d i_{L_{1}}}{d t} L_{1} \\
\frac{d i_{L 1}}{d t}=\frac{\Delta i_{L_{1}, \text { charging }}}{\Delta t} \\
\frac{\Delta i_{L_{1}, \text { charging }}}{\Delta t}=\frac{\Delta i_{L_{1}, \text { charging }}}{\mathrm{DT}}
\end{gathered}
$$

Combining ( 3-1 ) \& ( 3-4)...

$$
\begin{gathered}
V_{1}=\frac{\Delta i_{L_{1}}, \text { charging }}{\mathrm{DT}} L_{1} \\
\Delta i_{L_{1}, \text { charging }}=\frac{V_{1} \mathrm{DT}}{L_{1}}
\end{gathered}
$$

State 2 (shown as red in Figure 3.26):

Again, starting by observation, voltage across the inductor can be equated as...

$$
\begin{gathered}
V_{L 1}=-V_{2} \\
\frac{d i_{L 1}}{d t}=\frac{\Delta i_{L_{1}}, \text { discharging }}{\Delta t} \\
\frac{\Delta i_{L_{1},} \text { discharging }}{\Delta t}=\frac{\Delta i_{L_{1}, \text { discharging }}}{(1-\mathrm{D}) \mathrm{T}}
\end{gathered}
$$

Combining ( 3-7) \& (3-9)... 


$$
-V_{2}=\frac{\Delta i_{L_{1}, \text { discharging }}}{(1-\mathrm{D}) \mathrm{T}} L_{1}
$$

Using ( 3-6 ) \& ( 3-11)...

$$
\Delta i_{L_{1}, \text { discharging }}=\frac{-V_{2}(1-\mathrm{D}) \mathrm{T}}{L_{1}}
$$

Noting, average current through inductor is 0 .

$$
i_{L_{1}, \text { average }}=\Delta i_{L_{1}, \text { charging }}+\Delta i_{L_{1}, \text { discharging }}=0
$$

Substituting ( 3-6 ) \& (3-11)...

$$
\begin{gathered}
\frac{V_{1} \mathrm{DT}}{L_{1}}=\frac{V_{2}(1-\mathrm{D}) \mathrm{T}}{L_{1}} \\
\frac{V_{2}}{V_{1}}=\frac{D}{1-D}
\end{gathered}
$$

Rearranging ( 3-14 ) also leads to...

$$
D=\frac{V_{2}}{V_{1}+V_{2}}
$$

(3-14) is the transfer function of a four switch bidirectional buck-boost converter which proves it is indeed a non-inverting buck-boost. The normal buck-boost is difficult to use since it inverts the output voltage, but this converter does not have such issues. The converter and buck-boost mode is ideal for a V2G power converter since the voltage is required to be stepped up, down, or both during operation. There is a high count of 
switches and diodes from the 2-legged HB, but not when compared to DC-DC converters that offer bidirectional power flow with buck, boost, and buck-boost operation in either direction. Otherwise, only an additional inductor is required. One capacitor represents the DC link bus capacitor and the other was to be tied to the battery to protect from voltage transients.

\subsection{Grid Filter}

Since a PWM voltage source inverter (VSI) will be used, an appropriate grid filter is needed to ensure current harmonics are lowered to acceptable levels. There are 3 popular filter topologies to consider: L, LC, and LCL (shown in Figure 3.27). An L is the simplest with $20 \mathrm{~dB} /$ decade attenuation. This requires a high switching frequency to be effective and converter-filter system dynamics are decreased. A second order LC filter may be used and is simple to design. Problematically, the resonant frequency is dependent on the grid impedance and a high inductance is required to achieve demanded cut-off frequency [57]. A set of LC filter traps are used to attenuate switching frequency harmonics that are too low for an LCL. The switching frequency in that case would be hundreds of hertz [42]. This thesis will use a switching frequency much higher to push PWM harmonics to increase filter attenuation. Having a set of LC traps will increase cost, volume, and weight as well, all of which is undesirable. Standards and grid codes are stringent for high frequencies. Hence, high order filters such as the LCL are used [42]. It provides $60 \mathrm{~dB} / \mathrm{decade}$ attenuation and allows lower switching frequencies to be used [57]. As frequency is decreased, efficiency is increased. Benefits mentioned previously also mean a decrease in size and cost when compared to an L filter [58]. 


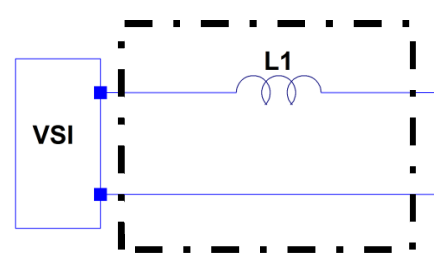

(a)

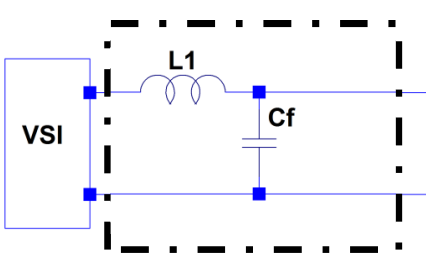

(b)

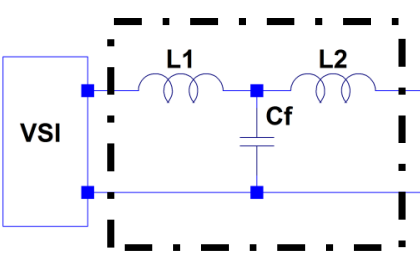

(c)

Figure 3.27 - VSI grid filters: (a) L, (b) LC, c) LCL.

The LCL filter has disadvantageous that must be considered. The cut-off frequency must have enough distance from the grid and switching frequency harmonics. Otherwise, resonance may cause instability or unwanted oscillations [58]. This may be avoided by choosing a switching frequency which allows padding between the filter cutoff frequency and switching frequency. Damping may be added to minimize oscillations as well. Being a $3^{\text {rd }}$ order filter, the LCL is difficult to design. Although complicated, LCL design is still viable. Thanks to the popularity of GTIs, literature has explored and optimized LCL design [59]. The LCL filter will is the most ideal candidate for V2G operation at AC level 2. 


\section{Proposed Topology \& Design Calculations}

An integrated $\mathrm{G} 2 \mathrm{~V}-\mathrm{V} 2 \mathrm{G}$ power converter is proposed in this chapter (shown in

Figure 4.1). First, changes to drivetrain layout systems are explained. Second, how to enable G2V or V2G mode is discussed. The proposed power converter topology controls for V2G are explained and G2V controls are discussed. 


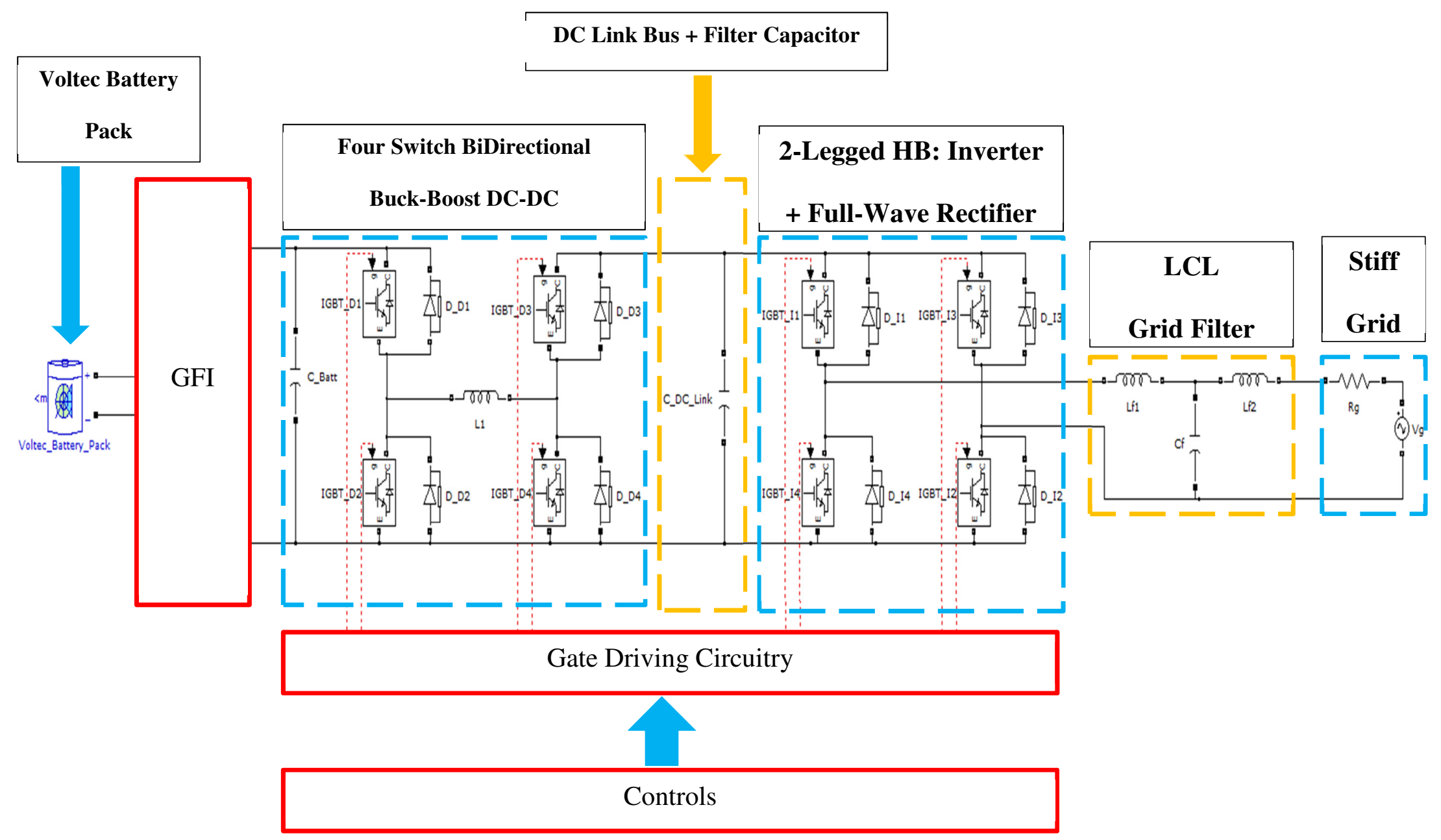

Figure 4.1 - G2V-V2G power converter system layout. 


\subsection{Integration}

Only a few modifications are required to integrate G2V-V2G power converter functionality into the 2011 Chevy Volt's drivetrain. Original drive layout (see Figure 2.1) is modified to Figure 4.2. Changes are highlighted in red. Notice the previous charger is replaced with PIM-A DC-DC connections, heater is moved, and GFI is added in front of the RESS. Heater was moved to a position where the full wave rectifier ensures power to the heater when vehicle is plugged in. GFI is used to limit leakage current since there is no galvanic isolation. When GFI is triggered, only traction and V2G bidirectional power converter electronics lose power. Vehicles $12 \mathrm{~V}$ rail and low voltage subsystems are still powered. The number of relays remains at five.

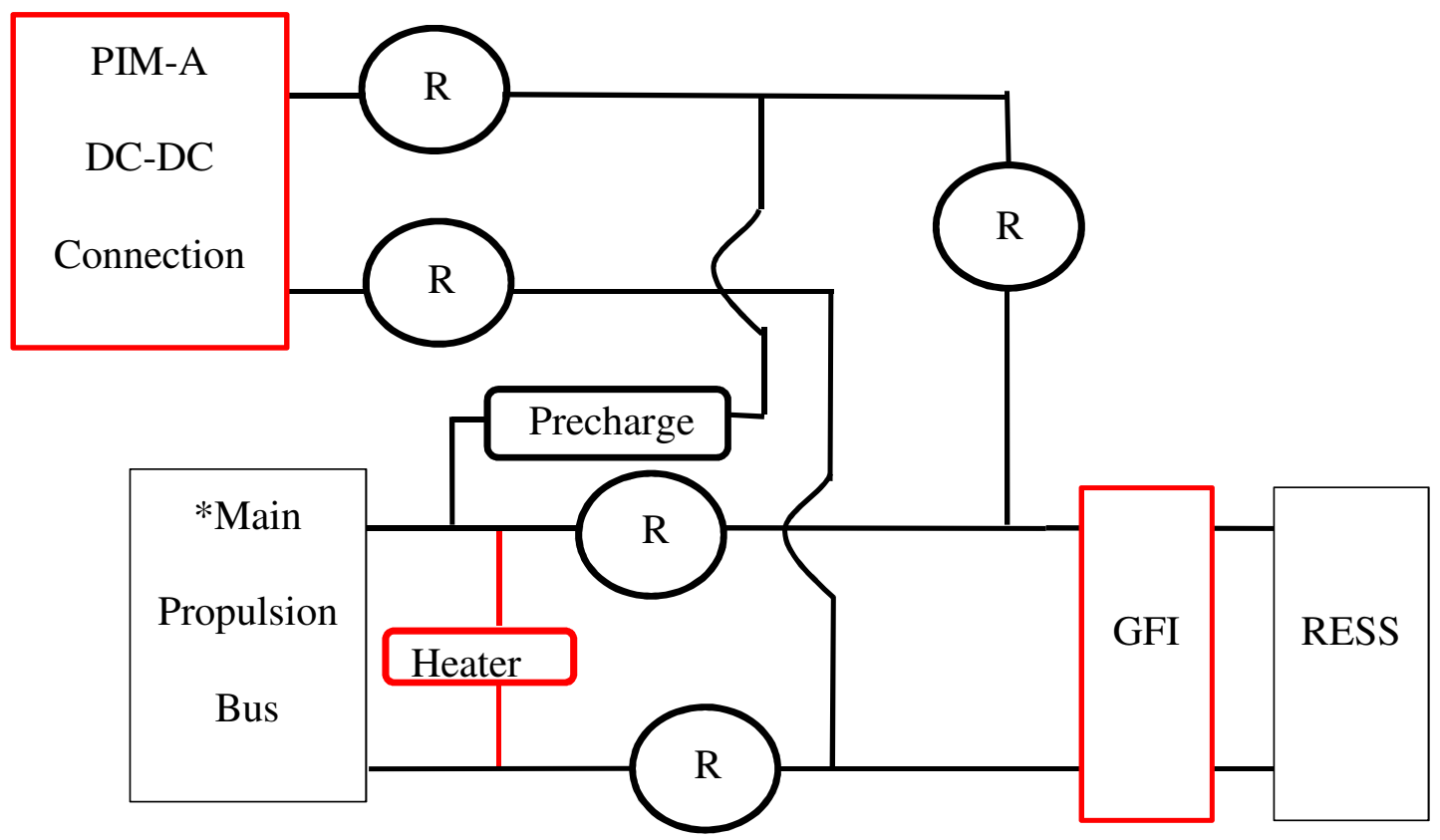

*Also known as DC Link Bus

Figure 4.2 - Modified general layout. 
A relatively small addition of passive and relay components are required to modify the system to enable G2V-V2G power conversion. The modified system interface during G2V-V2G mode with generator off is shown in Figure 4.3. Also V2G-mode with generator on is shown in Figure 4.4. For Figure 4.3 and Figure 4.4, relays are in correct positions for respective modes. Note, GFI and main propulsion bus relays are not shown in Figure 4.3 or Figure 4.4.

If all additional relays are single pole single throw (SPST), only an addition of nine relays are required. Relays R4 and R7 were already available in the original system. Relays R1, R2, R5, and R6 are shown as single pole double throw (SPDT) in the previous figures. SPDT combos may be implemented double throw double throw (DTDT) as well. The proposed G2V-V2G integrated topology is advantageous since a separate power converter is needed. Component, cost, volume, and weight is minimized for plug-in battery charging and V2G functionality. Relays are low in cost, volume, and weight in comparison to creating another power converter. In terms of passive components, the proposed integrated G2V-V2G power converter only requires an addition of LCL grid filter $\left(\mathrm{L}_{\mathrm{f} 1}, \mathrm{~L}_{\mathrm{f} 2}, \mathrm{C}_{\mathrm{f}}\right)$, buck-boost inductor $\left(\mathrm{L}_{1}\right)$, and battery side buck-boost capacitor $\left(\mathrm{C}_{\mathrm{D}}\right)$. The DC link bus filter capacitor is actually the traction capacitor bank. Although a minimum capacitance was calculated in section 4.3.3, the available capacitor bank should be much larger than the required size. Anti-parrallel diodes may already be present in Voltec's TPIM hex IGBT modules. If they are not, switching to a hex IGBT module is simple and has a low increase in cost.

Previous integrated G2V-V2G systems have used drive motor inductances as filters $[5,17,18,46]$. Due to little information available about motors, this topology does 
not use them. In actuality that may not be the case, motors can be modified during manufacturing to make them suitable.

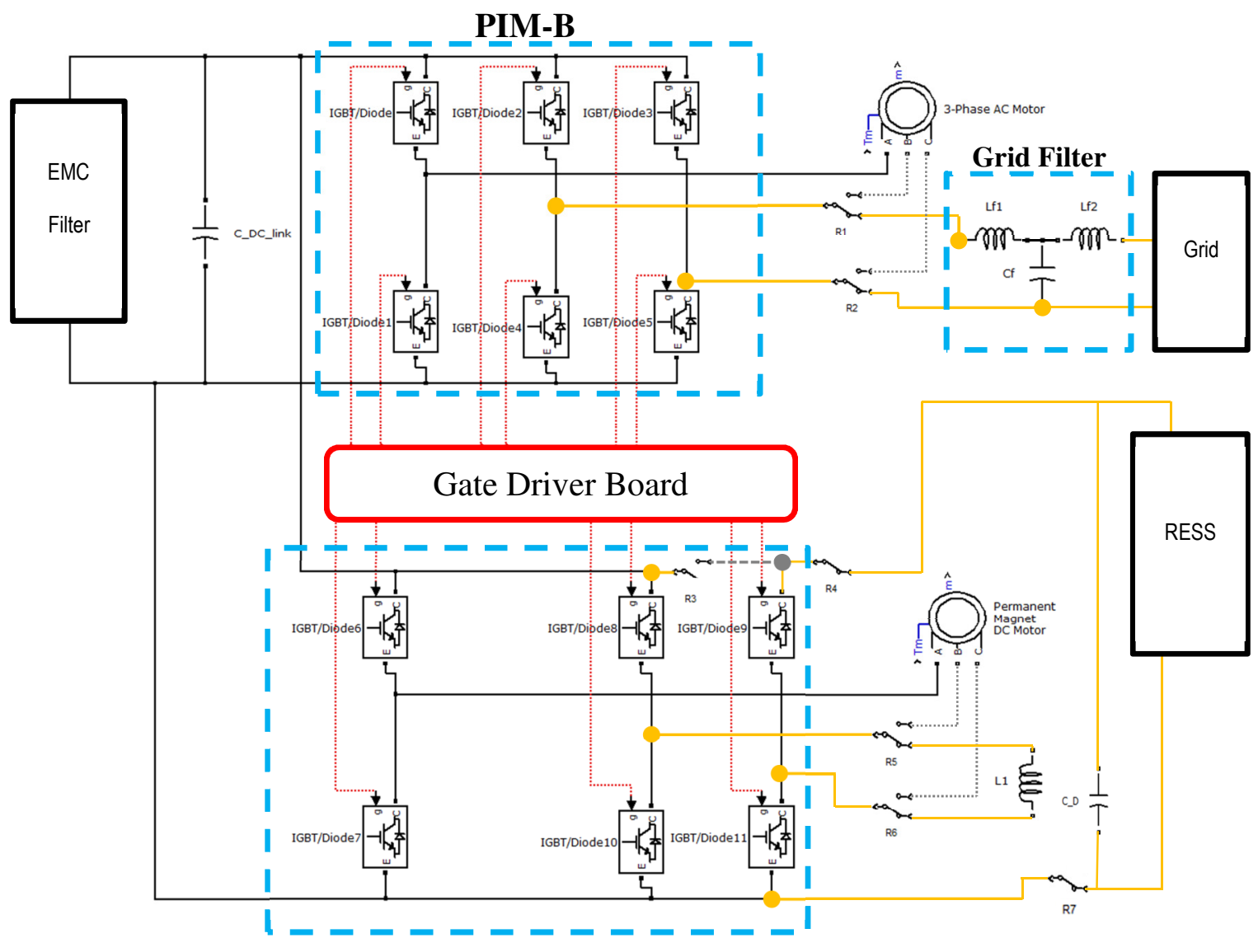

\section{PIM-A}

Figure 4.3 - Modified system interface for PIM-A, PIM-B, and main propulsion bus with relays engaged in $\mathrm{G} 2 \mathrm{~V}-\mathrm{V} 2 \mathrm{G}$ power converter mode. The RESS is connected while the generator is disconnected. 


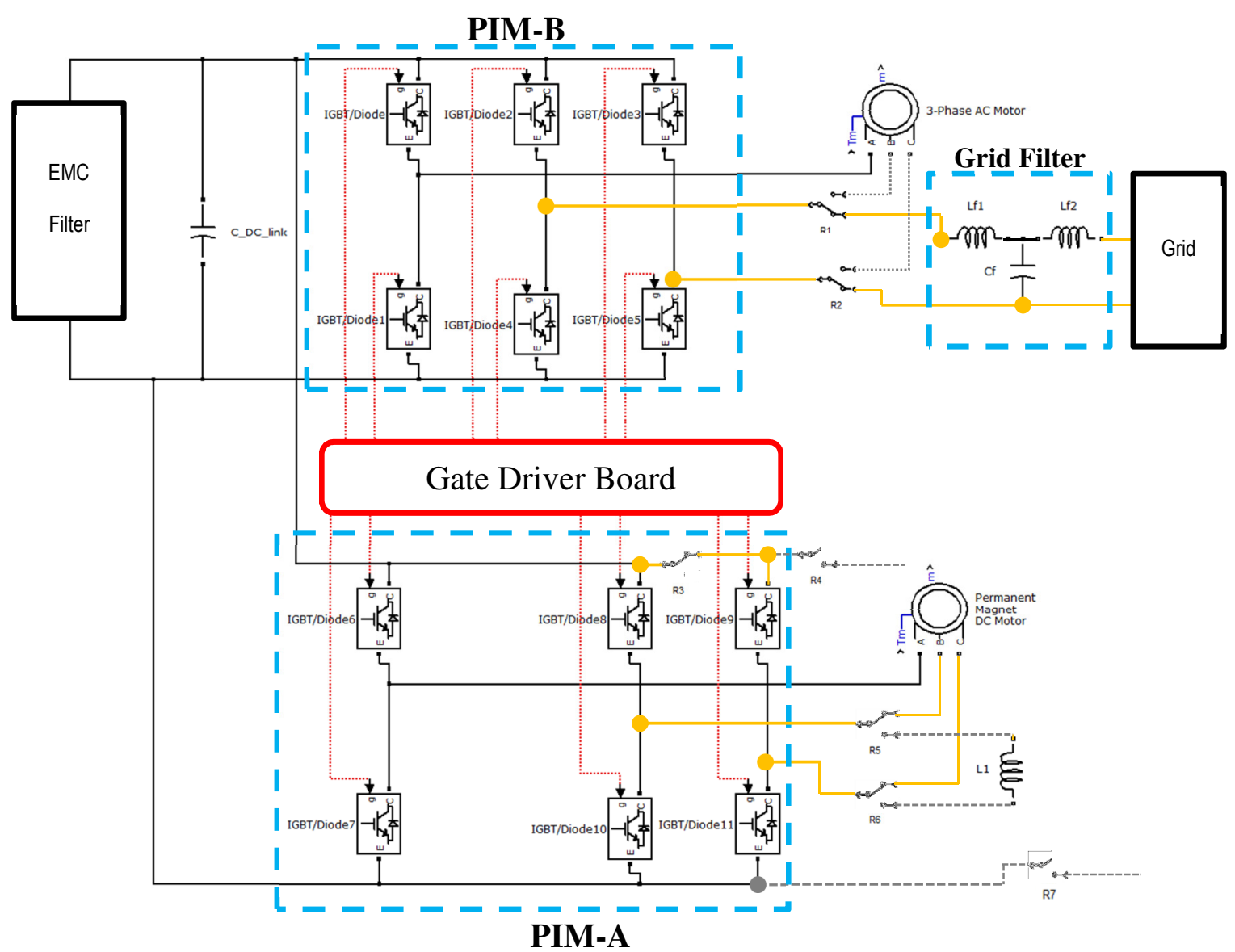

Figure 4.4 - Modified system interface for PIM-A, PIM-B, and main propulsion bus with relays engaged in $\mathrm{G} 2 \mathrm{~V}-\mathrm{V} 2 \mathrm{G}$ power converter mode. The RESS is disconnected while the generator is connected.

The DC generator can be used to feed power during V2G or vehicle-to-home $(\mathrm{V} 2 \mathrm{H})$ as well. $\mathrm{V} 2 \mathrm{H}$ is not within the scope of this thesis, but basically involves the vehicle acting as a back-up generator (i.e. during blackouts). The 2011 Chevy Volt, most EREVs, and most series parallel hybrid electric drivetrains will be able to take advantage of the DC generator or even an $\mathrm{AC}$ generator for $\mathrm{V} 2 \mathrm{G}$ or $\mathrm{V} 2 \mathrm{H}$ operations. This is especially useful if the battery pack does not contain enough energy, but power is required. The fuel cost to increase energy capacity must be considered. The fuel source of the generator may be gasoline, ethanol, or fuel cell. In the case of the Chevy Volt, it has 
an ICE using gasoline as the fuel source. The thesis will explore this G2V-V2G topology feeding power via V2G using the on board generator. On board generator charging the battery or used in synch with the battery pack will not be explored. First of all, it does not make sense to charge the battery and discharge the battery while the generator is powering V2G. Secondly, gasoline costs are much higher than electricity prices so the battery should not be charged up by the on board generator. Lastly, when the vehicle is driven while the battery pack is at a low SOC, the generator already has a system to maintain battery SOC.

\subsection{Controls}

Each mode assumes relays are triggered into the proper positions. Also the 2011 Chevy Volt is in park so AC traction motor will not be used. When power is fed via battery, ICE and DC generator will not be used as well. This means TPIM will be available for G2V-V2G function. ICE and DC generator will only be used when power is fed from the DC generator for V2G operation.

\subsubsection{V2G Mode}

V2G mode has two different controls: battery fed or generator fed. At the beginning of each mode, DC link bus voltage is checked before the grid switch is closed. If the DC link bus voltage $\left(\mathrm{V}_{\mathrm{DC}}\right)$ is less than $380 \mathrm{~V}\left(\mathrm{~V}_{\mathrm{DC}}{ }^{*}\right)$, pre-charge control is enabled. Pre-charge uses either battery and DC-DC converter or ICE and DC generator to charge DC link bus voltage to at least $380 \mathrm{~V}$.

V2G mode DC-DC converter controls begin with high signal from V2G_Start. The starting proportional integral (PI) controller is enabled and the switch is left in position as shown in Figure 4.5. When DC bus is at or above specified voltage $\mathrm{V}_{\mathrm{DC}}{ }^{*}$, the 
grid switch controller waits for the appropriate time to start V2G operation. Grid switch controller code is available via Appendix A. When the grid switch is closed, the inverter unipolar hysteresis current control and nominal PI control $\left(\mathrm{PI}_{\mathrm{nom}}\right)$ is enabled. Switch position is changed appropriately via V2G_Enable. PI output fed from switch is compared with a $50 \mathrm{kHz}$ triangle wave to create a duty cycle for V2G_SW.V2G_SW is tied to gate drivers for IGBTs in four switch bidirectional buck-boost, specifically S1 \& $\mathrm{S} 4$ of Figure 3.26. Where battery side is $\mathrm{V}_{1}$, DC link side is $\mathrm{V}_{2}$, IGBTs S2 and S3 gates are held low.

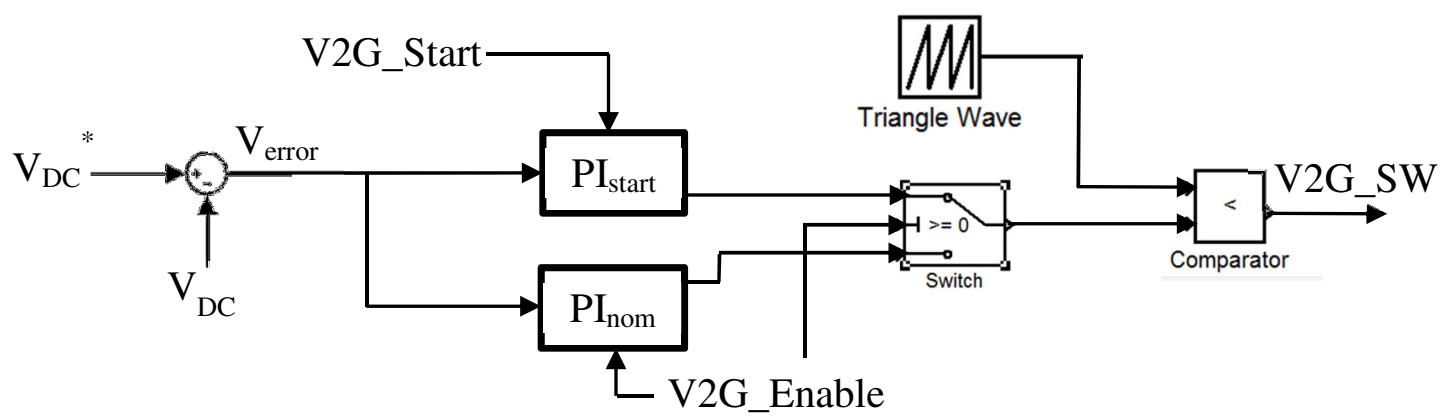

Figure 4.5 - V2G mode DC-DC controls.

Similarly, V2G mode DC generator controls begin from signal V2G_Start_DC. The starting PI controller is enabled and switch is left in position as shown in Figure 4.6. When the DC bus is at or above specified voltage $\mathrm{V}_{\mathrm{DC}}{ }^{*}$, the grid switch controller waits for the appropriate time to start V2G operation. When the grid switch is closed, inverter unipolar hysteresis current control and nominal PI control $\left(\mathrm{PI}_{\text {nom }}\right)$ is enabled. Switch position is changed appropriately via V2G_Enable. PI output fed from switch controls DC generator shaft speed (w [rpm]) via ICE. Gain "Ke Scale" is used to scale voltage to shaft speed (rpm). 


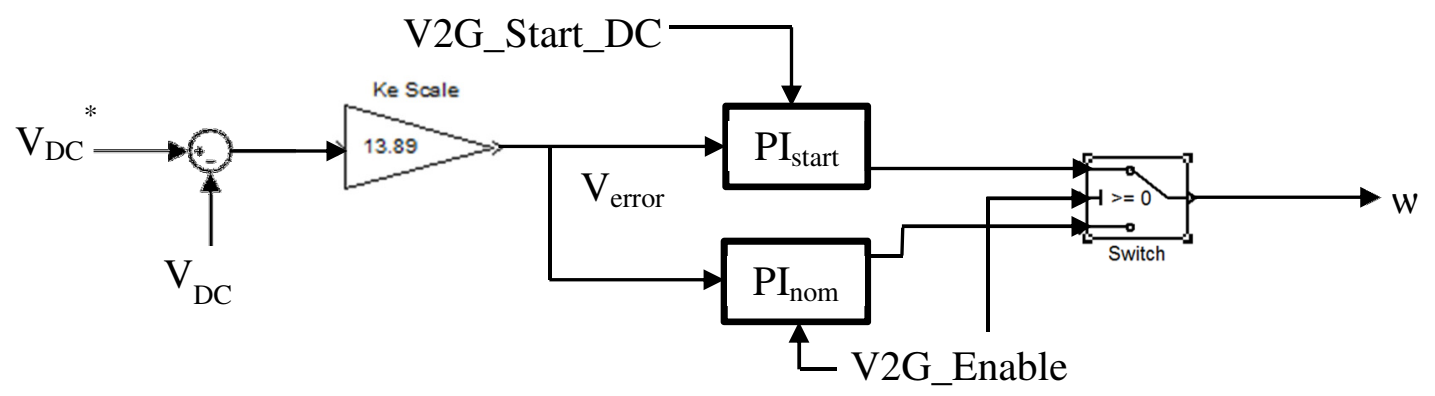

Figure 4.6 - V2G mode generator controls.

Inverter current control is shown in Figure 4.7. Phase-locked loop (PLL) fed by grid voltage. PLL outputs sinusoid reference to grid voltage phase with an amplitude of 1. The product is taken with reference peak grid current $\left(\mathrm{I}_{\mathrm{g}, \mathrm{pk}}{ }^{*}\right)$ and generates reference grid current $\left(\mathrm{I}_{\mathrm{g}}{ }^{*}\right)$. Error current $\left(\mathrm{I}_{\mathrm{error}}\right)$ is fed into unipolar hysteresis controller with grid voltage $\left(\mathrm{V}_{\mathrm{g}}\right)$ and hysteresis band $(\mathrm{H})$. Inverter IGBT gate drivers are driven appropriately by controller as shown in Figure 3.6, 3.7, and 3.8. Signal V2G_Enable is triggered high when inverter operation begins. Hysteresis controller code is available via Appendix B.

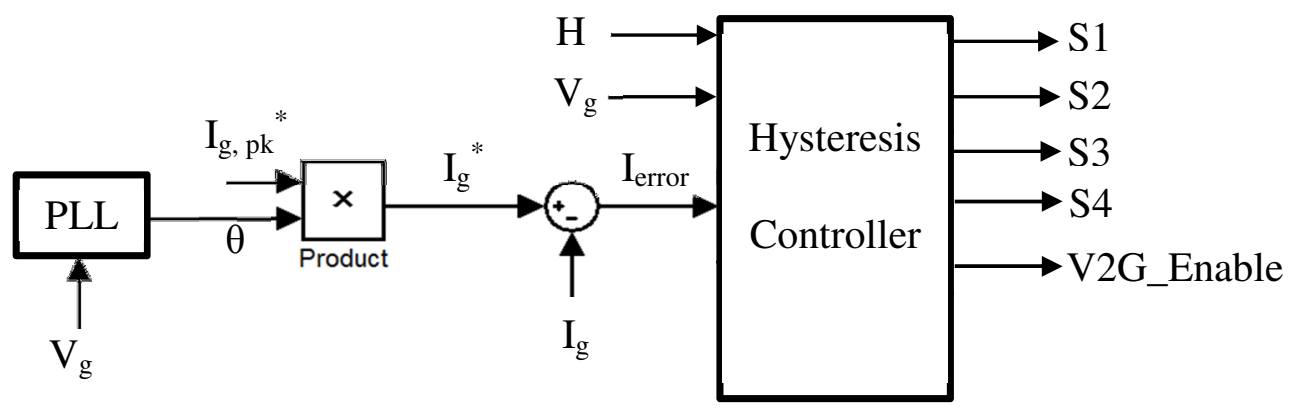

Figure 4.7 - V2G mode inverter controls.

Hysteresis band $(\mathrm{H})$ is varied to try maintaining a constant switching frequency $\left(f_{\mathrm{sw}}\right)$ of $20 \mathrm{kHz}$ ( $4-1$ ) is used to calculate appropriate hysteresis band, given from [60]. Inverter side LCL inductance $\left(\mathrm{L}_{\mathrm{f} 1}\right)$ and switching frequency $\left(\mathrm{f}_{\mathrm{sw}}\right)$ are constant values. 
LCL capacitor voltage $\left(V_{C_{f}}\right)$ and DC link voltage $\left(\mathrm{V}_{\mathrm{DC}_{-} \mathrm{LINK}}\right)$ are updated from voltage sensors. The code for hysteresis band calculations is given in Appendix C.

$$
H=\left|V_{C_{f}}\right| \frac{V_{D C_{-} \text {Link }}-\left|V_{C_{f}}\right|}{L_{f 1} f_{S W} V_{D C_{-} \text {Link }}}
$$

\subsubsection{G2V Mode}

Controls for G2V or plug-in battery charging are mainly dependent on the chosen battery charging algorithm. Typically constant current control is used until a set SOC. Once the set SOC is reached, a constant current constant voltage algorithm is imposed to limit cell voltages. The proposed four switch buck-boost provides great flexibility in battery charging. Batteries can be charged at voltages less than, approximately equal to, or greater than input voltage [55]. G2V simulations are not within the scope of this thesis. G2V will not be explored any further since GM engineers have already chosen their preferred method to maintain battery life. It is most likely the charging algorithm and control can be implemented via four switch bidirectional buck-boost converter.

\subsection{Passive Component Design Calculations}

\subsubsection{Grid Impedance}

This section uses worst case (weak grid) and best case (stiff grid) p.u. impedance values from [42]. A stiff grid will be modeled with an impedance of $2 \%$ p.u. and purely resistive. Base values are based on AC level 2 ratings and given in Table 4.1.

Table 4.1 - AC level 2 ratings used as base values.

\begin{tabular}{|l|l|l|}
\hline$V_{\text {base }}^{\text {grid }}$ & $I_{\text {base }}^{\text {grid }}$ & $S_{\text {base }}^{\text {grid }}$ \\
\hline $240 \mathrm{~V}$ & $32 \mathrm{~A}$ & $7.7 \mathrm{kVA}$ \\
\hline
\end{tabular}


Base grid impedance can be found as $7.5 \Omega$ from ( 4-2 ).

$$
Z_{\text {base }}^{\text {grid }}=\frac{V_{\text {base }}^{\text {grid }}}{I_{\text {base }}^{\text {grid }}}
$$

Stiff grid resistance $\left(\boldsymbol{R}_{\boldsymbol{g}}^{\text {stiff }}\right)$ is .15 $\Omega$ from ( 4-3 ) and inductance $\left(\boldsymbol{L}_{\boldsymbol{g}}^{\text {stiff }}\right)$ is $0 \mathrm{H}$.

$$
R_{g}^{\text {stiff }}=2 \% * Z_{\text {base }}^{\text {grid }}
$$

A weak grid will be modeled with an impedance of $15 \%$ p.u. The reactance will be assumed as $41 \%$ of the total impedance.

$$
\begin{gathered}
Z_{g}^{\text {weak }}=15 \% * Z_{\text {base }}^{\text {grid }} \\
X_{g, L}^{\text {weak }}=41 \% * Z_{g}^{\text {weak }} \\
L_{g}^{\text {weak }}=\frac{X_{L, g}^{\text {weak }}}{2 \pi f_{g}}
\end{gathered}
$$

Combining ( 4-4 ), ( 4-5 ), ( 4-6 )...

$$
\begin{gathered}
L_{g}^{\text {weak }}=\frac{41 \% * 15 \% * Z_{\text {base }}^{\text {grid }}}{2 \pi f_{g}} \\
R_{g}^{\text {weak }}=\sqrt{\left(Z_{g}^{\text {weak }}\right)^{2}-\left(X_{g, L}^{\text {weak }}\right)^{2}}
\end{gathered}
$$

Combining ( 4-4 ) \& ( 4-5 )... 


$$
R_{g}^{\text {weak }}=\sqrt{\left(15 \% * Z_{\text {base }}^{\text {grid }}\right)^{2}-\left(41 \% * 15 \% * Z_{\text {base }}^{\text {grid }}\right)^{2}}
$$

Weak grid resistance $\left(R_{g}^{\text {weak }}\right)$ is $1.0261 \Omega$ from ( 4-8 ) and inductance $\left(L_{g}^{\text {weak }}\right) 1.2235 \mathrm{mH}$ from ( 4-9 ). Respective grid impedance parameters are summarized in Table 4.2.

Table 4.2 - Stiff and weak grid impedance parameters.

\begin{tabular}{|c|c|c|}
\hline \multirow{2}{*}{ Stiff } & $R_{g}^{\text {stiff }}[\Omega]$ & .15 \\
\cline { 2 - 3 } & $L_{g}^{\text {stiff }}[\mathrm{mH}]$ & 0 \\
\hline \multirow{2}{*}{ Weak } & $R_{g}^{\text {weak }}[\Omega]$ & 1.0261 \\
\cline { 2 - 3 } & $L_{g}^{\text {weak }}[\mathrm{mH}]$ & 1.2235 \\
\hline
\end{tabular}

\subsubsection{LCL Filter}

To appropriately size a LCL for hysteresis current control, first the inverter side inductor $\left(\mathrm{L}_{\mathrm{f} 1}\right)$ must be found. The inductor can be calculated by the max inverter ripple current [42].

$$
\Delta I_{M A X}=\frac{V_{D C_{-} L I N K}}{n L_{f 1} f_{S w}}
$$

Choosing a max ripple current of $10 \% \ldots$

$$
\begin{gathered}
\Delta I_{M A X}=10 \% * I_{o, p k} \\
\Delta I_{M A X}=.1 \frac{P_{\text {base }}^{\text {converter }}}{V_{\text {base }}^{\text {converter }}} * \sqrt{2}
\end{gathered}
$$

Combining (4-10) \& (4-12)... 


$$
\mathrm{L}_{f 1}=\frac{V_{D C_{-} \text {LINK }}}{n f_{s w}\left[.1 \frac{P_{\text {base }}^{\text {converter }}}{V_{\text {base }}^{\text {converter }}} * \sqrt{2}\right]}
$$

DC voltage bus $\left(\mathrm{V}_{\mathrm{DC} \_ \text {LINK }}\right)$ is chosen to be $400 \mathrm{~V}$. Unipolar switching is used so the number of levels (n) is 3. UP modulated 2-legged HB is has three levels since it can output at $+\mathrm{V}_{\mathrm{DC}}, 0$, and $-\mathrm{V}_{\mathrm{DC}}$. Hysteresis control is assumed to be at constant switching frequency $\left(\mathrm{f}_{\mathrm{sw}}\right)$ of $20,000 \mathrm{kHz}$. Convert base power $\left(P_{\text {base }}^{\text {converter }}\right)$ is $3.3 \mathrm{~kW}$ and base voltage $\left(V_{\text {base }}^{\text {converter }}\right)$ is $240 \mathrm{VAC} . \mathrm{L}_{\mathrm{f} 1}$ will be chosen to be $3.5 \mathrm{mH}$ from ( $4-13$ ).

Next the LCL filter capacitor $\left(\mathrm{C}_{\mathrm{f}}\right)$ must be sized. Typically, $\mathrm{C}_{\mathrm{f}}$ is chosen to be large to lower inductance requirements and ensure robustness of resonant frequency [42]. The maximum power factor variation accepted by the grid is $5 \%$ and will be used to determine max value for $\mathrm{C}_{\mathrm{f}}[60]$.

$$
\begin{gathered}
C_{f} \leq 5 \% * C_{\text {base }}^{\text {converter }} \\
C_{\text {base }}^{\text {converter }}=\frac{1}{\omega_{g} Z_{\text {base }}^{\text {converter }}} \\
Z_{\text {base }}^{\text {converter }}=\frac{V_{\text {base }}^{\text {converter }}}{I_{\text {base }}^{\text {converter }}} \\
Z_{\text {base }}^{\text {converter }}=\frac{\left(V_{\text {base }}^{\text {converter }}\right)^{2}}{P_{\text {base }}^{\text {converter }}} \\
C_{\text {base }}^{\text {converter }}=\frac{1}{2 \pi f_{g} \frac{\left(V_{\text {base }}^{\text {converter }}\right)^{2}}{P_{\text {base }}^{\text {converter }}}}
\end{gathered}
$$

Combining (4-14) \& (4-18)... 


$$
C_{f} \leq \frac{.05}{2 \pi f_{g} \frac{\left(V_{\text {base }}^{\text {converter }}\right)^{2}}{P_{\text {base }}^{\text {converter }}}}
$$

In the USA, grid frequency ( $\mathrm{f}_{\mathrm{g}}$ ) is $60 \mathrm{~Hz}$. ( 4-19) gives $\mathrm{C}_{\mathrm{f}} \leq 7.6 \mu \mathrm{F}$. A large $\mathrm{C}_{\mathrm{f}}$ of $5 \mu \mathrm{F}$ is chosen.

Lastly, the grid side inductor $\left(\mathrm{L}_{\mathrm{f} 2}\right)$ is required [60].

$$
\mathrm{L}_{f 2}=r \mathrm{~L}_{f 1}
$$

$\mathrm{L}_{\mathrm{f} 2}$ is chosen to be $1 \mathrm{mH}$ from ( 4-20) after choosing a ratio (r) of .3.

The resonant frequency can be found $[57,60]$ :

$$
\mathrm{f}_{\text {res }}=\frac{1}{2 \pi} \sqrt{\frac{\mathrm{L}_{f 1}+\mathrm{L}_{f 2}}{\mathrm{~L}_{f 1} \mathrm{~L}_{f 2} C_{f}}}
$$

Substituting into ( 4-21) leads to a $\mathrm{f}_{\mathrm{res}}$ of $2.552 \mathrm{kHz}$. LCL components must have a proper resonant frequency $\left(f_{\text {res }}\right)$ with respect to grid and switching frequency. To ensure proper distance, (4-22 ) must be obeyed as the proposed LCL values [57, 60].

$$
\mathrm{f}_{g} * 10<\mathrm{f}_{r e s}<\frac{1}{2} \mathrm{f}_{s w}
$$


To check robustness to varying grid impedances, the following equation can be used to find the change in resonant frequency $\left(\Delta \mathrm{f}_{\text {res }}\right)$ for varying grid inductances [42]

$$
\begin{gathered}
\Delta \omega_{\text {res }}=\frac{1}{2 \omega_{\text {res }} \mathrm{C}_{f}}\left(\frac{1}{\mathrm{~L}_{f 2}+\mathrm{L}_{g 1}}+\frac{1}{\mathrm{~L}_{f 2}+\mathrm{L}_{g 2}}\right) \\
\Delta \mathrm{f}_{\text {res }}=\frac{\Delta \omega_{\text {res }}}{2 \pi}=\frac{1}{8 \pi^{2} f_{\text {res }} \mathrm{C}_{f}}\left(\frac{1}{\mathrm{~L}_{f 2}+\mathrm{L}_{g 1}}-\frac{1}{\mathrm{~L}_{f 2}+\mathrm{L}_{g 2}}\right)
\end{gathered}
$$

From the following equations, $\mathrm{L}_{\mathrm{g} 1}$ and $\mathrm{L}_{\mathrm{g} 2}$ are the minimum and maximum expected grid inductances respectively. From Table 4.2, minimum expected grid inductance is $0 \mathrm{mH}$ and maximum expected grid inductance is $1.2235 \mathrm{mH}$. By substituting appropriate values into ( 4-24 ), $\Delta \mathrm{f}_{\text {res }}$ is $546 \mathrm{~Hz}$. Even with the shift, $\mathrm{f}_{\text {res }}$ obeys ( 4-22 ). Designed LCL filter is considered robust.

Since hysteresis control is used, switching frequency may overlap resonant frequency causing the current to oscillate. A damping resistor $\left(\mathrm{R}_{\mathrm{fd}}\right)$ may be added in series with $C_{f}$ to lower the resonant peak and minimize resonant oscillation effects [57, $60]$.

$$
\begin{gathered}
R_{f d}=\frac{1}{3 \omega_{r e s} \mathrm{C}_{f}} \\
R_{f d}=\frac{1}{3\left(2 \pi \mathrm{f}_{r e s}\right) \mathrm{C}_{f}}
\end{gathered}
$$

From ( 4-26), $\mathrm{R}_{\mathrm{fd}}$ is chosen to be $4 \Omega$. A summary of LCL component values are available in Table 4.3. 
Table 4.3 - LCL component values.

\begin{tabular}{|c|c|c|c|}
\hline $\mathrm{L}_{\mathrm{f} 1}[\mathrm{mH}]$ & $\mathrm{L}_{\mathrm{f} 2}[\mathrm{mH}]$ & $\mathrm{C}_{\mathrm{f}}[\mu \mathrm{F}]$ & $\mathrm{R}_{\mathrm{fd}}[\Omega]$ \\
\hline 3.5 & 1 & 5 & 4 \\
\hline
\end{tabular}

\subsubsection{Link Capacitor}

The $\mathrm{DC}$ link capacitor $\left(\mathrm{C}_{\mathrm{DC} \_ \text {link }}\right)$ can be designed as a single phase rectifier. The capacitor it as an "energy buffer" between the AC input and output DC power. Assuming a unity power factor, from [61]:

$$
\begin{gathered}
C_{D C_{-} \text {Link }}=\frac{\sqrt{\frac{\left(V_{g, p k}\right)^{2} *\left(I_{g, p k}\right)^{2}}{4}+\frac{\left(\omega_{g}\right)^{2} * L_{f 1}{ }^{2} *\left(I_{g, p k}\right)^{4}}{4}}}{2 V_{D C_{-} L i n k} \Delta V_{D C_{-} L i n k} \omega_{g}} \\
C_{D C_{-} \text {Link }}=\frac{\sqrt{\frac{\left(V_{g, p k}\right)^{2} *\left(I_{g, p k}\right)^{2}+\left(\omega_{g}\right)^{2} * L_{f 1}{ }^{2} *\left(I_{g, p k}\right)^{4}}{4}}}{2\left(V_{D C_{-} \text {Link }}\right)^{2} *\left(\%_{V, D C_{-} \text {Link }}^{\text {ripple }}\right) \omega_{g}}
\end{gathered}
$$

Grid peak voltage $\left(\mathrm{V}_{\mathrm{g}, \mathrm{pk}}\right)$ is $240 \sqrt{2}$. For an output power of $3.3 \mathrm{~kW}$, grid peak current is $13.75 \sqrt{2}$. Grid radian frequency $\left(\omega_{g}\right)$ is $2 \pi \mathrm{f}_{\mathrm{g}}$ and voltage ripple at DC link $\left(\%_{V, D C_{-} \text {Link }}^{\text {ripple }}\right)$ is chosen to be $5 \%$. From ( $4-28$ ), $\mathrm{C}_{\mathrm{DC} \_ \text {LINK }}$ is designed to be $565 \mu \mathrm{F}$.

\subsubsection{DC-DC Four Switch Bidirectional Buck-Boost Converter}

The critical inductance required for a four switch bidirectional buck-boost can be found with a few equations and manipulations. First minimum inductor current must be found $\left(\mathrm{I}_{\mathrm{L}, \mathrm{min}}\right)$. Assuming no power loss... 


$$
\begin{gathered}
P_{o}^{D C}=P_{i n}^{D C} \\
\left(V_{o, \text { avg }}\right) *\left(I_{o, \text { avg }}\right)=V_{\text {in }} I_{L, \text { avg }} D \\
I_{L, \text { avg }}=\frac{\left(V_{o, \text { avg }}\right) *\left(I_{o, \text { avg }}\right)}{V_{I N} D} \\
I_{L, \min }=I_{L, \text { avg }}-\frac{\left|\Delta i_{L_{1}, \text { charging }}\right|}{2}
\end{gathered}
$$

The critical inductance $\left(\mathrm{L}_{\mathrm{c}}\right)$ is found by setting $\mathrm{I}_{\mathrm{L} \text {, min }}=0$. Next, combining ( 3-6 ) and ( 4-32) $\ldots$

$$
L_{c}=\frac{\left(1-\frac{V_{o}}{V_{o}+V_{i n}}\right)^{2} * V_{o}^{2}}{2 f_{s w}^{D C} P_{o}^{D C}}
$$

A padding factor of $120 \%$ is chosen for the actual four switch buck-boost inductor $\left(\mathrm{L}_{1}\right)$.

$$
\begin{gathered}
L_{1}=120 \% * L_{c} \\
L_{1}=\frac{1.2\left(1-\frac{V_{o}}{V_{o}+V_{i n}}\right)^{2} * V_{o}{ }^{2}}{2 f_{S w}^{D C} P_{o}^{D C}}
\end{gathered}
$$

From ( 4-35 ), $\mathrm{L}_{1}$ largest when output voltage $\left(\mathrm{Vo}_{\mathrm{o}}\right)$ is largest and input voltage $\left(\mathrm{V}_{\text {in }}\right)$ is largest. For nominal operation, maximum $\mathrm{V}_{\mathrm{o}}$ and $\mathrm{V}_{\text {in }}$ is each $400 \mathrm{~V}$. Switching frequency of DC-DC converter is chosen to be $50 \mathrm{kHz}$ to lower inductance. ( 4-35 ) leads to a chosen $\mathrm{L}_{1}$ of $145 \mu \mathrm{H}$. 
Battery capacitor $\left(C_{B}\right)$ for four switch buck-boost converter can be found from first calculating capacitor charge (q).

$$
\begin{gathered}
C_{B} \Delta V_{B}=q \\
q=I_{B, \operatorname{avg}} T_{o n}
\end{gathered}
$$

Combining ( 4-36 ) \& ( 4-37) and some work...

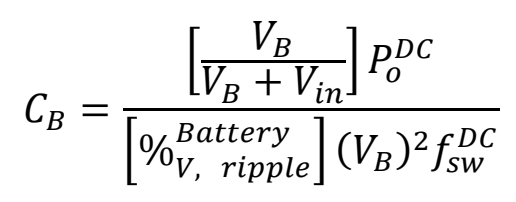

$C_{B}$ is maximized in (4-38) when battery voltage $\left(V_{B}\right)$ and input/DC link voltage $\left(V_{\text {in }}\right)$ are both minimized. The worst case condition for such an event is AC level 2 charging when the battery SOC is at its minimum. In that case, assume $V_{B}$ is $330 \mathrm{~V}$ and $V_{I N}$ is $340 \mathrm{~V}$. Battery ripple voltage is chosen to be 5\%. Equation ( 4-38) leads to a chosen $\mathrm{C}_{\mathrm{B}}$ of $5 \mu \mathrm{F}$. 


\section{Simulations \& Analysis}

\subsection{Overview}

Matlab Simulink simulations of V2G operations are shown and discussed in this chapter. First simulation is for stiff grid impedance in V2G mode with the generator off. It is simulated with a fully charged battery of $100 \%$ SOC. Although the battery should not be allowed above $85 \%$ SOC, this shows DC-DC converter flexibility of battery voltage. Using the same conditions, V2G mode is simulated during low SOC of $35 \%$. This ensures battery fed V2G is capable for highest to lowest battery voltage. Robustness of the LCL filter and controller is explored next. V2G is simulated for a weak grid impedance condition with a full battery. Finally, V2G operation fed via ICE and DC generator is simulated in a stiff grid condition. For each instance, harmonics are discussed in comparison to IEEE 1547 requirements as shown in Table 2.2.

\subsection{V2G - Stiff Grid, Generator Off, Battery Full SOC}

Before V2G operation can begin, DC link voltage must be at least 380V. Precharge is ensured via DC-DC converter. Simulink implementation of control for DC-DC converter is shown in Figure 5.1. DC-DC converter PI controllers run at converter switching frequency. Tuned DC-DC converter starting PI controller parameters are summarized on Table 5.1. Pre-charge is proven as it is shown in Figure 5.2. At that instant, the grid switch is closed with a high signal. Inverter unipolar modulation begins at that instant as well. 


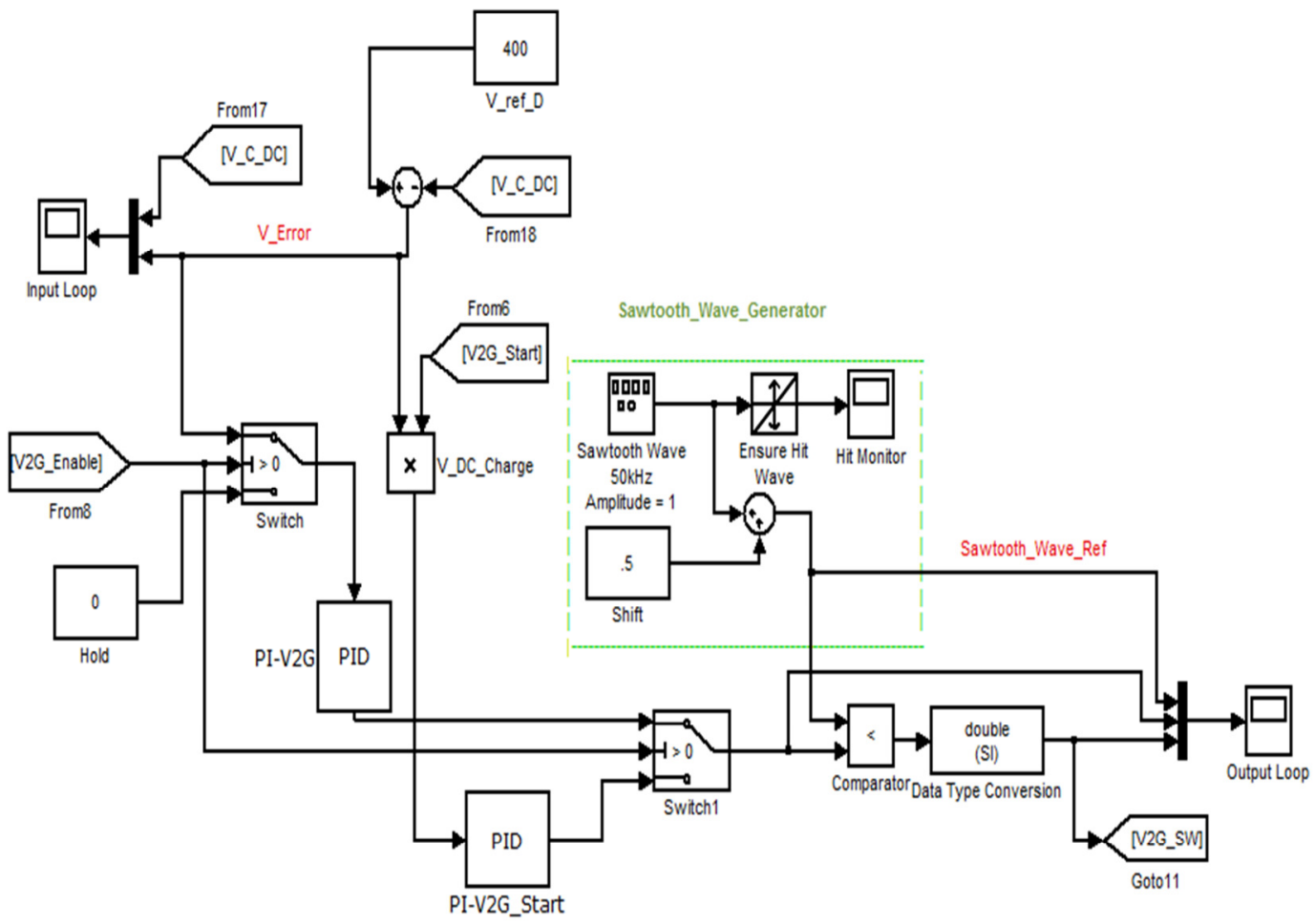

Figure 5.1 - Simulink implementation of DC-DC Controls for V2G with generator off.

Table 5.1 - Pre-Charge DC-DC converter PI parameters.

\begin{tabular}{|c|c|c|}
\hline \multicolumn{3}{|c|}{$\mathrm{PI}_{\text {start }}$} \\
\hline $\mathrm{Kp}$ & $\mathrm{Ki}$ & $\mathrm{f}[\mathrm{kHz}]$ \\
\hline .001 & .7 & 50 \\
\hline
\end{tabular}


(a)

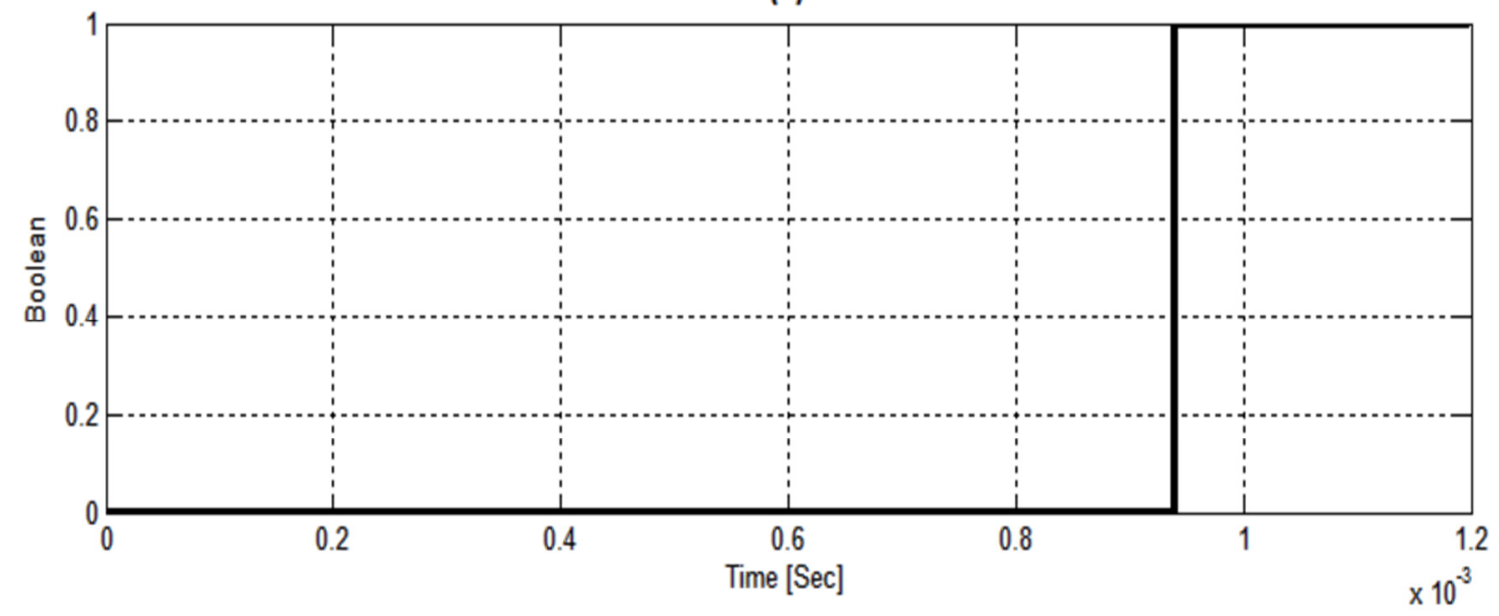

(b)

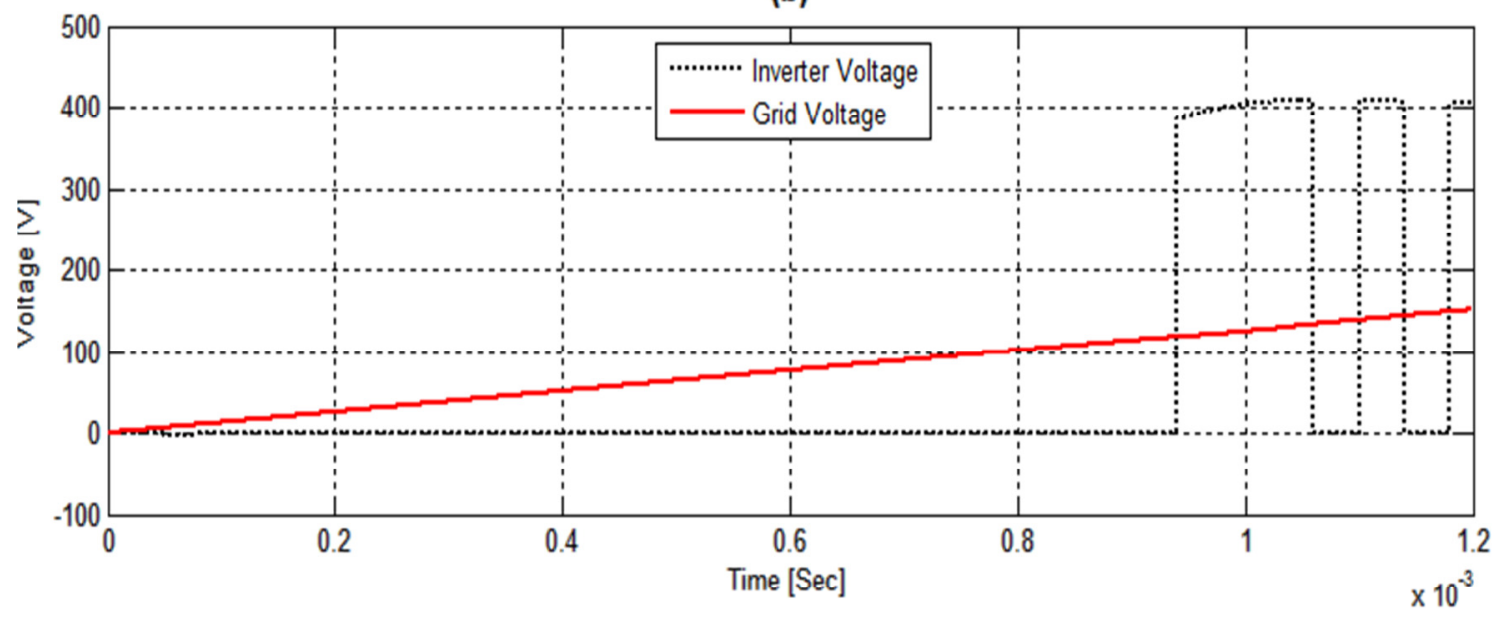

(c)

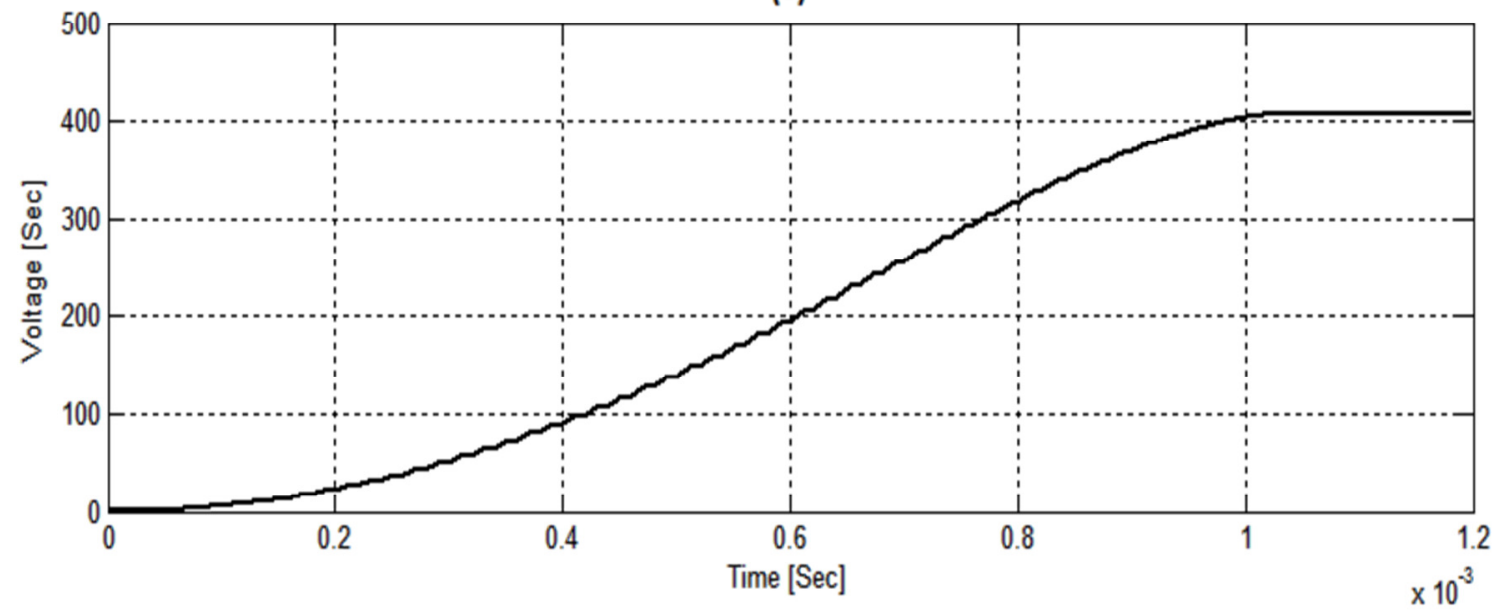

Figure 5.2 - Pre-charge of DC link capacitor via DC-DC converter: (a) grid switch (b) actual grid voltage and inverter unfiltered unipolar modulated voltage (c) DC link bus voltage. 
After pre-charge is finished, V2G operation begins. Tuned DC-DC converter nominal PI controller parameters are summarized on Table 5.2. Stiff grid impedance with full battery V2G simulation implementation in Simulink is shown in Figure 5.3. Inverter output unipolar modulated voltage and current is available Figure 5.4. The current displayed is unfiltered and has a strong sinusoidal shape. Figure 5.5 shows grid voltage and grid current; steady state filtered/grid current has a strong sinusoidal shape. This means THD is low and should be near IEEE 1547 requirements. Grid current and voltage are basically in unity power factor which is desired. Grid current is shown alone in Figure 5.6. At start of V2G, there are unwanted transient oscillations which quickly settle. Once steady state is reached, distortion of grid current is only found zero crossing, peaks, and troughs regions. DC link bus capacitor voltage and current is shown Figure 5.7. DC link voltage is maintained at within $5 \%$ of $400 \mathrm{~V}$ as designed. Capacitor discharge current follows an absolute value of grid voltage sinusoidal shape for inverter to output sinusoidal current. Finally, battery voltage and current is shown Figure 5.8. Battery voltage is full SOC at maximum $430 \mathrm{~V}$. A battery voltage drop is inherent as current is discharged to DC-DC converter to feed the DC link capacitor. The battery pack is definitely discharging power as current is negative.

Table 5.2 - DC-DC converter V2G PI parameters.

\begin{tabular}{|c|c|c|}
\hline \multicolumn{3}{|c|}{$\mathrm{PI}_{\text {nom }}$} \\
\hline $\mathrm{Kp}$ & $\mathrm{Ki}$ & $\mathrm{f}[\mathrm{kHz}]$ \\
\hline .007 & 3 & 50 \\
\hline
\end{tabular}




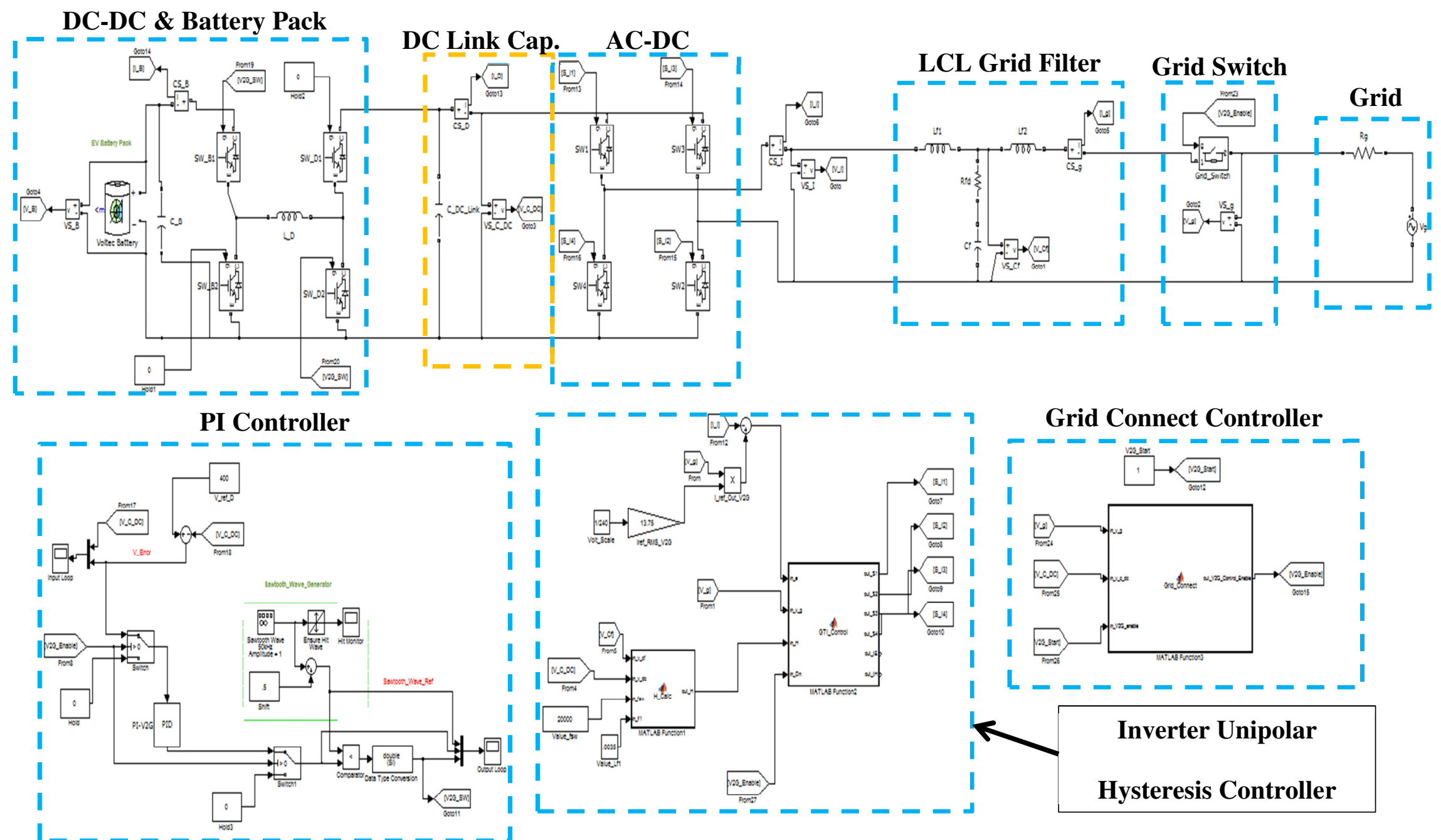

Figure 5.3 - Simulink implementation of V2G with a stiff grid connection. Battery is connected and generator disconnected. 
(a)

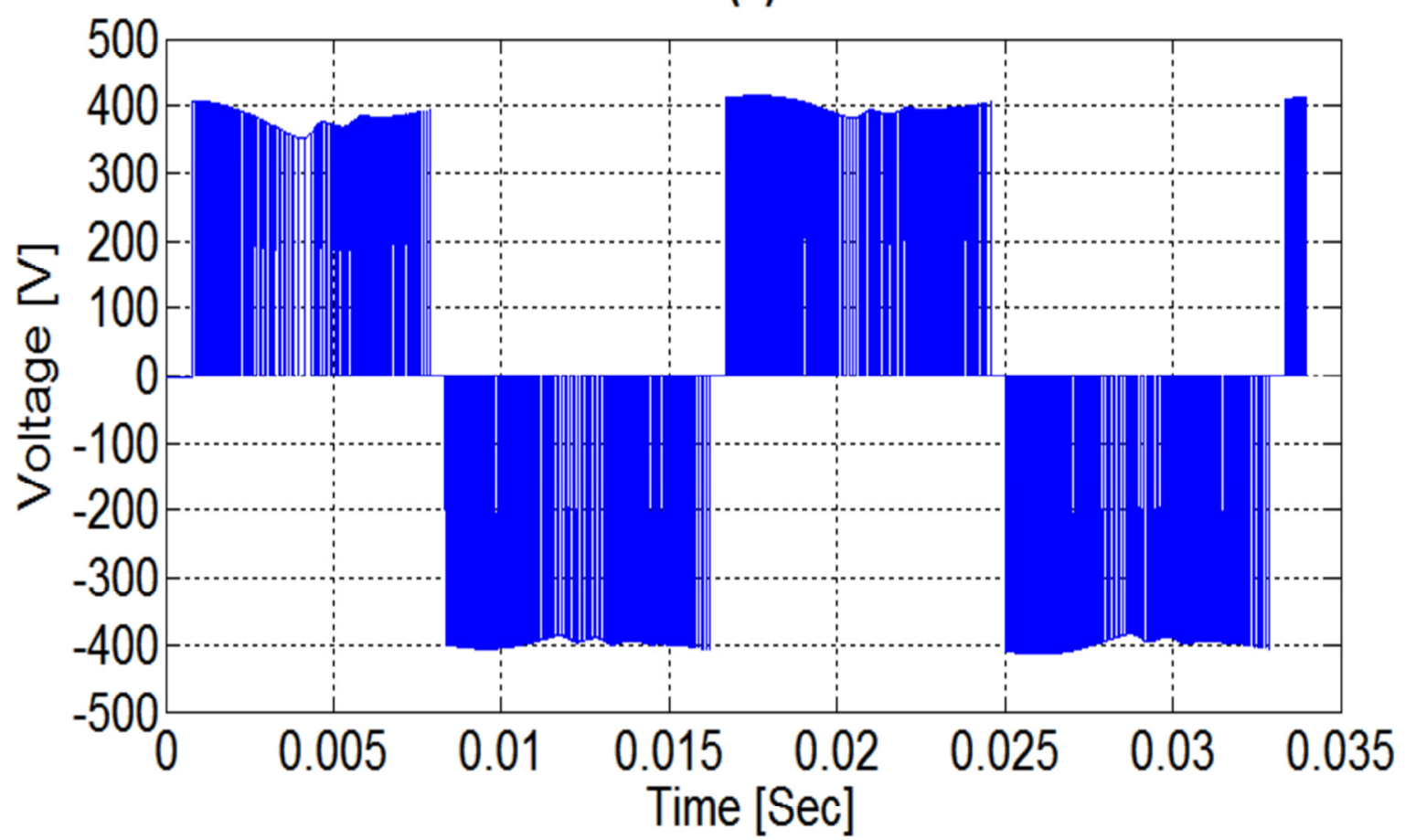

(b)

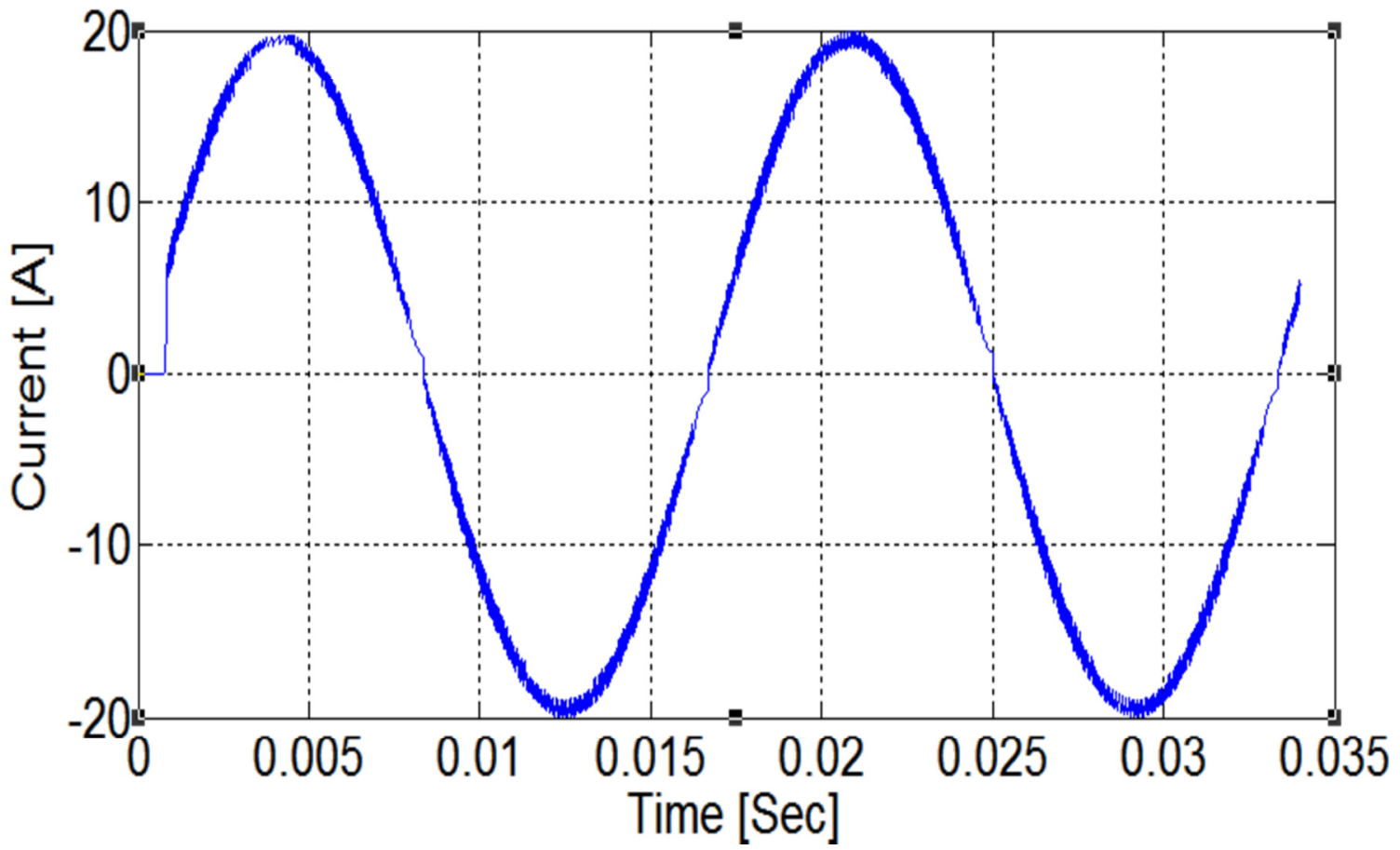

Figure 5.4 - V2G simulation results of inverter's unfiltered output with a stiff grid connection: (a) unipolar modulated voltage (b) current. Battery is at full SOC and connected. Generator is disconnected. 


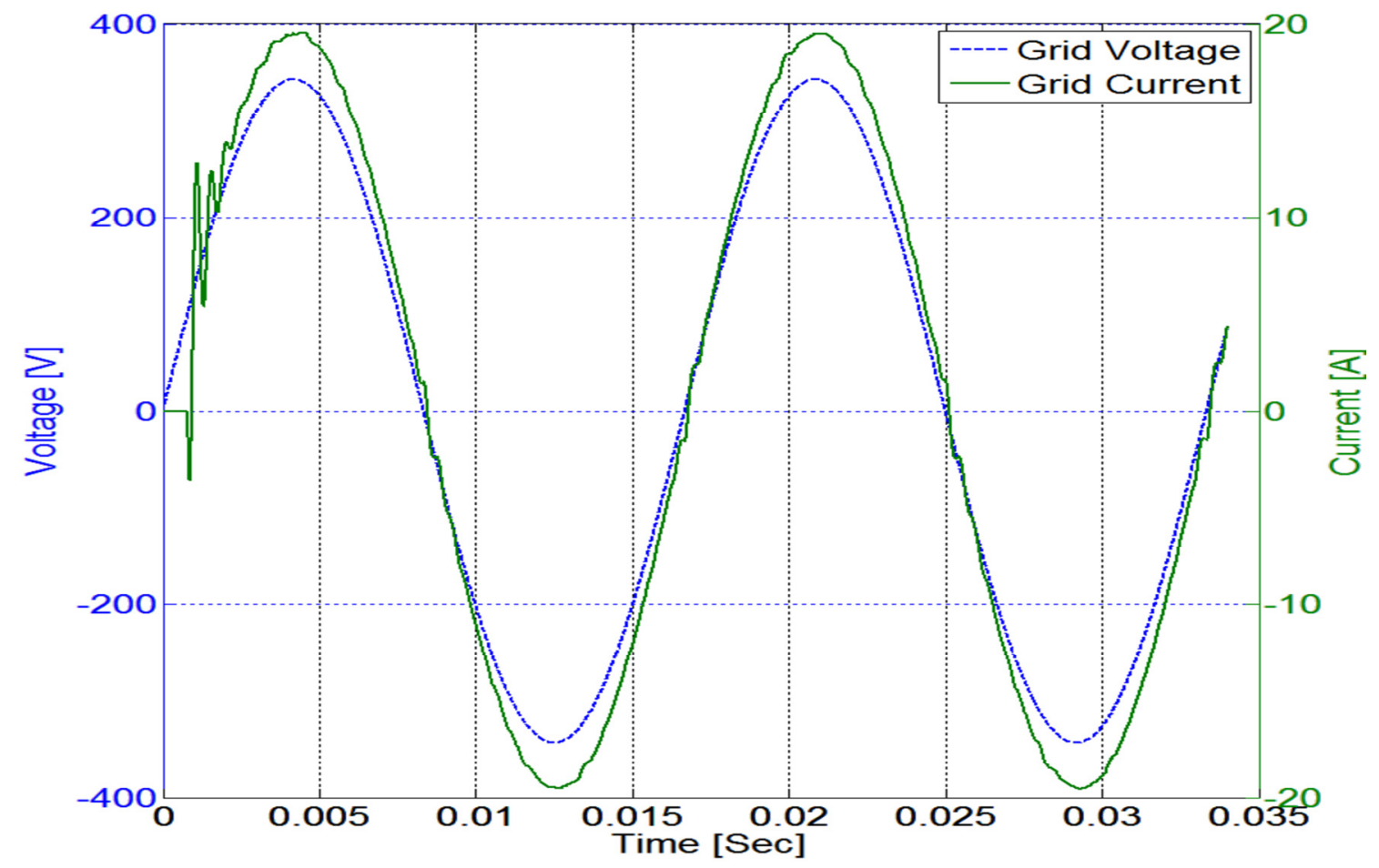

Figure 5.5 - V2G simulation results of grid voltage and filtered output current with a stiff grid connection. Battery is at full SOC and connected. Generator is disconnected.

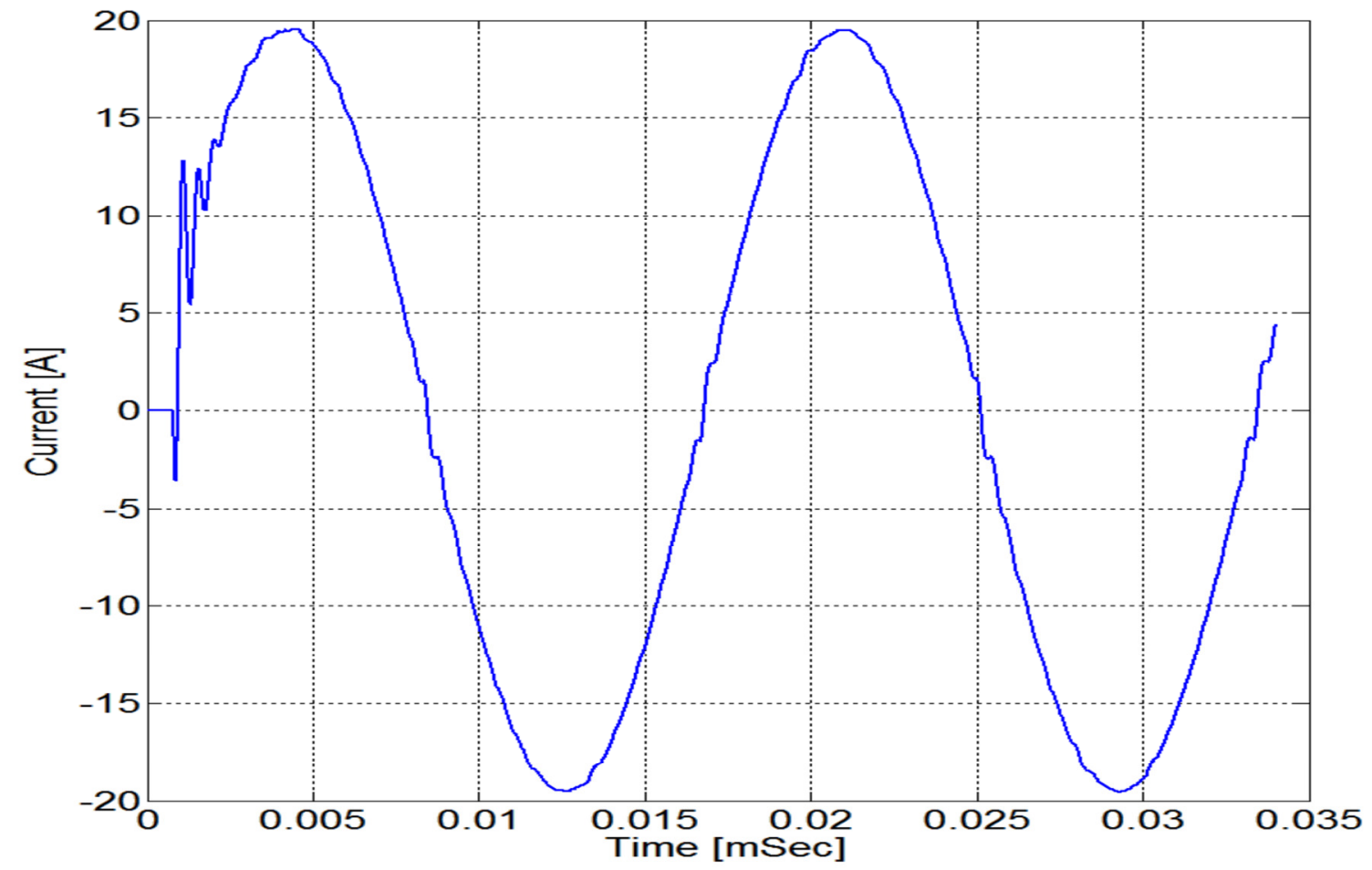

Figure 5.6 - V2G simulation results of filtered output current with a stiff grid connection. Battery is at full SOC and connected. Generator is disconnected. 
(a)

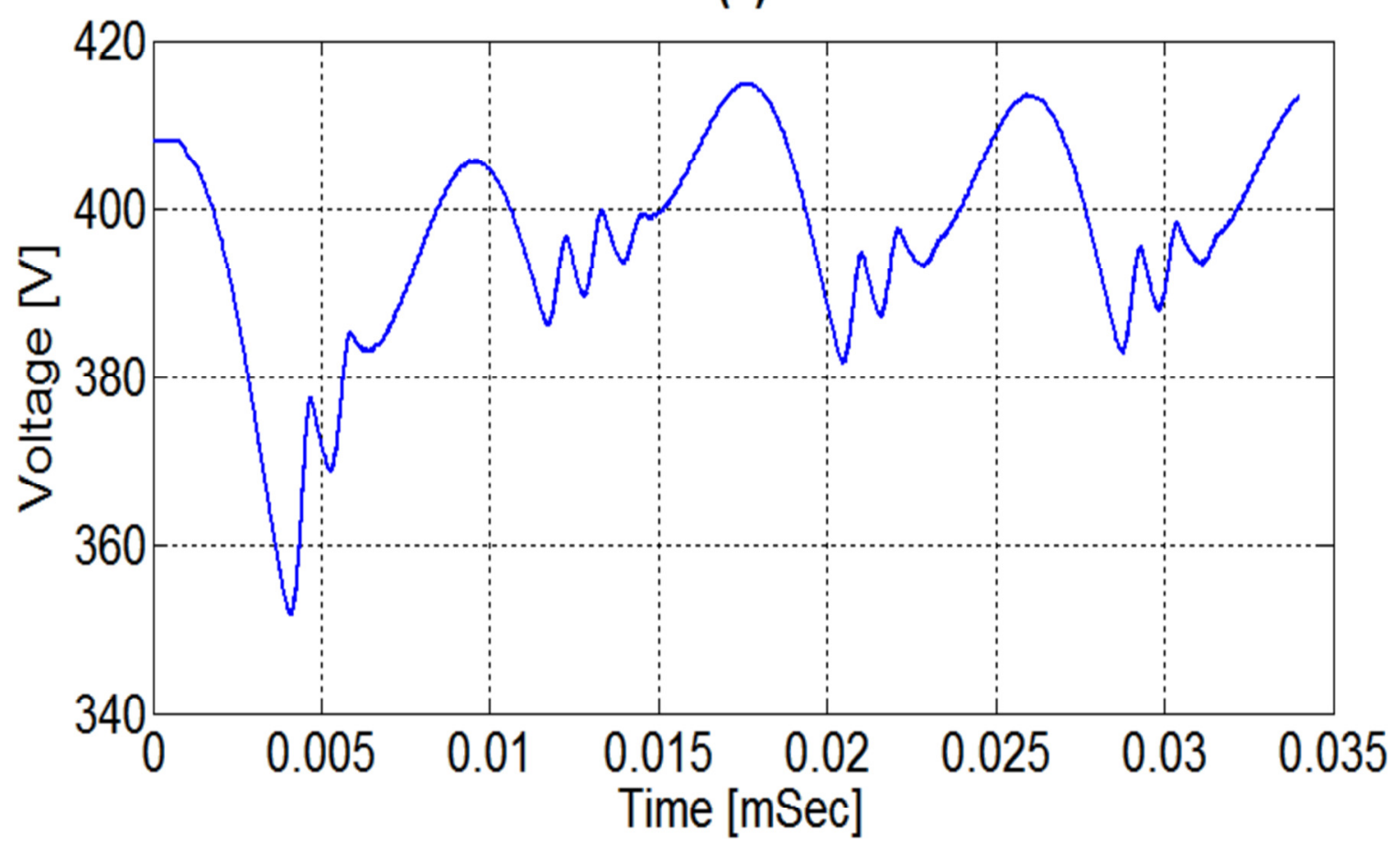

(b)

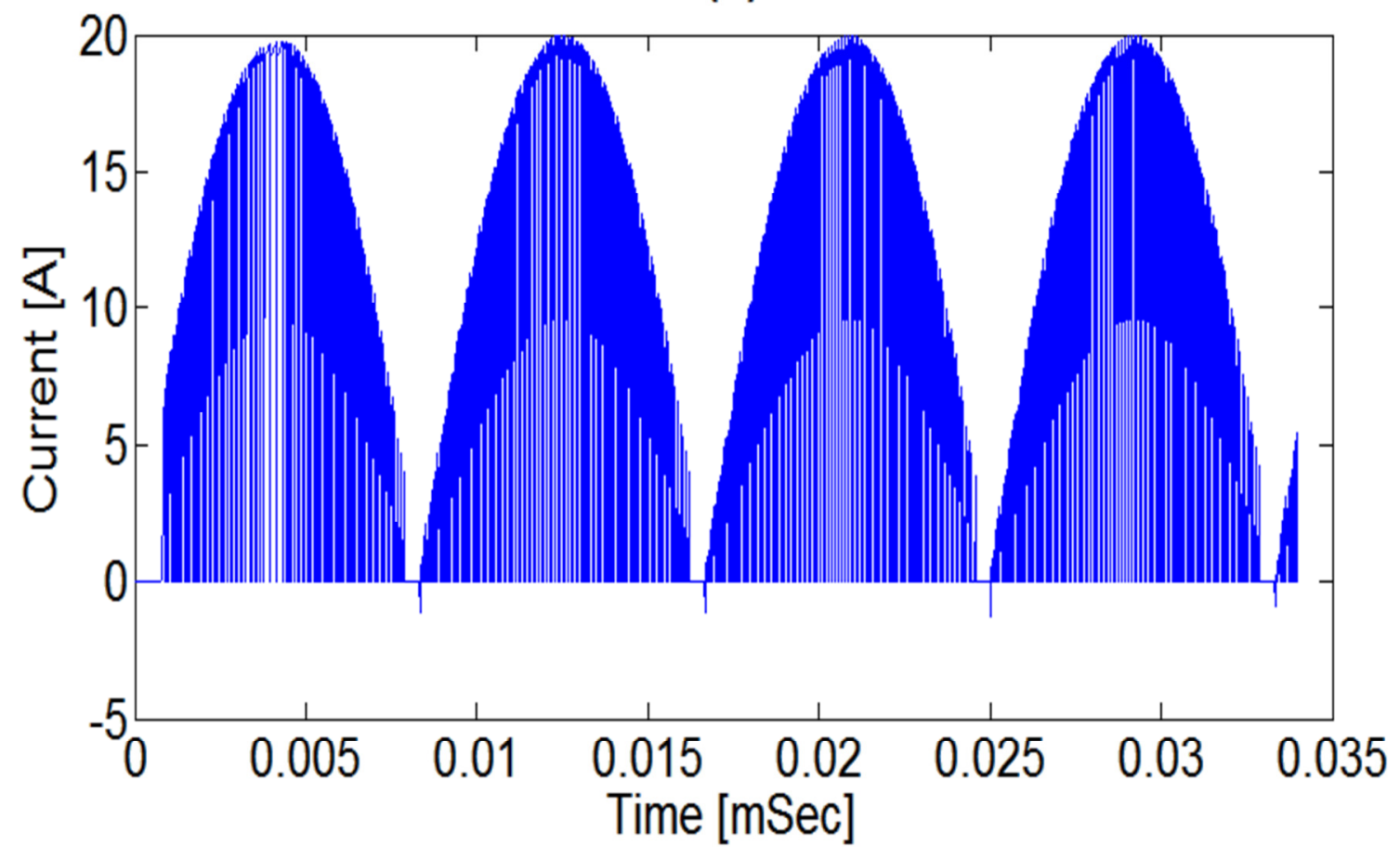

Figure 5.7 - V2G simulation results of DC link bus capacitor voltage (a) and current (b). Connection is to a stiff grid. Battery is at full SOC and connected. Generator is disconnected. 
(a)

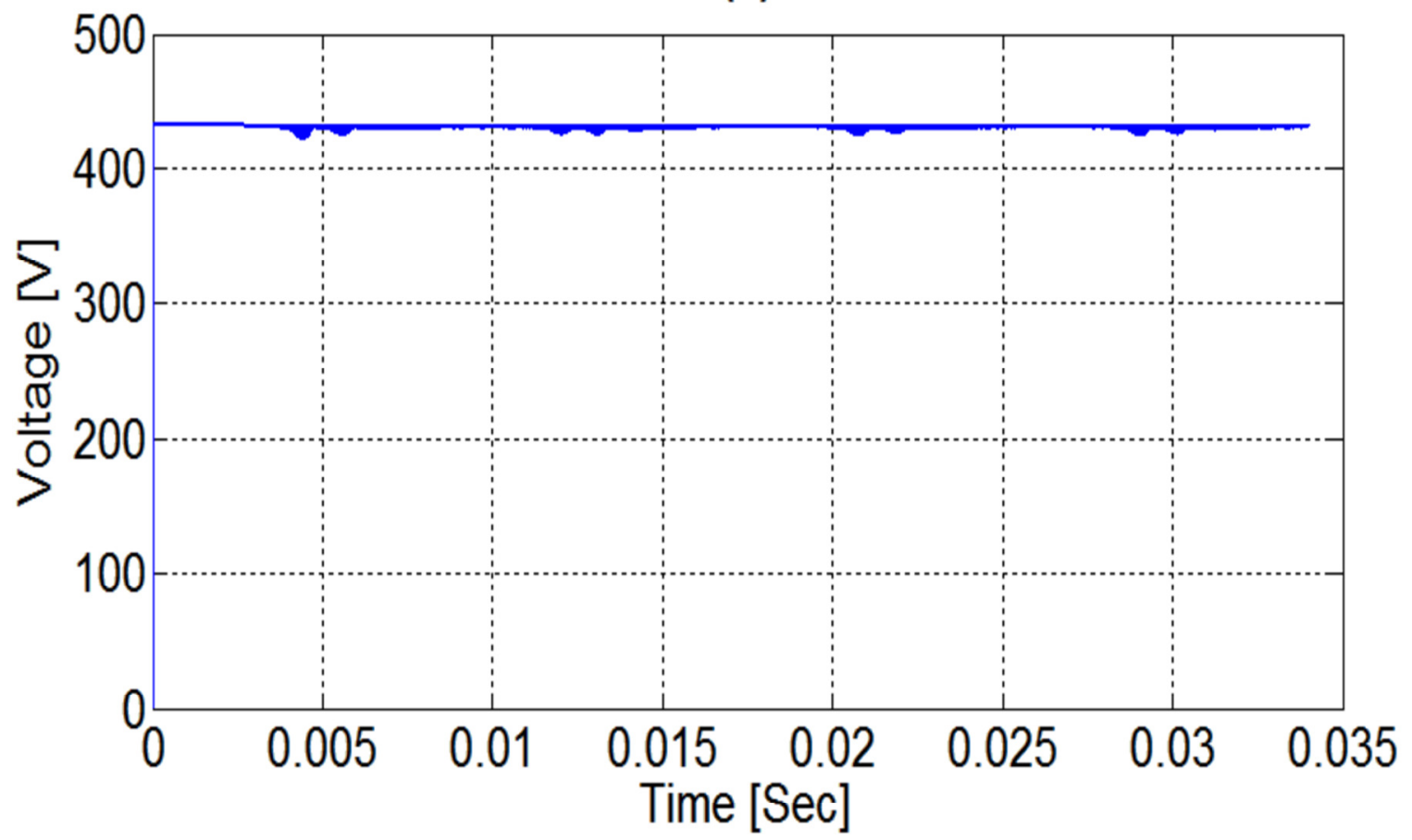

(b)

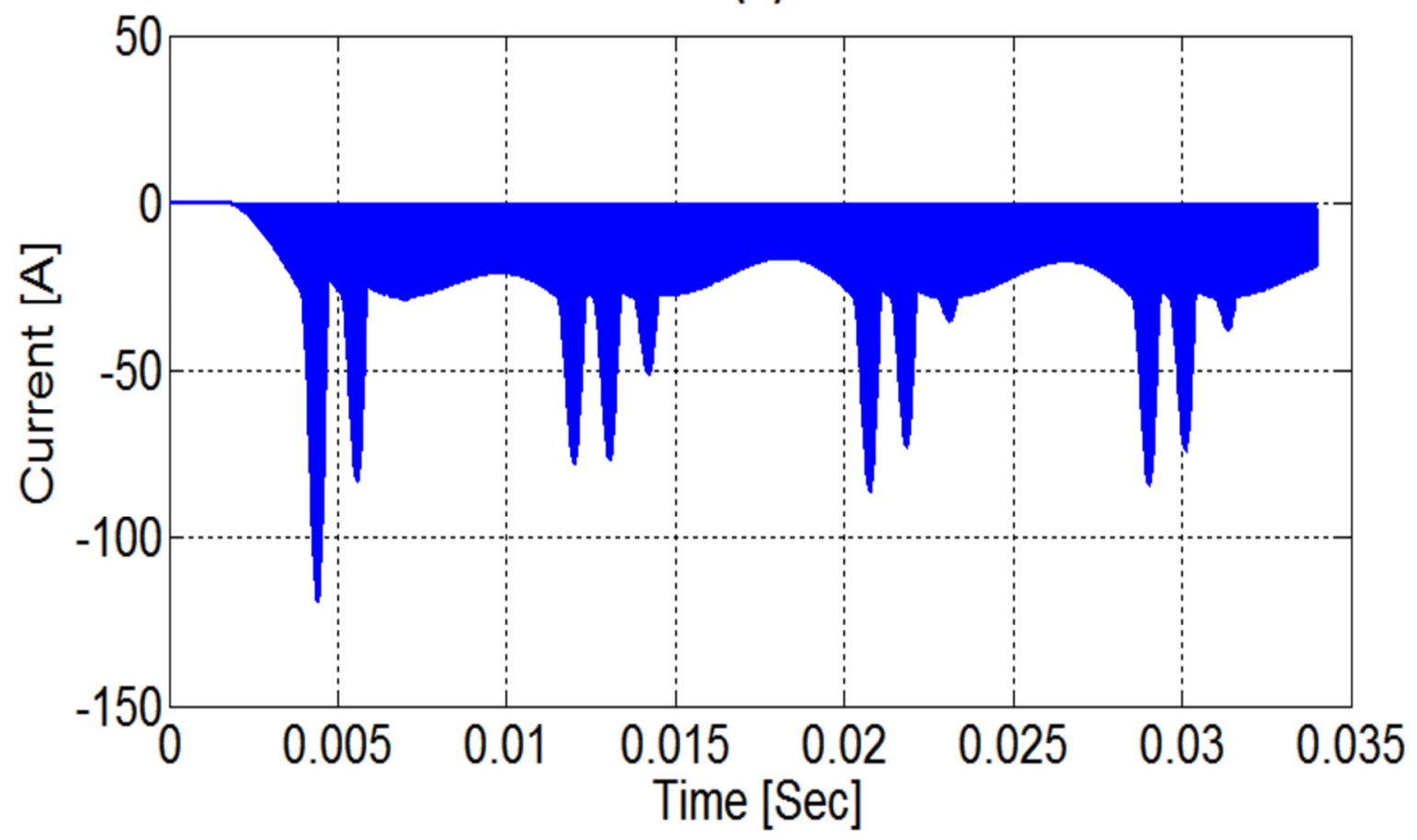

Figure 5.8 - Simulation results of full SOC battery pack powering V2G operation. Battery pack voltage (a) and current (b) are shown. Connection is to a stiff grid. Generator is disconnected. 
The simulation resulted in a THD of only $1.53 \%$ which is much lower than the 5\% requirement of IEEE 1547 (see Appendix D). Harmonic spectrum is shown up to the $60^{\text {th }}$ harmonic order in Figure 5.9 and up to $22 \mathrm{kHz}$ in Figure 5.10. Analyzing Figure 5.9 with IEEE 1547 requirements (see Table 2.2), harmonics start at a magnitude of $.42 \%$ and begin to decrease. Near the $35^{\text {th }}$ harmonic order $(2100 \mathrm{~Hz})$, the harmonic order region has a spike in magnitude before decreasing again. The spike is near LCL filter resonant frequency of $2552 \mathrm{~Hz}$ which explains the spiking. Unfortunately, the spiking causes harmonic distortion to not meet IEEE 1547 requirements. Analyzing Figure 5.10, the adaptive width hysteresis band does not do a good job at maintaining a constant frequency. Maximum inverter switching frequency seems to be $18 \mathrm{kHz}$. A list of current harmonics is available in Appendix D. From Appendix D, current DC component is only $.009 \mathrm{~A}$ or $\sim .045 \%$ (see Figure 5.9). That is well below IEEE 1547's .5\% requirement.

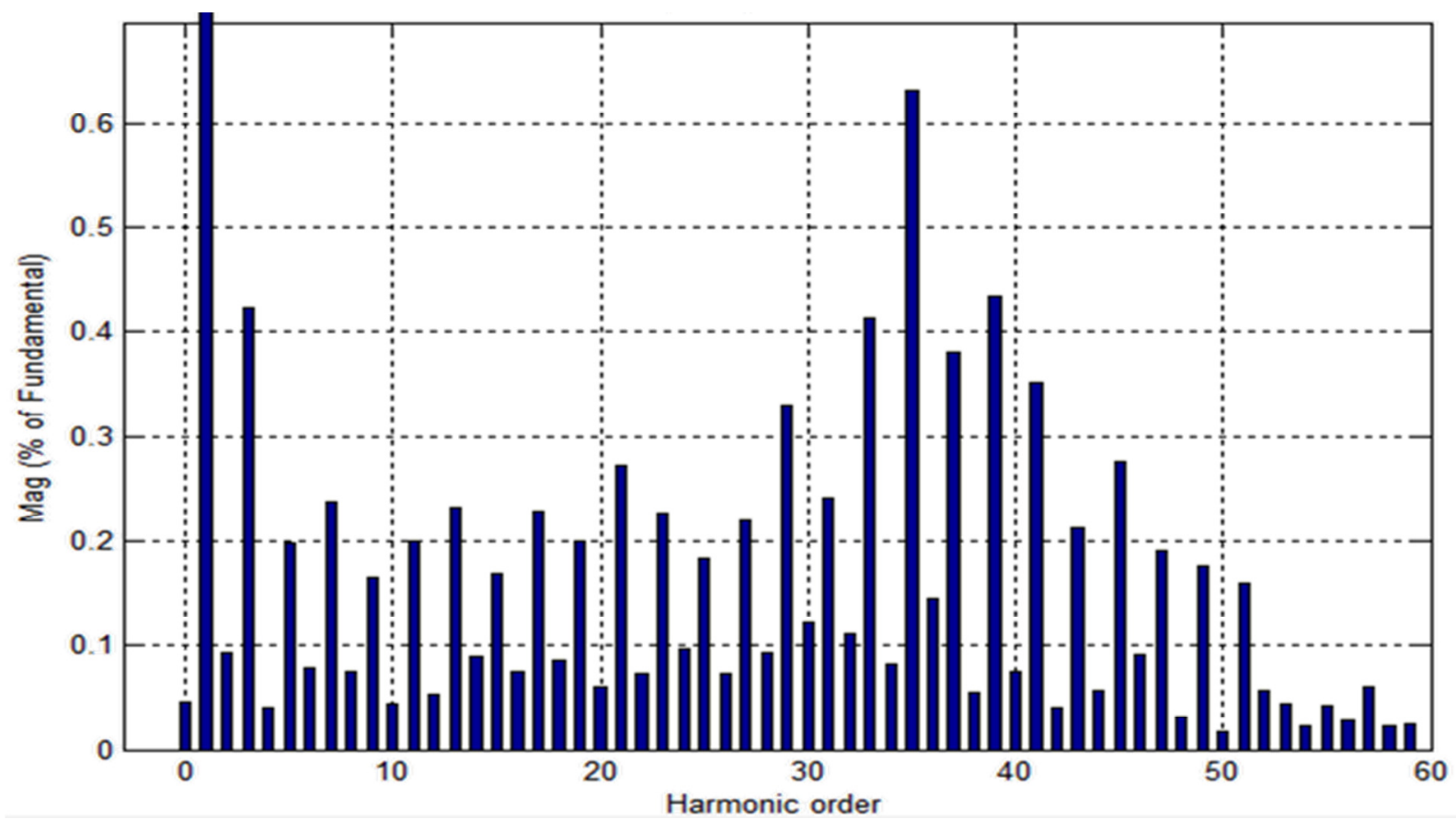

Figure 5.9 - V2G simulation results of grid current harmonics in respect to harmonic order. Connection is to a stiff grid. Battery is at full SOC and connected.

Generator is disconnected. 


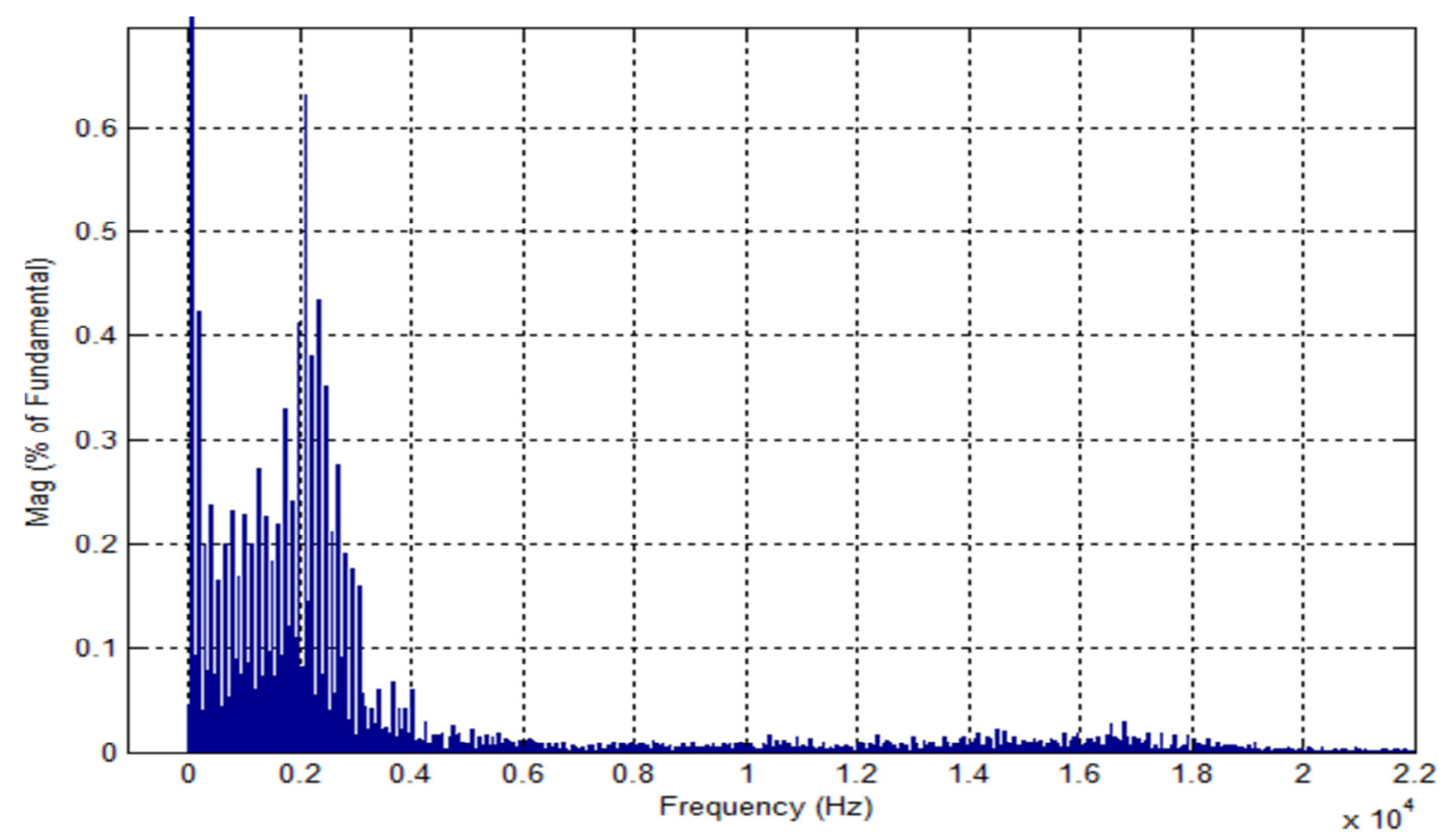

Figure 5.10 - V2G simulation results of grid current harmonics in respect to frequency. Connection is to a stiff grid. Battery is at full SOC and connected. Generator is disconnected.

The following sections in this chapter will each contain slight differences to this section. Simulation situation and results will have similarities. This section will be the main point of comparison to show differences from varying situations.

\subsection{V2G - Stiff Grid, Generator Off, Battery Low SOC}

This simulation and situation is almost the same as section 5.2. The only difference is the lower battery pack voltage due to low SOC shown in Figure 5.11. All waveforms are nearly identical; grid voltage and filtered current is available via Figure 5.12. Again, grid voltage and current has low distortion. The first sinusoidal peak has a larger transient ripple current (see Figure 5.13). This simulation case resulted in a THD of $\begin{array}{lllll}1.44 \% & \text { versus } & \text { section } & 5.2 \text { 's } & 1.50 \%\end{array}$ 
Figure 5.14, Figure 5.15, and Appendix E). As expected between the two cases, the difference is negligible and performance is similar.

(a)

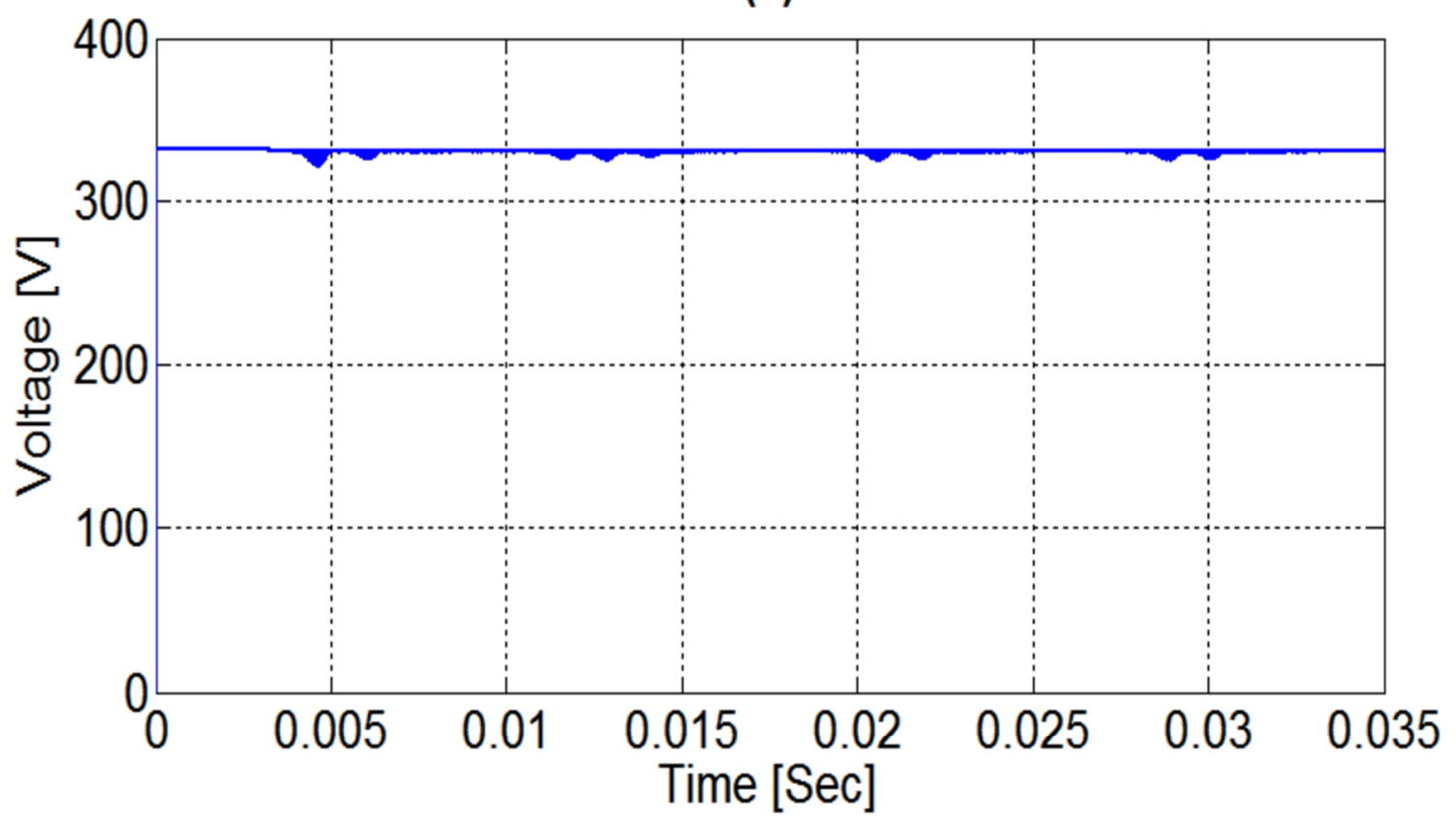

(b)

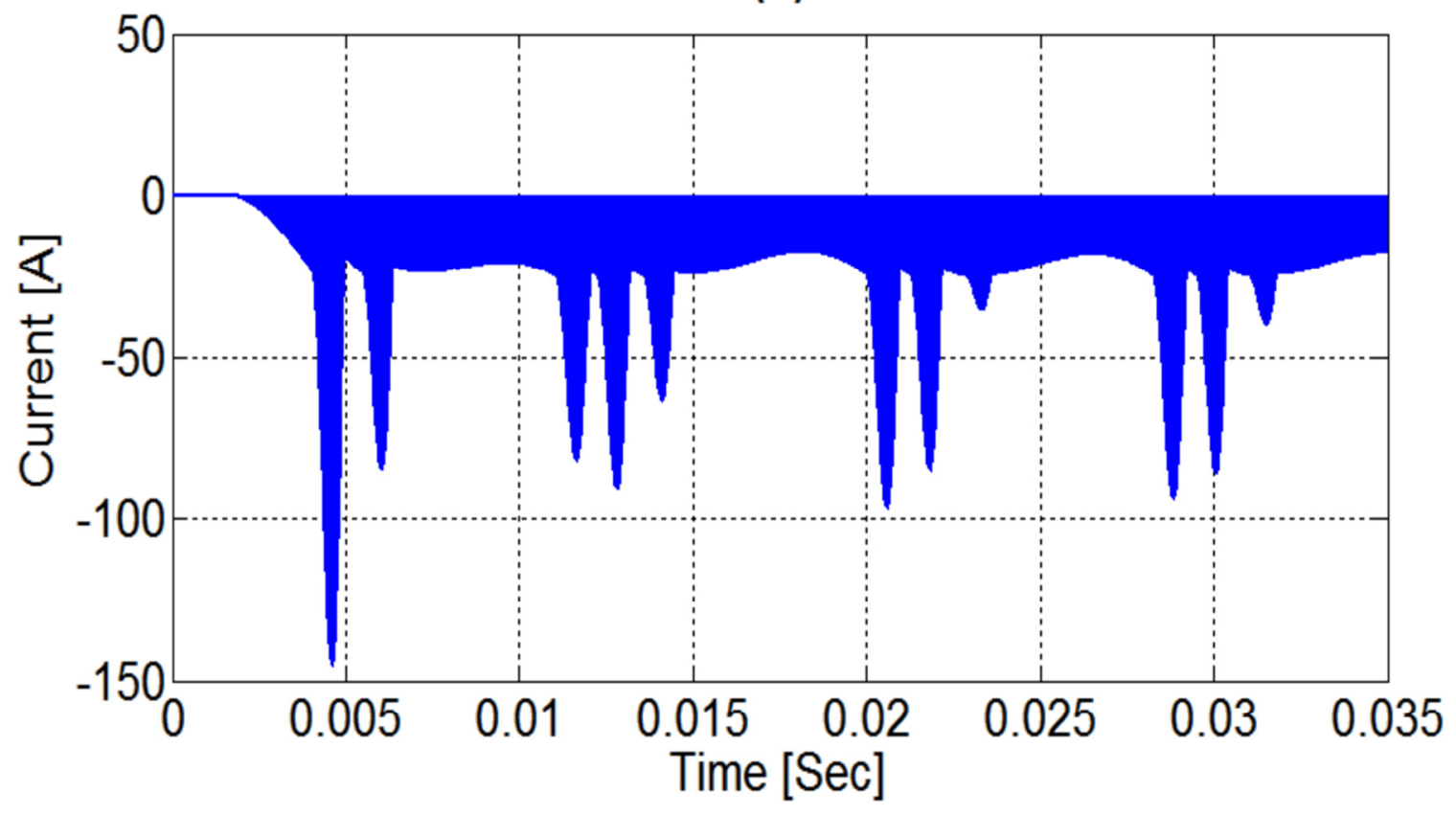

Figure 5.11 - Simulation results of low SOC battery pack powering V2G operation. Battery pack (a) voltage and (b) current are shown. Connection is to a stiff grid. Generator is disconnected. 


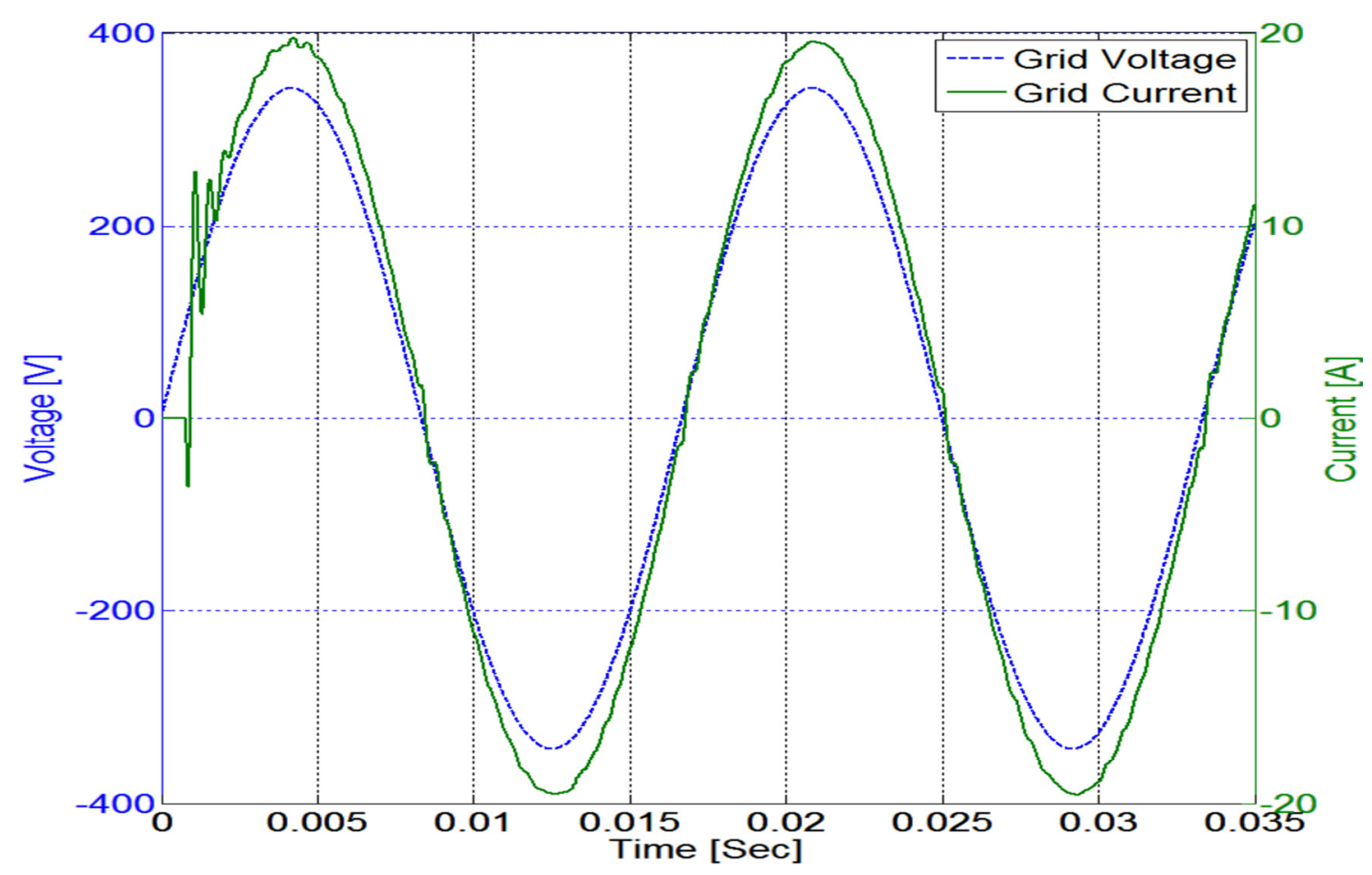

Figure 5.12 - V2G simulation results of grid voltage and filtered output current with a stiff grid connection. Battery is at low SOC and connected. Generator is disconnected.

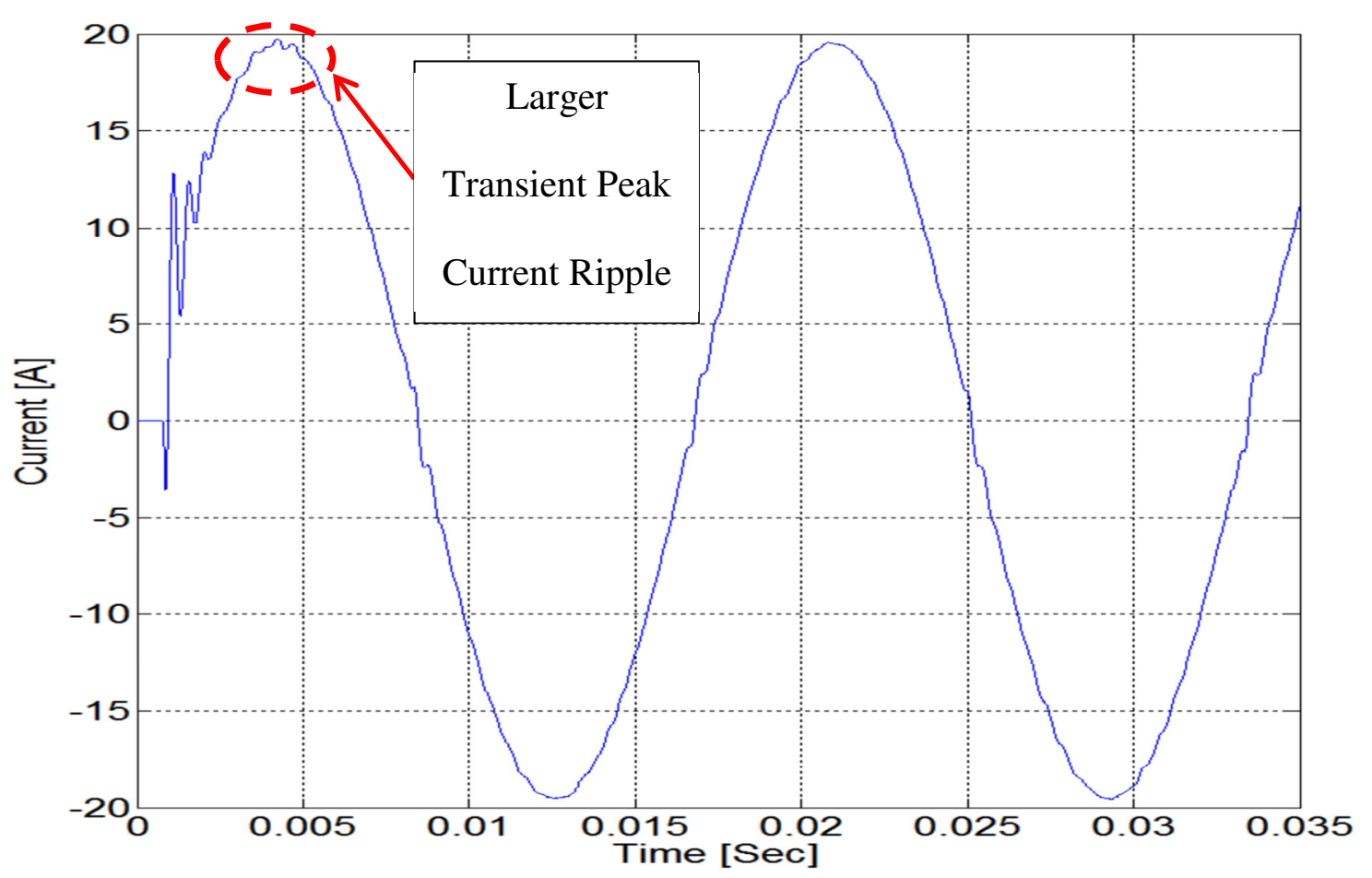

Figure 5.13 - V2G simulation results of filtered output current with a stiff grid connection. Battery is at low SOC and connected. Generator is disconnected. 


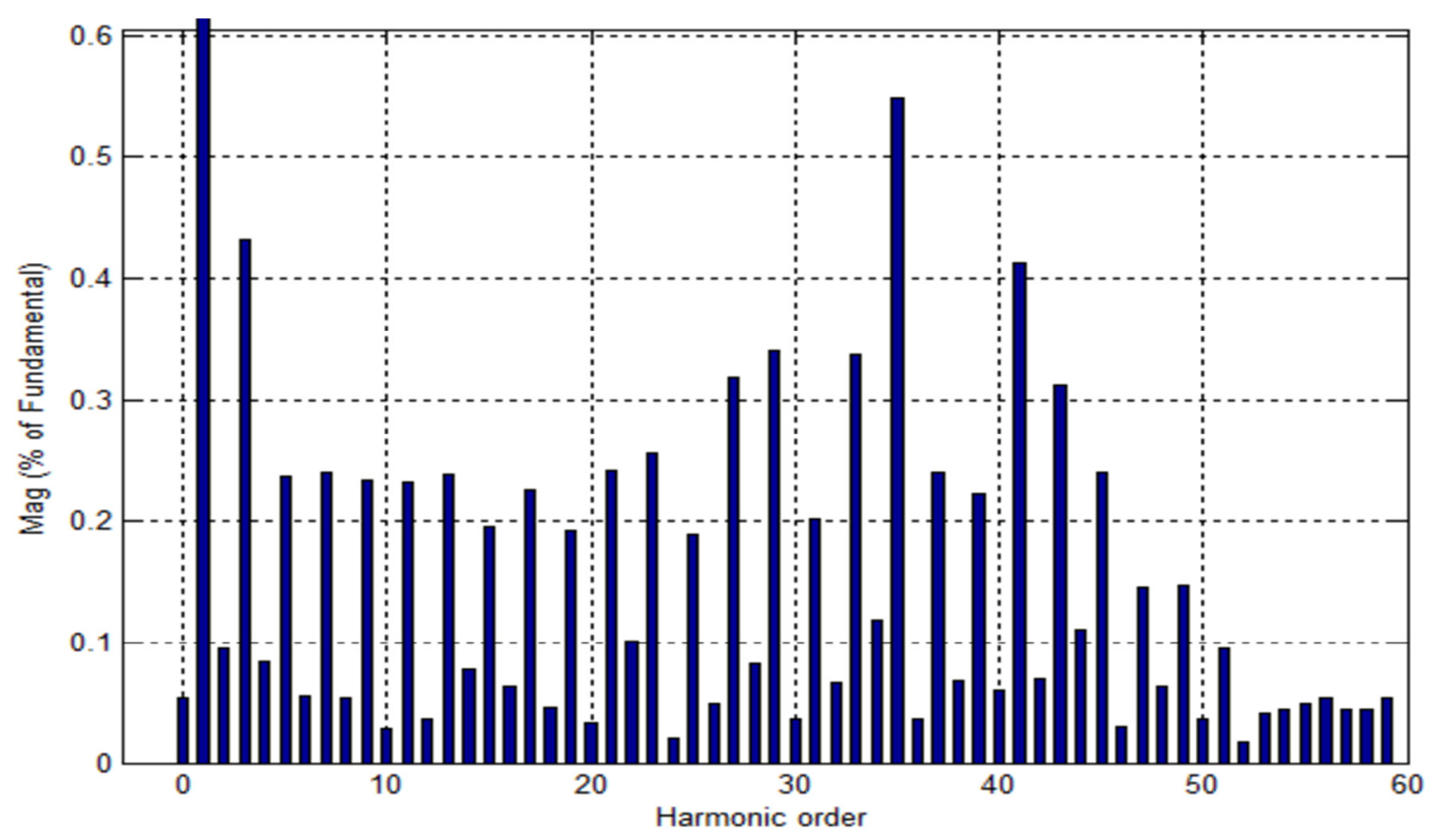

Figure 5.14 - V2G simulation results of grid current harmonics in respect to harmonic order. Connection is to a stiff grid. Battery is at low SOC and connected. Generator is disconnected.

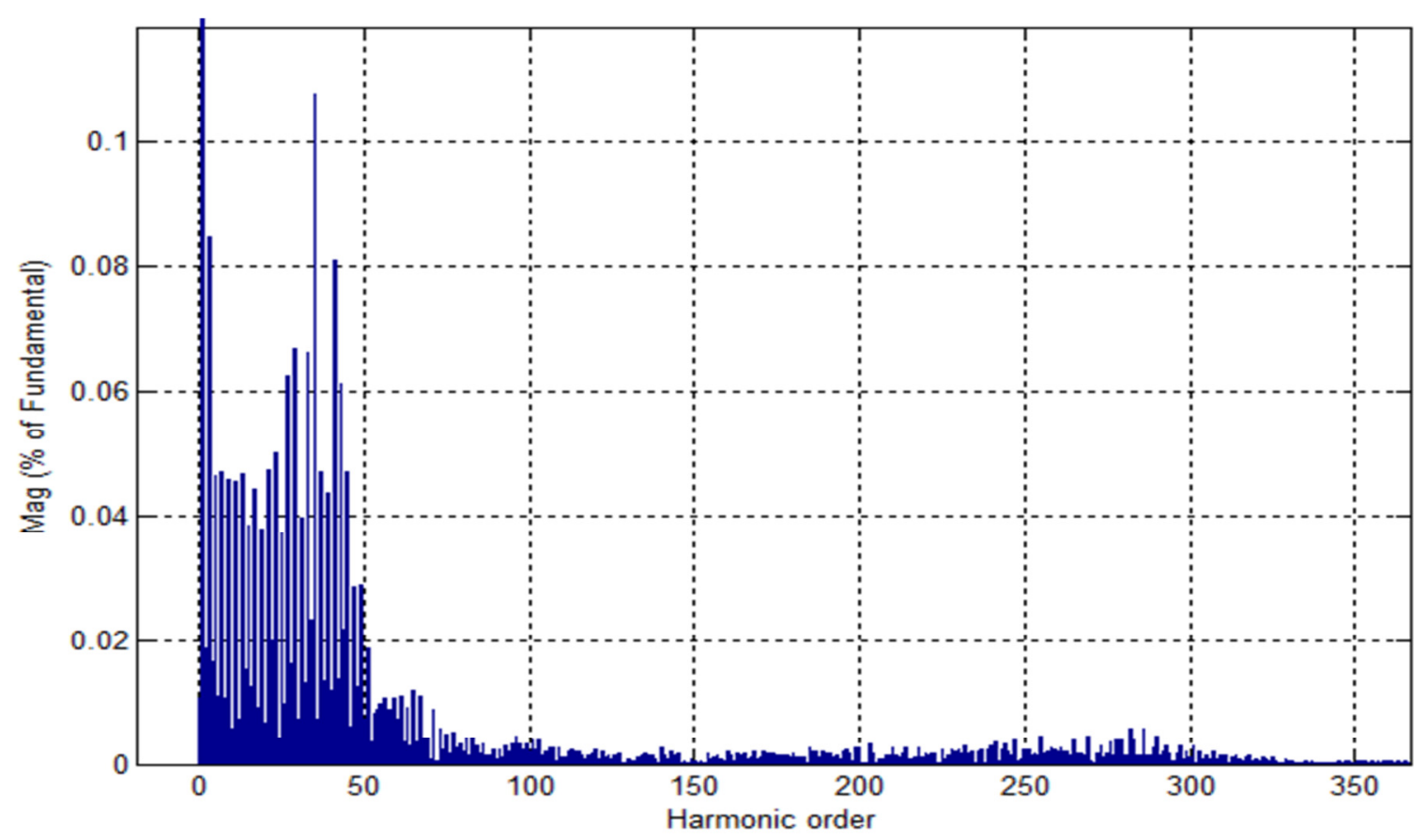

Figure 5.15 - V2G simulation results of grid current harmonics in respect to frequency. Connection is to a stiff grid. Battery is at low SOC and connected. Generator is disconnected. 


\subsection{V2G - Weak Grid, Generator Off, Battery Full SOC}

In comparison to section 5.2's simulation and situation, the results are similar. Simulation implementation is basically the same as from Figure 5.3, but grid impedance is changed. A grid inductor $L_{g}$ is added in series to $R_{g}$. Values for $L_{g}$ and $R_{g}$ are changed appropriately to weak impedance values (see section 4.3.1). Like before, V2G operation begins after pre-charge is finished. Results of these simulations determine if LCL filter was robustly designed for varying grid impedances. To determine grid filter robustness, both grid current and voltage must be assessed.

In contrast to stiff grid impedance (see section 5.2) simulations, there are noticeable differences. Filtered grid voltage and current are shown in Figure 5.16 with zoomed views available in Figure 5.17. In a weak grid condition, grid voltage now has transient oscillation behavior which was not present in a stiff grid condition. Differences between stiff grid versus weak grid for filtered/grid current can be seen (see Figure $5.6 \&$ Figure 5.18 respectively). Ripple current oscillations are more pronounced and transient current last longer durations. However, time duration of undesirable oscillations from transient behavior can be viewed as approximately equal. Oscillation peaks are not much greater and are within respectable levels.

Regardless of grid impedance, a similar level of distortion from grid steady state current and voltage are present. Filtering capabilities are expected to be hindered as a weaker grid impedance shifts grid LCL filter resonant frequency. Simulation proves this from voltage and current increased transient oscillation, transient duration, and current distortion. However, steady state grid current distortion is respectable with only a slight increase to 2.19\% THD (see Appendix F). Current harmonic magnitudes have a similar 
shape as well (see Figures 5.19 and 5.20). The simulated results have shown the robustness of designed LCL grid filter.

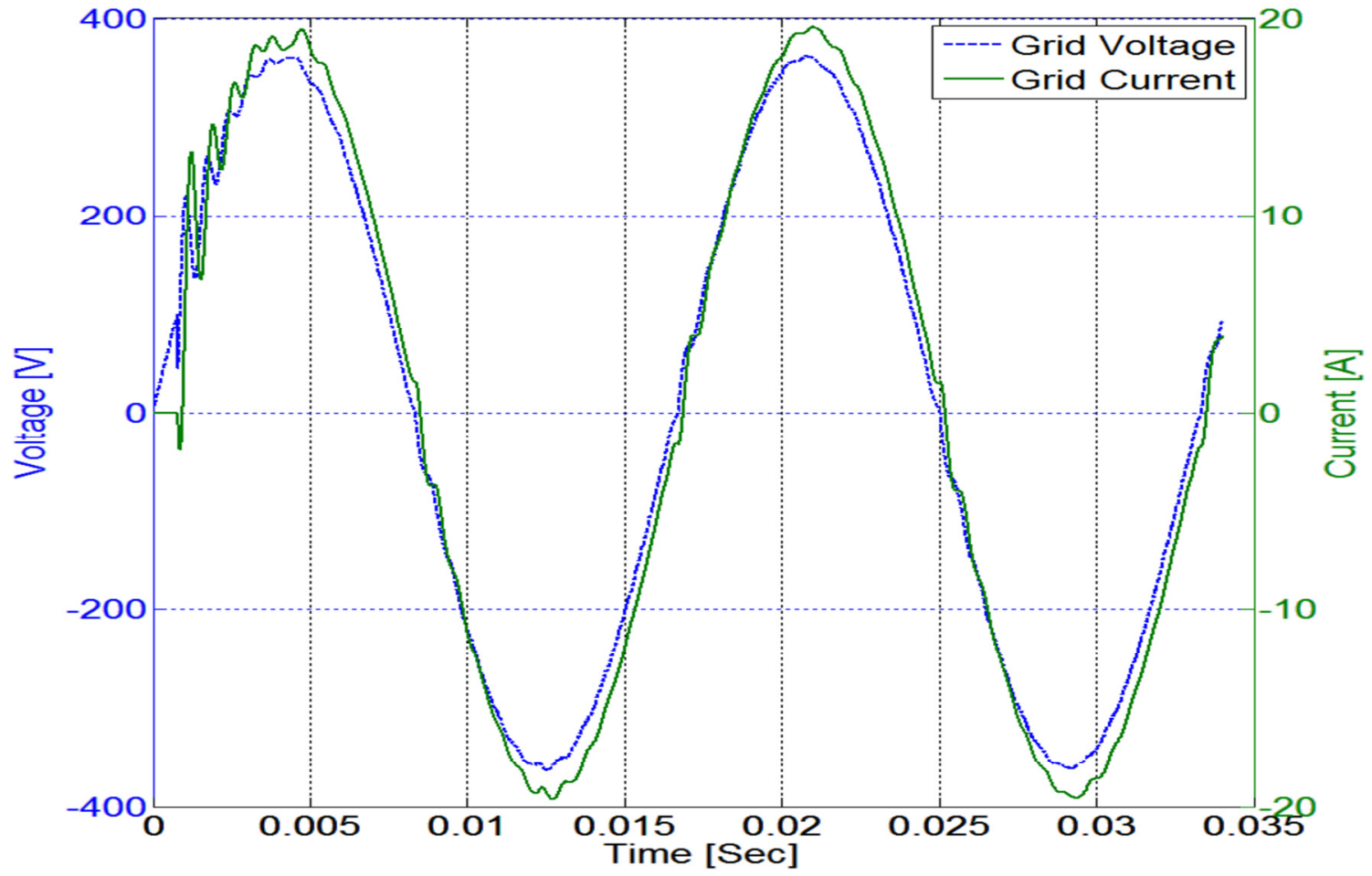

Figure 5.16 - V2G simulation results of grid voltage and filtered output current with a weak grid connection. Battery is at full SOC and connected. Generator is disconnected. 
(a)

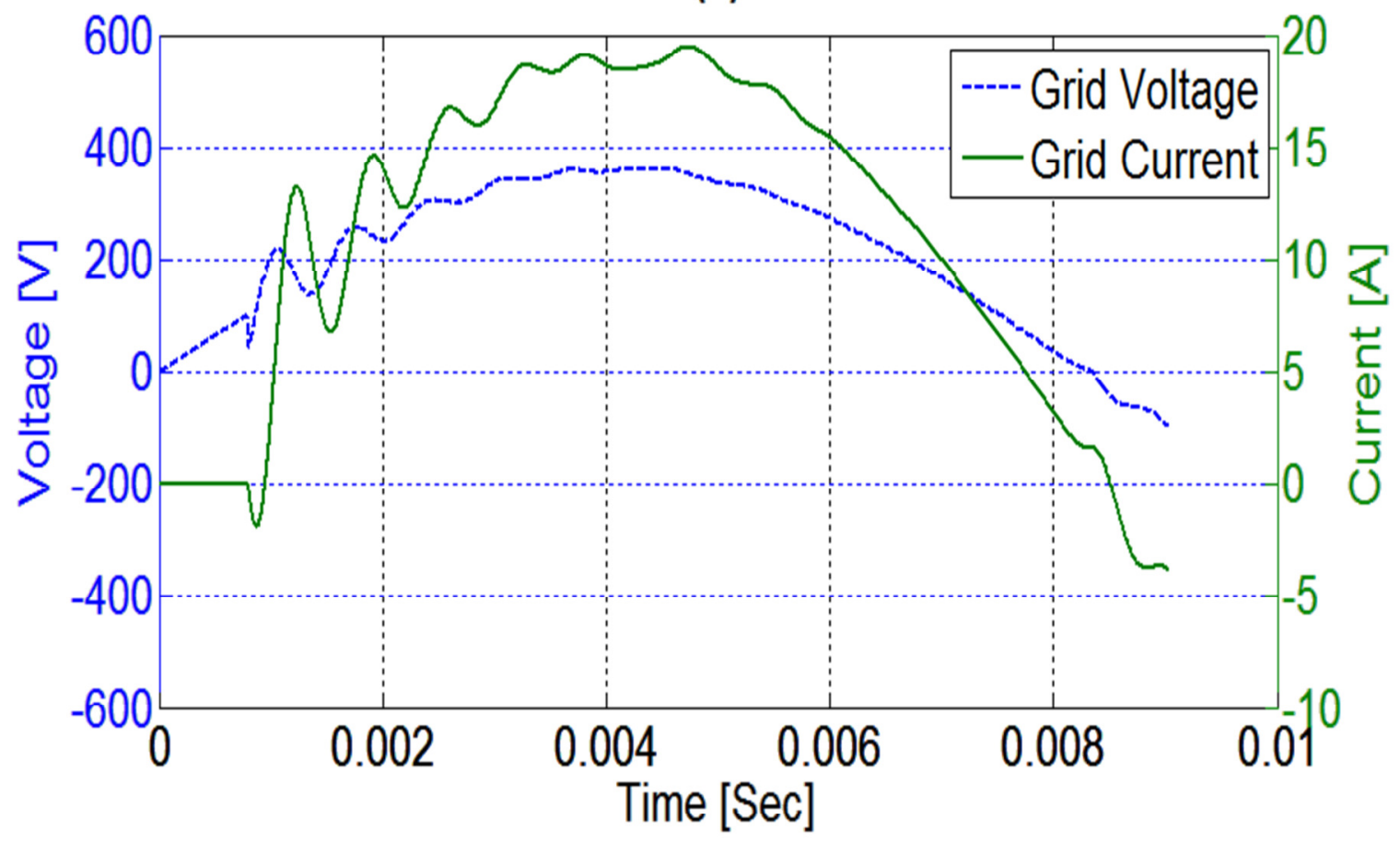

(b)

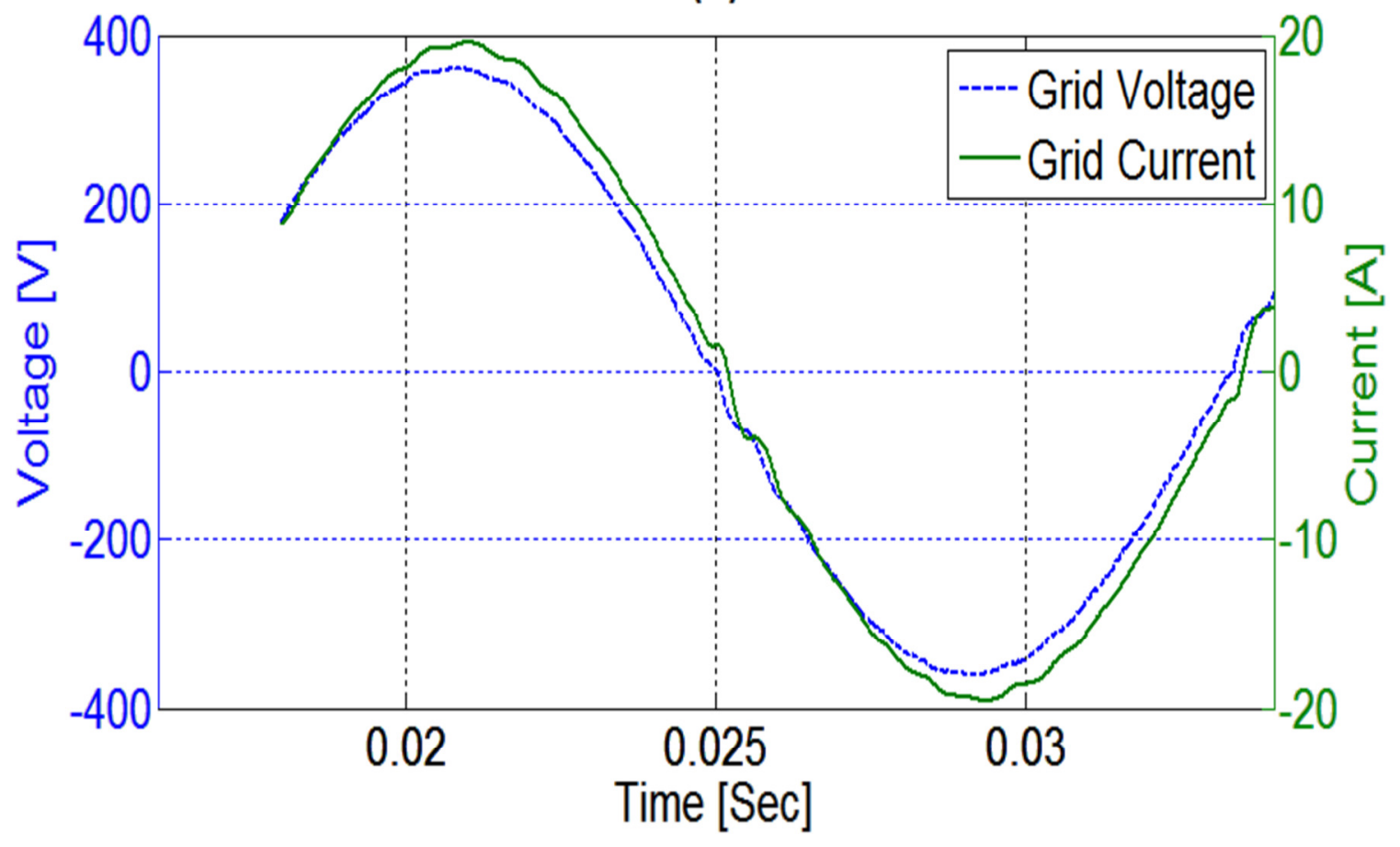

Figure 5.17 - Zoomed view of grid voltage and current simulation results (see Figure 5.16): (a) starting transient and (b) steady state. 


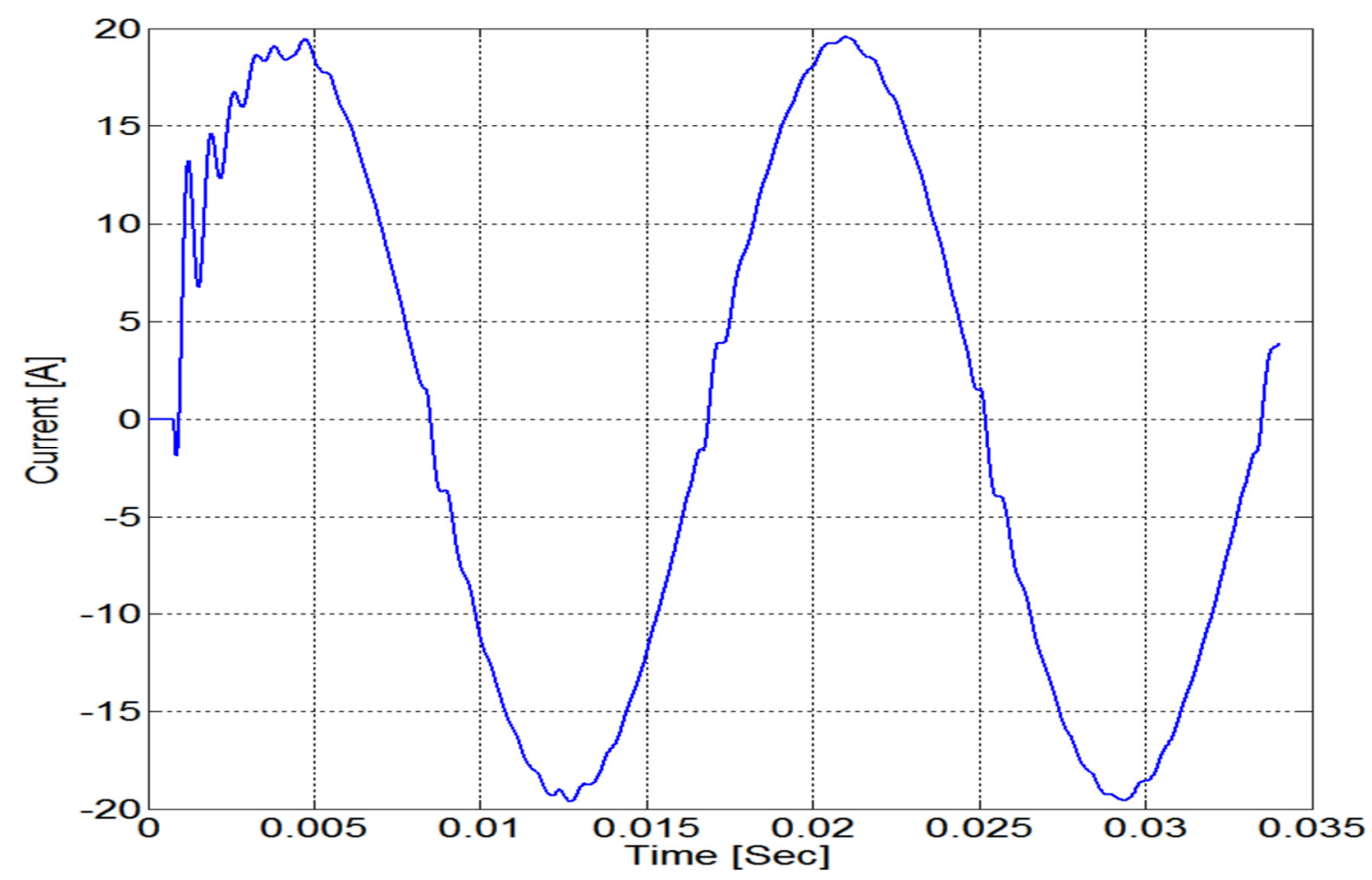

Figure 5.18 - V2G simulation results of filtered output current with a weak grid connection. Battery is at full SOC and connected. Generator is disconnected.

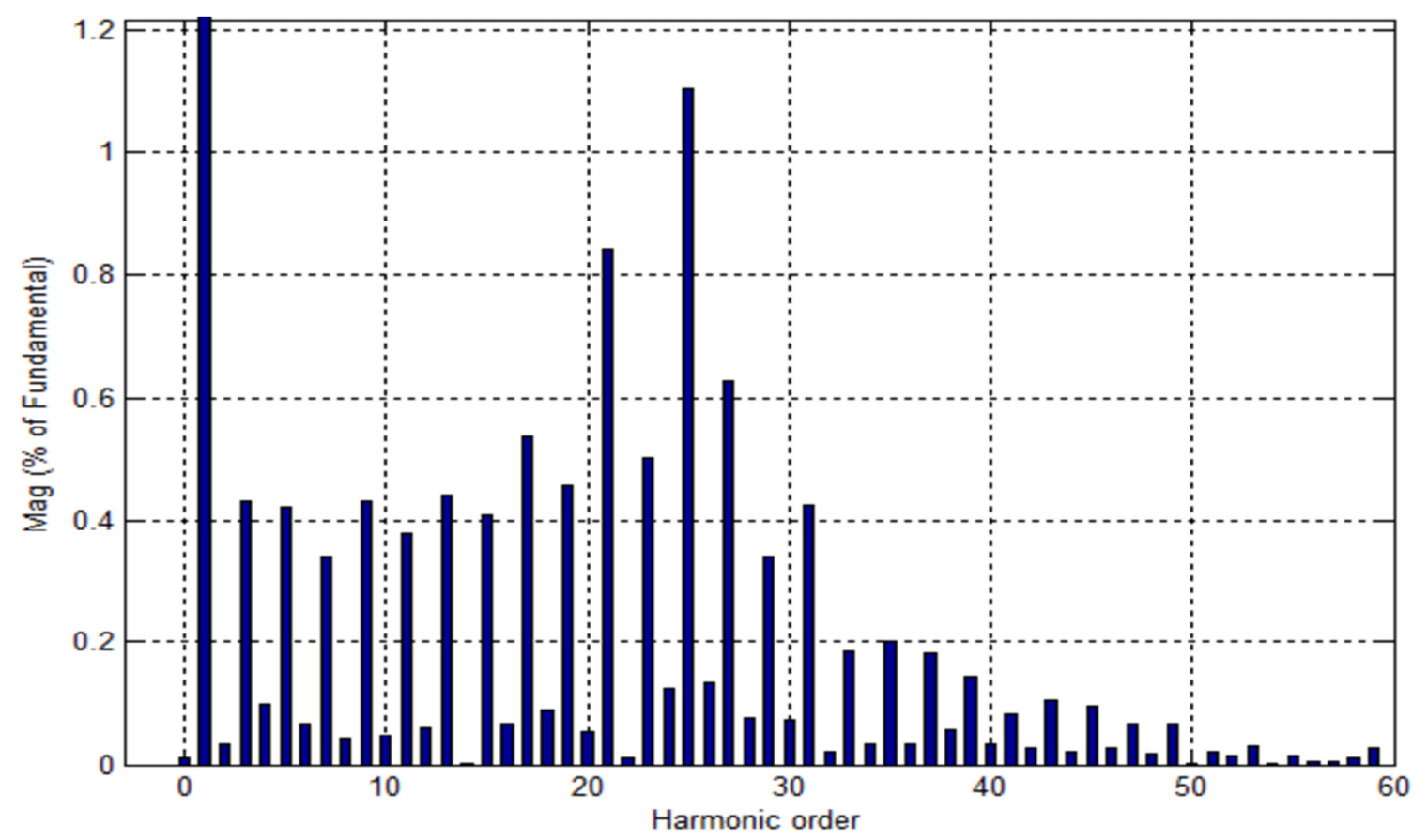

Figure 5.19-V2G simulation results of grid current in respect to harmonic order. Connection is to a weak grid. Battery is at full SOC and connected. Generator is disconnected. 


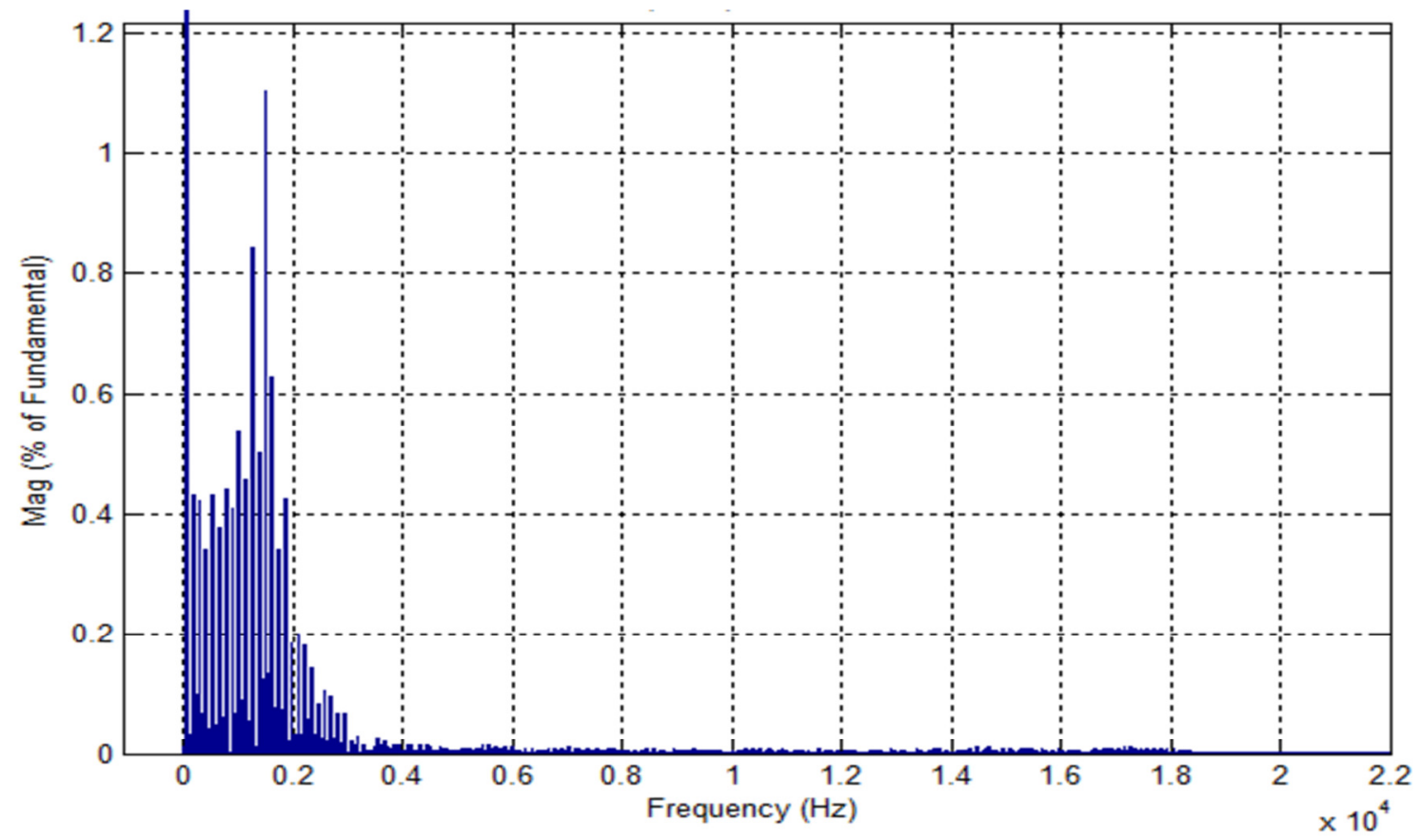

Figure 5.20 - V2G simulation results of grid current harmonics in respect to frequency. Connection is to a weak grid. Battery is at full SOC and connected. Generator is disconnected.

\subsection{V2G - Stiff Grid, Generator On}

Powering DC link bus for V2G GTI operation via DC generator is different than via battery through DC-DC converter. Mainly, a DC generator reacts much more slowly due to physical properties such as inertia of the rotating mass. This was simulated by using slower frequencies for PI controllers. Simulink implementation is shown in Figure 5.21. Notice the DC generator connection to 2-legged HB takes advantage of anti-parallel diodes. The diodes ensure no current is into the DC generator unless PIM-B switch gates are driven on. PIM-B switch gates will all be held off during V2G DC generator operation. DC generator Simulation values of DC generator winding resistance (Ra), winding inductance (La), and back electromagnetic force (EMF) are listed on Table 5.3. DC generator model and characteristic values are generic. DC generator tuned PI values 
for pre-charge and nominal operation are available in Table 5.4 and Table 5.5 respectively. 


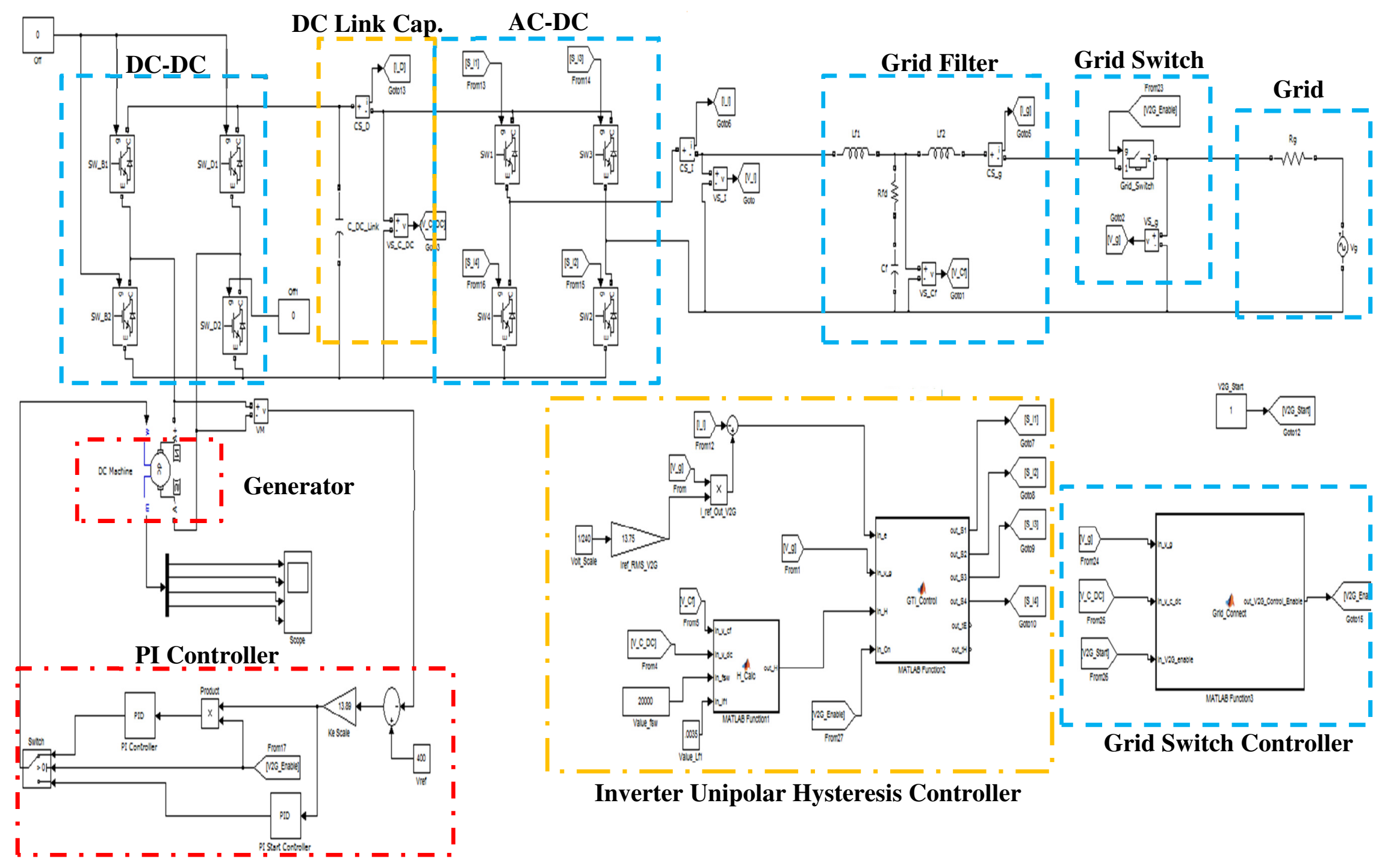

Figure 5.21 - Simulink implementation of V2G in a stiff grid connection. The battery is disconnected and generator is on. 
Table 5.3 - DC generator characteristics.

\begin{tabular}{|c|c|}
\hline $\mathrm{Ra}[\Omega]$ & .2828 \\
\hline $\mathrm{La}[\mathrm{mH}]$ & 4.453 \\
\hline Back EMF [V/RPM] & .072 \\
\hline
\end{tabular}

Table 5.4 - Pre-Charge DC generator PI parameters.

\begin{tabular}{|c|c|c|}
\hline \multicolumn{3}{|c|}{$\mathrm{PI}_{\text {start }}$} \\
\hline $\mathrm{Kp}$ & $\mathrm{Ki}$ & $\mathrm{f}[\mathrm{kHz}]$ \\
\hline 1.17 & 4 & 10 \\
\hline
\end{tabular}

Table 5.5 - DC generator PI parameters.

\begin{tabular}{|c|c|c|c|}
\hline \multicolumn{3}{|c|}{$\mathrm{PI}_{\text {nom }}$} \\
\hline $\mathrm{Kp}$ & $\mathrm{Ki}$ & $\mathrm{f}[\mathrm{kHz}]$ & Output Limit [Rpm] \\
\hline .12 & 500 & 10 & 5400 \\
\hline
\end{tabular}

After the DC generator powered pre-charge is finished, V2G operation begins. Figure 5.22 shows DC link bus capacitor voltage is pre-charged until $\sim 4 \mathrm{mSec}$, where voltage peaks. Peak voltage of bus capacitor is $\sim 430 \mathrm{~V}$ which is at given maximum operating voltage rating of TPIM (see Table 2.2). Voltage ripple at DC link bus is much more substantial than with a DC-DC converter. Previously, voltage ripple was within $\sim 420-380 \mathrm{~V}$ (see Figure 5.7), but now is within $\sim 450-340 \mathrm{~V}$. In this situation, voltage ripple is no longer within design specifications (5\%) or TPIM ratings.

Figure 5.23 shows pertinent DC generator information during simulation, at first a large amount of current is generated during to pre-charge DC link bus cap. During steady state, shaft RPM stays approximately at maximum allowed shaft speed of 5400 RPM. 
When observing current and torque, the DC generator is only delivering power for half a period every cycle. This is the same as with a DC-DC converter, but slower PI controller frequency leads to larger voltage fluctuations at DC bus. Hence, slower PI controller is unable to react as fast to mitigate voltage ripple. Again, slower PI controller was used to show if there are any possible differences between DC-DC converter and DC generator. The main effect is to emphasize the slow response times from physical properties such as inertia of a DC generator and ICE. The slower frequency was arbitrarily chosen. Ramifications may be overestimated or underestimated. This must be further explored with a more accurate model. This is not possible with this thesis as more specific information entailing ICE and DC generator are unavailable.

Even with DC bus voltage fluctuations undesirably larger, robustness of GTI controller is able to deliver approximately the same desirable results. Figure 5.24 shows grid voltage and grid current; again, there is a strong sinusoidal current shape. Power factor is basically at unity. Transient current oscillations have a greater peak than previously, but are due to starting $\mathrm{V} 2 \mathrm{G}$ operation later. $\mathrm{V} 2 \mathrm{G}$ operation was started later since the DC generator takes longer to charge the DC link bus capacitor. If grid switch controller and GTI controller were programed to only start at lower voltage levels, current peak can be mitigated. Increased current peak is irrelevant as well; PIM-B components are rated at much higher power levels. Grid/filtered current is shown in Figure 5.25, steady state current has very low THD. Current distortion can only be seen at peak, trough, and zero crossing regions, but are negligible. Simulation results of current harmonic reiterate low THD (see Figure 5.26, Figure 5.27, and Appendix G). 
Comparable to other situations and simulations (see section 5.2-4), THD is found to be only $1.46 \%$ with the same approximate shape (see Appendix G).

(a)

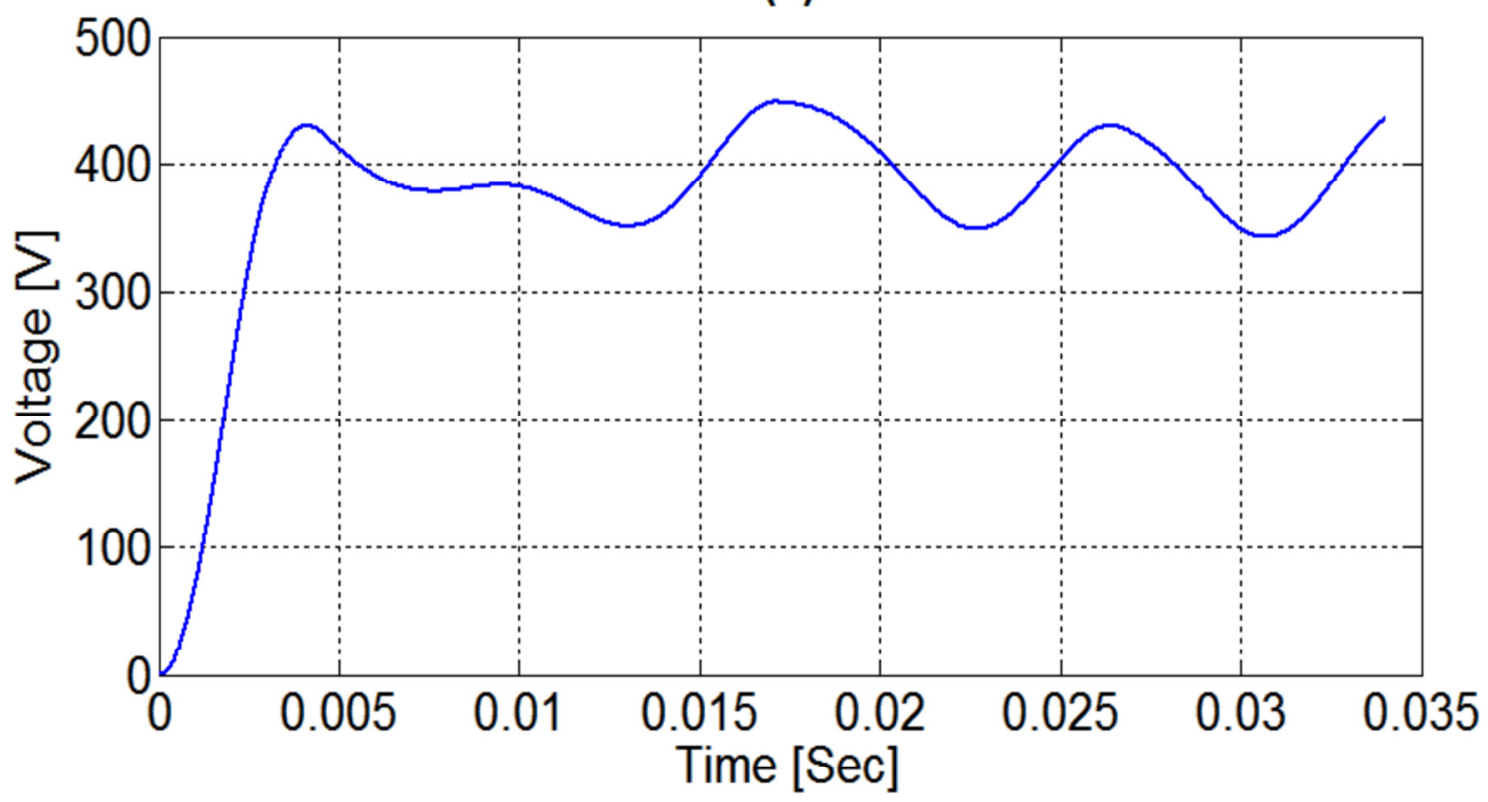

(b)

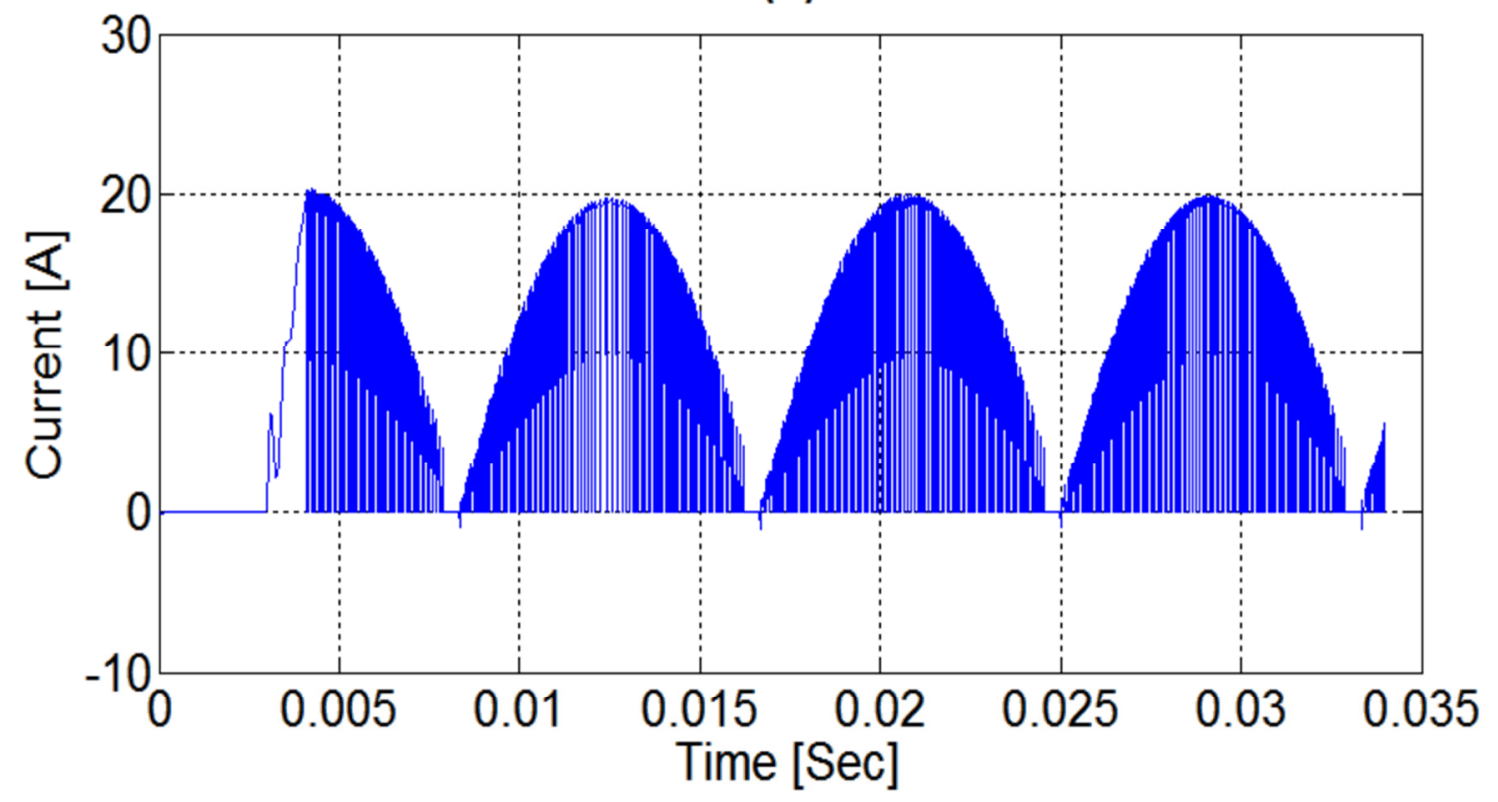

Figure 5.22 - V2G simulation results of DC link bus capacitor voltage (a) and current (b). Connection is to a stiff grid. Battery is disconnected. Generator is connected and on. 
(a)

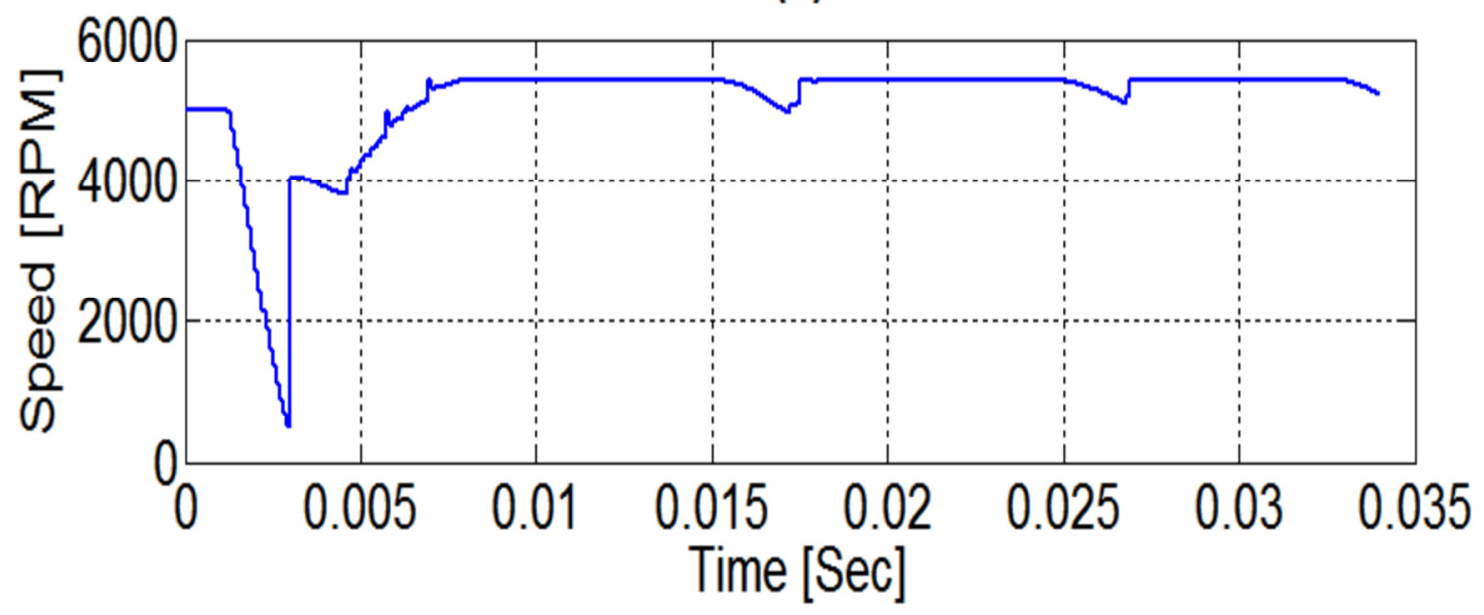

(b)

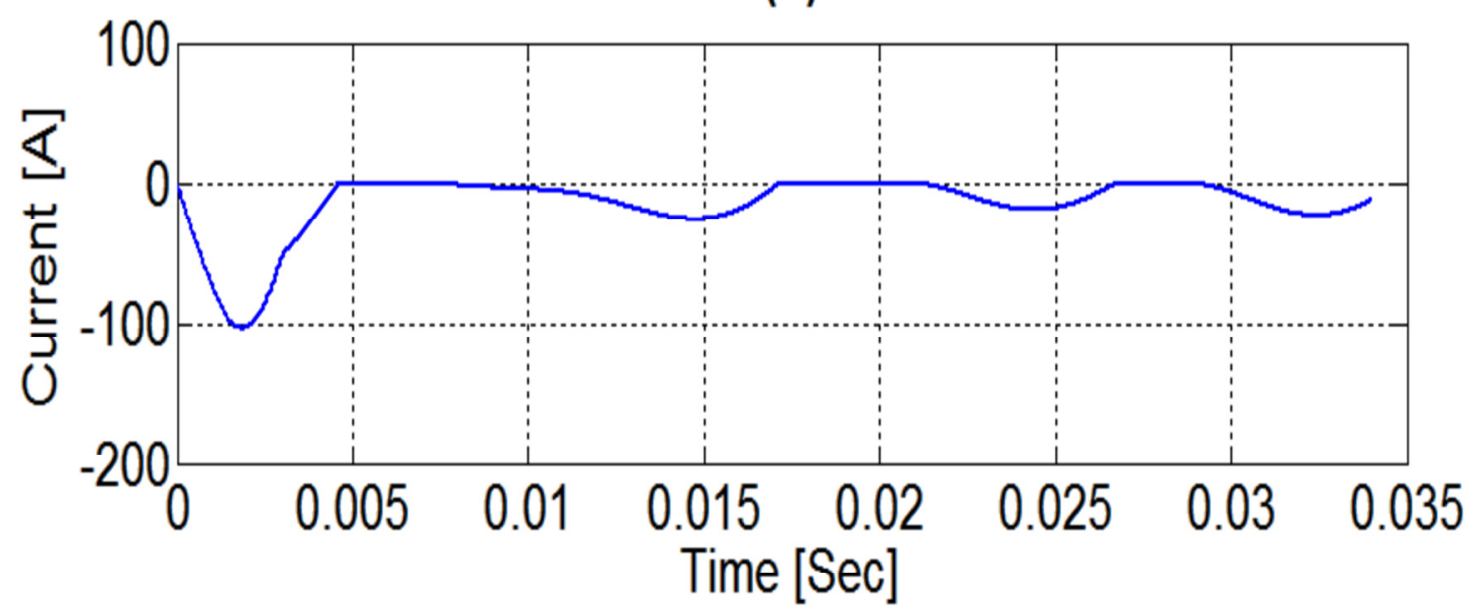

(c)

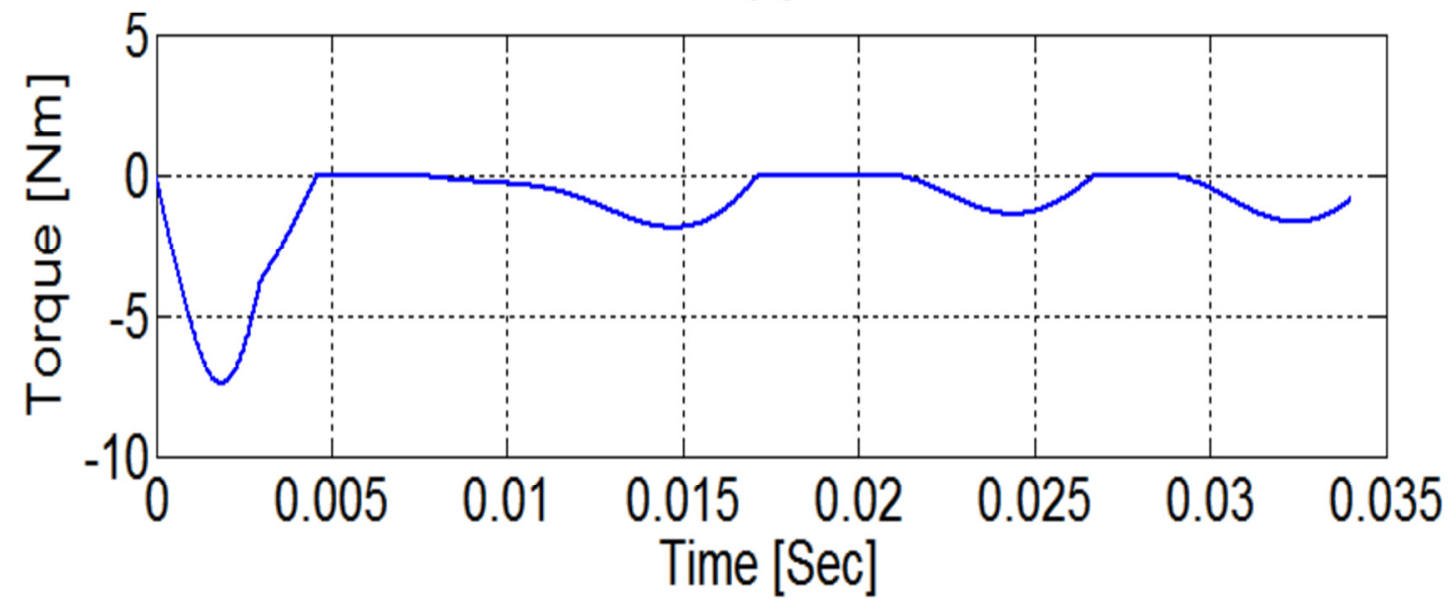

Figure 5.23 - V2G simulation results for DC generator shaft speed (a), current (b), and torque (c). Connection is to a stiff grid and battery is disconnected. 


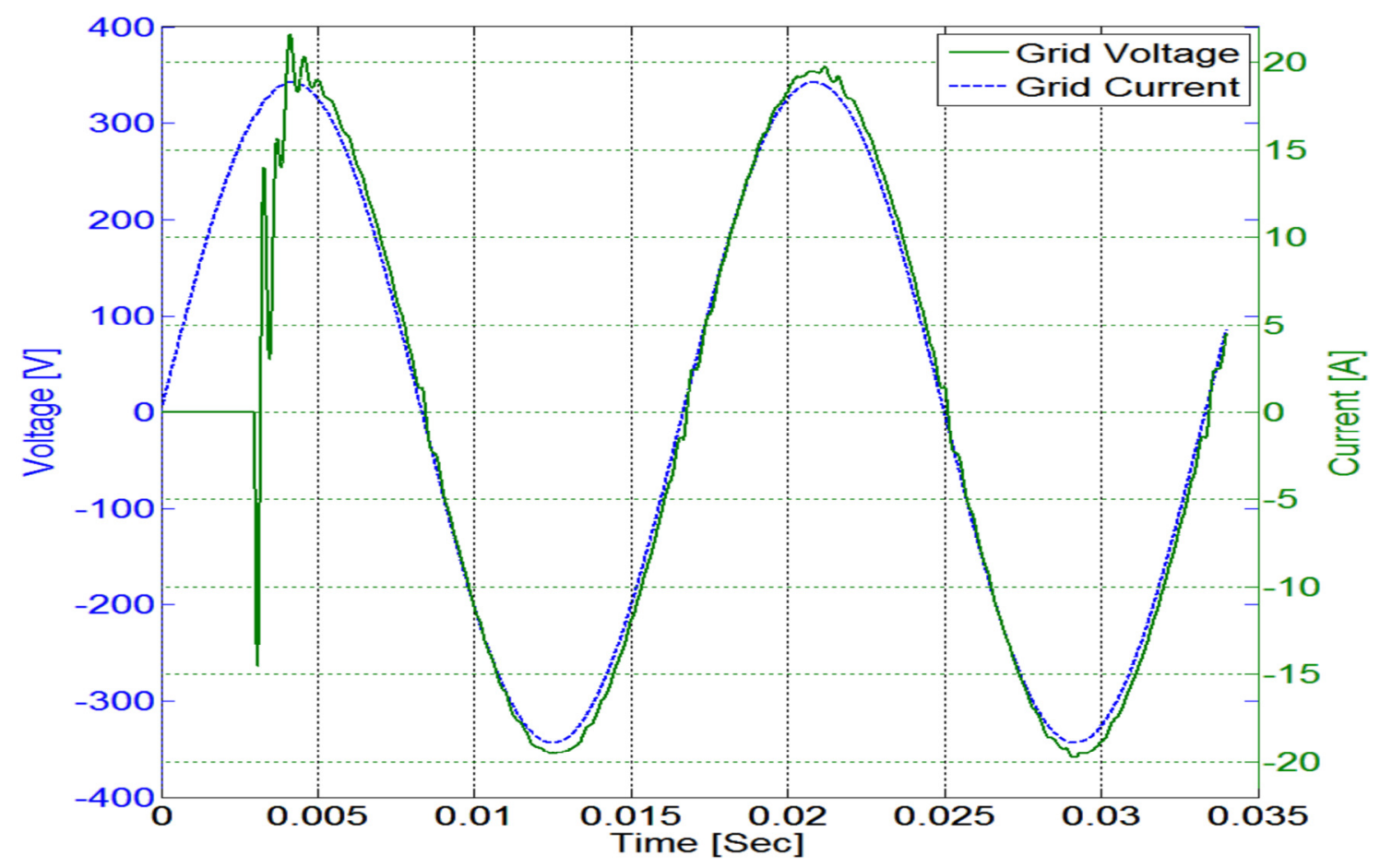

Figure 5.24 - V2G simulation results of grid voltage and filtered output current with a stiff grid connection. Battery is disconnected. Generator is connected and on.

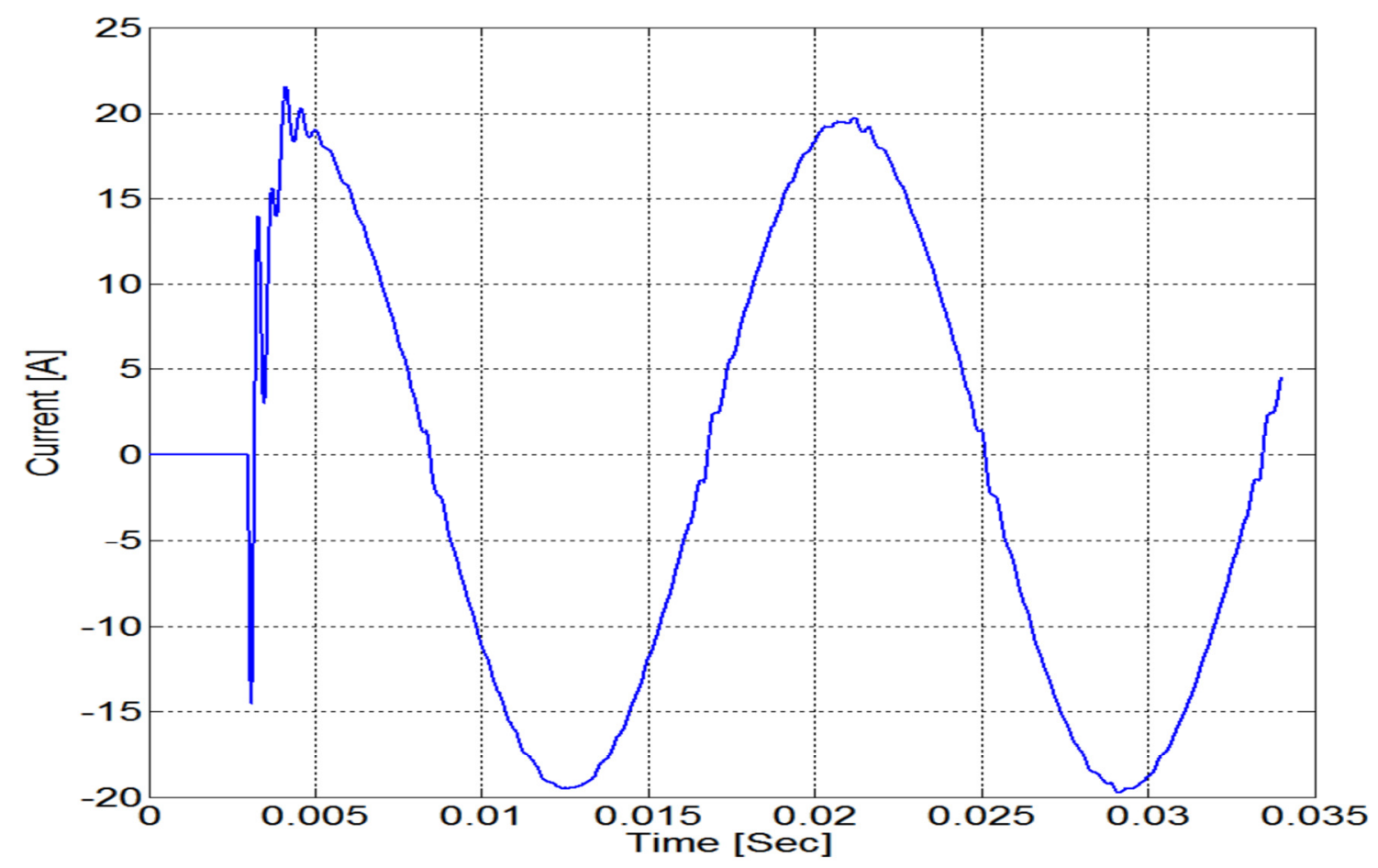

Figure 5.25 - V2G simulation results of filtered output current with a stiff grid connection. Battery is disconnected. Generator is connected and on. 


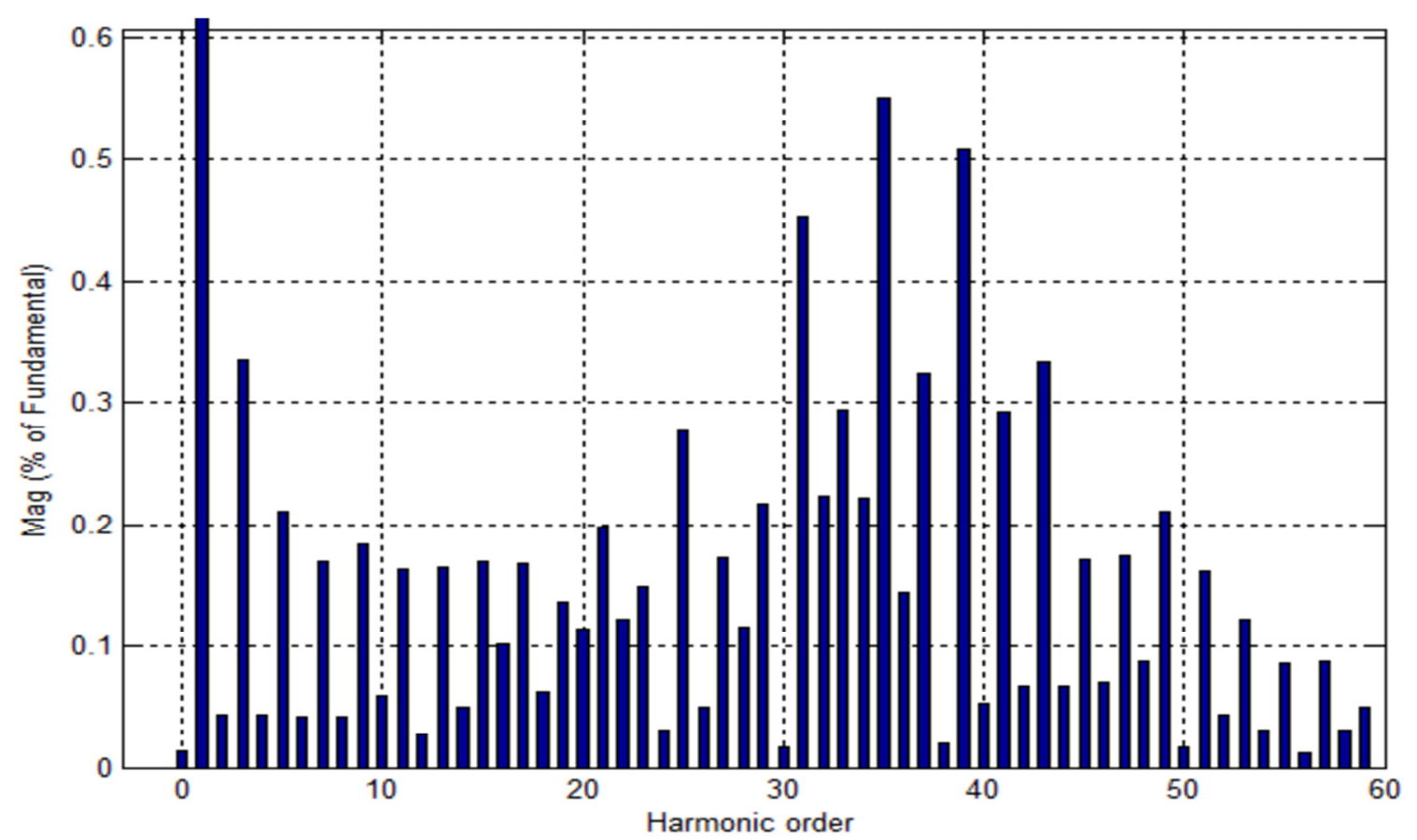

Figure 5.26 - V2G simulation results of grid current harmonics in respect to harmonic order. Connection is to a stiff grid. Battery is disconnected. Generator is connected and on.

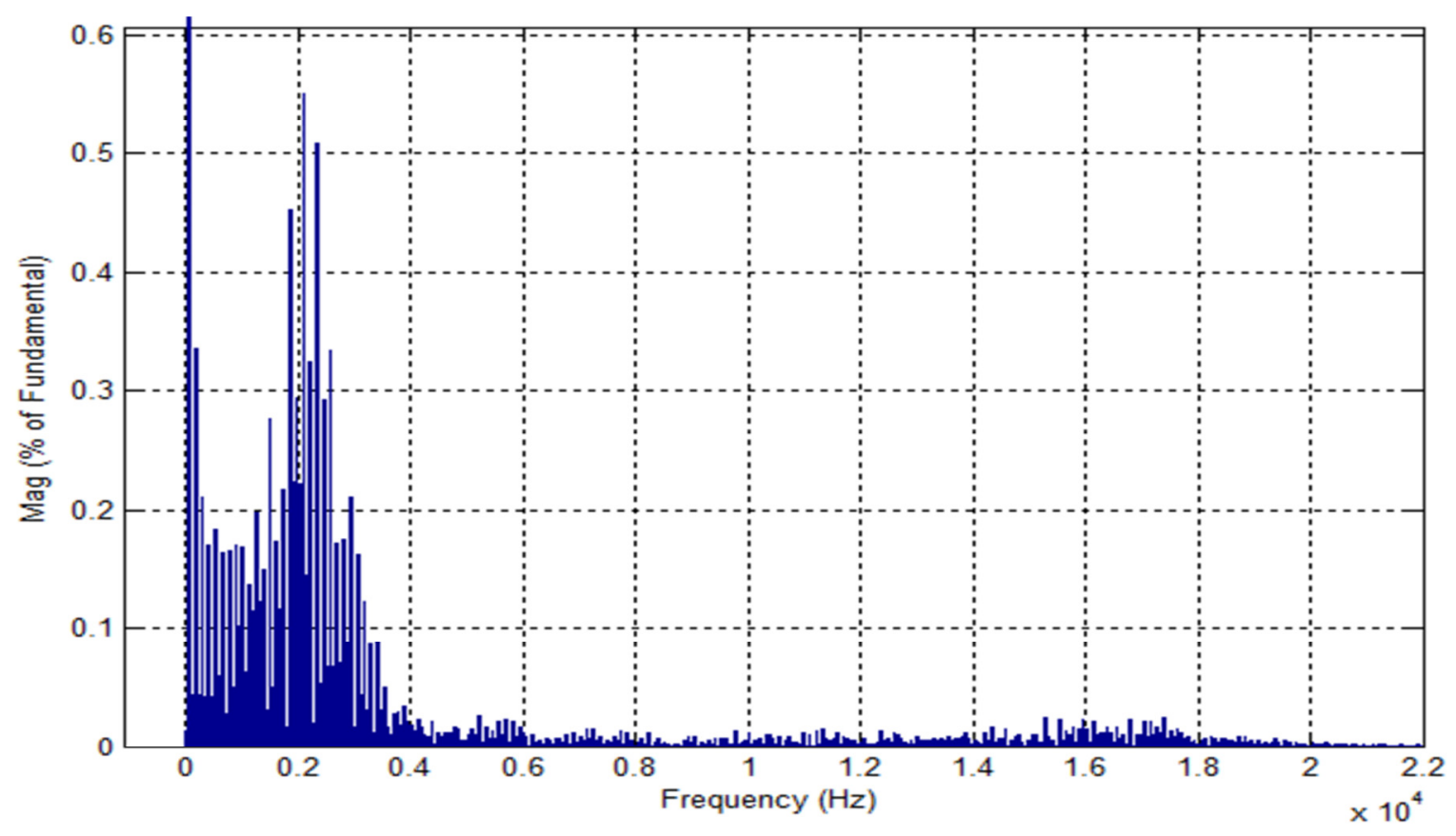

Figure 5.27 - V2G simulation results of grid current harmonics in respect to frequency. Connection is to a stiff grid. Battery is disconnected.

Generator is connected and on. 


\section{Conclusion}

To summarize, this thesis successfully explored an extensively integrated topology for G2V-V2G implementation in 2011 Chevy Volt from GM's (car manufacturer) perspective. Primary objective of the proposed topology was to minimize additional cost, volume, and weight through integration. Previous work has designed integrated electrified drivetrain components by utilizing traction motor inductance for filtering and motor drive IGBTs for inverter functionality. The proposed topology takes another leap forward, using additional components in EREV drivetrain. An integrated DC-DC converter is utilized as well as a DC generator. The proposed converter is able to perform battery charging $(\mathrm{G} 2 \mathrm{~V})$ for a variety of input and output voltages through a buck-boost converter. Simulations have proven that $\mathrm{V} 2 \mathrm{G}$ can be performed from a wide range of battery voltages or the DC generator itself. An LCL filter is a robust grid filter for varying grid impedances. The integrated design requires only an addition of GFI, relays, inductors, diodes, and capacitors. It may be possible to take advantage of existing microprocessors to implement PI and hysteresis controls.

It is important to note that designs were limited to only $3300 \mathrm{~W}$ from current Chevy Voltage allowances. TPIM is components are capable of 360V @ 100A. This leaves the possibility of fully rated AC level 2 charging and V2G operation. DC level 3 charging and $\mathrm{V} 2 \mathrm{G}$ is possible if connected to DC link bus or controlling 2-legged HB to supply DC voltage. Although relays and passive components must be upsized, this may be worth it. The integrated topology allows the flexibility of all charging levels without relying on charging station power electronics. 
This thesis was a proof of concept. Additional work can be done to improve performance. Firstly, the damping resistor should be removed from LCL filter. An adaptive resistor control should be implemented to reduce undesirable harmonics and decrease power losses. Secondly, LCL filter should also be optimized for cost, volume, and weight while maintaining adequate performance. Third, certain harmonics should be lowered to meet IEEE 1547 requirements. Another inverter control scheme may be required such as a better constant frequency hysteresis current controller. Fourth, G2V for AC level 1, AC level 2, and DC level 3 should be explored with this integrated topology. Fifth, four switch bidirectional buck-boost converter can be improved via bidirectional buck+boost control. Sixth, the topology should be verified in hardware. Seventh, a more accurate study with V2G powered by DC generator should be done. DC generator and ICE must be accurately modeled. Specifically, section 5.5 has issues of large fluctuating voltages at the DC link bus. That should be mitigated. Eighth, controls for vehicle-tohome $(\mathrm{V} 2 \mathrm{H})$ functionality should be added. The proposed structure allows for $\mathrm{V} 2 \mathrm{H}$, but requires a different controls scheme for V2H. Finally, as DG regulations evolve, so will the requirements of this converter. Futuristic functions that may be required are LVRT, reactive power compensation, power factor correction, active power filtering, etc. 


\section{BIBLIOGRAPHY}

[1] Pike Research Report, "The Global Outlook for PHEVs: Business Issues, Technology Issues, Key Players, and Market Forecasts," third quarter, 2009.

[2] X. Zhou, S. Lukic, S. Bhattacharya, A. Huang, "Design and Control of Gridconnected Converter in Bidirectional Battery Charger for Plug-in hybrid electric vehicle Application," in Proc. IEEE Vehicle Power Propulsion Conf., 2009, pp. 1716-1721.

[3] L. J. Beck, in $V 2 G-101,1^{\text {st }}$ ed. Lexington, 2009.

[4] J. Tomić, W. Kempton, "Using fleets of electric-drive vehicles for grid support," in Journal of Power Sources, vol. 168, no. 2, pp. 459-468, Jun. 2007.

[5] W. Kempton, J. Tomić, "Vehicle-to-grid power fundamentals: calculating capacity and net revenue," in Journal Power Sources, vol. 144, no. 1, pp. 268279 , Jun.

2005.

[6] L. Sanna, "Driving the Solution the Plug-in Hybrid Vehicle," EPRI, 2005.

[7] S. N. Vaishnav, H. Krishnaswami, "Single-stage isolated bidirectional converter topology using high frequency AC link for charging and V2G applications of PHEV," in Vehicle Power and Propulsion Conf. (VPPC), 2011 IEEE, pp.1-4, 6-9 Sept.

2011.

[8] H. Chen, X. Wang, A. Khaligh, "A single stage integrated bidirectional AC/DC and DC/DC converter for plug-in hybrid electric vehicles," in Vehicle Power and Propulsion Conf. (VPPC), 2011 IEEE, pp.1-6, 6-9 Sept. 2011.

[9] M. C. Kisacikoglu, B. Ozpineci, L. M. Tolbert, "Effects of V2G reactive power compensation on the component selection in an EV or PHEV bidirectional charger," in Energy Conversion Congr. and Expo. (ECCE), 2010 IEEE, pp.870876 , $12-16$

Sept.

2010.

[10] M. C. Kisacikoglu, B. Ozpineci, L. M. Tolbert, F. Wang, "Single-phase inverter design for V2G reactive power compensation," in Applied Power Electronics Conf. and Expo. (APEC), 2011 Twenty-Sixth Annual IEEE, pp.808-814, 6-11 March

2011.

[11] M. C. Kisacikoglu, B. Ozpineci, L. M. Tolbert, "Examination of a PHEV bidirectional charger system for V2G reactive power compensation," in Applied Power Electronics Conf. and Expo. (APEC), 2010 Twenty-Fifth Annual IEEE, pp.458-465,

$21-25$

Feb.

2010. 
[12] M. Rosekeit, R. W. De Doncker, "Smoothing power ripple in single phase chargers at minimized dc-link capacitance," in Power Electronics and ECCE Asia (ICPE \& ECCE), 2011 IEEE 8th Int. Conf. on, pp.2699-2703, May 30 - June 3, 2011.

[13] B. Bilgin, A. Emadi, and M. Krishnamurthy, "Design considerations for a universal input battery charger circuit for phev applications," in Industrial Electronics (ISIE), 2010 IEEE Int. Symp. on, July 2010, pp. 3407 -3412.

[14] N. D. Weise, K. K. Mohapatra, N. Mohan, "Universal utility interface for Plug-in Hybrid electric vehicles with vehicle-to-grid functionality," in Power and Energy Society General Meeting, 2010 IEEE, pp.1-8, 25-29 July 2010.

[15] J. Gallardo-Lozano, M. I. Milanes-Montero, M. A. Guerrero-Martinez, E. Romero-Cadaval, "Three-phase bidirectional battery charger for smart electric vehicles," in Compatibility and Power Electronics (CPE), 2011 7th Int. Conf.Workshop, pp.371-376, 1-3 June 2011.

[16] X. Wang, P. Yan, L. Yang, W. Yao, G. Shi, "A V2G vector control model of electric car charging and discharging machine," in Advanced Mechatronic Systems (ICAMechS), 2011 Int. Conf. on, pp.342-347, 11-13 Aug. 2011.

[17] W. E. Rippel, "Open Delta Motor Drive with Integrated Recharge," U.S. Patent 0 316 461, issued date Dec. 29, 2011.

[18] A. G. Cocconi, "Combined Motor Drive and Battery Recharge System," U.S. Patent 5341 075, issued date Aug. 23, 1994.

[19] X. Zhou, G. Wang, S. Lukic, S. Bhattacharya, A. Huang, "Multi-function bidirectional battery charger for plug-in hybrid electric vehicle application," in Energy Conversion Congr. and Expo., 2009. ECCE 2009. IEEE, pp.3930-3936, 20-24

Sept.

2009.

[20] J. Wang, F. Z. Peng, J. Anderson, A. Joseph, R. Buffenbarger, "Low cost fuel cell converter system for residential power generation," in IEEE Trans. Power Electron., vol. 19, no.5, pp. 1315-1322, Sep. 2004.

[21] D. C. Erb, O. C. Onar, A. Khaligh, "An integrated bidirectional power electronic converter with multi-level AC-DC/DC-AC converter and non-inverted buck-boost converter for PHEVs with minimal grid level disruptions," in Vehicle Power and Propulsion Conf. (VPPC), 2010 IEEE, pp.1-6, 1-3 Sept. 2010.

[22] S. Jaganathan, W. Gao, "Battery charging power electronics converter and control for plug-in hybrid electric vehicle," in Vehicle Power and Propulsion Conf., 2009. $\begin{array}{llllll}V P P C & \text { '09. IEEE, } & \text { pp.440-447, } & \text { 7-10 } & \text { Sept. }\end{array}$ 
[23] W. Kempton, A. E. Letendre, "Electric vehicles as a new source for electric utilities," in Transport. Res. Part D Transport. Envir., vol. 2, no 3, pp. 157-175, Sept.

1997.

[24] W. Kempton, J. Tomić, "Vehicle-to-Grid Power Fundamentals: Calculating Capacity and Net Revenue," in Journal of Power Sources, vol. 144, pp. 268-279, 2005.

[25] W. Kempton, J. Tomić, "Vehicle-to-Grid Power Implementation: From stabilizing the grid to supporting large-scale renewable energy," in Journal of Power $\begin{array}{lllll}\text { Sources, } & \text { vol. } & 144, & \text { pp. 280-294, } & \end{array}$

[26] A. N. Brooks, "Vehicle-to-grid Demonstration Project: Grid Regulation Ancillary Service with a Battery Electric Vehicle," Final report, Contract number 01-313, Prepared for the California Air Resources Board and the California Environmental Protection Agency, Dec. 2002.

[27] "Bottling electricity: storage as a strategic tool for managing variability and capacity concerns in the modern grid." Electricity advisory committee, December 2008. [Online]. Available: http://energy.gov/sites/prod/files/oeprod/DocumentsandMedia/final-energystorage_12-16-08.pdf.

[28] Z. Wang, X. Sun, L. Liu, "Study on control strategy of V2G in power peaking," in Power Electronics Systems and Applications (PESA), 2011 4th Int. Conf. on, pp.1-3, 8-10 June 2011.

[29] Y. Du, X. Zhou, S. Bai, S. Lukic, A. Huang, "Review of non-isolated bidirectional DC-DC converters for plug-in hybrid electric vehicle charge station application at municipal parking decks," in Applied Power Electronics Conf. and Expo. (APEC), 2010 Twenty-Fifth Annual IEEE, pp.1145-1151, 21-25 Feb. 2010.

[30] I. Cvetkovic, T. Thacker, D. Dong, G. Francis, V. Podosinov, D. Boroyevich, F. Wang, R. Burgos, G. Skutt, J. Lesko, "Future home uninterruptible renewable energy system with vehicle-to-grid technology," in Energy Conversion Congr. and Expo., 2009. ECCE 2009. IEEE, pp.2675-2681, 20-24 Sept. 2009.

[31] G. Choe, J. Kim, B. Lee, C. Won, T. Lee, "A Bidirectional battery charger for electric vehicles using photovoltaic PCS systems," in Vehicle Power and Propulsion Conf. (VPPC), 2010 IEEE, pp.1-6, 1-3 Sept. 2010.

[32] I. Cvetkovic et al., "Future home uninterruptable renewable energy system with vehicle-to-grid technology," in IEEE Energy Conversion Congr. \& Expo. (ECCE'09), San Jose, CA, pp. 2675-2681, 20-24 September 2009. 
[33] D. C. Erb, O. C. Onar, A. Khaligh, "Bidirectional charging topologies for plug-in hybrid electric vehicles," in Proc. IEEE Applied Power Electronics Conf. and Expo., Palm Springs, California, pp. 2066-2072, 2010.

[34] L. Tang, G. J. Su, "A low-cost, digitally-controlled charger for plugin hybrid electric vehicles," in Energy Conversion Congr. \& Expo. (ECCE'09), San Jose, CA, 20-24 2009.

[35] E. Tate, P. Savagian, "The CO2 Benefits of Electrification E-REVs, PHEVs and Charging Scenarios," in SAE Tech. Paper 2009-01-1311, 2009.

[36] Volt 2013 [Online]. Available: http://www.chevrolet.com/volt-electric-car/

[37] Vehicle Overview: The 2012 Nissan Leaf [Online]. Available: http://www.nissanusa.com/leaf-electric-car/vehicle-

overview?next=ev_micro.section_nav.

[38] Brooke, "Chevrolet Volt: Development Story of the Pioneering Electrified Vehicle," SAE International Vehicle Electrication Series, 2011.

[39] Voltec Charge Station [Online]. Available: https://homecharging.spx.com/volt/pdf/GM10-463A.pdf.

[40] Chevrolet Volt Will Utilize 10.4 KWH of Battery to Achieve EV Range [Online]. Available: http://gm-volt.com/2010/10/26/chevrolet-volt-will-utilize-10-4-kwhof-battery-to-achieve-ev-range/.

[41] A. Briones, J. Francfort, P. Heitmann, M. Schey, S. Schey, J. Smart, "Vehicle-toGrid (V2G) Power Flow Regulations and Building Codes Review by the AVTA," Idaho National Laboratory, Idaho National Laboratory, Idaho, Rep. INL/EXT-1226853 ,

2012.

[42] R. Teodorescu, M. Liserre, P. Rodriguez, Grid Converters for Photovoltaic and Wind Power Systems, 1st ed. West Sussex, UK: Wiley, 2011.

[43] Physical and Electrical Interconnections between Utility and Distributed $\begin{array}{llll}\text { Generation, } & \text { IEEE } & \text { Standard } & 1547,\end{array}$

[44] Electric Vehicle Charging System, NEC Article 625, 2011.

[45] T. Kerekes, "Analysis and Modeling of Transformerless Photovoltaic Inverter Systems," Ph.D. dissertation, Dept. Elect. Eng., Aalborg University, 2009.

[46] Y. J. Lee, A. Khaligh, and A. Emadi, "Advanced integrated bidirectional ac/dc and $\mathrm{dc} / \mathrm{dc}$ converter for plug-in hybrid electric vehicles," in Vehicular 
Technology, IEEE Trans. on, pp. 3970-3980, Oct. 2009.

[47] D. S. Dolan, Taufik, "Introduction to Power Electronic," Lecture Notes, $8^{\text {th }}$ Revision

2010.

[48] M. E. Ropp, "Similarities between vehicle-to-grid interfaces and photovoltaic systems," in Vehicle Power and Prop. Conf., 2009. VPPC '09. IEEE, pp.12211225, 7-10 Sept. 2009.

[49] M. Victor et al. US Patent Application, Publication Number US 2005/0286281 A1, $29 \quad$ December 2005.

[50] H. Schmid et al. US Patent 7046534, issued 16 May 2006.

[51] A. Nabae, I. Takahashi, H. Akagi, "A New Neutral-Point-Clamped PWM Inverter," in Industry Applications, IEEE Trans. on, vol. IA-17, no.5, pp.518-523, Sept.

1981.

[52] P. Knaup, International Patent Application, Publication Number WO 2007/048420 A1, $\quad 3 \quad$ May 2007.

[53] N. Su, D. Xu, M. Chen, J. Tao, "Study of bidirectional buck-boost converter with different control methods," in Vehicle Power and Propulsion Conf., 2008. VPPC '08. IEEE, $\quad$ pp.1-5, 3-5 2008.

[54] S. Waffler, J. W. Kolar, "A Novel Low-Loss Modulation Strategy for High-Power Bidirectional Buck Boost Converters," in Power Electronics, IEEE Trans. on, vol.24, no.6, pp.1589-1599, June 2009.

[55] High Efficiency, Synchronous 4-Switch Buck-Boost Controller [Online]. Available: $\quad$ http://cds.linear.com/docs/Datasheet/3789fa.pdf.

[56] M. A. Khan, I. Husain, Y. Sozer, "A bidirectional DC-DC converter with overlapping input and output voltage ranges and vehicle to grid energy transfer capability," in Electric Vehicle Conf. (IEVC), 2012 IEEE Int., pp.1-7, 4-8 March 2012.

[57] J. Lettl, J. Bauer, L. Linhart, "Comparison of Different Filter Types for Grid Connected Inverter," in PIERS Proceedings, Marrakesh, MOROCCO, 2011, pp. 1426-1429.

[58] A. Yepes, "Digital Resonant Current Controllers for Voltage Source Converters," Ph.D. dissertation, Dept. Elect. Tech., Vigo University, 2011.

[59] G. Zeng, T. W. Rasmussen, R. Teodorescu, "A novel optimized LCL-filter designing method for grid connected converter," in Power Electronics for 
Distributed Generation Systems (PEDG), 2010 2nd IEEE Int. Symp. on, pp.802805 , 16-18

[60] J. Bauer, "Single Phase Voltage Source Inverter Photovoltaic Application," in Acta Polytechnica, vol. 50, no. 4, 2010, pp. 7-11.

[61] X. Zhou, "Design and Control of Bi-Directional Grid-Interactive Converter for Plug-in Hybrid Electric Vehicle Applications," Ph.D. dissertation, Dept. Elect. Eng., North Carolina University, 2011. 


\section{Appendix A - Grid Switch Controller Code}

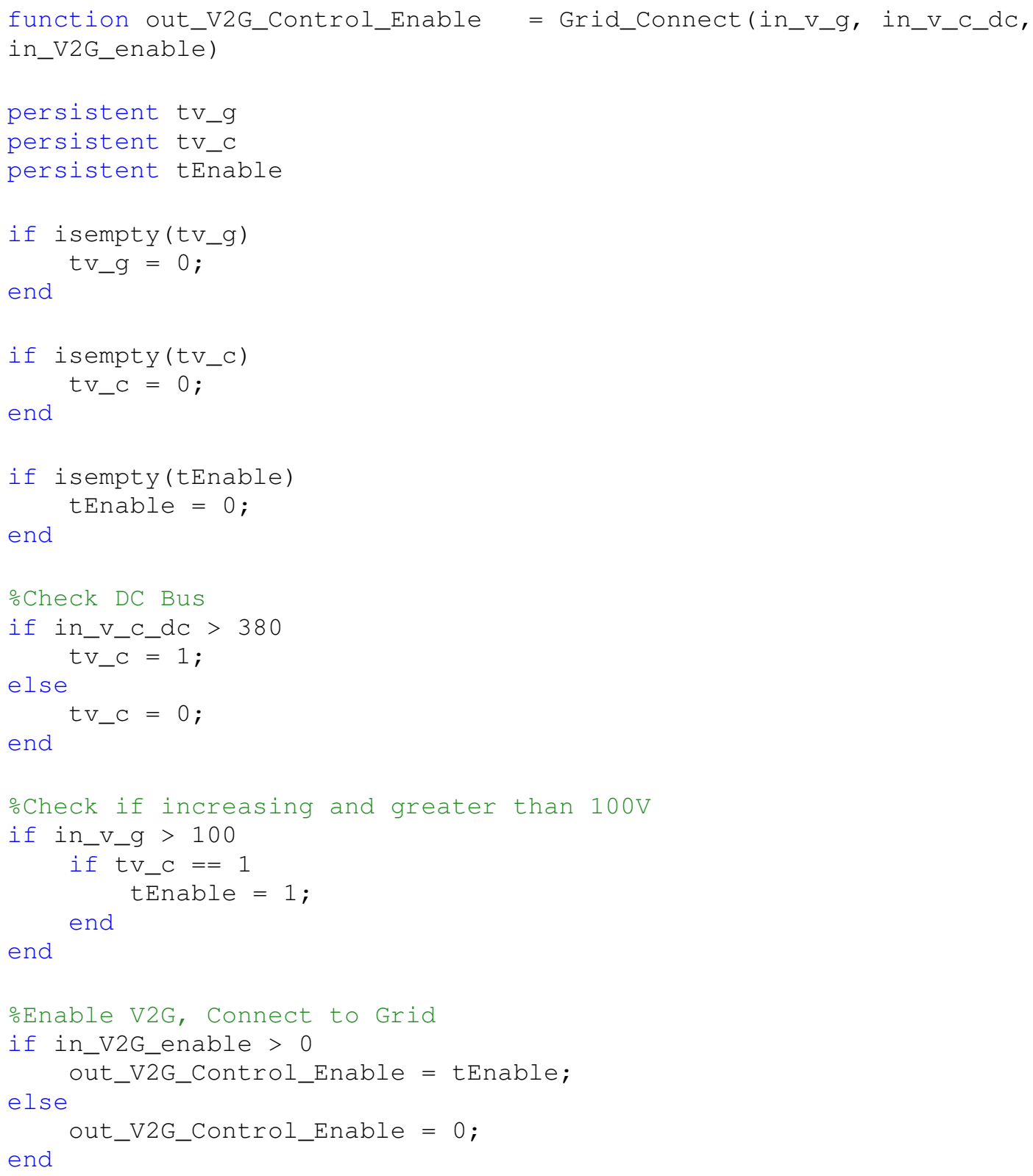




\section{Appendix B - Inverter Unipolar Hysteresis Controller Code}

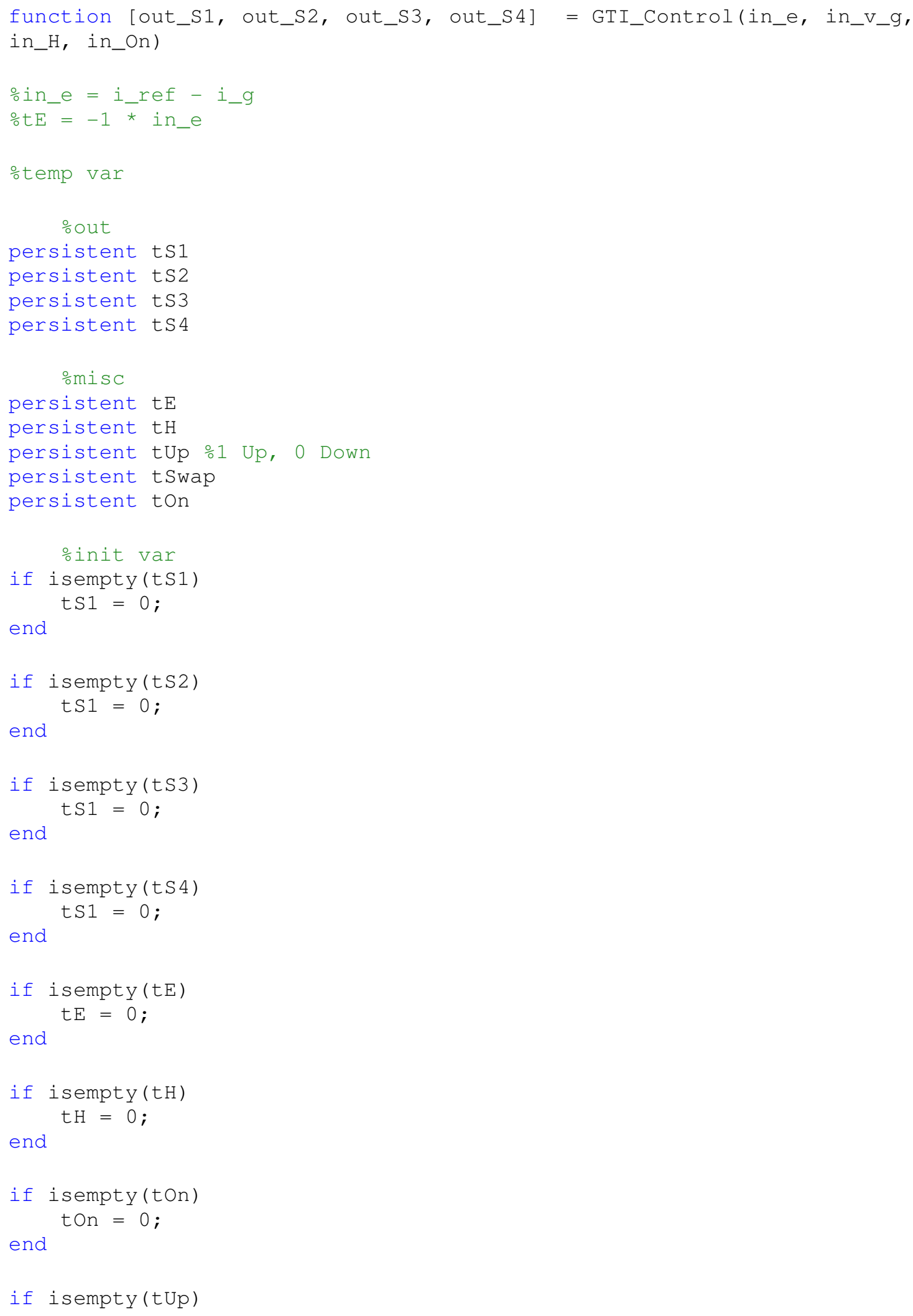




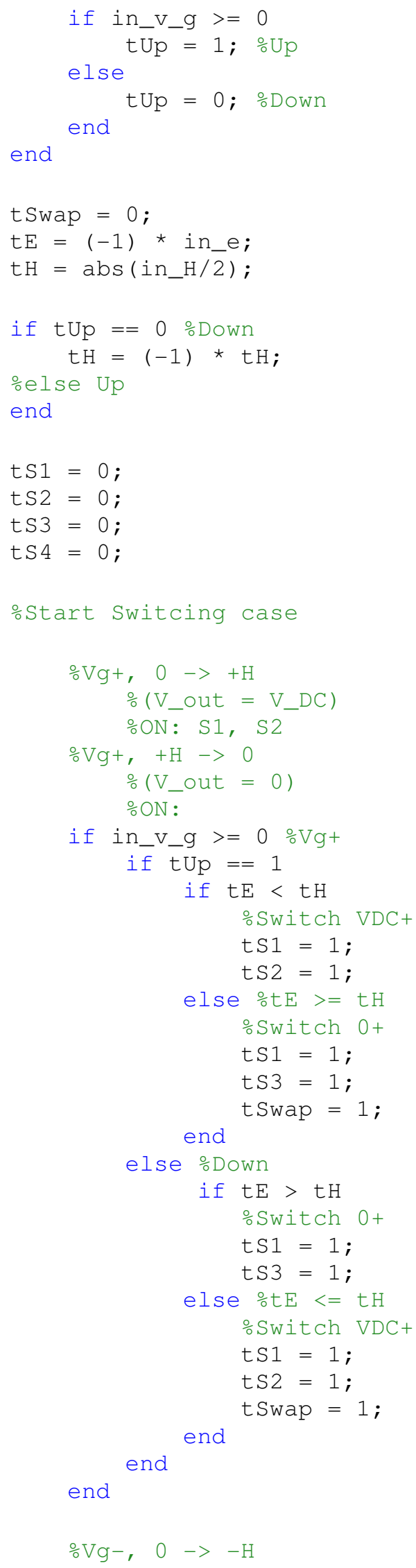




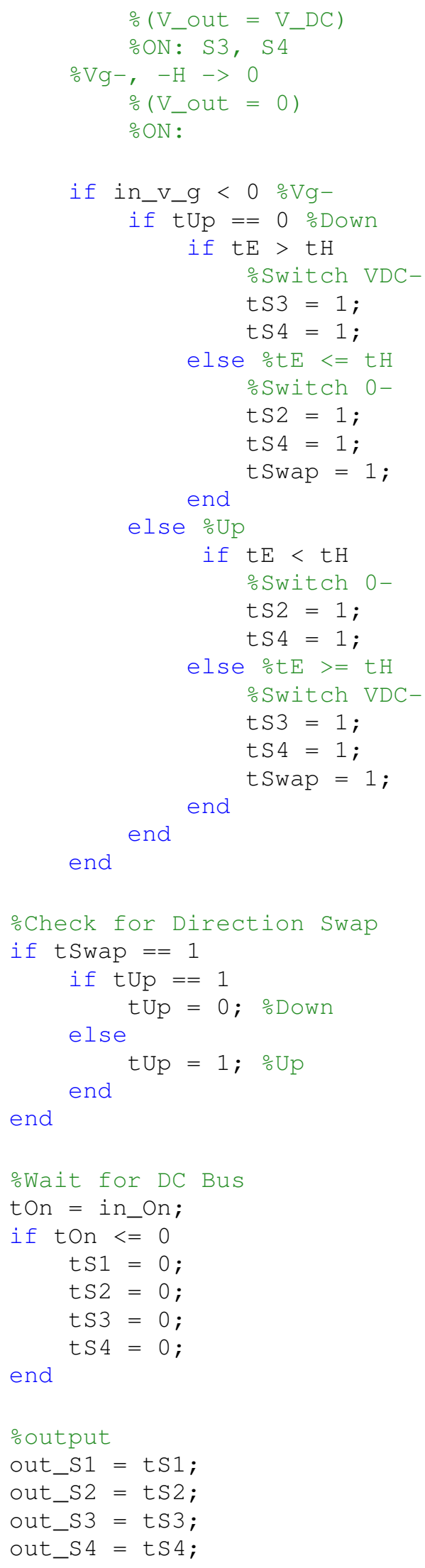




\section{Appendix C - Hysteresis Band Calculation Code}

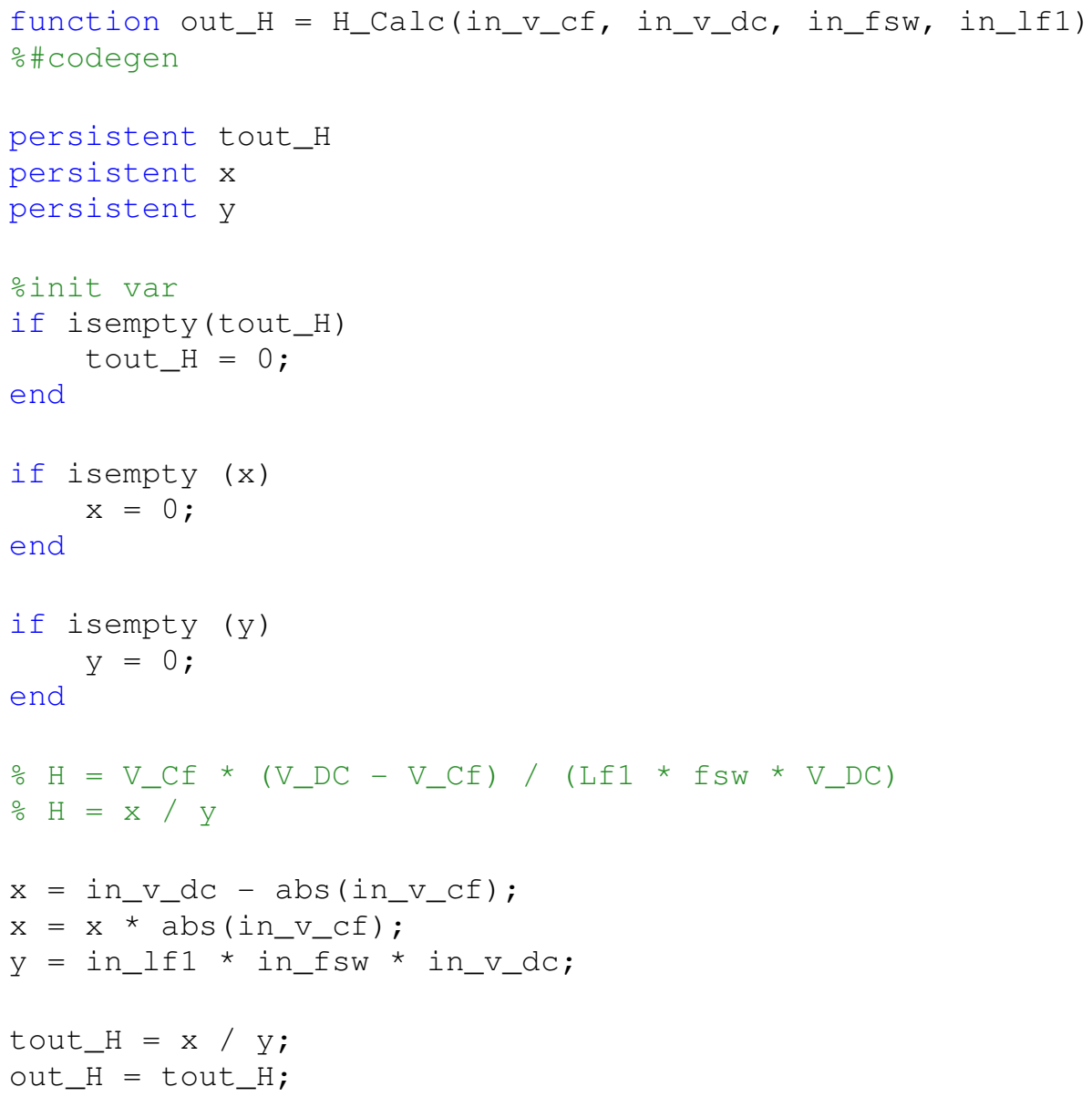




\section{Appendix D - List of Current Harmonic Characteristics:}

\section{V2G Mode - Stiff Grid, Generator Off, Battery Full SOC}

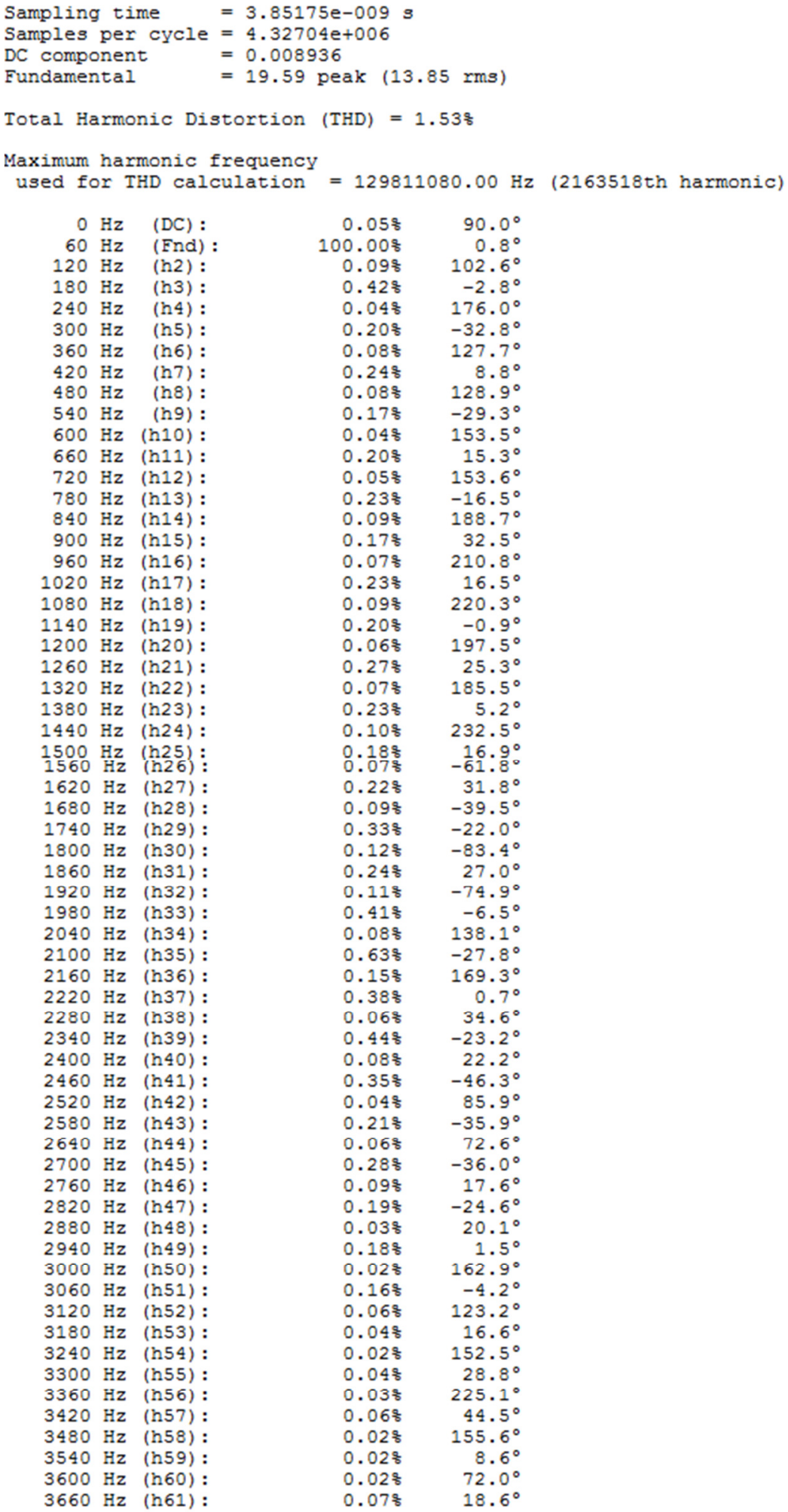

$90.0^{\circ}$

$0.8^{\circ}$

$102.6^{\circ}$

$-2.8^{\circ}$

$176.0^{\circ}$

$-32.8^{\circ}$

$127.7^{\circ}$

$8.8^{\circ}$

$128.9^{\circ}$

$-29.3^{\circ}$

$153.5^{\circ}$

$15.3^{\circ}$

$153.6^{\circ}$

$-16.5^{\circ}$

$188.7^{\circ}$

$32.5^{\circ}$

$210.8^{\circ}$

$16.5^{\circ}$

$220.3^{\circ}$

$-0.9^{\circ}$

$197.5^{\circ}$

$25.3^{\circ}$

$185.5^{\circ}$

$5.2^{\circ}$

$232.5^{\circ}$

$16.9^{\circ}$
$-61.8^{\circ}$

$31.8^{\circ}$

$-39.5^{\circ}$

$-22.0^{\circ}$

$-83.4^{\circ}$

$27.0^{\circ}$

$-74.9^{\circ}$

$-6.5^{\circ}$

$138.1^{\circ}$

$-27.8^{\circ}$

$169.3^{\circ}$

$0.7^{\circ}$

$34.6^{\circ}$

$-23.2^{\circ}$

$22.2^{\circ}$

$-46.3^{\circ}$

$85.9^{\circ}$

$-35.9^{\circ}$

$72.6^{\circ}$

$-36.0^{\circ}$

$17.6^{\circ}$

$-24.6^{\circ}$

$20.1^{\circ}$

$1.5^{\circ}$

$162.9^{\circ}$

$-4.2^{\circ}$

$123.2^{\circ}$

$16.6^{\circ}$

$152.5^{\circ}$

$28.8^{\circ}$

$225.1^{\circ}$

$44.5^{\circ}$

$155.6^{\circ}$

$8.6^{\circ}$

$72.0^{\circ}$

$18.6^{\circ}$ 


\begin{tabular}{|c|c|c|c|}
\hline $3720 \mathrm{H}$ & $\mathrm{Hz}(\mathrm{h} 62)$ : & $0.02 \%$ & $157.7^{\circ}$ \\
\hline $3780 \mathrm{H}$ & $\mathrm{Hz}$ (h63): & 0.048 & $49.2^{\circ}$ \\
\hline $3840 \mathrm{~F}$ & $\mathrm{~Hz}(\mathrm{~h} 64):$ & $0.02 \%$ & $217.8^{\circ}$ \\
\hline $3900 \mathrm{H}$ & $\mathrm{Hz}(\mathrm{h} 65)$ : & 0.048 & $29.2^{\circ}$ \\
\hline $3960 \mathrm{H}$ & $\mathrm{Hz}(\mathrm{h} 66):$ & $0.02 \%$ & $-80.5^{\circ}$ \\
\hline $4020 \mathrm{H}$ & $\mathrm{Hz}(\mathrm{h} 67):$ & $0.06 \%$ & $23.3^{\circ}$ \\
\hline $4080 \mathrm{H}$ & $\mathrm{Hz}(\mathrm{h} 68):$ & $0.01 \%$ & $-57.3^{\circ}$ \\
\hline $4140 \mathrm{H}$ & Hz (h69): & 0.018 & $-13 \cdot 9^{\circ}$ \\
\hline $4200 \mathrm{H}$ & $\mathrm{Hz}(\mathrm{h} 70):$ & 0.018 & $-37.6^{\circ}$ \\
\hline $4260 \mathrm{H}$ & $\mathrm{Hz}(\mathrm{h} 71)$ : & $0.03 \%$ & $48.9^{\circ}$ \\
\hline $4320 \mathrm{H}$ & $\mathrm{Hz}(\mathrm{h} 72):$ & $0.01 \%$ & $-11.7^{\circ}$ \\
\hline $4380 \mathrm{H}$ & $\mathrm{Hz}$ (h73): & $0.02 \%$ & $61.4^{\circ}$ \\
\hline $4440 \mathrm{H}$ & $\mathrm{Hz}(\mathrm{h} 74):$ & $0.02 \%$ & $-8.9^{\circ}$ \\
\hline $4500 \mathrm{H}$ & $\mathrm{Hz}(\mathrm{h} 75)$ : & $0.02 \%$ & $219.7^{\circ}$ \\
\hline $4560 \mathrm{H}$ & $\mathrm{Hz}(\mathrm{h} 76):$ & $0.02 \%$ & $-51.4^{\circ}$ \\
\hline $4620 \mathrm{H}$ & $\mathrm{Hz}(\mathrm{h} 77):$ & $0.00 \%$ & $200.1^{\circ}$ \\
\hline $4680 \mathrm{H}$ & $\mathrm{Hz}(\mathrm{h} 78):$ & $0.02 \%$ & $-39.4^{\circ}$ \\
\hline $4740 \mathrm{H}$ & $\mathrm{Hz}(\mathrm{h} 79):$ & $0.03 \%$ & $-4.6^{\circ}$ \\
\hline $4800 \mathrm{H}$ & $\mathrm{Hz}(\mathrm{h} 80)$ : & 0.028 & $12.0^{\circ}$ \\
\hline $4860 \mathrm{H}$ & $\mathrm{Hz}$ (h81): & $0.02 \%$ & $23.3^{\circ}$ \\
\hline $4920 \mathrm{H}$ & $\mathrm{Hz}(\mathrm{h} 82):$ & $0.01 \%$ & $94.1^{\circ}$ \\
\hline 4980 & $\mathrm{~Hz}$ (h83): & $0.01 \%$ & $72.2^{\circ}$ \\
\hline $5040 \mathrm{H}$ & $\mathrm{Hz}$ (h84): & $0.01 \%$ & $72.7^{\circ}$ \\
\hline $5100 \mathrm{H}$ & $\mathrm{Hz}$ (h85): & $0.02 \%$ & $39.8^{\circ}$ \\
\hline $5160 \mathrm{H}$ & $\mathrm{Hz}(\mathrm{h} 86)$ : & $0.00 \%$ & $65.4^{\circ}$ \\
\hline $5220 \mathrm{H}$ & $\mathrm{Hz}$ (h87): & $0.02 \%$ & $63.2^{\circ}$ \\
\hline 5280 & $\mathrm{~Hz}$ (h88): & $0.01 \%$ & $101.0^{\circ}$ \\
\hline $5340 \mathrm{H}$ & $\mathrm{Hz}(\mathrm{h} 89)$ : & $0.02 \%$ & $81.5^{\circ}$ \\
\hline $5400 \mathrm{H}$ & $\mathrm{Hz}(\mathrm{h} 90):$ & $0.01 \%$ & $251.0^{\circ}$ \\
\hline $5460 \mathrm{H}$ & $\mathrm{Hz}$ (h91): & 0.018 & $91.8^{\circ}$ \\
\hline $5520 \mathrm{H}$ & Hz (h92): & $0.01 \%$ & $261.4^{\circ}$ \\
\hline $5580 \mathrm{H}$ & $\mathrm{Hz}$ (h93): & $0.02 \%$ & $148.5^{\circ}$ \\
\hline 5640 & $\mathrm{~Hz}$ (h94): & $0.01 \%$ & $244.7^{\circ}$ \\
\hline $5700 \mathrm{H}$ & $\mathrm{Hz}(\mathrm{h} 95)$ : & $0.01 \%$ & $140.4^{\circ}$ \\
\hline 5760 & $\mathrm{~Hz}(\mathrm{~h} 96)$ : & $0.01 \%$ & $-74.0^{\circ}$ \\
\hline $5820 \mathrm{H}$ & $\mathrm{Hz}$ (h97): & $0.01 \frac{8}{8}$ & $129.5^{\circ}$ \\
\hline
\end{tabular}


Appendix E - List of Current Harmonic Characteristics:

\section{V2G Mode - Stiff Grid, Generator Off, Battery Low SOC}

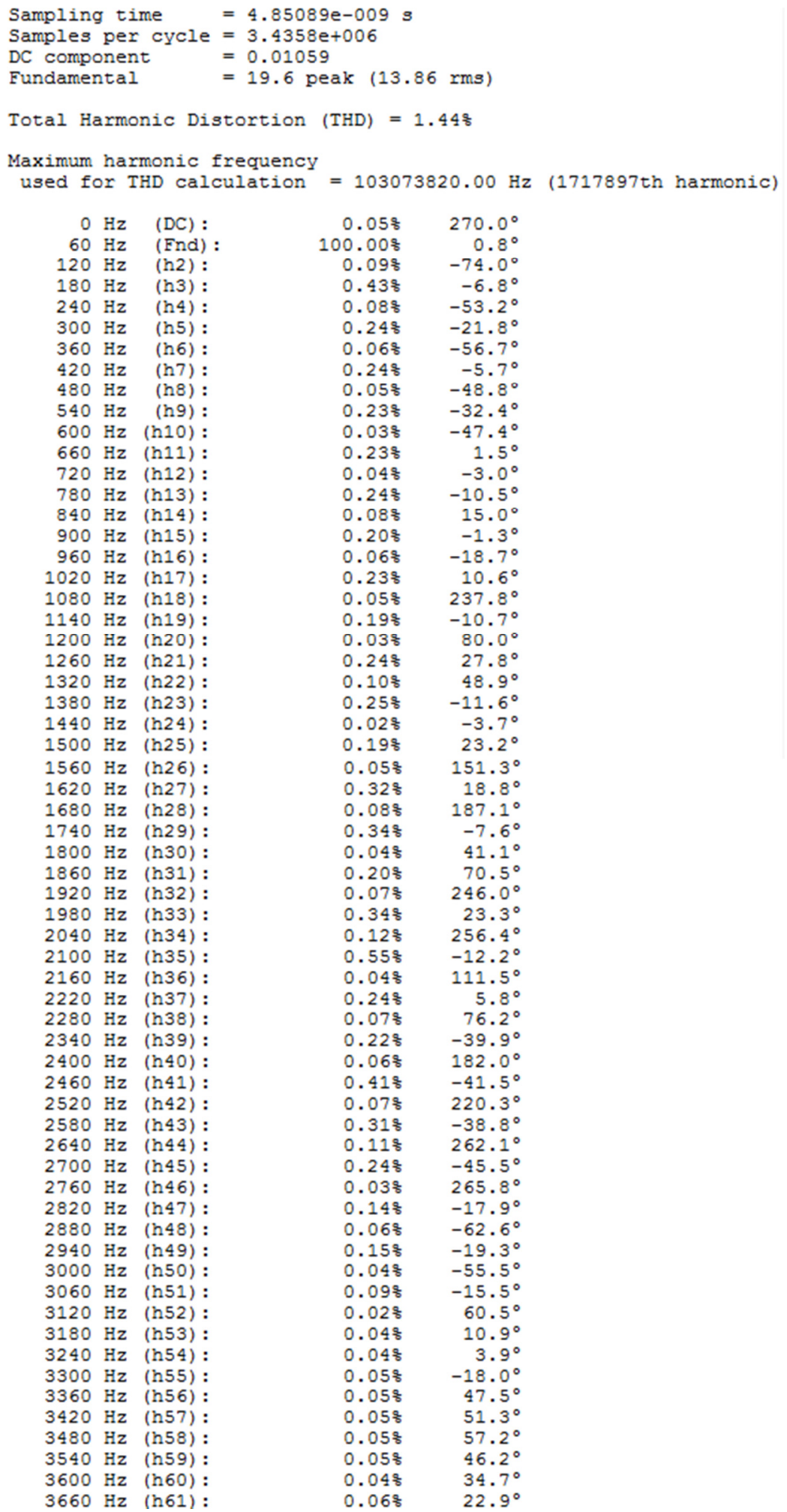




\begin{tabular}{|c|c|c|c|}
\hline 3720 & $\mathrm{~Hz}(\mathrm{~h} 62)$ : & $0.02 \%$ & $23.3^{\circ}$ \\
\hline 3780 & Hz (h63): & $0.05 \%$ & $38.7^{\circ}$ \\
\hline 3840 & $\mathrm{~Hz}(\mathrm{~h} 64)$ : & $0.02 \%$ & $164.8^{\circ}$ \\
\hline 3900 & Hz (h65): & $0.06 \%$ & $40.7^{\circ}$ \\
\hline 3960 & Hz (h66): & $0.02 \%$ & $154.7^{\circ}$ \\
\hline 4020 & $\mathrm{~Hz}(\mathrm{~h} 67)$ : & $0.06 \%$ & $32.3^{\circ}$ \\
\hline 4080 & $\mathrm{~Hz}$ (h68): & $0.02 \%$ & $114.4^{\circ}$ \\
\hline 4140 & Hz (h69): & $0.02 \%$ & $48.0^{\circ}$ \\
\hline 4200 & Hz (h70): & $0.00 \%$ & $22.5^{\circ}$ \\
\hline 4260 & Hz (h71): & $0.05 \%$ & $29.8^{\circ}$ \\
\hline 4320 & Hz (h72): & $0.00 \%$ & $12.1^{\circ}$ \\
\hline 4380 & $\mathrm{~Hz}(\mathrm{~h} 73)$ : & $0.03 \%$ & $81.5^{\circ}$ \\
\hline 4440 & Hz (h74): & $0.01 \%$ & $115.4^{\circ}$ \\
\hline 4500 & Hz (h75): & $0.02 \%$ & $129.6^{\circ}$ \\
\hline 4560 & $\mathrm{~Hz}(\mathrm{~h} 76)$ : & $0.01 \%$ & $-4.4^{\circ}$ \\
\hline 4620 & Hz (h77): & $0.03 \%$ & $65.2^{\circ}$ \\
\hline 4680 & $\mathrm{~Hz}(\mathrm{~h} 78)$ : & $0.01 \%$ & $-59.6^{\circ}$ \\
\hline 4740 & Hz (h79): & $0.02 \%$ & $57.0^{\circ}$ \\
\hline 4800 & $\mathrm{~Hz}(\mathrm{~h} 80)$ : & $0.01 \%$ & $186.0^{\circ}$ \\
\hline 4860 & Hz (h81): & $0.02 \%$ & $77.4^{\circ}$ \\
\hline 4920 & $\mathrm{~Hz}(\mathrm{~h} 82):$ & $0.01 \%$ & $-81.5^{\circ}$ \\
\hline 4980 & Hz (h83): & $0.02 \%$ & $118.6^{\circ}$ \\
\hline 5040 & $\mathrm{~Hz}($ h84): & $0.01 \%$ & $-17.8^{\circ}$ \\
\hline 5100 & $\mathrm{~Hz}(\mathrm{~h} 85)$ : & $0.01 \%$ & $204.1^{\circ}$ \\
\hline 5160 & $\mathrm{~Hz}(\mathrm{~h} 86)$ : & $0.02 \%$ & $39.2^{\circ}$ \\
\hline 5220 & Hz (h87): & 0.018 & $64.6^{\circ}$ \\
\hline 5280 & Hz (h88): & $0.01 \%$ & $27.2^{\circ}$ \\
\hline 5340 & Hz (h89): & $0.01 \%$ & $72.1^{\circ}$ \\
\hline 5400 & Hz (h90): & $0.00 \%$ & $0.7^{\circ}$ \\
\hline 5460 & Hz (h91): & 0.018 & $83.2^{\circ}$ \\
\hline & $\mathrm{Hz}(\mathrm{h} 92)$ : & $0.01 \%$ & $15.0^{\circ}$ \\
\hline 5580 & $\mathrm{~Hz}$ (h93): & $0.01 \frac{8}{8}$ & $105.6^{\circ}$ \\
\hline 5640 & Hz (h94): & $0.01 \%$ & $58.4^{\circ}$ \\
\hline 5700 & Hz (h95): & $0.02 \%$ & $76.8^{\circ}$ \\
\hline 5760 & Hz (h96): & $0.02 \%$ & $85.4^{\circ}$ \\
\hline 5820 & $\mathrm{~Hz}$ (h97): & $0.02 \%$ & $118.9^{\circ}$ \\
\hline
\end{tabular}




\section{Appendix F - List of Current Harmonic Characteristics:}

\section{V2G Mode - Weak Grid, Generator Off, Battery Full SOC}

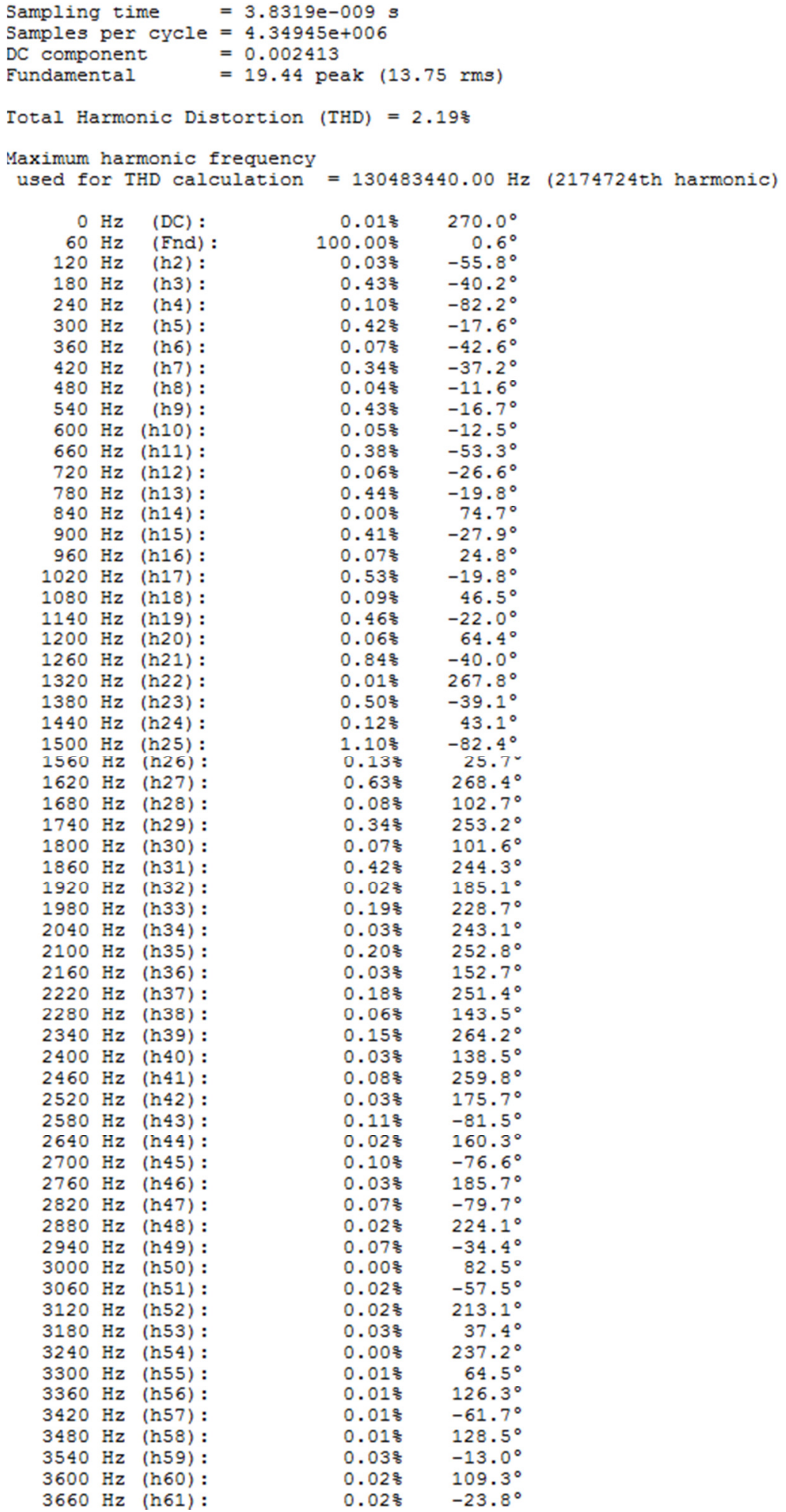




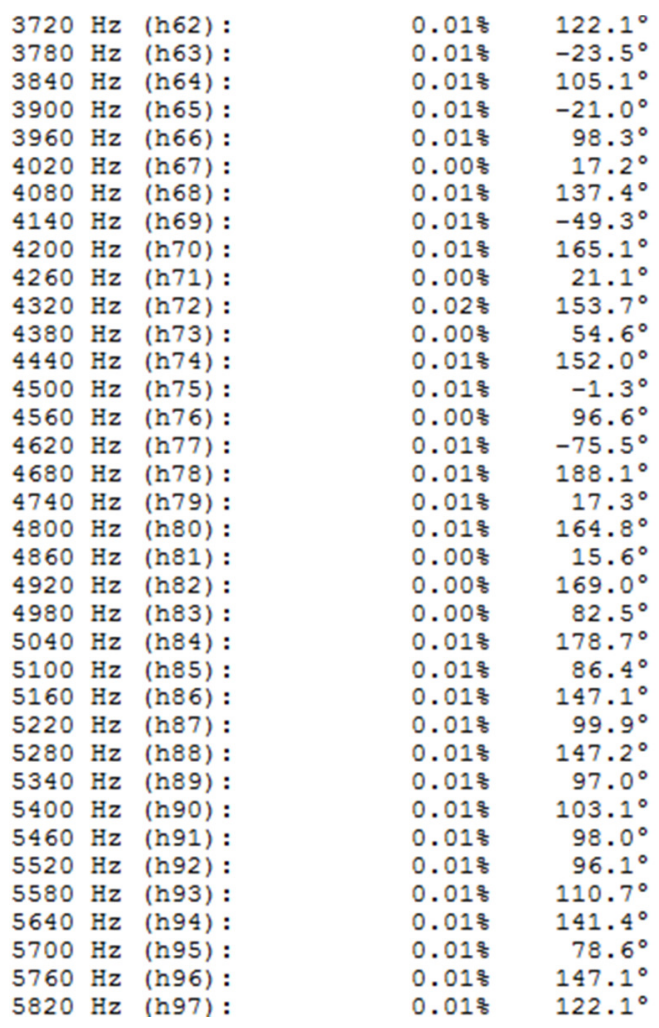




\section{Appendix G - List of Current Harmonic Characteristics:}

\section{V2G Mode - Stiff Grid, Generator On}

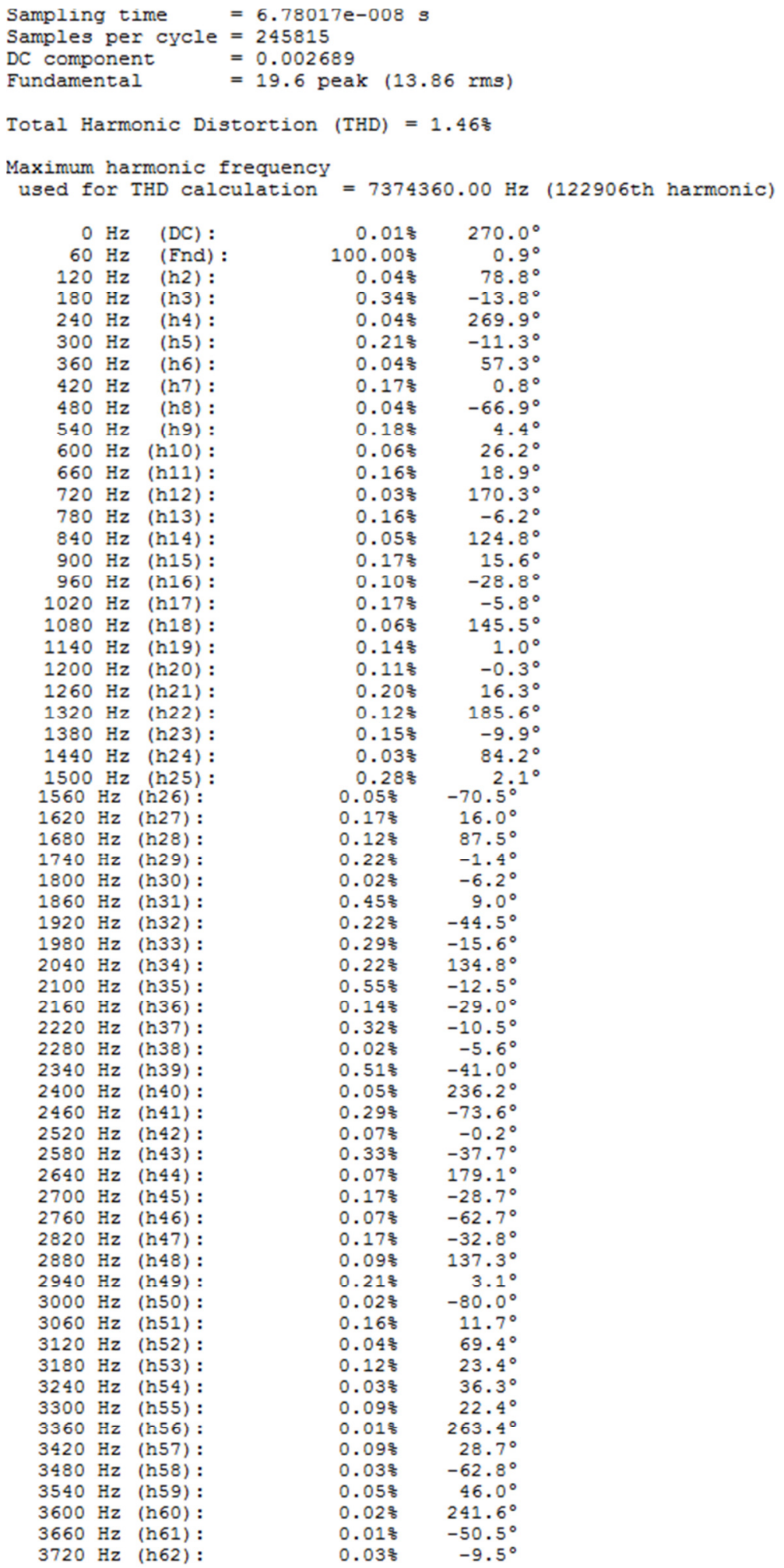




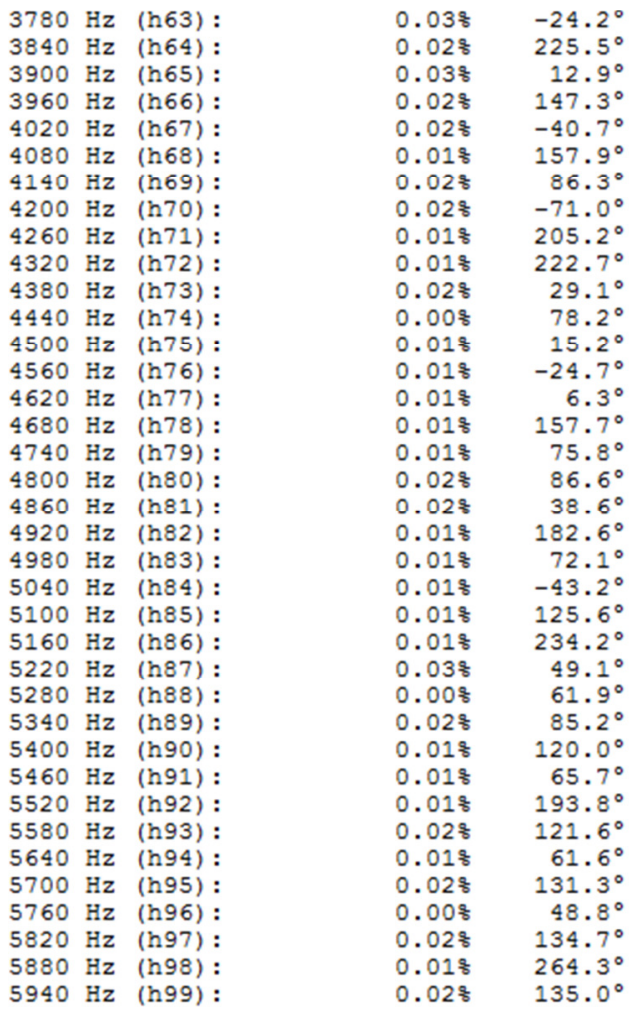

